\title{
READING ANONYMITY: \\ NARRATIVE DIFFERENCE AND FRAMEWORK SELECTION \\ IN THE CLAIMING OF TERRORIST VIOLENCE
}

\author{
Victoria Davis
}

A Thesis Submitted for the Degree of MPhil at the University of St Andrews

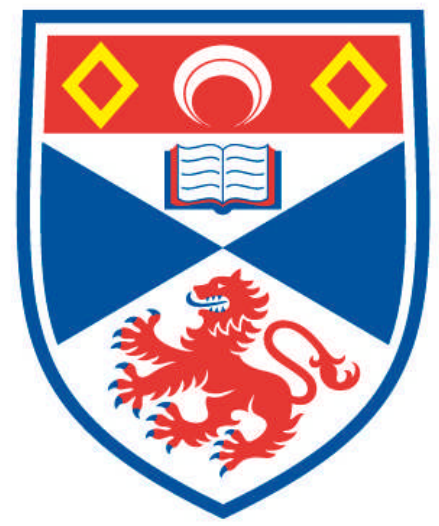

2012

Full metadata for this item is available in

Research@StAndrews:FullText

at:

http://research-repository.st-andrews.ac.uk/

Please use this identifier to cite or link to this item: http://hdl.handle.net/10023/2699

This item is protected by original copyright 
READING ANONYMITY:

NARRATIVE DIFFERENCE AND FRAMEWORK SELECTION IN THE CLAIMING OF TERRORIST VIOLENCE

\author{
by \\ VICTORIA DAVIS
}

A THESIS SUBMITTED IN PARTIAL FULFILLMENT OF THE REQUIREMENTS FOR THE DEGREE OF M.PHIL IN INTERNATIONAL RELATIONS AT THE UNIVERSITY OF ST ANDREWS 


\section{Candidate's declarations:}

I, Victoria Paige Davis hereby certify that this thesis, which is approximately $\underline{39,000}$ words in length, has been written by me, that it is the record of work carried out by me and that it has not been submitted in any previous application for a higher degree.

I was admitted as a research student in [September 2010] and as a candidate for the degree of M.Phil in [February 2011]; the higher study for which this is a record was carried out in the University of St Andrews between [2010] and [2011].

Date March 27, 2012

signature of candidate

\section{Supervisor's declaration:}

I hereby certify that the candidate has fulfilled the conditions of the Resolution and Regulations apprupriate for the degree of M.Phil in International Relations in the University of St Andrews and that the candidate is qualified to submit this thesis in application for that degree.

Date signature of supervisor

3. Permission for electronic publication: (to be signed by both candidate and supervisor)

In submitting this thesis to the University of St Andrews I understand that I am giving permission for it to be made available for use in accordance with the regulations of the University Library for the time being in force, subject to any copyright vested in the work not being affected thereby. I also understand that the title and the abstract will be published, and that a copy of the work may be made and supplied to any bona fide library or research worker, that my thesis will be electronically accessible for personal or research use unless exempt by award of an embargo as requested below, and that the library has the right to migrate my thesis into new electronic forms as required to ensure continued access to the thesis. I have obtained any third-party copyright permissions that may be required in order to allow such access and migration, or have requested the appropriate embargo below.

The following is an agreed request by candidate and supervisor regarding the electronic publication of this thesis:

Add one of the following options:

(iii) Embargo on both [all or part] of printed copy and electronic copy for the same fixed period of 2 years (maximum five) from the date that the thesis is lodged in the University Library on the following ground(s): publication would preclude future publication.

Date March 27.2012 signature of candidate signature of supervisor

A supporting statement for a request for an embargo must be included with the submission of the draft copy of the thesis. Where part of a thesis is to be embargoed, please specify the part and the reasons.

Supporting Statement

Request for Embargo on all of printed copy and electronic copy for 2 years

I would like to petition for an embargo on the entireties of both the printed and electronic copies of the MPhil thesis for a two year period, given that within this timeframe I intend to submit for publication articles based upon the research contained therein. While it is true that material submitted to peer-reviewed journals, once it undergoes revision and reformatting, is often very different from the original text, extensive content from the thesis is likely to feature in said scholarship. The two-year embargo will provide ample opportunity to revise and publish the desired material while precluding potential conflicts over publication. 


\section{TABLE OF CONTENTS}

$\begin{array}{ll}\text { Abstract } & 4\end{array}$

I. Introduction $\quad 5$

A. History of Anonymity in Terrorism 5

B. Statement of Purpose 6

$\begin{array}{ll}\text { C. Value of Research } & 7\end{array}$

II. Review of Scholarship $\quad 9$

A. Communicative Nature of Terrorism 9

$\begin{array}{ll}\text { B. Contextualizing the Terrorist Message } & 10\end{array}$

C. Current Explanations for Unclaimed Attacks 12

D. Another Look at Credit Claiming 23

III. Research Query and Methods $\quad 25$

$\begin{array}{ll}\text { A. Query } & 25\end{array}$

B. Case Study Design and Selection 26

C. Methodology: Justification of the Discourse Analytic Approach 31

D. Methodology: Method of Discourse Analysis 35

$\begin{array}{ll}\text { E. Data Sources } & 37\end{array}$

IV. Constructivism as a Theoretical Approach $\quad 42$

V. Case Study Narratives 46

A. A Brief Introduction to Anonymity 46

B. Introduction to Case Studies $\quad 47$

C. Case Study: 1998 US Embassy Bombings 50

D. Case Study: 2008 Danish Embassy Bombing 64

E. Case Study: 2000 USS Cole Bombing $\quad 70$

F. Case Study: 2000 Aqaba Rocket Bombings $\quad 80$

G. Case Study: 2004 Madrid Train Bombings 85

H. Case Study: 2005 London Train Bombings 95

VI. Summary of Narrative Trends Across Case Studies 107

$\begin{array}{ll}\text { A. Civilization vs. Barbarism } & 107\end{array}$

B. Attacked vs. Attacker: The Exoneration of Suspects 113 
C. Attacked vs. Attacker: The State and State Foil 118

$\begin{array}{ll}\text { D. Inability to Demarcate Relevant Information } & 124\end{array}$

$\begin{array}{ll}\text { E. Possibility of future attack as legitimizing state action } & 128\end{array}$

$\begin{array}{ll}\text { VII. Analysis } & 134\end{array}$

A. Risk and the Notion of Risk Society 134

B. Why Risk is Not an Appropriate Framework for the Terrorist Attack 135

C. The Distinction between Uncertainty and Ambiguity 136

D. Claimed/Unclaimed Terrorist Attacks as Framed under Uncertainty, Ambiguity 138

E. Ambiguity as Applied to Claim Scholarship 143

VIII. Importance of Findings and Suggestions for Future Research 148

$\begin{array}{ll}\text { References } & 149\end{array}$

$\begin{array}{ll}\text { News Reference Key } & 162\end{array}$

$\begin{array}{ll}\text { Appendices } & 298\end{array}$ 


\section{ABSTRACT}

While a significant proportion of terrorist attacks have always gone unclaimed scholarship has noted an increasing number of such acts over the past half-century, which appears to indicate that the claiming of violence may no longer constitute an essential terrorist strategy. The increasing gap between claimed and unclaimed attacks (where "unclaimed" is understood as a terrorist attack for which no credible assertion is issued by the perpetrating individual or group) cannot be explained by existing assumptions, which posit that terrorist groups will seek to advertise their success. This thesis attempts to develop a more complete understanding of this phenomenon by examining al Qaeda's claim variation within a series of paired case studies to explore the presumption of narrative difference between the two types of attacks. Findings indicate that claimed acts of terrorism tend to be presented via a framework of uncertainty whereas unclaimed acts are presented within a framework of ambiguity. The distinction of ambiguous frameworks is that they allow the terrorist to operate in a newly created narrative space to perpetuate and expand the fear-provoking effects of violence by destabilizing mutually exclusive identities of blame and rendering attacker and victim indistinct, while at the same time confirming the imminent possibility of lethal harm. The variation between models has significant implications for policymakers given that the choice of framework limits or guides one towards particularized courses of action. Given the creative authority of the targeted society as definer of this framework, it remains within the attacked population's power to eliminate the narrative advantage allotted terrorist actors under conditions of ambiguity. 


\section{CHAPTER 1: INTRODUCTION}

\section{A. History of Anonymity in Terrorism}

While a significant proportion of terrorist attacks have always gone unclaimed (see Cordes et al. 1985; Pluchinsky 1997), scholarship has noted an increasing number of unclaimed acts of terrorism over the past half-century (Gearson 2002; B. Hoffman 1996, 1997, 1999, 2006; Rorie 2008) that appears to indicate that the claiming of violence may no longer be an essential terrorist strategy. An average of $60 \%$ of terrorist attacks from 1970 to 1979 were claimed; this proportion dropped to 39\% between 1980 and 1982 (Cordes et al., 1985, p.23), and has further declined in subsequent decades. LaFree and Dugan (2008) note the percentage of claimed attacks between the late 1990 s and 2004 fell to $14.5 \%$ (p.28-9). In a study of terrorist claim staking between 1970 and 1997, Rorie (2008) finds evidence of a definitive shift towards anonymity over time with 1982 as the median of claimed attacks and 1993 as the median of unclaimed attacks (p.38). Contrary to conventional wisdom regarding the presumed publicity ambitions of terrorist organizations, there has been a similar drop in the claiming of the "terrorist spectacular" (B. Hoffman 1997). This is particularly unusual given that previous examinations of unclaimed attacks have found the majority of such incidents to be low-level actions that are not intended to cause casualties (Cordes et al., 1985, p.15).

The increasing gap between claimed and unclaimed attacks cannot be explained by existing assumptions, which posit that terrorist groups will seek to advertise their success so as to establish themselves as a threat, call attention to their cause, and generate support amongst sympathetic populations (Crenshaw 1995; A.M. Hoffman 2010; Knutson 1980; LaFree \& Dugan 
2004; Nacos 2002; Picard 1993; Staun 2009; Waugh Jr. 1983). Explanations involving the advent of new technologies — such as remote time bombs that eliminated the "personal heroism" required by the anarchist bomb thrower of the $19^{\text {th }}$ century and allowed for a less discriminating and more anonymous attack (Wardlaw, 1989, p.31) —also cannot explain the variation in claiming behavior between the late 1970s, 1980s and subsequent decades, given that such technologies existed throughout the aforementioned period. The decline in claiming tendency has persisted despite the fact that, due to the supposedly poor communicative properties of violence (Cordes et al. 1985; Johnston 1995; Sper 1995), anonymity and lack of context have been found to generate confusion with regard to actor, motive, and message content that undermines the terrorist's ability to gain support/understanding and elicit policy concessions from governments (A.M. Hoffman 2010). Furthermore, this tendency towards anonymity has increased in spite of the knowledge that the absence of media coverage (and the publicity it brings) is repeatedly cited as a factor in the decline of terrorist groups (Cordes et al. 1985; DeGhetto 1994; Horowitz 1983; Lockett 1995) and that the media is more likely to report on attacks in which responsibility has been established (Bockstette, 2008, p.19; Weimann \& Winn 1993). This behavior is particularly puzzling in the case of large-scale or high-profile attacks, as current logic dictates that such an event requires a higher level of planning, expertise, and execution from which a successful terrorist group would benefit in terms of audience outreach through greater media coverage.

\section{B. Statement of Purpose}

This thesis seeks to develop a more complete understanding of terrorists' decision-making strategies in relation to the planning and execution of acts of violence by examining the variation in credit taking behavior of a single terrorist organization and developing an account of the 
fluctuating relationship between terrorists' conflicting desire for publicity and anonymity. Specifically, discourse analysis situated within a constructivist framework will be used to explore paired claimed/unclaimed ${ }^{1}$ acts of terrorism to investigate the presumed difference in terrorist identity narratives attached to both types of attacks and determine whether claim status is correlated with certain actor characterizations that may attest to the increase in unclaimed attacks.

It should be noted that the use of a case study approach in the instance of a singular organization, though providing valuable insight from the perspective of "building-block" theory development, does caution against the overgeneralization of findings to all unclaimed terrorist acts.

Furthermore, the study does not profess to evaluate the effect of claim status on actors outside of the perpetrating terrorist organization and the target audience/government, such as sympathetic constituencies or rival terrorist groups. It is hoped that the foundational research conducted by this study will assist with the future development of a broader theoretical model for unclaimed terrorist attacks, particularly those that are religiously motivated.

\section{Value of Research}

Claims of responsibility provide a more complete understanding of the terrorists' decisionmaking and planning strategy, as well as insight into variations between terrorist groups (Rapoport 1997). According to A.M. Hoffman (2010), credit taking has the potential to reveal a great deal about the nature of the threat groups pose, their ultimate aims, the incentives affecting

\footnotetext{
1 "Unclaimed" is understood to mean a terrorist attack for which no credible, formal claim of responsibility has been issued by the author(s). Consequently, it does not imply an absolute lack of claims issued, simply that the validity of said claims has been discounted by authorities.
} 
their behavior, and the adequacy of government and audience response to their attacks. For instance, Enders and Sandler (2006) suggest that anonymous attacks presume groups are disinterested in establishing grassroots support and do not place value in the possibility of future compromise, whereas claimed attacks are viewed as signaling a lack of fear of government counter-terrorism efforts (as cited in B. Hoffman 1997). According to Clarke and Newman (2006), choice-structuring properties not only provide information regarding the incident but also testify to the criminal offender (e.g. his/her needs, preferences, personal characteristics, and perceptions); understanding how acts of violence are driven and exploited by terrorist motivations will enable law enforcement to manipulate situations to increase risk and difficulty of execution while minimizing rewards (as cited in Rorie 2008). The proposed comparative format allows for the empirical identification and investigation of circumstances under which a group will seek to formally claim their attacks as well as variation in the reception and interpretation of such acts by the target government and mass public, information that may prove valuable towards future predictive models of terrorist behavior. 


\section{CHAPTER 2: REVIEW OF SCHOLARSHIP}

\section{A. The Communicative Nature of Terrorism}

There is a dispute in both the academic and political world over who or what qualifies as worthy of the label "terrorism"; however, one of the most common elements of these varied depictions is the phenomenon's communicative nature. Terrorism is conceptualized most broadly as a public act intended to coerce an audience (A.M. Hoffman 2010; Horgan, 2004, p.31; Weinberg et al. 2004). Scholarship has documented various aspects of this communicative function, including its manipulative power over audience perception (Schmid \& Jongman, 1988, p.28), dependence upon context reading (Crelinsten 1989a), and its claim for attention and legitimacy (Crelinsten 1989b). According to Louise Richardson, "the point of terrorism is to communicate a message. It is not violence for the sake of it, or even violence in the expectation of defeating the enemy; rather it is violence to convey a political message" (2006, p.21). It is in fact this characteristic, the tendency to seek maximum attention and exposure as well as the necessity of justifying the violence in terms of social values, political or religious meaning, that distinguishes terrorism in the amorphous world of violent crime (Crenshaw, 1995, p.15; LaFree \& Dugan, 2004, p.59; Staun, 2009, p.11).

Based upon terrorism's communicative tendencies, acquiring and maintaining publicity is essential to terrorist legitimacy, garnering attention and fear-inspiring potential (Nacos 2002; Picard 1993; Wardlaw 1989), securing a favorable understanding of the terrorist cause (Perl 1997), recruitment and support (A.M. Hoffman 2010; Waugh Jr., 1983, p.7) and justifying the use of terror in societies where alternative means of redress are ever more accessible (Apter, 
1997, p.2,5; Cordes, 1987, p.2; Rapoport, 2004, p.1502). The absence of media coverage has been cited as a factor in the downfall of terrorism (see Cordes et al., 1985, p.17; DeGhetto, 1994, p.17); as Lockett (1995) notes, “[a]n ignored terrorist group does not influence” (p.20). Failure to attract media attention may stem from the group's failure to provide the extraordinary (Horowitz 1983; Knutson, 1980, p.206) or from credit claiming; Weimann and Winn (1993) find that the media is more likely to report on attacks in which responsibility has been established (see Bockstette, 2008, p.19; Rorie, 2008, p.8). However, the consequences of a poorly communicated message may outweigh even a lost media opportunity. Instances in which the audience fails to interpret or attributes an incorrect interpretation to an act of violence may result in the loss of popular sympathy as well as group legitimacy, decreasing the pool of potential recruits and available resources and posing a threat to organizational sustainability. This is especially true when the public perceives the victims of terrorist attacks to be entirely random (Ross \& Gurr, 1989; USIP, 1999, p.4).

\section{B. Contextualizing the Terrorist Message}

In order to engender psychological effects that will translate into political gains for the terrorist group, the audience who receives the terrorist message must "know or have a good idea who is responsible for the act, and (...) must understand the message, that is, why the terrorists attacked that target" (Cordes et al., 1985, p.15). Yet on their own, acts of violence appear to be a poor means of expression that often require clarification through other means. Decker and Rainey (1980) argue that terrorism has become a "carefully designed and rhetorically sophisticated attempt at communication" (p.3). However Cordes (1987) appears less optimistic at the transmitting potential of violence, judging it to be a crude method of communication capable of 
sending only as complicated a message as "be afraid." Sper (1995) concurs that "one cannot assume a terrorist group's intent by its actions alone" (p.17). Without a clarifying discursive element, the terrorist act is left to speak for itself — a feat which it appears ill-equipped to accomplish.

According to Cordes et al. (1985), the principal method by which terrorists attempt to influence the behavior of their target audience is via the claiming of an act of terrorism (p.15). Claims add additional information to attacks (Wright, 2009, p.6) and are helpful in providing insights into the mindset of those who view violence as an effective and justified instrument in pursuing their aims (Kellen, 1982, p.2). Claims of responsibility reflect the plans upon which terrorist groups rely in ways that warnings cannot, given the control the terrorist exercises over their timing and content; claims are not filtered through governing authorities who possess editing potential (A.M. Hoffman, 2010, p.6).

Claiming responsibility for an attack is further attractive to terrorist groups because of the difficulty of credibly claiming acts committed by others given temporal proximity (A.M. Hoffman, 2010, p.7). As many groups have a vested interest in similar targets and tactical innovations can be copied (Fleming et al. 1988; B. Hoffman, 2006, p.148; Jenkins, 1981, p.6; Nacos 2009), credit taking allows groups to distinguish themselves from other publicity seekers and reap the presumed benefits thereof. Furthermore, given the constraints under which terrorist organizations function, credit claiming is an inexpensive and comparably simple method of projecting influence whereas alternative methods—such as attack signatures or specially 
designed bombs - require highly trained operatives that are both difficult to recruit and exceedingly hard to retain and or replace (A.M. Hoffman, 2010, p.6).

\section{Current Explanations for Unclaimed Attacks}

Given the perceived benefits — even necessity_of claiming an attack, what circumstances would deter a terrorist group from making such a claim? The following paragraphs review the limited yet contested scholarship addressing explanations of such groups' propensity to anonymously commit acts of violence.

\section{The New Religious Character of Terrorism}

In comparison to previous secular ethno-separatist or left-wing terrorist groups, the religious character of the "new terrorism" does not necessitate the justification of violence to an earthly audience. With regard to political ideology, Rapoport (1997) argues that groups driven by ideologies championing material goals and the notion of mass support (e.g. Marxism or nationalism) are more likely to take credit, as it serves to generate popular support for the movement. In turn, Crenshaw's (1996) research on terrorist renunciation of violence counters that ideologies stressing mass involvement (e.g. communism or socialism) may reject terrorism on principle due to its "elite" character (p.252).

Likewise, terrorists adhering to religious and millenarian beliefs are less likely to claim credit as they lack a real-world constituency to whom they can be held accountable (Enders \& Sandler, 2000, p.311; Post, 2005, p.461; Rapoport 1984, 1997). Post (2007) asserts that none of the rules developed for "ordinary" terrorists apply to religiously motivated groups as they "are not 
constrained by their audience on earth" (p.240); rather, they place service to God over political ambitions (Ranstorp 1996) and thus have no need of justifying the commitment of violence in service of an approving omniscient deity (Post, 2005, p.452; Rapoport 1984; Wright, 2009, p.18).

However, this sharp dichotomy between "religious" and "political" terrorism—and indeed between all general categories of non-state terrorist groups - as discrete and mutually exclusive is untenable. Neumann (2009) asserts that "if the objective is to change or transform societies by introducing aspects of religious law, creating a theocracy or even a caliphate (...) the political nature of the terrorist campaign can no longer be in doubt" (p.95). As with other politically motivated terrorist organizations, regardless of the grounds for their impetus, "[terrorists'] political programmes are violent expressions of ideological currents which are located on the radical fringes of mainstream society. In other words, they reflect broader political and/or social trends" (Neumann, 2009, p.95). This notion was confirmed by B. Hoffman (2006) in his observation of the preeminence of the ethno-nationalist and/or irredentist aims over religious motives in groups such as the PLO, the IRA, and the FLN (p.82)

This blurring of boundaries is further documented in that essentially "religious" terrorist groups, such as Hamas or Palestine's al-Jihad al-Islam, have displayed nationalist sentiments. Groups such as al Qaeda express a consistent ideological agenda targeting the expulsion of foreign forces and influences from Islamic nations and the creation of an Islamic caliphate ruled by sharia law, but the foundation of their rhetoric (which has remained constant over the past decade) is that Muslims, considering themselves as a single nation, should unite to resist anti-Islamic aggression 
based upon the principle of defensive jihad (Blanchard, 2005, p.6). This may necessitate joining al Qaeda and likeminded organizations in opposing those attempting to construct secular democratic governments or seeking to prop up existing regimes deemed non-Islamic (Blanchard, 2005, p.8) - a task that requires recruiting from sympathetic populations in much the same manner as any politically-oriented group. One may well argue that this goal (though perhaps grounded on religious principles) is clearly political in its objective, the pursuit of which requires public support in the same manner as a secular campaign.

\section{Media Coverage and the Establishment of Legitimacy}

Media attention does not automatically confer legitimacy, and the risk of inaccurately communicating the terrorist message may provide an advantage to policymakers and depress the terrorists' desire to claim responsibility. Risk of erroneous communications or interpretations by the media may lead to a loss of support for the terrorist group (Abrahms 2006). Due to the eventoriented and for-profit nature of the media (Rorie, 2008, p.10), publicity of a terrorist act may cover tactics used and their fallout but is unlikely to review the conditions that precipitated the attack (Altheide 1987). As Rapoport (1997) notes, "legitimizing terror is a difficult, usually impossible, always problematic task (...) to those who think justification is possible, very special circumstances are required: no alternatives, a desperate and/or exceedingly propitious situation, monstrous enemies unwilling to recognize limits who by their actions have made the terrorist in fact the true victim" (p.12). Unlike legislators-who possess large media relations departments - terrorist-media relations are furtive and provide less opportunity to refine communications (Altheide 1987; Clarke \& Newman 2006; Rorie, 2008, p.10). Likewise, the limited nature of terrorist media coverage allows policymakers to detract attention from the 
underlying issues and focus on punishing the perpetrators (Chermak \& Gruenewald 2006; Picard 1993).

However, this argument does not take into account that terrorists are capable of, and often engage in, clarifying interpretations of violent acts; in fact both small and large organizations conduct a wide variety of formal press relations activities (Picard 1989). Note the videotapes publicized by Osama bin Laden, a more recent example of which attempted to direct audiences to the proper sources of interpretation and "clarify the "message"" of the September $11^{\text {th }}$ terrorist attack (VOA 2009). Furthermore, terrorist organizations often have significant media resources at their disposal, possibly through a political $\mathrm{arm}^{2}$ that has full access to legitimate media sources and is capable of marshaling its own resources. Indeed, the asymmetry of media coverage in the terrorists' favor (Bockstette 2008) has led policymakers to express concern at such groups' ability to manipulate the media in the way they desire (see Isbell et al. 2006). The use of the Internet as a means of communication is also considered central to terrorist communications (Talbot 2005, p.48), and offers a broad publicity tool that is free of the media's interpretive constraints. There have furthermore been instances in which terrorists were granted media opportunities to freely air their grievances; recall, for instance, the 1-hour uninterrupted interview of Osama bin Laden by CNN's Peter Arnett in 1997, wherein the Saudi exile was free to expound on these underlying "causalities."

2 e.g. Sinn Fein and the IRA (see Horgan 2004). 


\section{The Interpretive Power of Audience}

One argument against the utility of claiming is that it is unnecessary; the message will reach the intended audience in any case (e.g. B. Hoffman, 1997, p.4). As Gearson (2002) suggests, "[t]he need to claim 'credit' for an attack is not as important if, in the minds of the terrorists, the act speaks for itself" (p.11). Following the September $11^{\text {th }}$ attacks, for instance, even Osama bin Laden trumpeted "[t]hose young men [inaudible] said in deeds, in New York and Washington, speeches that overshadowed all other speeches made everywhere else in the world. The speeches are understood by both Arabs and non-Arabs—even by Chinese" (USDOD 2001). Yet a quick survey of notable terrorist incidents contests this assumption. In the case of Pan Am Flight 103unaccounted for until Libya's 2003 admission of responsibility—investigators in the immediate wake of the attack were unable to pinpoint either perpetrator or grievance (USCIA 1988), leaving press and public alike speculating as to message and motive. As previously noted, this also occurred in the case of the 1995 Oklahoma City bombings, which provided no contextual clues pointing to Timothy McVeigh's anger at the federal government and the handling of the 1993 Waco Siege and the Ruby Red incident. This confusion was further compounded by various expert misattributions that the bombing was the product of Islamist militarism. Furthermore, as described in the previous literature on credit claiming (e.g. Wright 2009), common attack techniques (e.g. bombings) are not easily distinguished from one another, requiring groups to differentiate themselves via credit claiming or expensive signature attacks. As the organizations with the resources to continuously fund such signature attacks are arguably outweighed by those who must rely upon more resource-conserving methods, no such distinguishing element of violence can be expected. 


\section{The Embarrassment of Failure}

An argument put forth by Pluchinsky (1997) in the case of the failed terrorist attempt is that organizations may be too embarrassed to claim credit; terrorism is not for amateurs, and the benefits of being viewed as such by potential supporting communities and sponsors may be detrimental to the terrorist's resource pool. Yet events over the past decade have demonstrated otherwise - such organizations appear to find utility in associating themselves even with failed plots, which calls into question whether it is the quantity or quality of media coverage that is most important. Al Qaeda in the Arabian Peninsula claimed responsibility for a failed mail bomb plot on American cargo planes in November 2010 as well as failed attempts to shoot down the Saudi royal family's plane in October 2010 and assassinate the nation's Anti-Terrorism Campaign head in August of the previous year. The Pakistani Taliban claimed ownership of a failed September 2008 bombing of Barcelona trains and more recently the attempted May 2010 attempted car bomb in New York City's Times Square. Even al Qaeda and Osama Bin Laden claimed the failed 2009 Christmas Day Flight 253 bombing plot. Nor is this phenomenon limited to Islamist terrorist organizations; Continuity IRA claimed multiple failed attacks on police bases in April 2000 and June 2009, while the Real IRA accepted responsibility for a 2002 attempted police car bombing and 2004 bomb attempt in Derry. Thus, groups appear to derive some benefit from associating their names even with failed acts of violence; rather than hiding their involvement, many go out of their way to advertise it.

\section{Fear of Retaliation by Authorities}

This line of argument maintains that claiming exposes terrorist organizations to counterterrorism measures (B. Hoffman 1996, 1997; Rapoport 1997) by providing governments with 
otherwise unavailable materials for destroying terrorists. According to Rapoport (1996), publicity "helps an outraged public to mobilize its vast resources and produces information that the public needs to pierce the veil of secrecy all terrorist groups require" (p.viii).

However, scholarship has noted that high-profile methods such as hijackings, kidnappings, barricade-and-hostage events, and suicide attacks are claimed nearly all of the time-whether due to the possible link between, for instance, suicide and cultures of martyrdom (Hafez 2006, cited in A.M. Hoffman 2010) or due to the fact that high-profile methods often require the perpetrator to identify him/herself (Cordes et al., 1985, p.25)—whereas low-profile methods such as hit-and-run attacks are the least likely to be claimed. Assumption of responsibility for terrorist acts and exposure to government recrimination neither necessarily signals the end of an organization nor poses a significant hindrance to the ability to launch attacks. For instance, groups such as ETA, the IRA, and FARC were targets of government counter-terrorism efforts for significant lengths of time yet continued to conduct operations that impacted the target audience. Furthermore, heightened environmental pressure or governmental retaliatory measures often serve as predictors of increased internal cohesion (Bjorgo, 2009, p.34) by suppressing internal group conflict (Crenshaw 1992) while justifying and reaffirming the terrorist organization's views (Post 1987). As Sper (1995) notes, “creating a common enemy (...) draws group members together and increases group cohesion by increasing the salience of intra group bonds and core values as a source of security (p.72). Post (1987) does indicate, however, that retaliatory measures may have some effect on state-sponsored violence, as the survival of the state and furtherance of national goals are paramount; in instances where terrorist activity 
threatens those goals it can be reduced or abandoned, as the state does not require violence to justify its existence (p.488).

Scholars have noted that attacks on the public at large may pressure governments to increase counter-terrorism measures, which may diminish the utility of claiming authorship of an attack (Gearson 2002; B. Hoffman 1996, 1997; Rapoport 1997). Yet conflicting literature cites that the general populace is less likely to be seen as a "legitimate" target and thus such an attack will result in greater backlash and compel the perpetrating group to publicly justify their target selection (B. Hoffman 1999; Picard 1993; Ross \& Gurr 1989), which inevitably requires assumption of responsibility. Rorie's (2008) study on terrorist target selection finds that an attack on a specific target, as opposed to the general public, does not decrease the likelihood that it will be claimed.

In turn, the literature offers a relatively uniform prediction that state sponsorship of terrorism reduces the probability of credit taking as governments generally find little utility in associating themselves with perceived illegitimate actors (Cordes et al. 1985; Pluchinsky 1997; Post 1987). Yet the effect of state retaliation in response to an act of terrorism remains indeterminate. B. Hoffman (1997) argues that terrorists prefer not to shoulder blame when governments retaliate indiscriminately - yet the direction of public anger in such instances may not target the terrorist organization at all but rather the offending government. Public resentment may delegitimize the government and lead to greater constituent support for the terrorist group (Frey 2004) as well as increased internal cohesion and a rise in the organization's terrorist activity (Post 1987). Bueno de Mesquita (2005) identifies a U-curve with respect to government action; infrequent military 
responses allow terrorists to claim credit with little fear of retaliation, whereas frequent counterstrikes allow groups to capitalize on public outrage.

Even given the premise that claim making provides otherwise unknown information to authorities, one must consider that terrorist groups may be functioning on organizational rather than individual rationality; acts of violence, though possibly unrelated to the group's professed agenda, are therefore critical to its identity and legitimacy and may cause the group to continue such activities despite additional risks (Crenshaw 2001; DeGhetto 1994; Post 1987; Sper 1995; Waugh Jr. 1983). In such instances, the compulsion of organizational maintenance may diminish the cost of harsher counter-terrorism penalties given the comparative need to provide a source of validation and purpose for group members.

\section{Public Relations Maintenance}

A further argument in favor of anonymous attacks asserts that in cases where the action either conflicts with the established group image or produces casualties over the acceptable level, groups tend not to stake claims (DeGhetto, 1994, p.10; Pluchinsky, 1997, p.7). However, this does not explain the general declining tendency among organizations to claim attacks; to allow for this argument, one must make the case that terrorist attacks have become bloodier across the spectrum, suppressing the claiming tendency. Yet if the level of violence spiked across the entire gambit of terrorist organizations over the past few decades (and it would have to have done so, in order to exhibit an overall decline in claim making), one can also assume that societies exposed to such violence for a protracted period adjusted their accepted level of violence accordingly, rendering such terrorism routine and mundane (Horowitz 1983). 
Additionally, empirical studies indicate that the idea terrorists will damage their image by killing is not supported by hard evidence. In a study of public attitudes towards terrorism in Uruguay, Spain, Italy, Germany, and Northern Ireland, Hewitt (1990) observes that it is rather those groups that kill the most (e.g. ETA and the IRA) that have the most positive ratings, while groups who have killed far fewer (e.g. the Baader-Meinhof gang and the Red Brigades) have the most unfavorable image. (p.142-3). The study finds that attitudes towards political violence depend primarily upon structural-historical elements, and are therefore "little affected by either terrorist actions or by government policies"; moreover, "those (...) who assume that terrorist sympathizers will be alienated by atrocities are equally deluded" (p.155).

\section{Greater Fear-Inciting Potential}

This strand of scholarship cites that terrorists maximize the element of surprise whichcombined with the random targeting of victims - evokes higher levels of public anxiety (Garrison 2003; Gearson 2002; B. Hoffman 1997, 2006; Perl 1997; Wardlaw 1989) and presumably makes a greater contribution towards the furthering of the terrorist agenda. As an aside to her investigation of domestic terrorist targets, Rorie (2008) notes that in a comparison of claimed/unclaimed violence in newspaper reports, the media focused on the pervasiveness of public fear in the instance of anonymous terrorist acts. In the case of the former, the public was not as generally apprehensive but instead channeled their fear towards specific locations while expressing contempt for those responsible (p.52-3). According to Wardlaw (1989), if a victim of terrorism cannot understand the source of danger it is likely s/he will turn to a leader who appears to be knowledgeable and competent; if the incumbent forces prove unable to provide this interpretive framework and guarantee personal security, the fear and panic inspired by an attack 
may be heightened (p.34-5). Cordes et al. (1985) observes that in the context of major terrorist unclaimed events the offender's anonymity "enhances the confusion and tension surrounding the attack. Speculation abounds and theories of attribution are batted back and forth" (p.15), as was borne out in the previously mentioned 1995 Oklahoma City bombing and Pan Am Flight 103.

Yet there are problematic elements within this theory as well. According to Cordes et al. (1985), a number of unclaimed attacks achieve greater publicity than they would have had they been claimed due to public fear of a repeat performance by a mysterious and seemingly more effective unidentified perpetrator (p.15). Yet this finding conflicts with that of Weimann and Winn (1993), who note that the main benefit_-increased publicity_ of formally claiming responsibility for a terrorist attack derives from the fact that the media is more likely to report on attacks in which responsibility is known. Even if one assumes that anonymous terrorist acts are more adept at inciting fear, if the phenomenon's primary purpose is to communicate or further a particular agenda (rather than mindless fear mongering), given the assumed limited communicative nature of violence it would appear that not claiming an attack may be counterproductive to the terrorist agenda.

\section{Impact of Environmental Characteristics}

Environmental characteristics, such as geographic/cultural factors or competition between terrorist groups, may suppress claiming behavior. Assumption of responsibility may vary according to competition for supporters and resources; A.M. Hoffman (2010) finds that credit taking is dependent upon the number of active terrorist groups in a given theater of operations. Given relatively low competition an organization may not have incentive to claim attacks, 
whereas in areas of high competition it will choose to advertise its accomplishments to supporters and potential recruits. A.M. Hoffman's study, however, limits itself to a single country (Israel); Wright's (2009) multi-country analysis finds little support for this conclusion.

Wright instead explains claim variation based upon cultural discrepancy in the utility of claiming as a signaling mechanism. Yet Cordes et al. (1985) find no correlation between the geographic theater of the attack and its claim status; neither is any explanatory power inherent to the nationality of the target itself (p.25). Furthermore, in cases where those responsible are eventually discovered, unclaimed attacks have not demonstrated a statistical proclivity to be the product of any particular ethnic or religious group.

\section{Another Look at Credit Claiming}

Existing claim making literature tends to assume the poor communicative ability of acts of violence, yet anonymity is often cited as one of the primary strengths of violent non-state actors (see Kiras, 2009, p.189; Mulaj, 2010, p.19). It is unlikely, given the frequency of the strategy's use and the agenda-driven nature of terrorism, that an organization would repeatedly select an attack style bereft of communicative potential or utility. A significant oversight (given its presumed theoretical importance) throughout the existing literature is the untested presumption of qualitative difference and causal linkage between the claimed/unclaimed status of an attack and its impact on an audience. There is a broad assumption that unclaimed attacks, lacking the context provided by association with a named group or cause, cannot effectively communicate a political message or that terrorists must choose between inspiring fear and avoiding government retaliation and conveying a message to constituencies and potential recruits. 
Scholarship generally refers to formal claims of responsibility only in passing, focusing instead on the propensity of terrorist groups to issue warnings prior to or manifestoes following an act of violence; indeed, compilations of these communiqués are not uncommon ${ }^{3}$. Instances where publicity is not sought by an organization are generally not discussed in relation to the terrorist decision-making strategy ${ }^{4}$, and where present are couched within a review of other circumstantial factors (e.g. Pape 2003 and suicide terrorism) ${ }^{5}$. Within this literature, failure to take credit for a violent act tends to be based upon theoretical supposition ${ }^{6}$. Those few studies that do empirically analyze claim making are furthermore often applicable only as it relates to a particularized case or country of study (e.g. A.M. Hoffman 2010, Rorie 2008), and there appears yet to have been an examination of a single terrorist organization's claiming patterns, which might provide insight into the circumstantial factors that influence claim making. A satisfactory explanation of unclaimed attacks, their communicative potential, and their place as a strategic tool for terrorist organizations to connect with their audience has yet to be offered.

${ }^{3}$ See Alexander \& Pluchinsky 1992; Baader-Meinhof/Red Army Faction 1977; Smith \& Moncourt 2009.

${ }^{4}$ Exceptions include B. Hoffman 1997, Pluchinsky 1997

${ }^{5}$ As noted by Rorie, 2008, p. 17

${ }^{6}$ Exceptions include Rorie 2008, Wright 2009 


\section{CHAPTER 3: RESEARCH QUERY AND METHODS}

\section{A. Query}

Identity, as it is socially constructed by humans, is relational (in that the understanding of oneself is predicated on the creation of another grouping of characteristics of which one is not a part and the inclusiveness of each group is affected by social interaction) and cognitively processed based upon habit or prior experience (e.g. humans categorize experiences under a limited number of models that can be readily applied to new situations in order to organize and understand stimuli). It stands to reason that a society's relationship with terrorism and its proponents consists of a cyclical application and re-definition/application of such frames based upon an amalgam of past and present experience. Consequently, the nature of terrorist actors should function as a research question rather than an assumption; not all terrorists may be "created equal" in the mind of the public (Klotz \& Lynch 2007). The British public's post-ceasefire understanding of and relationship with the IRA, for instance, may differ widely from their understanding of the same group during The Troubles or their comparative conceptualization of al Qaeda following the 2005 London bombings.

This research seeks to explore the presumed difference in meaning attached to claimed/unclaimed acts of terror by examining the identity of a single terrorist group under both conditions so as to determine whether claim status is correlated with certain characterizations of the terrorist actor that may assist in explaining the increasing prevalence of unclaimed attacks. 
The thesis addresses the following questions:

- Do claimed/unclaimed acts of terrorism differ in their depictions of the terrorist actor with regard to intrinsic characteristics, ascribed motivation, attack brutality, or the breadth of power attributed to the perpetrators? How is this understanding conveyed to the audience?

- Who is the "we" functioning as the counter to the terrorist "other," and how are certain understandings of both actors encouraged or limited by the discourse? How does the emphasis or omission of certain aspects regarding the terrorist group affect the resulting identities?

- How does the resulting discourse affect the meaning attached to the event and the resulting significance of the perpetrators as defined by the target audience?

- How does the understanding of al Qaeda's identity as well as that of the "other" fluctuate over time given continued attacks? How does this speak to the evolving relationship between a terrorist group and society?

\section{B. Case Study Design and Selection}

The use of the comparative case study format is appropriate for multiple reasons; first, the theoretical understanding of identity used here is predicated on the intersubjective, structural, social identity proposed by Hopf (2009). This necessitates the assumption that identities operate independently of whomever occupies the position of head of state-continuity in identity relations across governments - and excludes approaches rooted in the presence or absence of any 
one leader or administration (Hopf, 2009, p.286). ${ }^{7}$ The comparative structure permits examination of the phenomenon of interest within its original context, yet the inclusion of several case studies as part of a single investigation provides a body of alternative explanations, preventing the frequent interpretivist trap of defining terms in such a specific manner that parallels to other situations are unfeasible (Lin 1998).

It is understood among social scientists that the ideal conditions for paired comparisons rarely exist, and that the distinction between cases and non-cases may not be well defined (Klotz \& Prakash, 2009, p.46). Certainly, in the case of "claimed" and "unclaimed" attacks, the dividing line is not always clear; claim issuance may be delayed, which renders problematic the case's categorization under one mutually-exclusive label. For instance, in the case of the September $11^{\text {th }}, 2001$ attacks, al Qaeda leader Osama bin Laden denied responsibility for the bombings until a sudden video broadcast established his authorship in October 2004; should the attacks then be labeled as claimed, or divided into separate segments with October $29^{\text {th }}, 2004$ as the dividing point? What of those attacks claimed under a pseudonym, or attempts by non-credible or false actors to assume responsibility? Or, if the attack is committed anonymously, what of authorities' identification of the perpetrator immediately or shortly after the attacks; does true anonymity matter, or is it simply public attribution of ownership that tips the balance between claimed and unclaimed acts of violence?

Given this constraint, Goertz (2006) proposes a case selection based upon a synthesis of the typology and "fuzzy set" approaches as it concerns "defining ideal types in terms of the most

\footnotetext{
${ }^{7}$ This assumption was borne out in Hopf's own research, which found that Soviet identity did not alter significantly following the removal of Khrushchev (2009, p.303).
} 
exclusive features ('and') while recognizing that cases will evince a subset ('or') of those characteristics" (p.84, cited in Klotz \& Prakash, 2009, p.57). The demarcation of "claimed" and "unclaimed" attacks is similarly "fuzzy" and necessitates definition as it is applied to the research presented here. Yet as Klotz and Prakash (2009) recognize, "the tendency to contextualize concepts need not be an insurmountable problem for comparing across cases (...) even an elusive concept like 'regime' has fuelled reams of insightful research on international cooperation and global governance, despite abiding definitional disputes" (p.45). Thus, even within the contested area of terrorism studies, scholarly and policy-related gains may be made despite the absence of absolute consensus as to definitional particulars, both as it concerns claim status as well as the subject of terrorism itself.

This study posits an understanding of a "claimed" terrorist attack as follows: any attack committed by a terrorist actor $^{8}$ for which a credible and authentic claim of responsibility ${ }^{9}$ was issued by the perpetrator. An "unclaimed" attack is understood as follows: any attack by the aforementioned range of actors for which no credible or verified claim was issued, including those claims made via a pseudonym, false claiming by a group not responsible for the attack, or those groups to whom an attack is attributed solely on the basis of material evidence, political speculation, or historic behavioral patterns rather than formal claim making. An attempt was made to minimize the time lapse between attack execution and any issued claim of responsibility in order to preserve the integrity of distinct categories.

\footnotetext{
${ }^{8}$ As defined by the 2010 United States list of Foreign Terrorist Organizations and the University of Maryland START database, or those homegrown groups inspired/trained by an actor contained therein.

${ }^{9}$ As determined by investigating authorities
} 
With regard to the dimensions along which the cases were paired, care was taken to match the attacks according to Mill's Method of Difference by selecting from the gambit of al Qaeda attacks (or those of homegrown cells whit it trained or inspired) those cases sharing similar circumstantial factors aside from claim status. In particular, the researcher attempted to account for those characteristics identified by previous scholarship as having an effect on claim making behavior, such as group ideology, attack method, target type, degree of state sponsorship, nature of the proffered grievance, and cultural roots of both attacker and attacked. With the exception of the 2004 Madrid bombings, each unclaimed case is furthermore one for which al Qaeda founder Osama bin Laden explicitly denied involvement. The particulars of each pairing are related below.

Table 1: Selected Pairs of Unclaimed/Claimed Case Studies

\begin{tabular}{|c|c|}
\hline Unclaimed Attacks & Claimed Attacks \\
\hline $\begin{array}{c}\text { 1998 US Embassy bombings, } \\
\text { Nairobi, Kenya \& Dar es } \\
\text { Salaam, Tanzania }\end{array}$ & $\begin{array}{c}2008 \text { Danish Embassy } \\
\text { bombing, Islamabad, Pakistan }\end{array}$ \\
\hline $\begin{array}{c}\text { 2000 USS Cole bombing, Aden, } \\
\text { Yemen }\end{array}$ & $\begin{array}{c}2005 \text { Aqaba rocket attacks, } \\
\text { Jordan }\end{array}$ \\
\hline $\begin{array}{c}\text { 2004 Madrid train bombings, } \\
\text { Spain }\end{array}$ & $\begin{array}{c}2005 \text { London subway } \\
\text { bombings, United Kingdom }\end{array}$ \\
\hline
\end{tabular}

\section{US Embassy Bombings vs. 2008 Danish Embassy Bombing}

Both operations appear to have been conducted by the Afghanistan-based al Qaeda faction and were similarly executed through the use of late-morning suicide truck bombers. Perpetrated by the same group of actors and without the benefit accorded by state sponsorship, the two cases control for religious and ideological doctrine as well as motivating grievance. The bombings 
were conducted in response to a perceived slight against the Muslim nation and galvanized by the "plight" of the terrorists' "Muslim brothers and sisters." In turn, the attacked states ascribe to similar Western-democratic values or, in the case of the host nations, share a contested space as both a product and current ally of former Western colonizing powers. Furthermore, though the attacks were targeted primarily towards American and Danish nationals, in both instances the causalities consisted mainly of local civilian staff. The selected targets represent outposts of the attacked countries' prestige and influence in addition to constituting their primary channel of communication with the host society.

\section{USS Cole Bombing vs. 2005 Aqaba Rocket Attacks}

Perpetrated against physical projections of American military might, the attacks targeted US naval ships deployed in the Middle East that were not engaged in combat activities at the time of attack. Both operations were attributed to one of the primary al Qaeda factions (e.g. the Afghani and Iraqi branches), though to differing outcomes; the attack on the USS Cole resulted successfully in structural damage and the deaths of American sailors, whereas the Aqaba rockets missed their intended target and produced only collateral damage. Executed without state support, both cases are viewed by the United States Armed Forces as of key significance within the context of attacks against their naval forces.

\section{Madrid Train Bombings vs. 2005 London Subway Bombings}

This pairing is unique to the study in that both bombings were committed by homegrown, selfradicalized terrorist sects relying on al Qaeda training and/or inspiration against the transit systems of major Western European capitals using similar detonating devices and tactics. For a 
time, each operation was considered the worst bombing in Europe since the Second World War as well as the worst terrorist atrocity within each country. Both bombings were shortly followed by another failed attempt (a bomb planted under the rail in Spain and a second attempt to bomb the London Underground), with the justification for the initial attacks centering on the country's support for the US-led War on Terror. At the time of the bombings both the United Kingdom and Spain were considered leading allies of the United States (particularly in counter-terrorism matters), though both have long been considered havens or transit points for Islamic radicals despite decades-long traditions of handling domestic nationalist terrorism. It should be noted that in both instances the grassroots nature of the perpetrating cell resulted in substantial bewilderment as to the exact nature of the relationship between the bombers and al Qaeda Central. In the case of the London bombings, the confusion accompanying al-Zawahiri's delayed claim (roughly two months after the fact) appears to have been an organizational strategy rather than an inability to communicate, given that the group has a documented history of following up ambiguous claims with more substantive and credible messages when it so desires (see the 2008 Danish Embassy bombing or the 2002 Mombasa attacks).

\section{Methodology: Justification of the Discourse Analytic Approach}

This study is designed as the initial foray of a larger research agenda that proposes to examine the linkage between the media content surrounding claimed/unclaimed terrorist events, public opinion, and the formulation of counter-terrorism and security policy. The research utilizes a discourse analytic approach modeled off that of Hopf (2009) to investigate the assumed but untested variation in the construction of a terrorist identity and that of their target counterpart within claimed/unclaimed attacks. If such a distinction exists, the findings of the current 
investigation would be advantageous to the application of process-tracing in identifying media content and its use of problem-framing as a causal mechanism in influencing public sentiment and the formulation of government policy.

Like process-tracing, discourse analysis and the accompanying constructivist framework demonstrate a proclivity towards the examination of process and change (Fierke 2003); indeed, it has been suggested that an interpretivist research agenda can serve both as a precursor of and compliment to a process-tracing research design. Why, in the context of terrorism, is it then essential to examine terrorist operations as processes delineated both temporally and discursively rather than treating them as separate incidents? As Davis (2005) observes, "[t]hough it may make sense for some purposes to conceive of cases as discrete empirical entities, sometimes it makes more sense to think of them as complex phenomena, each of which comes with a history" (p.175). Simply put, a population's experience with terrorism cannot be summarized as a list of distinct events but more accurately resembles a complex web of sustained relationships, wherein the response to every new attack is built upon understandings of and reactions to previous incidents and their perpetrators. Within this conceptualization, the use of discourse analysis may partially compensate for the loss of certain essential information and the oversimplification that Alexander George admits could undermine the validity and usefulness of a more positivist process-oriented approach (1979, p.47).

In applying an interpretivist methodology and ontology to the examination of terrorist claimmaking, not only does the current study seek to compensate for the oversights of previous scholarship that has limited itself to a purely positivist framework but it also seeks to provide a 
foundation for anticipated future research. As Lin (1998) has convincingly advised, should researchers have the opportunity to combine positivistic and interpretivist research they should begin with an "exploratory interpretivist study" in order to suggest hypotheses and mechanisms that may serve as the basis for positivist research. The reverse forces researchers to "impose a 'plausible' theoretical structure on the data before they examine it, which could easily leave out an important variable or include a nonessential one." Because a positivist study will by definition exclude contextual information that may be relevant to an interpretivist study, the initial use of an interpretivist approach will, at the least, allow positivist studies to justify the omitted information as nonessential to the relationships under study based upon previous findings (Lin 1998). Hopf (2009) confirms this assessment: "noninterpretivist methods are most appropriate to the analysis of evidence that already has been collected through interpretivist, hermeneutic, ethnographic, or discourse analytic means" (p.293). Before examining a link between terrorist identity and public opinion in constraining policy formulation, it is necessary to first establish the nature of that identity, the alternative discourses available, and how the dominant narrative interacts and delineates the corresponding understanding of both terrorist and target.

The research proposed here is intended to answer the "what" of terrorist identity in media content and thereby shed light on how such depictions contribute to the cultivation of a certain public perspective. Yet as Wendt (1999) has argued, such constitutive questions are in fact explanatory and not merely descriptive: "[t]here are always 'two stories to tell, ${ }^{10}$ but they are not causal versus descriptive (...) Arguments from disparate sources [e.g. Charles Cross on the double-helix model or William Dray on the appropriate role of historians] suggest that theories

\footnotetext{
${ }^{10}$ For more on this concept, see M. Hollis \& S. Smith, Explaining and Understanding International Relations. USA: Oxford UP, 1990.
} 
which answer 'what' or 'how possible' do 'explain' the world" (p.86). What follows, then, is a discussion of current interpretivist standards of scholarship as they relate to positivist criteria.

One must first recognize the divergence and consequential incomparability of interpretivist and positivist criteria of acceptable scholarship. For those in the positivist camp, the standard to which one's results must be compared is the "averaging" effect — the "effect that one might imagine a variable having if the world allowed for a series of replication under the same conditions"- so as to be representative in the sense of the "typical." Comparatively, interpretivists seek a standard based upon accuracy of detail so as to produce a complete and specific representation, representative in the sense of the "faithful" (Lin 1998). There is further divergence in the handling of uncertainty within both types of research designs. Positivist approaches reduce uncertainty through the comparison of as many observations as possible on particular dimensions (those deemed important by the hypothesis), whereas interpretivists rely on exacting reportage of the circumstances under study and the thickness of the description to produce accurate research (Lin 1998). As such, the primarily constitutive questions investigated by interpretivists, critical theorists, and so forth elicit misunderstanding when judged by the standards of positivists' primarily causal investigations (Wendt, 1999, p.85), despite the fact that both aspire to and generally succeed in "explaining" the world.

Both positivist and interpretivist researchers utilizing qualitative methods have developed sophisticated methods of evaluating and analyzing data to address concerns of validity; both traditions require the documentation of research procedures that may be understood by outsiders and are justified in terms of the knowledge to be obtained (Lin 1998). The standards of both 
groups are legitimate standards by which to evaluate the validity and truth of a body of research, and their incommensurability makes one neither better nor worse but simply employed for different reasons. Within the context of this research, the interpretivist approach is preferred given the need for particularized detail; in seeking to establish the nature of terrorist identity as an affecting factor, the study relies on an exhaustive and nuanced recounting of such narratives to produce a complete and accurate representation. Every detail is important in its ability to potentially affect audience interpretation. Positivist approaches, which pass over such fine distinction in favor of comprehensive averages, would be unable to provide the necessary depth of description. Despite the incomparability of positivist and interpretivist research aims, answers to "why" questions necessitate answers to "how" and "what" questions (Lin 1998; Lupovici 2007; Wendt 1999) so that even positivist researchers must engage in at least implicit constitutive analyses. Given that some of the most important natural science theories are of this type (e.g. the double-helix model of DNA or the kinetic theory of heat) (Wendt 1999, p.85), the value of meticulous interpretivist research has proven essential to expanding the field of knowledge.

\section{Methodology: Method of Discourse Analysis}

The method of discourse analysis employed in this investigation is taken from Hopf's procedure for investigating Soviet identity using mass texts (2009). Consisting of four distinct steps, the design proceeds as follows:

1. Finding identities: the enumeration of the "we" and "other" identities found in each text in terms of who is being represented, and how. 
2. Contextualizing identities: the process of discerning what an identity means within the particular context of the original text. At the end stages of this process, the identities that predominate in the literature are quantitatively identified.

3. Intertextualizing identities: the process of identifying whether an identity holds the same meaning across sources. If so, this step renders a powerful case for intertextual consensus on a particular identity: "the deepest stability a social structure can attain is when no questions of disruption arise, not when ideas of disrupting it are periodically entertained, but then rejected after calculating relative costs and benefits, or after deciding one had better not" (Hopf 2009, p.284). If not, the revealing of alternate understandings across sources given a nominally same identity is equally noteworthy.

4. Intertextualization to discourses of identity: the process of conveying how the intertextualized identities relate to one another in constructing a coherent account of the identity in question to form a discourse. A "discourse of identity" is the collection of intertextualized identities that appear repeatedly when a certain identity is constructed. A discourse predominates to the extent that it is numerically superior to alternate discourses; however, true dominance of a discourse means that this superiority must prevail over all other discourses across the range of sources. An alternative identity may be defined as one that exists across sources and consists of a collection of identities forming a counter to the primary view of self. These non-dominant identities may be subordinate, marginalized, or silenced as compared to the dominant identity (Klotz \& Prakash, 2009, p.51) 


\section{E. Data Sources}

\section{The Use of Large-Sized Newspapers}

Newspapers have often served as a critical medium for social science investigations; prior scholarship has faithfully documented their utility as a source, including more detailed content (Nacos 2003; Paletz et al. 1982, cited in Altheide 1987), ease of access, and archival completeness (Padilla 2007). Though these advantages are important to the investigation at hand, newspapers have been selected as the primary medium for another important reasoncommunicative impetus of their journalists. As David Skok, Senior Producer of Online Content for Global News notes, the "ultimate purpose of journalism is to communicate with, and on behalf of, the audience” (Hogg 2010). The Pew Research Center's Project for Excellence in Journalism elaborates on this assessment, endowing journalism with the central aim of providing audiences with "accurate and reliable information" that "creates a map for citizens to navigate society" for the purpose of functioning in society (2011). The mainstream conceptualization of journalism and its practitioners consequently assumes that individuals are able to understand and make use of what they read and implies that one of the duties of the journalist is to communicate said information in the most readily understandable fashion that both accounts for and is sensitive to the culture and experiences of his/her readership. The advantage afforded by such mass popular texts - for even if some characterize papers such as The New York Times as elitist, there is often an overlap of shared content with smaller, localized papers in the form of wire service articles (e.g. Reuters or The Associated Press) or even small newspapers' reprinting of articles authored by their large-circulation counterparts - parallels R. Williams's assertion that the authors of texts aimed at the masses (e.g. novels) "show people and their relationships in essentially knowable and communicable ways" (1973, p.165). Thus, it may be said that 
journalists also "deliberately select words the average reader will immediately recognize as communicating enough information about the character. Because of their desire to be understood," such authors act as "unintentional ethnographers for the societies about which they write" (Hopf, 2009, p.288). Consequently, the use of newspaper articles provides the researcher with an articulate, detailed record of the identities and related assumptions under investigation written in a manner accessible to and shaped by elite and popular culture. This prevents an investigation restricted to a select few and provides a more accurate and relevant base for future research on media content and public opinion.

The case that must be made here is, therefore, justification for the use of large-circulation newspapers as a source of analysis. At the most rudimentary level is the quantitative explanation; newspapers of this scale simply reach a larger number of individuals in the population, meaning that their content is able to both reflect and affect the perceptions of a proportionately larger group. Furthermore, in terms of data availability, Pew Research Center's State of the Media 2004 Report records that articles in smaller newspaper are shorter in length; $64 \%$ of large newspaper stories topped 1000 words, whereas only $13-29 \%$ of small to medium-sized newspapers did so. At the largest papers, the average article length totaled approximately 1200 words, whereas the average fell short of 600 at the smallest papers (PEJ 2004). Shorter articles may be less likely to yield the detailed accounts that are required for source-intensive qualitative methods such as discourse analysis. Aside from content length, it must also be noted that the news reported becomes more local and less international as circulation size decreases (PEJ 2004). Given that the events under investigation in this study take place overseas - though they may involve 
American forces or interests - newspapers with a rapport for covering national and international events are essential.

Yet in order to compensate for accusations of elitism that have been occasionally levied against major newspapers, this study also includes data from the wire services of The Associated Press and Reuters. These services supplement national and international coverage not only for large papers but also for those with smaller circulations that rely on such sources to complement their limited news gathering resources (PEJ 2004). Consequently, the sources that have been identified in this study are ones made available to and consumed by all segments of the literate population, which strengthens the likelihood that their content would reflect the dominant cultural discourses on terrorism.

\section{Justification of Country-Specific Sources}

For this study, The Associated Press, The New York Times and The Washington Post will be used as representative measures of American media culture. The New York Times and The Washington Post are two of the largest, nationally-circulated broadsheet papers in the country; in the case of the former, it is also the most highly-trafficked American news website and boasts the highest volume of articles as compared to other papers (PEJ 2004). The Washington Post, headquartered in the nation's capital, produces a superior quantity of articles on national politics and provides intensive coverage of US interests abroad. For its part, The Associated Press is the leading national wire service; innumerable news sources within and outside of the United States utilize its articles. 
British coverage of the terrorist acts will be collected from Reuters, The Guardian, The Daily

Telegraph and The Times. Reuters, headquartered in London, is the world's largest international news agency and has a stated policy of "neutral language" when covering terrorist events (Thomson Reuters 2011). Also based in London, the left-leaning Guardian is one of the topselling broadsheets and the largest English-language newspaper presence on the Internet behind The New York Times - in the case of the United Kingdom, it is also the highest-trafficked virtual news presence (Reid \& Teizeira 2010). To balance the political leanings of The Guardian, content from the center-right The Daily Telegraph and The Times will be used in combination, given the difference in article output between these sources and their more liberal competitor. Both broadsheets are amongst the top three most-circulated of their kind in Britain.

When identifying sources from a non-English speaking nation in which an attack occurred, English translations of articles from the primary newspapers in each respective nation were gathered via the World News Connection (WNC) service. Prior scholarship has established that high-quality English translations of original sources (such as those offered by the WNC) yield approximately the same scores under the rigor of content analysis as the originals and thus the use of such translations will not distort conclusions drawn from translated documents (Hermann 1980; Winter 1973).

\section{The Selection of Articles}

News articles span a year from the date of the terrorist incident in order to capture not only the immediate aftermath of the attack but also the lingering repercussions of trauma and details of the ongoing investigation. In instances where the quantity of articles was of a scope that 
reasonably permitted an analysis of all relevant articles, the analysis included the entire body of stories pertaining to the attack in question. For events where the quantity of articles generated surpassed the temporal resources of the investigator and given that selecting a random sample of articles would potentially eliminate key stories and bias the resulting analysis, the following methods were followed: (1) duplicate articles (the same story released for subsequent editions on the same day) were eliminated; (2) articles grounded in subjective opinion (those from the “commentary," "opinion," or "editorial" sections) were eliminated ${ }^{11}$; (3) those articles meeting the 600-word threshold of the "average article in a medium-sized paper" (according to the PEJ 2004) were retained, as it was assumed they were among the main features of the paper and were of sufficient length to provide data for the qualitative methodology employed.

\footnotetext{
${ }^{11}$ The elimination of these articles was justified on an authorial basis; opinion or editorial pieces are generally composed or decided by an Editorial Board, the staff of which are separate from the newspaper's primary news staff (see USA Today or The New York Times) and who are generally distanced from news meetings, story assignments, and day-to-day newsroom operations (Passante, 2007, p.28). Additionally, many of these pieces were more opinionated restatements of news content previously touched upon in the primary news article and therefore a narrative to which the audience would have already been exposed.
} 


\section{CHAPTER 4: CONSTRUCTIVISM AS A THEORETICAL APPROACH}

The adoption of a constructivist theoretical framework is predicated upon both the investigative limitations established by strictly positivist assumptions as well as the suitability of constructivism as an approach to the phenomenon of terrorism. It is noteworthy that a significant proportion of relevant scholarship assumes a positivist interpretation of the world, and in so doing inherently perpetuates certain contradictions within the theory's application to claim making. First, the limited body of empirically tested claim-related literature relies overwhelmingly on the use of quantitative data, which narrows the understanding of terrorist events by quantifying only a portion of the elements inherent to an attack (those able to be translated into numerical form, such as casualty figures, location, group or single actor, etc.). Such datasets tend to be inadequate in their ability to perform a detailed examination of relevant factors - for instance, the nature and intensity of public response.

Perhaps due in part to the privileging of quantitative techniques, positivist theory limits valid data to that associated with observable phenomenon. This has contributed to the conceptualization of violence as a "poor communicator," in that it discounts the idea that who commits a terrorist act is equally significant to the understanding and interpretation of the act itself. An IRA bombing in Belfast, for instance, may not inspire the same level of shock and awe as the unpredicted detonation of a bomb in sleepy Oklahoma by persons unknown or an airborne assault on New York City's iconic symbol of American economic power. Yet the same scholarship simultaneously assumes the existence of a qualitative difference between claimed/unclaimed attacks and their potential audience impact that cannot be explained under the 
positivist framework, given that the primary factor of variance between the two types is, in fact, actor identity. Positivism fails to explain the divergence of response to attacks that are similar in all considerations except claim status. Where terrorists are concerned, all may not be created equal in the minds of the public; the nature of terrorist actors in particular should function as a research question rather than an assumption (Klotz \& Lynch, 2007, p.94).

In ignoring the non-material, positivism additionally excludes elements such as cultural difference that previous literature (e.g. Wright 2009) has indicated may affect the utility of claiming terrorist attacks. Given the constraints on a terror cell's material resources and its ability to physically inflict harm (Mulaj, 2010, p.20), one of the greatest power reserves such actors possess is their potential for coercive persuasion so as to convince others of the threat's reality (Fierke, 2003, p.67), which may or may not involve a physical demonstration.

Furthermore, positivist theory does not account for change across time and space and thus does not explain the fluctuation in public perception a terrorist actor over time (e.g. the perceived threat from a relatively unknown al Qaeda in 1998 as compared to that conceptualized by a desensitized population following a decade of extensive public dissection of the group and its agenda).

In comparison, constructivist theory accounts for both the material and non-material elements of terrorist incidents, including the changing awareness of a particular actor in the minds of the government and public. It examines an act of terrorism within a framework of sociallyconstructed identity and interests that permits the attribution of significance to elements outside of the physical through a focus on the interaction between terrorist and audience. Factors such as 
historical context and processes of knowledge production may help to explain the variation in reaction to atrocities that positivist theory is unable to address. The compatibility of the constructivist framework with qualitative methods yielding richly detailed data allows for greater insight into this phenomenon. Moreover, given that power can be exercised through both physical capabilities as well as relationships (Klotz \& Lynch, 2007, p.11), constructivism's challenge to the positivist conceptualization of power as material resources is particularly relevant.

Constructivism provides a means to explore the fluctuating relationship between particular terrorist identities and audience response that has been ignored in traditional terrorism research, a factor made even more relevant given that the meaning of a terrorist event is collectively generated by the interaction between terrorist and audience (Hulsse \& Spencer, 2008, p.576; Zulaika \& Douglass, 2008, p.29). This is even more pertinent in the instance of the unclaimed attack, in which the identity of the perpetrator is unknown. When paired with the method of discourse analysis, constructivism allows the researcher to inductively develop a pattern of meaning from these interactions that accounts for the fact that the complex picture of reality is superior to predictive positivist mechanisms.

The use of constructivist theory also addresses a gap in the strategic choice framework used to explain terrorist mannerisms, in that the strategic choice model neglects the reality that few (if any) sub-state activist groups engage in their struggles solely for strategic power concerns; there is inevitably a plethora of social, ideological, theological, and other factors that must be taken into consideration (Brannan et al., 2010, p.6). The study of terrorist claim making behavior 
necessitates constructivism's ability to account for the influences of language, culture, and historical context, as well as its deviation from the over-determination of "structure" in neorealist and neoliberal theory (Fierke, 2010, p.180). Constructivist theory incorporates a social dimension that is lacking from both the strategic choice framework as well as positivist approaches while still acknowledging the rationality of individuals within a social context. 


\section{CHAPTER 5: CASE STUDY NARRATIVES}

\section{A. A Brief Introduction to Anonymity}

What constitutes uncertainty depends on "what we want to be able to predict, what we can predict, and what we might be able to do about it" (Marris, 1996, p.16). Arguably, uncertainty is at its most prevalent when there is urgent need for definitive identification despite the lack of evidence and there is little that can be done to alter these odds. Anonymity comprises a particular type of uncertainty that is linked with the inability to detect the identity of another individual or group - the inability to place an entity within the known pantheon to allow for prediction of behavior and appropriate response.

According to Williams (1988), anonymity is a "condition that frees individuals from social evaluation or scrutiny" (p.765); having a name for something makes it "knowable" to the audience. There "may be individuals with whom we have spoken on the phone, whose names we know and on whose behalf we might have had to advocate in some way. In this regard, the anonymity of individuals is overcome for us primarily because we know them by name" (p.763). Yet thus stated, it may be argued that it is impossible for any entity to achieve true anonymity. Human nature dictates the delegation of a name and estimated attributes to unspecified phenomenon so as to render them able to be processed and categorized; our knowledge is relative, depending upon comparisons with other "knowns" for understanding. In the case of an anonymous terrorist bombing, for instance, before the perpetrator's identity is revealed by investigative proceedings, s/he is merely that - the perpetrator, the bomber. An identity, however temporary, is constructed to compensate for that which is missing. We may not know activist 
Dorothy is guilty of a recent string of jewelry robberies, but we do know that the robber snatches only diamonds (and nothing else) from establishments accused of selling blood diamonds, which allows us to ascribe certain motivations or principles to the thief. In essence, anonymity is a war of labels between the sender and recipient underlined by the assumption that the sender derives some benefit, whether material or psychological, from the identity that is attributed to him (otherwise s/he would find an alternate means of expression). Anonymity is the set of characteristics, motivations, and persona that is attributed to a specific actor or actors in the absence of his/her given identity; it is the degree to which a message recipient perceives the source as unknown and unspecified (Anonymous, 1998, p.387) but it is also the content with which the recipient fills said gap and the resulting relationship between sender and recipient via a new mediator.

\section{B. Introduction to Case Studies}

Within the context of the following case studies, this research has identified a list of primary actors: (1) perpetrators; (2) suspects; (3) general terrorists; (4) al Qaeda; (5) Osama bin Laden; (6) the attacked state (the United States, Denmark, Spain, the United Kingdom); (7) the state foil (Kenya/Tanzania, Pakistan, Yemen, Jordan, the United States). Perpetrators encompasses those individuals responsible for the bombings before they are identified as particularized suspects. Alternately, suspects describes flesh-and-blood persons possessing unique histories and names once they have been detained by authorities. Note that perpetrators and suspects act as complements in that perpetrators forms the anonymous counterpart to suspects, just as al Qaeda 
and Osama bin Laden form the named counterparts to general terrorism ${ }^{12}$. The aforementioned pairs (perpetrators-suspects, general terrorism-al Qaeda/Osama bin Laden), as they relate to the present case studies, describe the same actors with varying degrees of specificity; suspects and al Qaeda/Osama bin Laden are "known" to the broader audience and therefore the subjects of memory recall, while the creation and development of perpetrators and general terrorism must be formulated by the receivers at the same time the message is being processed.

Anonymity is, ironically, a fundamentally social phenomenon, requiring an audience of at least one person—one cannot be anonymous if no one is aware of his or her existence (Marx, 1999, p.100). Rather, it is the recognition that there is "something to predict" and the realization that we have limited means by which to do so that creates the condition of flux within which anonymity functions. Thus, the analysis also encompasses the attacked state (the primary state target of the attack) as well as the state foil (either the nation in which the attack occurred, if not the attacked state, or that most frequently mentioned in comparison) as they respond to the multi-faceted identity of the bombers.

Analyses examine the case study data by dividing the investigative period into four stages, as determined by the shifting terrorist identity:

- No Claims of Responsibility: no groups or individuals have accepted responsibility for the bombing. There is scant evidence illuminating the criminals' identities and attempts at further definition are captured by attributions to the perpetrator.

${ }^{12}$ This is possible given that the "general terrorism" discussed throughout the selected case studies is used by the media to refer almost exclusively to Islamic terrorism (except where otherwise specified). 
- Unverifiable Claims of Responsibility: several groups have unreliably claimed credit for the attack but a perceived lack of authenticity invalidates the assertions, resulting in continued use of perpetrator as bomber.

- Tentative Arrest of Suspects: authorities detain the first group of individuals whose extent of involvement is yet undetermined, establishing a parallel between perpetrators and suspects.

- Formal Arrest/Indictment of Suspects: convinced of the suspects' involvement and guilt, authorities announce certainty of guilt for those detained, theoretically accompanied by shifting blame from perpetrators to suspects.

The discourse surrounding the previously identified actors is explored and summarized across the four investigative phases for each of the six paired cases; for the purpose of readability, unclaimed attacks immediately precede their claimed counterparts. Thereafter, overall themes and differences surrounding the identity narratives within all claimed/unclaimed attacks are examined, followed by an analysis of those patterns from a problem-solving and decision making framework. 


\section{Case Study: 1998 US Embassy Bombings}

What follows is a summary of the narrative discourse surrounding the primary actors in the 1998 US Embassy bombings, divided by investigative phase to highlight shifting understandings in media characterizations. The principally descriptive format presents the reader with a detailed accounting of evolving identity roles linked to each actor, the significance of which will be evaluated following the presentation of all case studies.

\section{No Claims of Responsibility}

The immediate media reaction to the bombing reads nothing extraordinary into the attack, committed by skilled but normal criminal actors against a world superpower well accustomed to such antagonistic actions. The unknown perpetrators are seen as untouchable by state authorities. Their inability to be apprehended is not so much a product of American investigative failure as simply a result of the group's operative sophistication. The difficulty in identifying the bombers can be attributed to four factors: (1) the skill of the terrorist group - careful, coordinated, and experienced, the bombers are hardly amateurs (NYT6, WP1, WP2, AP2, AP3, AP5, G3, R10, R13, R140); (2) the overwhelming array of possible bombers - the bombers could be any of 200,000 suspect individuals or 3,000 groups (NYT3, WP1, DTT2); (3) possible government backing - the attack may have been conducted by a combination of terror cells and state governments, whose extensive resources assisted in the cover-up of the operation (G4, R7); (4) the "superman" complex - the perpetrators are inhuman, equipped with the ability to surpass normal security measures and unable to be "stopped by normal means" such as metal detectors, armed guards, or concrete barriers (AP2, R5). 
Barring the less prevalent "superman" discourse, the perpetrators constitute a skilled but normal threat. The United States consequently does not respond with panic or hysteria, despite initial surprise and concern. Rather, such demonstrations of aggression are "old news"; the recipient of 30,000 threats annually (WP2, AP4, AP5), the US is "a major power, and people are going to try to embarrass us or take us down" (WP3) given the superpower is an "obvious target for anything the West is considered responsible for" (AP2, R4). Grim, deliberate, and decidedly statesmanlike, America's vows to "never give up" and "spare no effort and use all means at our disposal" in locating the bombers (NYT4, G6, DTT1, R5, R8, R9) resonate with credibility and experience (AP5, G1). The country projects confidence in its ability to deal with catastrophe and signals this with the immediate dispatch of aid and investigators (NYT1, AP3, AP4, G3, R3), sending knowledgeable teams who embody the "best chance for those trapped in the rubble" (AP7).

Given that the perpetrators are seen as a normal threat, Osama bin Laden is likewise framed as a moral deviant and social outcast, defined primarily by the absence of "civilized" characteristics. An exile rejected by both state and family (NYT1, DTT2), the threat posed by bin Laden is be undermined by his marginaled status (DTT2) as a sub-state criminal actor whose argument with the American superpower is subject to asymmetric power imbalances. The leader of al Qaeda is a matter best handled by law enforcement officials, not the Pentagon.

\section{Unverifiable Claims of Responsibility}

Yet with the onset of attack claims, the contained normalcy of the perpetrator threat is eschewed by its more inhuman qualities, causing the United States to falter in its defensive strategy. The 
bombers now constitute a novel, never before seen danger (AP13) capable of rendering the "end of the world" (NYT18) via atrocities far "better than Oklahoma City" (NYT24), the previous benchmark of extremist carnage. This far-reaching conspiracy extends beyond the actual bombers to a larger web of hostility (NYT20, AP20), made all the more serious as the perpetrators are not "crazies" but rational actors who execute deliberate, advanced (WP12, AP17), well-planned attacks (NYT8, NYT29, R14) with "audacious timing and...breathtaking...logistical skill” (NYT24), facing death with utter calm (DTT3, DTT4). Having escaped greater devastation only by luck or chance (NYT22), America's prior assurances of security ring hollow.

Attempts to specify the exact nature of this new evil result in the application of the classic "villainous mastermind" archetype. No longer a predictable bombing plot, the attacks are so extraordinary that they could have emanated only from one of the "masterminds of international terror" or are the brainchild of a rogue state government (WP5). Complimenting this new understanding of perpetrators, Osama bin Laden likewise evolves from isolated patron to charismatic terrorist leader (NYT7, NYT8, NYT20) whose influence spans the entirety of Africa and the Middle East (NYT8, WP5, AP8).

Faced with new insecurities, the US issues repeated vows to deliver justice (WP5, AP8, AP17, DTT3, R17, R24) and its presence in Africa adopts a correspondingly martial quality that all but eliminates previous humanitarian assistance (WP10, AP21, DTT5, R19, R20, R34). Amid accusations of anti-Kenyan bias, "wide-eyed and battle bright" Marines prowl in full battle gear as America barricades itself behind razor wire and sandbags (NYT7, DTT5). These images of 
separation contrast with repeated oaths to forswear isolationism (NYT22, NYT23) which are motivated not by aforementioned American bravery and defiance but by a grudging obligation to support global peace and democracy (NYT8, AP12, AP20, R26).

Yet the inability of the US to deliver on its promises and identify, much less apprehend, the perpetrators calls into question the nation's credibility as well as its anti-terrorist resources. Despite the dedicated thoroughness of American investigators, who continue to "pour (...) over repots," "raking through the grass" on hands and knees in search of evidence (NYT19, NYT22, R18, R24, R32), America has repeatedly proven itself second best in handling previous terrorist attacks. Unable to gather court-worthy evidence against even known terrorists, the nation has not found or prosecuted those guilty of the Pan Am Flight 103 bombing, the 1996 Khobar Towers bombing, or even the 1975 murder of Athens station chief Richard Welch (NYT8, AP8, AP10, R18, R28). Worse still, America's very ability to "understand and nullify Islamic terrorism" was lost with the 1983 bombing of the Beirut Embassy (NYT24), implying that the state is incapable of apprehending these non-traditional perpetrators.

\section{Tentative Arrest of Suspects}

An interesting phenomenon occurs during the third phase of the investigation, the first instance in which there is a blatant paralleling of known and unknown identities. In the case of perpetrators, public outrage is directed at bombers who now are not only skilled executors but morally responsible for the tragedy. Even as credit is allotted to their considerable skill (NYT39, NYT55, AP25, DTT6, DTT7, R61), technological proficiency (NYT30), and intelligent, meticulous planning (WP18, WP45, AP22, G8), perpetrators are condemned as cowards (WP14, 
AP22, AP23, AP26, AP28, G18, R46, R52), murderers (AP23, AP28, AP49, R39, R75), and ruthless killers (DTT7). They are not small-time criminals but rather the new, more vicious enemy of Western Civilization with coercive power and reach equivalent to that of a nuclear superpower: "not even the Soviets dared to strike at the civilian population of the West as bloodily as terrorists have in recent weeks" (DTT11). The morally corrupt perpetrators are capable of independent action and constitute a serious threat in their attempts to kill massive numbers of people (NYT48, NYT52). They form a criminal conspiracy that has "tentacles stretching to other countries" (NYT55) with "threads all over the world" (NYT55, DTT18). The terrorists in question are slimy, repulsive, and subhuman, insects that infest manifold places in innumerable unseen quantities. When paired with indicators of disproportionate power potential, such repulsive qualities lend themselves to a true security threat.

In the case of suspects, outrage is ironically channeled not towards the arrested individuals but rather at the nation of Pakistan, the first to make an investigative "break" and issuer of a snub to the US Government in transferring the primary suspect directly to Kenyan, not American, authorities (AP45, R73). This sentiment is complimented by a good measure of contempt for the continued incompetence of African authorities, despite the assistance of "advanced" Western nations (NYT31, NYT38, NYT55). Kenya in particular is a backwater (WP16), a web of inefficiency and corruption (R45); in what should be the largest case ever handled by the domestic police forces, said units are instead "trying to fix a brass padlock on the jail door that had frozen in the open position" while suspects are held in a "ramshackle lockup" at the Home Ministry (WP26). The fact that the suspects are not, as in the case of perpetrators, similarly endowed with herculean qualities renders this failure even more bitter (incongruously, American 
domestic media paints the US as a victim of rather than colluder in others' failures). The suspect "round-up" by the Tanzanian and Kenyan police is childish, with individuals detained on the basis of "suspicious" characteristics such as possessing Arab ancestry (NYT49, AP37, AP39, R43, R69, R70). Even the authorities themselves admit their detainees are "not prime suspects" and not a credible threat (AP22, AP23). Furthermore, doubt is cast on Pakistan's contribution given the nation's flexible relationship with torture (NYT38, NYT48)—“American legal niceties do not apply [and] a suspect might be tempted to confess to anything" (WP37) — and the lack of a follow-up confession to American investigators (NYT49, NYT55, WP38, WP41, AP46, AP48).

A final distinction between perpetrators and suspects is the growing tendency to characterize the former as autonomous agents, whereas the latter are unfailingly depicted as "disciples" (NYT45) of bin Laden or part of a team ultimately controlled by the Saudi (DTT15). The independent agency of each suspect as a potential bringer of destruction is therefore inferior to that of the more capable perpetrator, who has been established from the first as a complete terrorist unit and whose external networks act to augment rather than constrain unilateral action. Suspects are thus dependent not only for their resources but for their very status as a threat on their relationship with a more intimidating figure.

Bin Laden steps in to fill this position, escalating his transformation from marginalized criminal to legitimate, center-stage actor. Terms of separation such as "exile" and "extremist" are increasingly replaced by verbiage generally associated with positions of authority in Western society. The "president" of a "terrorist university" (NYT46, WP49, G9), his role evolves to that 
of "supreme commander" (NYT38) of a "financial empire" (NYT30, DTT15). He is further outfitted with daunting weaponry (an "arsenal of surface-to-air missiles, mortars, rockets, and tanks (WP42)), a private army of Islamic zealots (G8), and thousands of well-trained, seasoned terrorists and guerilla fighters (NYT30, WP54, DTT12) commanded by lieutenants worldwide (NYT54, NYT66). A formidable foe, bin Laden fulfills the promise of his Napoleonic trappings as a "state unto himself" (NYT30, WP46). A skilled executive (NYT30), the Saudi is endowed with the ability to declare war (NYT45, NYT46, AP54, G8), alliances with Sudan, Afghanistan, and Iran (WP49, DTT7), the means to pursue WMD (NYT44, NYT45), and even a fortified mountaintop stronghold linking him to a "diplomatic core" of fanatics posted across the Middle East, Asia, Europe, the United States, and Africa (WP38, WP39, WP47, DTT7). The debates in American tabloids of whether or not the CIA could legally assassinate the Saudi exile, given the presidential stay on assassinations against state leaders, implies that bin Laden has in fact become a head of state. An enemy of American creation (given the history between the CIA and Afghani rebels in the 1980s), it is arguable that the presentation of bin Laden as a state actor also attempts to justify American retaliatory actions of a state-to-state magnitude.

However, Osama bin Laden the statesman now also inherits supernatural attributes akin to those of the perpetrators, rendering indistinguishable the real and the fantastic. A legend (WP24), the Saudi exile is a "force majeure" (WP32), the "bogeyman" (NYT52) who exists "beyond the reach of justice" (WP38). Indeed, he can survive America's most advanced anti-terrorist weaponry, escaping unscathed from an attack by $\$ 79$ million worth of missiles, each equipped with 166 bomblets individually capable of destroying an area the size of a football field (NYT61, 
WP51). This "enemy of humanity" (WP47) lurks in his mountaintop "lair" (WP39, DTT9), a shadowy overlord and vampiric figure that seeks to dim the light of Western democracy.

While bin Laden the statesman may be countered with traditional force, the new emergence of bin Laden the myth surpasses even American defensive capabilities. Consequently, the nation is cast as a trigger-happy cowboy (NYT53) in a "Wild-West shoot-first-and-ask-questions-later" script (AP90), retaliating to "mete out rough justice" (WP52) for the bombings; tabloid magazines in New York scream the headlines, “Take that!” (R87). Despite scant evidence and weak justifications (NYT45, WP49, G9, R82), the United States lashes out with gratuitous violence (NYT49, NYT50, WP46, WP52, G10, DTT15, R53, R81, R94) more befitting a cornered animal (NYT51, NYT53, DTT11) than an international superpower. As hyperbolic claims of success riddle the speeches of American authorities in increasingly unbelievable attempts at reassurance - the US is "far, far away from a dead end" (NYT31) and are gathering "the strongest evidence ever obtained in a major terrorist case" (NYT44) - the once poised nation appears diminished, closing embassies (WP33, WP41, AP29, AP35, R46), curtailing NATO participation (NYT33), and evacuating Americans with “panicky” supplications (NYT40, WP41, AP52). No longer a calculating global power, the US is an underdog under siege, striking out in a hopeless attempt to forestall the inevitable.

\section{Formal Arrest/Indictment of Suspects}

The final phase of the investigation sees a complete divorce in the attributes associated with perpetrators and suspects; the cosmic battle against the superhuman perpetrators does not compare to the normalized threat presented by bin Laden, his al Qaeda organization, or the 
innocent suspects. Popular outrage turns upon the US Government and its allies, who are seen as corrupt and bringers of risk, as it becomes evident that America is incapable of tackling the terrorist threat.

Media outlets initiate a complete divorce of personal agency from suspects as well as those skill sets and depravities accorded the terrorist actor. In comparison to the morally twisted perpetrators (WP55, AP55, AP124, AP125), the suspects as individuals are "devout family men" (NYT98) coerced into making confessions (NYT60) by threats to their families and pregnant wives (WP59). Nice, honest, and ordinary (NYT59, NYT67, WP64), "nobody had an inkling” (NYT56) of any proclivity towards violence. The men could have committed the attack only given the assistance and deceptive mechanisms of an outside mastermind (WP57). Since their arrest, the suspects have further been the victims of rights violations, stripped of a fair trial (NYT85, NYT88), unable to comprehend the charges against them (NYT86, NYT101) and isolated from a family for whose welfare they care more than their own (NYT91, WP66). These models of upstanding behavior, some even of American origin (NYT82, NYT98, NYT105, WP63, WP64, R109, R111), know very little about Osama bin Laden and his organization (NYT60); indeed, they would not know the terrorist leader if he "knocked at the door and tried to sell [them] cookies" (NYT108). Their roles as terrorists were a product of learned behavior rather than innate depravity and required that they be "trained in the tools of terror" (NYT57, NYT58, WP55) prior to the commitment of violence. Moreover, the suspects' roles as “followers" or "disciples" (NYT60, WP57, WP70, AP86) ultimately displace responsibility onto the shoulders of others; they have been exonerated of guilt in favor of the perpetrators, who are the "true" terrorists. 
Now the preeminent focus of the bombing investigations, Osama bin Laden is confirmed with international legitimacy as "emir" of his own nation (NYT83, NYT90, WP57, WP73). A “master puppeteer" with "marionettes distributed around the globe" (WP65, WP70, AP100), the Saudi directs his armies on worldwide campaigns like a game of Risk (NYT80), declaring war on the West (NYT87, WP74, A68) and constructing an anti-Western alliance between the bin Laden kingdom, Iran, and Sudan (NYT73, WP68). A hero to his subjects, intelligent, brave, polite, and community minded (NYT100, AP56, AP115), to his enemies the once marginalized criminal is now the "harbinger of a new era" (WP68), a monstrous legend (AP56). The danger that he poses is such that the world superpower is forced to make unprecedented foreign policy concessions that are "not the usual way of doing things" (R114). Osama bin Laden's ability to wield textbook coercive power in forcing the United States - the most powerful state in the international system - to engage in policies it would not otherwise turns the global hierarchy on its head.

Ironically, now that America has individuals in custody its investigation begins to flag (NYT61, NYT89, WP70, G20) as public outcry targets not arrested suspects but bin Laden and the mythical perpetrators. The apprehending of "family men" is no longer what the public needs to feel safe. Once brilliant American integrity, already soiled by the failure to apprehend bin Laden, is further weakened by baseless insistence on the part of investigators that they have made “extraordinary discoveries" (NYT62, WP60) and are "convinced beyond a doubt" (WP56) that they have mounted "one of the largest and most successful overseas investigations in history" (G19, R106). Alternate leaks of the "real" story from US officials note that the Government “can't say for sure what [is] going on" (NYT103) and is "unsure how much progress has been made" (NYT68). The United States has misled the public in its justifications for bombing Sudan 
and Afghanistan (WP56, WP70, AP61, G19, R110) and can provide no direct evidence linking the targets to al Qaeda's leader (NYT76, NYT89). Compared to America, which has not only failed to deal honestly with and protect its citizens but furthermore engaged in grievous rights violations (its simultaneous attacks against Sudanese and Afghani "innocents" that bear uncomfortable similarity to the Embassy bombings themselves), bin Laden appears positively virtuous.

Public outrage for the Africa bombings expands its circle of contempt from American allies to the US itself; it is the United States who bears "a measure of responsibility" for the existence of bin Laden — “we did spawn a monster" (AP72). Furthermore, had America followed the 1985 Inman recommendations (referring to security upgrades for American embassies in the wake of the Beirut bombing), "you wouldn't have had this loss of life" (WP83). Collective governmental failure to anticipate the terrorist threat as well as brash US action in the aftermath of the bombings have forced Americans to "now have to worry about security everywhere" (NYT63), even on "safe" home soil (NYT80, WP71, R109). Kenya and Tanzania have facilitated this failure; initially praised for their cooperation and foresight (NYT64, WP65, WP75), they have been rough-handed in their handling of the investigation, raiding charity offices (AP66) and killing the ailing father of a suspect during a house search (NYT77). The Governments now also stand accused of failing to implement measures that would have decreased American vulnerability; Kenyan authorities previously denied a request to initiate an armed guard service (NYT64) (guards wield only long sticks), refused the creation of a special radio frequency dedicated to embassy security (NYT94), and refused to order local police to guard the building (NYT95). Blame for the bombings is laid at the feet of an adversary both reachable and familiar, 
whose failures facilitated the materialization of the attack. Incumbent authorities have increased the danger through actions likely to draw retaliation, introducing the terrorist threat to the social reality of the average citizen. This new enemy could appear anywhere at any time- - even next door-but the mythical perpetrators who constitute the "real" bombers are so far beyond the known reality of most citizens that there is not even the satisfaction of defining what, exactly, is to be feared.

Note that the contest between the United States and the al Qaeda organization has changed little from a traditional confrontation of state/sub-state or state/state actors; it is expected both sides will conform to the tactics and ability levels suggested by previous confrontations. Comparatively, perpetrators and general terrorists are exempted from the traditional rules of power politics; the threat they pose extends beyond physical security to a moral conflict of Biblical proportions that threatens the very fabric of Western society and is not readily defeated. Discussions of the al Qaeda threat are grounded in customary understandings of guerrilla bands; the group's structure and aims are recognizable and therefore able to be countered. Al Qaeda is depicted as one of two models: (1) a "run-on-a-shoestring" (NYT90) extra-curricular association for the socially inept, or (2) a mafia gang (WP82, R65). In the first, the organization is comparable to an after-school club and has approximately the same retention rate, as membership dips with lack of interest or action: “[al Qaeda] didn’t have a purpose except to carry out the jihad, and since nobody carried out the jihad, it lost a lot of members" (NYT103). Its affiliates consist of "people who had no success in life and wanted to join just to keep from falling on their noses, people who love their religion but had no idea what their religion really meant, [and] people who have nothing in their heads but to fight and solve on the problems in the 
world with battle” (NYT103). Neither well-organized nor hierarchical (G17, DTT7), al Qaeda has been constantly pressured and repeatedly compromised (WP81) and could hardly pose an insurmountable threat.

The parallel narrative is no more terrifying than the first; al Qaeda functions as an "organized crime family" (NYT78) whose members swear fealty (WP73) to their leader in written contracts (WP82). Formidable opponents, they plot attacks against America in secret meetings and seek backroom deals with equally shady actors, such as Sudan or Iran (NYT44, NYT73, NYT84, DTT7), seeking to drive Western influence from the Middle East and overthrow nearly all Muslim governments (NYT53, R14, R107) - a goal that seems out of proportion with al Qaeda's known resources. Similar sentiments have been voiced by previous territorially-conscious rebel groups (e.g. the IRA or the Tamil Tigers), and have been kept relatively contained through the use of political bargaining or martial force. Regardless which frame is employed, al Qaeda also remains ultimately dependent upon bin Laden's status as a threat, rendering the group a less fearinspiring figure.

In contrast, the fight against perpetrators or general terrorists is a cosmic struggle of good versus evil that has played itself out through selected representatives, of which America has proven itself the weaker. Terrorist acts are more than a violation of the rules of civility, they are part of a timeless struggle for the fabric of civilization and the path of righteousness. The participants are not social misfits or Italian-style mobsters, but inhuman, cold-blooded killers and fanatics (WP55, AP22, AP55, DTT7, R39), cruel beings “eager to kill” innocents (NYT52) and depraved in ways that al Qaeda, for all of its bluster, fails to match. The world they inhabit, for 
certainly such evil cannot be a product of our own, is a "viper's nest" (NYT95) of cruelty, a "netherworld" (WP79) that permits the terrorists to "loom out of the mist and vanish again" (DTT17). Able to commence "the end of the world" (NYT18) and bring about divine intervention in the form of a "cataclysmic blow over which mortals have no control" (WP22) or "the arrival of Satan" (WP48, AP55), these phantasms are deadly adversaries with otherworldly powers to match. Organized, educated, and equipped with both worldly and divine powers they have "joined the US in battle" (NYT52) with abilities the superpower lacks and has no means of acquiring; the punishing arm of the law has no jurisdiction over this confrontation. The collateral damage of losing to such an enemy is not merely another bombed embassy but the loss of a way of life, civilization, and humanity itself (NYT52, AP95, G9) — the advent of "new dark age" (DTT11). The perpetrators pose a threat to the very souls of all who oppose them and will perpetuate the battle eternal; America is outgunned by forces it cannot match, sucked into "a race [with] no finish line" (WP65); defeat, though perhaps not immediate, is inevitable. 


\section{Case Study: 2008 Danish Embassy Bombing}

What follows is a summary of the identity narratives surrounding the 2008 Danish Embassy bombing; given the unchanging nature of the discourse (and to save the reader from repetition), presentation of the four investigative phases was condensed to (1) pre-claims of responsibility ("no claims of responsibility"), and (2) post-claims of responsibility ("unverifiable claims of responsibility," "tentative arrest of suspects," and "formal arrest/indictment of suspects").

\section{Pre-Claims of Responsibility}

Unlike the 1998 Embassy bombings, al Qaeda is identified as the primary suspect immediately following the 2008 attack (NYT116, AP125, AP126, AP131, DTT21, G25, G26, N4). The media retraces the group's recent threats of violence (WP85, DTT20, DTT21, N4) and its "extensive justification" of revenge against Danish diplomatic facilities and personnel (AP125, AP126, AP131). Given the well-documented nature of these threats, the potential involvement of al Qaeda is assumed to be unquestionable (AP127, AP131, DTT21, N4); consequently, it is from this group that the perpetrators and general terrorists of the discourse borrow much of their narrative attributes. All three actors share a common geographic origin in Pakistan's tribal areas (NYT116), fury over Denmark’s publication of the controversial Mohammed cartoons (AP131), and rely upon suicide bomber tactics (NYT117, AP131, DTT20, R128). It is significant that unlike the unclaimed attack narrative (in which unnamed terrorist actors are divorced from named counterparts), al Qaeda acts as a filter of understanding that presumes whomever is ultimately found responsible for the operation will be similarly well-understood by requisite authorities and thus able be subdued with existing tactics. 
Consequently, the motivations attributed to perpetrators are reminiscent of al Qaeda's ambitions to bring about the fall of Western governments and sympathetic regional autocrats. The bombers are motivated by a desire to avenge Denmark's offense against the Muslim nation and to cripple Pakistan's foreign relations and isolate its government (NYT116, WP84, DTT20, R130, CP2). Unlike the epic conflict between bombers and targets in the 1998 Embassy narratives, any truly damaging repercussions are confined to the target countries rather than the entirety of the human race, supposing both a limit to the perpetrators ' power as well as their desire to cause harm.

Tentative initial suggestions of a superhuman perpetrator-bombers that can "slip through" new security measures using mysteriously-acquired "inside knowledge," leaving authorities unable to "explain at this moment why this is possible" (NYT116, NYT117)—are dispelled within the very same articles. Hardly otherworldly beings, perpetrators are simply skilled criminals who have taken advantage of Pakistan's multitude of security failures. Though a sovereign nation in its own right, Pakistan is depicted as a struggling post-colonial society, an abortive younger brother attempting to emulate the thriving governmental models of Western nations whose patronizing assistance (NYT116) cannot compensate for domestic failures. Overcoming the security precautions of such a weakling is hardly a great accomplishment, particularly given the deterioration in the national security situation since 2007 (N2, N3, N5) and the provocation of terrorist activities by domestic policymakers (NYT116, NYT117, WP84, R128). Against the advice of Western allies (NYT116, AP125), the inexperienced and unstable Pakistani Government (NYT116, AP125, DTT21, DTT22, R130, R132) entreated radical militants with peace agreements such mendacious persons could not be expected to uphold (NYT116, NYT117, AP125, G25, DTT20, DTT21, R128, R133). Under such circumstances, overtures to "illogical 
fanatics" could only result in such an attack (N4, N5). Though talented, the perpetrators are not possessed of unnatural skills; rather, the Danes "have simply trusted the Pakistani's ability to protect us too much" (AP131).

Though the recipient of the attack, it was furthermore Denmark's foreign policy choices that constituted the nation as a knowing target for terrorist violence, particularly through the reprinting of the controversial Mohammed cartoons (NYT116, NYT117, AP125, AP126, AP127, G25, G26, DTT20, R128, N4). Indeed, the state had already invested in precautionary measures and relocated foreign workers from the embassy structure (WP84, G24, G25, G26, N4), negating the bombers' ability to render the desired lethal blow. Unapologetic for its presumed offense, Denmark strongly condemns the violence, and its subsequent refusal to capitulate wins it the admiration of the larger international community (NYT116, AP126, DTT21, R128, CP2).

Likewise, the attack was not unpredictable (N5) but rather part of an ongoing campaign against resident foreigners in Pakistan following the Government's peace deals with Islamic militants (AP125, AP126, G25, G26, DTT21). Certain to increase unease in the foreign community (NYT116, NYT117, R130) and prompting the closure of the Norwegian and Swedish embassies (AP125, AP126, DTT20, DTT21, R130, CP2, N1), the retaliatory measures in response to blasphemous pictures (DTT20, DTT21, R128) constitute an "open and shut case of jihadis fulfilling an open-ended threat to attack the embassy" (R130). An Islamist suicide attack against Western targets on Pakistani soil is hardly unprecedented or unusual (R130, N1, N3, N4, N5); in fact, one might consider this embassy bombing odd given its realization in spite of its predictability. 


\section{Post-Claims of Responsibility}

In spite of al Qaeda's claim of authorship, the post-claim discourse varies little from the previous narrative in which skilled (but not unusually so) perpetrators overcome the security measures of a failed government to seek revenge against a nation contemptuous of Muslim values - a trope easily recognizable from previous public dissections of bin Laden's group. Here, to, al Qaeda involvement is logical given the group's threat posturing over the publication of the Mohammed caricatures (NYT120) and oft-repeated oaths of revenge (NYT120, AP133, AP134, G27, R131, R132, CP6). Interestingly, the organization's assurances of pending imminent attacks (NYT122, AP132, AP137, R131, R134, CP6, CP9, CP14) do not become speculative fodder for press officers given al Qaeda's questionable ability to deliver such promises in the face of organizational disintegration. A crumbling guerrilla troop badly damaged by the American "fightback" in Iraq, even al Qaeda leaders are "starting to prepare their people for strategic failure" (G28). With one third of its command staff killed in combat (NYT122, G30, G31, G32), the group's integrity is dubious; even now its attacks mostly function as propagandist slogans rather than crippling strikes (AP137, CP15). Given that general terrorists derive their attributed characteristics from the al Qaeda organization, such characterizations also call into question the threat potential of even unnamed terrorist actors (G30, G31).

Moreover, al Qaeda's legitimacy as a vehicle for retribution on behalf of Muslim populations is jeopardized as the discourse of martyrdom (AP133, AP134, AP135) is overwhelmingly silenced by the condemnation of suicide tactics (NYT120, AP146, G27, G29, R131, R133, R134, CP9, CP12), which locates the act in the criminal rather than the divinely righteousness (Fierke 2009). The invocation of "suicide bombing" over "car bombing" not only locates political legitimacy on 
the side of the targeted but also cultivates a moral superiority that delegitimizes the validity of grievance motivating the terrorists. In identifying al Qaeda as the bombers, the narrative establishes a model of virtuous victim versus depraved radical other, polarizing the liberal democratic West and an oppressive, backwards foe. The attacked nation consequently has no need to defend the legitimacy of its own actions given the contrast to the depraved methods of the terrorists.

Such an act of savagery is to be expected in a comparatively unprincipled country such as Pakistan, given its infantile and unstable system of governance (NYT118, AP132, AP134, G30, G31, R132) and repeated failure to improve security (WP86, AP133, AP134, AP135). The embassy bombing is the latest in a "wave of bombings" that has rocked the nation in preceding months (WP87) in response to authorities' well-intentioned but naïve attempts to deal with insincere tribal militants (AP132, G31). Ironically, in what was once considered "one of the safest places in Pakistan" prior to these efforts, residents are now "afraid to come out" (G33). Continual comparisons of this degeneration in security imply that were the misguided Pakistani Government willing to heed the advice of its more experienced and knowledgeable Western neighbors, such security could be easily restored.

Nor are the identities of the detained suspects of an unexpected nature, as they were already suspected in a string of previous bombings (AP138, N9) and have well-established links to top Taliban commanders in the Waziristan region (AP138). Consequently, both the operation and its authors were predictable and the atrocity therefore preventable; the scenario was not so much committed as allowed to happen, intimating that it could and should have been stopped. 
Denmark itself was both an active and aware target, having identified (AP136) and prepared for the al Qaeda threat in advance (NYT120, AP133, R132, CP8, CP12, CP13) as its publications resulted in a "sharpened [militant] focus" on the country (AP137). In turn, the European nation's blatantly unrepentant attitude (CP6, CP7) is interpreted by the international community as a strong defense of free speech in the face of adversity, rendering Denmark - to the consternation of al Qaeda leaders - the heroic figure. Given the clarity with which actors in this narrative assume their projected identities as well as the resolution presented by both the apprehension of the suspects and the recognition of feasible steps to prevent a similar future occurrence, the 2008 Danish Embassy bombing discourse leaves little to the imagination in terms of potential threats. 


\section{E. Case Study: 2000 USS Cole Bombing}

What follows is a summary of the discourse surrounding the 2000 USS Cole bombing. Given that a claim of responsibility (though considered incredible) was issued immediately after the attack, analysis begins at the "tentative claims" phase. The discourse appears to closely match the pattern exhibited by the 1998 US Embassy bombings, in that the credibility of the target nation and its allies is undermined by all-knowing nameless opponents who form a terrifying counterpart to the comparatively normalized and understood al Qaeda organization and its agents.

\section{Tentative Claims of Responsibility}

Authorities immediately reject existing claims as false (NYT127, R159, R162, R163) postulating that organizations are "expected to claim the attack as their own" and thus implying that none are responsible (R140, R141): "traditionally, those who run around claiming credit are not the ones doing these things" (WP95). The pool of potential perpetrators is consequently without limit; there is no shortage of suspects (NYT126, NYT134, WP95, R144, R165), who may include in their ranks collaborating terrorist groups (WP95), hostile governments, or a combination of the two (R165).

Safe in their camouflage of confusion, perpetrators possess abnormal abilities to render themselves inconspicuous by "disappearing” and "spiriting” themselves about (NYT140, WP114, G35); it is unclear how they managed to avoid watchful US Navy lookouts while circling the USS Cole in an otherwise empty harbor (NYT123, NYT125, NYT138, NYT142, WP90, WP95, AP159, DTT25). Infiltrating the safe haven of their victims (WP94, WP96, 
WP116), perpetrators are "snakes in the grass" (WP95) able to "sneak up" (NYT140, WP89, AP171, AP173) and wreak "crippling” blows against their targets (NYT127, NYT135, WP89, AP159).

Such stealth is further enhanced by strategic intelligence; prepared in the art of explosives (NYT125, AP150, AP155), perpetrators are well-organized, well-supplied, and endowed with excellent connections (NYT125, WP95, AP147, AP154, AP157, AP167) that allow for the use of weaponry "more sophisticated [and difficult to obtain] than that used by most terrorist organizations" (NYT132, NYT138, G25). The bombers possessed advanced knowing of the USS Cole's docking schedule, an intimate understanding of refueling procedures (NYT125, WP116, AP142), and foiled security officers through the use of classified information (NYT123, WP90, WP94, WP96, AP148, AP150, AP187, AP188, DTT25, R141, R144). Their prowess is unprecedented - 'I can’t think of a major terrorist operation that has involved, essentially, hardware of that magnitude" (NYT132) — and unstoppable (R157, R138).

Plotted months in advance and scrupulously organized (NYT123, G35, R165), the attack was "so meticulously disguised and carried out...that there was little the crew could have done to stop it" (NYT126, NYT127); it "really stands out" from the pantheon of terrorist attacks (NYT125). Though of "despicable" and "cowardly" origins (NYT123, WP88, AP139, AP150, R137, R143), the level of sophistication inherent to the attack (NYT126, WP114, AP148, R168) is evidence it was "not put together in a garage overnight" (DTT23). The magnitude of this expert achievement is astonishing; the USS Cole is one of the world's newest and most advanced warships (NYT138, NYT140, WP89, AP139, AP142, AP147, G34, DTT23, R135, R143, R158), a ship that was 
"built to fight" (AP146) and protect "itself and others against simultaneous attack by planes, missiles, and ships" (R137). Not only was this colossus helpless against the "maritime equivalent of a car bomb" (NYT123), but said skiff ravaged and absolutely devastated the USS Cole (AP104, AP162, AP163, DTT23, R161, R169) with a force so powerful it sent "terrified Aden residents fleeing into the streets" thinking the city had been "hit by an earthquake" (R135, R137).

Confronted by an unknown and seemingly all-powerful adversary, the United States attempts to bolster its confidence by relying on tried-and-true military strength. An "unrivaled military superpower" endowed with "precision guided weapons, well trained, troops, and global reach," it will bring the attackers to justice; indeed, it is because the US is "so powerful and [has] such good equipment that [its] enemies see that they have to use asymmetric methods" (NYT125). Somber reassurances of imminent arrests (NYT123, WP88, AP139, AP140, G34, R135) degenerate into "strongman" vows of “American justice” (NYT133) and vengeance (WP111, AP175); violent retaliation to "strike a hard blow" is both likely and effective (NYT123, AP150, AP155, R154). Reasserting its place in the global hierarchy, the United States commits itself again to the role of noble protector, "standing guard for peace, for freedom or stability... around the world" (NYT129, NYT133, G35, R138, R144): the USS Cole "not only protects the United States citizens, it protects the rest of the world as well" (AP186). ${ }^{13}$

The promised retaliation is imminent, given that the joint investigation between the United States and Yemen is progressing rapidly thanks to "superb support" from Yemen (NYT129, NYT131,

\footnotetext{
${ }^{13}$ Rare but contrasting references within this section hints at a world-weary, vulnerable superpower (NYT123, NYT133, WP93, WP112).
} 
NYT136, WP102, WP107); the investigation has advanced a "quantum leap" (AP170, AP174) and progress is "better than we could have thought" (WP116, R160, R161). Yet America had only previously averted such tragedy by luck (WP89), visiting Aden two dozen times despite a lack of personnel security checks and Yemen's porous coastline (NYT135). For its part, ally Yemen is characterized as savage and backwards, a pre-temporal "other." Dangerous and volatile (NYT129, WP96), it is an "exotic land with reputation for violence" (AP144, AP159) and a "place to make Westerners wary" (NYT139). The gnarled and dilapidated downtown facades, once elegant reminders of British imperial rule (WP106), frame a nation now ruled by a shadowy secret police whose efficiency results from torture (NYT131, WP107). Lacking a true centralized government (NYT129, NYT135, WP90, WP95), the failed state (NYT129) is fragmented and anarchic (WP95, AP144, AP147, R140, R153).

The Yemeni pseudo-state is particularly unfortunate given that it is "teeming" with terrorists (NYT123, NYT129, WP90, WP102, WP112, DTT24, DTT25, R140, R149), a "hotbed of crazies" (WP94): "next to Sudan and Iran, [it] has one of the highest concentrations of terrorist camps in the world" (AP155). With its "lax and inefficient" security (WP90, WP96), its “crumpled-looking Yemeni colonels in khaki uniforms" hardly compare to efficient American personnel with their "stiff salute[s] and immaculately tailored and crisply pressed [uniforms]" (NYT139). Yet the Yemeni Government denies this affliction (NYT123, WP90, WP95, AP139, AP142) and asserts that the incident was instead the product of an accident aboard the ship (NYT127, AP144, G34, R151), a position later reversed in the face of angry American protests (NYT131, AP167, AP168). 
Even in Yemen, al Qaeda remains under the direct control of "[US] public enemy No. 1" (NYT131, NYT136, AP155, R144, R165, R167) and thus is of immediate suspicion (AP172, AP173, AP174). Accused by the Americans for past terrorist activities (NYT136, AP155, AP157, R159, R167), Osama bin Laden himself is frustratingly untouchable, "surviving any strike against him" (WP107, AP171, AP172, AP174) and taunting that "the dream to kill [him] will never be completed" (AP177). However, it is the unidentified terrorist that here poses an even greater danger. An ever-present threat (WP101) and unavoidable risk (NYT125), these faceless specters "creep...ever closer" to the shores of a people unable to flee (WP101, R149). Savvy and impossible to pin down, they continually probe for America's "Achilles' heel” (NYT125) and new ways to carry out attacks (WP112, R149, R164): "where you shut them down...they go back and cook up a new way" (R164).

\section{Tentative Arrest of Suspects}

The arrest of unremarkable suspects during this phase results in an imagined perpetrator who excels far beyond the normal criminal. Organized (AP208) and well-financed (NYT146), perpetrators are highly disciplined in maintaining years of "airtight operational security" (NYT143, NYT149, NYT161, AP207, G36, R174, R176). Determined to attack until successful (NYT146, NYT149, AP215), these persons are more than “just two guys getting a week's training in the mountains of Afghanistan" (WP131). Utilizing "technological savvy unknown in [Yemen]" (WP134), the level of professionalism inherent to the operation (NYT149, AP199, R172) identifies it as possibly of state support (WP131, WP134, AP208). As explosive material is available in only four nations (of which two are the US and Israel) (NYT146, NYT155), the bombing was obviously conducted by resourceful experts (NYT143, NYT161, AP199, AP213, 
R174). The resulting explosion compares to "David killing Goliath" (NYT146) in crippling one of the world's most advanced combat ships (NYT159, WP132, AP131, AP202, R176, R177, R179) and delivering one of the "most violent and humiliating moments in the [US] Navy's peacetime history" (NYT150).

In contrast to these polished figures, the arrested suspects are painfully conspicuous with thick Arab accents and foreign appearances (NYT151), Saudi Arabian-born Yemenis from bin Laden's ancestral homeland (NYT159, NYT163, NYT164). Yet geography appears to be the only similarity between the al Qaeda leader and the detained, as the suspects are unskilled, requiring outside guidance (NYT161, WP121, AP210) and hardly capable of enacting a spectacle on the scale of the USS Cole.

In comparison to the viciousness of nameless terrorism (NYT146, WP128, AP212), Osama bin Laden is typified as a normalized threat. Commander of a foreign army and architect of a global anti-American crusade (NYT144, NYT146, NYT159), the Saudi is linked to the deadliest terrorist acts of the past decade (WP125) and poses a continued threat to the American people (WP137, R175). His excellent recruiting methods (NYT164, WP121, AP196, G36) have propelled bin Laden to the top of the FBI's "most wanted" list (NYT143, NYT163, AP210).

Its arrests proving unsatisfying, the United States tries instead to reinforce its commitment (NYT149, WP135, WP137, AP198, AP212) and role as “unbowed” superpower (NYT146, NYT150, WP128) vital to continued global security (NYT165, AP214). A "world of stunning technical sophistication and global reach barely imaginable amid the unchanging rhythms and 
beliefs of life [in Yemen]" (NYT159), American boasts still fail to disguise that the mighty superpower was "humbled by two Arab men in a motorized skiff" (NYT146) and limped away (NYT150), dependent upon allies for continued safety (NYT164).

Damaged American credibility also dampens investigative progress and casts the attack as the fault of political ambition. US officials had played down "two stark warnings" issued prior to the bombing (NYT143), and the Pentagon's top intelligence expert on regional terrorist threats resigned immediately claiming safety was sacrificed for stronger bilateral ties (NYT145, WP120, AP191, R170). Furthermore, it is revealed that "no conclusive progress" has actually been made in locating the conspirators, which may now take "weeks, months, or even longer" (NYT150). The "bogged down" state of the investigation (NYT149, AP203, AP209) is heavily influenced by Yemeni resistance, as the United States can "muster expertise and sophistication far beyond what is possible in Yemen" (NYT149, WP119, WP121, WP126) but has had the "door slammed on them” (NYT153, NYT160, AP130, R175).

Initial qualms regarding Yemeni stability and integrity are confirmed by accusations of duplicity. The country, given its savagery (NYT143, NYT151), human rights abuses (NYT148, WP125), lawlessness (NYT159, NYT164) and deluge of terrorist inhabitants (NYT148, NYT150, NYT154, WP120), is incapable of conducting a first-rate investigation. Yemen assumes a "haphazard" approach to the matter of criminal investigations (NYT153, WP119, WP199) and deliberately hinders the investigation for fear of incriminating government employees (NYT162, AP210, AP234); two of the capital's most influential people were one-time allies of Osama bin Laden (NYT164). Police obscure "crucial evidence" (NYT153) and block FBI involvement 
(NYT148, NYT149) with a maliciousness mirrored by the mass public, who express "a halting, half-expressed sense of astonishment, sometimes of satisfaction and even pleasure" at the attack (NYT146): "a few men pointed at [the crippled destroyer] and laughed. Women draped in chadors watching from windows and balconies shouted that the sight made them happy" (AP201). USS Cole crewmembers accuse harbor workers of acting suspiciously on the morning of the bombing (WP132), implying a pervasive and far-reaching conspiracy.

\section{Formal Arrest/Indictment of Suspects}

The final stages of the discourse capture a barbaric failed state and its much diminished superpower ally, the threat against whom remains continues to thrive and which is incomparable to normalized threats such as that posed by al Qaeda and its minions. As in the case of the 1998 US Embassy bombings, media characterization of suspects builds upon a previous discourse of unsuitability that results in detainees' de facto exoneration. The arrested are but henchmen (NYT176) acting on the command of others (AP222, AP225), victims of circumstance that hail from "frequently persecuted" Ismaili Muslim areas (NYT168) and who are unable to gain a fair trial in a country where defendants are denied lawyers and judges are swayed by bribes or government pressure (AP225). Even prime suspect Muhammad Omar al-Harazi, though admittedly a potential "main plotter" (NYT166, NYT169), obtained his skills by training at one of Osama bin Laden's many terrorist camps (NYT168, NYT169, NYT174). The fact that he is party to an organization "controlled by" bin Laden (NYT166, WP138) and his actions dictated by the Saudi exile (NYT177, DTT26) renders al-Harazi’s guilt not entirely of his own making. 
Moreover, despite the detainment of suspects, perpetrators continue to exist as "clever, committed terrorists" able to overcome our security to commit unprecedented atrocities (NYT172, AP223, AP224, R183); they are "predators who will always search and look for weaknesses" (AP229, AP230). Consequently, as the apprehension of suspects has not notably decreased the danger facing the United States, the nation is stripped of its role as global protector and superpower. Evidence comes to light that the military of which American authorities had boasted so confidently was partially responsible for the attack's success. Captain and crew of the USS Cole failed to follow at least 30 of 62 security procedures prior to the incident (NYT167, WP138, WP141, WP142), and the lack of timely intelligence, judgment, or coordinated strategy (NYT170, NYT173, AP220) criminalizes the entire chain of command (AP229, AP230, R185).

Furthermore, early investigative breakthroughs have petered out, leaving investigators with circumstantial evidence (NYT174) incapable even of assigning blame to bin Laden (NYT166, NYT177, WP138, AP232, R182, R183). Yemeni refusal to widen the inquiry to include domestic Islamic groups (R188) has confounded progress, while its authorities continue to frustrate FBI efforts (AP218): "much of the way the Yemenis have conducted the investigation has been troubling" (NYT176). Given its marginal system of governance and plethora of terrorist organizations (WP138), the Yemeni Government has "clamped down hard in the one place it could - Sana'a International Airport” (WP153). Unable to guarantee the safety of its investigators, America is forced to evacuate them (WP147, WP149) in yet another hasty retreat.

In direct contrast is the evermore statesmanlike Osama bin Laden, an icon Arab leaders cannot ignore (NYT169) and possessed of his "own Arab kingdom in southern Afghanistan” (WP149). 
Untouchable (NYT176) and sovereign (NYT176, AP222, DTT26), bin Laden and his foreign allies (WP145) "clearly [have] the US military on edge” (WP148). Capable of transnational operations (NYT166, AP231), the Saudi's power stems from singular control over the al Qaeda organization (NYT177, DTT26). General terrorists, however, pose a "pervasive and enduring threat" to America (AP224, R183, R185) that is more dangerous (NYT173) and encompasses the globe (NYT166). Such actors are at this very moment "plotting and conniving...to bring destruction" among American forces (R185) and are all the more terrifying given their lack of such an icon or controller such as bin Laden. What results is a superpower unable to guarantee even the safety of its own citizens pitted against an identified enemy whose minions are exonerated as well as an unidentified enemy who grows evermore dangerous but whose identification is blocked by the machinations of a scheming, duplicitous ally. 


\section{F. Case Study: 2000 Aqaba Rocket Bombings}

What follows is a summary of the discourse surrounding the 2005 Aqaba rocket bombings.

Given that a claim of responsibility (though considered incredible) was issued immediately following the attacks, analysis begins at the "tentative claims" phase. Deviating little throughout the course of the investigation, the discourse establishes the normalcy of the threat (a contagion of existing insurgencies) as well as the competence of Jordanian and American law enforcement in arresting those responsibility and thereby eliminating continued risk to both societies.

\section{Tentative Claims of Responsibility}

The investigation's beginning phase is quick to establish the threat as unoriginal and quickly addressed by competent law enforcement officials. As with the 2000 USS Cole bombing, the discourse immediately invalidates a bid for responsibility by the Abdullah al-Azzam Brigades (G37, G38, G39, DTT27, DTT28, R197) given that many forums "that originally posted the claim eventually removed it, citing doubts about its source" (NYT178). Speculation abounds as to the identity of the attackers (WP154, AP235, AP236, DTT27), but it is ultimately agreed that the perpetrators failed in their attempt to strike American targets (WP154, AP235, AP237, G37) due to inadequate preparation (R189). Regardless of accuracy, the perpetrators' ability to smuggle rockets into Jordan and launch them in one of the "most secured cities in the country" (NYT178) is a tribute to their dedication. Profaners of the Islamic faith, these persons have "distorted the image of Islam and Muslims" in order to obtain "a legitimate cover, to beautify [their] ugly acts" (AR1). 
The targeting failure does not, however, impact the perceived gravity of the operation. The most serious attack against the US Navy since the USS Cole (NYT178, WP154, AP237, G38, G39, G40), it wrought a damaging blow to Jordan's reputation for stability, as there "has not been such an attack on Jordanian soil in recent memory" (NYT178). The bombing heightened fears of militant contagion and raised fears that insurgents are "opening a new arena of combat" (NYT178, WP154) given that the attacks were highly coordinated (G38, G39, G40, R194) and utilized Soviet-designed battlefield weapons (AP236, G38, G39, G40). Note, however, that this characterization expresses not the establishment of a new threat but rather the spread of one with which both the United States and Jordan have significant experience. The narrow margin with which the rocket cleared the bow of the USS Ashland (WP154, AP236, AP237, G37, G39, DTT27, DTT28, R189) given the crude and inaccurate nature of the weapons (NYT178, WP154, G37, DTT27, R189, R193, R197), demonstrates the perpetrators' competency.

The concerned protector, United States declared its intent to "always make every effort to support and defend [its] servicemen and women" (R189) and its "serious concern" over said incident (WP154). To ensure the safety of its crewmembers, American ships immediately departed the Aqaba port (NYT178) in a precautionary measure permitted by the trusted reliability of Jordanian investigators. Jordan, whose constancy in an unstable region is grounded in its security traditions (NYT178, AP235, G38, G39, DTT27), has long been a close American ally (AP235, R189) and pro-Western force within the region, even forming cooperative relations with Israel (AP235, R189, R192, R194). The likelihood that the rocket launch was a "one-off" attack (G38, G39) is high simply given the dedication of Jordanian law enforcement, who 
initiated house to house searches and welcomed senior government officials on the ground within hours of the bombing (NYT178, R189).

\section{$\underline{\text { Tentative Arrest of Suspects }}$}

Media sources continue to emphasize the skill of authorities in addressing the normal insurgent threat, as investigative findings testify to the accomplished perpetrators; in a "well coordinated military operation" (R199), the bombers knowledgeably selected an industrial area overlooking the harbor where their equipment would not be suspicious and chose to pose the attack early on the Muslim Sabbath when few people would be in the area to identify them (NYT179). They likely possess the ability to hit other targets (R200, JT1) in their quest to topple governments in Egypt, Saudi Arabia, and Jordan (WP155). Yet regardless of proposed motivation, the criminals are without the support of a larger Muslim population (NYT179, R200); they "harm Islamic communities" while serving the "enemies of Islamic nations" (AR2). The bombers are "sinners," even if their actions were committed "under the illusion they were serving religion" (AR3). Demonstration of investigative competency is evident in the detainment of several probable suspects (NYT179, WP155) affiliated with the al Qaeda organization (R199, R200).

However advanced, the attack is comparable to other recent bombings, including that of the USS Cole (NYT179) and the 2002 murder of an American diplomat (R199). The bombings themselves are significant not for their novelty but as a "grim reminder that Jordan is not immune" (NYT179, JT1) from the chaos encompassing its neighbors and as a symbol of the "potential damage such an act could inflict on [Jordan's economy and security] in the long term" (R199, JT4). Given the significance of the attack to Jordan, the United States can comfortably 
rely on its ally's motivation and investigative prowess while it ensures the security of its own personnel (WP155, JT2). Washington's closest Arab ally (WP155, R199) and preserver of the "true message of Islam" (NYT179), Jordan has a strong incentive to minimize its own vulnerability to attack (NYT179, R199, JT1): "for us in Jordan, the most serious element is that the assailants used Jordanian territory to mount the attacks and this has bearings on everything we stand for" (JT4). The irregularity of violent incidents is a product of police experience in keeping the "violence in neighboring Iraq and the West Bank at bay" (NYT179, R199, JT4). Jordanian security amounts to a civic and religious duty; not only are security services expected to "tackle the scourge of terrorism," but defending the nation is "an act of worship" whose responsibility belongs to the entire society (JT1, AR2, AR3). Consequently, it is unthinkable that the bombers will not be brought to justice and existing security mechanisms strengthened.

\section{Formal Arrest/Indictment of Suspects}

The final phase of the investigation emphasizes the competence of the Jordanian authorities in doing exactly that, confirming the utility of existing counter-insurgency tactics while establishing the guilt of detainees and thus negating the possibility of future attack. With a history of thwarting terrorist attacks (including several planned within the past year) (NYT180, NYT181, AP243), it is a testament to law enforcement officials that the nation has "so far been spared major attacks on foreigners despite its proximity to Iraq and popularity as a tourist destination" (R201, R203, JT7). Likewise, prime bombing suspects were quickly arrested (NYT180, NYT181) given that authorities had predicted an imminent attack since 2004 (NYT180, AP238, AP240), and (though unable to prevent the operation) responded with alacrity. Investigative commitment and professionalism is underscored by Jordan's role as an American ally (AP238, 
AP240, AP243, AP244, R201, R202, R205) and the Arab army most closely allied to the West (DTT33), providing crucial logistics for the US-led War on Terror (R201, R204).

The suspects under arrest are worthy adversaries and thus their detainment dismisses the probability of more advanced "masterminds" harbored at large. Intelligent and well-trained (NYT180), the detainees are members of the al Qaeda organization, one of the "most ruthless and powerful insurgent groups" (AP240, AP244, DTT31). Regularly communicating their activities back to the sponsoring organization (NYT180, AP238, R201) the suspects formed a self-contained "militant cell" (AP247) consisting of a ringleader (R205) and his two sons (NYT180, AP238) that autonomously planned and executed the operation. Gripped by "devilish spirit[s]" (AP4), the accused knowingly set out to "kill civilians and terrorize peaceful people quite oblivious of their actions" (AR4, JT12), a far cry from the misguided and innocent suspects of the 2000 USS Cole bombing. The carefully orchestrated assault, which relied on "precise intelligence, weapons training and a smuggling run across the border form Iraq" (NYT180), posed the most serious threat to the US Navy since 2000 (AP238, AP239, AP240, AP244, AP247) and the most serious attack on American targets since the 2002 murder of diplomat Lawrence Foley (R201, R202, R203, R205). The terror cell readily identified and exploited a weak spot in Jordan's security (NYT180, JT6), the narrow margin of their targeting failure (NYT81, NYT182, WP157, AP238, AP246, R205, JT5, JT6) a testament to their logistical skills and the value of their arrest by Jordanian law enforcement. 


\section{G. Case Study: 2004 Madrid Train Bombings}

What follows is a summary of the discourse surrounding the 2004 Madrid train bombings. Given that a claim of responsibility (though considered incredible) was issued immediately following the attacks, analysis begins at the "tentative claims" phase of investigation. The Madrid discourse narrates the deterioration of powerful and credible target nations into progenitors of risk and human rights abuses in their efforts to confront an unprecedented and barbarous threat to which other insurgent groups cannot be compared.

\section{Tentative Claims of Responsibility}

The perpetrators of the Madrid attack are mysterious (AP254), unnamed and unidentifiable (NYT184, G42), though their identity may — if ever discovered-dramatically affect political events in Spain (R214, R218). The bombers possess an inhuman proclivity towards violence; "ruthless," "indiscriminate," and "clearly bent on killing as many civilians as possible" (NYT186, G25, DTT44, R208), normal humans could not have committed such an atrocity (G43). Morally bankrupt (AP249, AP254, R224), the terrorists are scum (NYT185), murderers (AP242, AP263, R213, R218, R224) capable of "butchery on a brutal scale" (DTT35, DTT43). The sheer brutality of the attack (AP249, AP256, DTT37) is a "crime against humanity" and God Himself (AP249, G41, EM1).

Yet the precision with which the attack was conducted (NYT184, NYT185, WP162, WP164, AP24, AP256, AP263, DTT41) birthed a "terrorist holocaust" to "define our age" (G41, DTT37), the likes of which are unprecedented (NYT184, WP163). This "monstrous assault on European democracy" (AP248, AP249, G45) has other European leaders scrambling to fortify their own 
security against an unfamiliar threat (NYT184, AP251, AP262, DTT40) in an age of "global terror inflation" (G41, G46, DTT38, R209, R210). Nor can one protect against such attacks (G46, DTT40, DTT41): "I think it is well for the man in the street to realize that there is no power on earth that can protect him from being bombed. Whatever people may tell him, the bomber will always get through" (DTT39, DTT40).

The specter of this "new threat" results in a contrast between nationalist (represented by ETA) and Islamist terrorism. The former is "relatively easy to crack," given that "its aims are concrete and well known and it has a political wing with whom to negotiate" (DTT39). Having never engaged in an atrocity comparable to the Madrid bombings (G41), ETA is morally salvageable and retains "some connection with the moral universe inhabited by the rest of us" (DTT39). Comparatively, the political agenda of the Islamists "has no coherence and their leaders have no desire to talk" (DTT39); dishonest and wily (NYT185, AP251, AP252, AP256, AP257, AP263, R210, R217), they resort to suicide tactics to achieve their aims (DTT40). This characterization also applies to bin Laden's al Qaeda organization, which has "no shortage of states in Europe [that it] wants to hit" (DTT39, DTT40, R217) and in pursuit of such has infiltrated Spain's Arab population since the early 1990s (NYT186, DTT38, DTT39).

In response to the attacks, Spain targets the well-known ETA (NYT186, WP164, AP248, G41, G42, DTT42, R217). Renowned for its resolute stand against terrorist organizations (AP249, AP252, AP256, G42, G46, R222, R223), the Aznar Government has moved "relentlessly against the terrorists" by employing "only the law but all of the law" (AP249, DTT44, R209) in a firm but legitimate crackdown. A leading US ally and staunch supporter of the War on Terror 
(NYT185, WP164, AP256, R208, R209), Spain is "painfully familiar" and "wearily used to" the “tremors of terrorism" (NYT184, NYT186, WP163, DTT45) and intimately familiar with antiterrorist procedures (DTT37). Spanish police and intelligence services have been "honed by 34 years experience... and have the support of virtually every civilian" (NYT186, DTT34); they have not previously and will not now "give in to the oppressor to which [they have] never shown fear" (EM1).

In turn the United States offers sympathy and solidarity (WP164, AP248, AP252, AP263, G42, R223, R224), taking steps to review its own security measures (WP162, AP253) and cautioning against the hasty assignment of blame (NYT186, AP252). This prudence is particularly relevant given the traumatized and disoriented state of the European nation (AP248, G42, G43), who is "engulfed" with pain and fear and "submerged in grief” (NYT184, AP254, AP255, AP257, AP258, AP263, R214) and thus of questionable rationality and judgment.

\section{Tentative Arrest of Suspects}

As the investigation continues, the credibility of Spain and the United States is shaken as both nations begin to pose a risk to allies. This phase furthermore evokes a contrast between the criminal perpetrators/general terrorists who are beyond the reach of government forces and innocent suspects potentially hailing from the al Qaeda organization, against whom the West has won past victories. Despite the arrest of suspects, the reputation of the perpetrators builds itself to more incredible heights; mysterious, unidentified enemies (WP166, AP292, G47, DTT49, DTT83, R225) who may "still be out there on the offensive" (G75), the ingenious bombers devised a novel tactical shift (NYT210) in executing their attack (NYT210, WP171, R235). The 
operation itself - the sheer scale of which necessitated months of planning, advanced technology, and local knowledge (WP182, G55, DTT60)—was tightly choreographed and complex (NYT188, NYT196, WP165, WP166, WP171, AP266, AP267). Enduring, hostile elements to freedom and democracy (DTT78, R259), the perpetrators are counter-terrorism officials' "worst fear" (WP176, DTT83), political actors (WP172) who have "defeated the government" in a “clear-cut victory" for extremism (WP174, DTT57, DTT67, DTT68). The bombing raised the possibility of future terrorist machinations that would undermine the political systems of the free world (NYT203, WP180, G52, DTT51), throwing the Spanish election “wide open” (AP270, AP271, AP273, AP274) as the first operation to directly affect a Western electoral outcome (G52).

Murderers (G48, G51, DTT47, DTT49, DTT52, R225) and assassins (NYT188, WP167, AP264), perpetrators "have no heart" (R230) but will continue to kill for their own enjoyment (DTT87, R229). Comparatively, detained suspects are decent, friendly young men (NYT194, WP175, G54, G70, DTT80). They are entrepreneurial (NYT194, WP175, AP272, AP275, AP277) and not notably religious (NYT194, WP175, G70, DTT85); attractive, fashion-forward, and without the beard or clothing to mark them as Islamists (G54, G70, DTT85, R245, R246), the fun-loving bachelors are frequent disco patrons (NYT214, WP175, DTT93) who have been arrested unfairly (WP175). It is unthinkable such youths could have been involved in executing such brutality (AP272, AP275, AP277, G54); their "ability to maneuver on the fringes of scrutiny is hardly unique" (NYT210), and it is plausible the men are "totally innocent" (G53). 
If any possibility of suspect involvement exists it is the fault of Spanish authorities, who acted in an enabling capacity. Zougam, the only truly plausible suspect of the detainees, was scrutinized by law and intelligence officials in France, Spain, and Morocco the previous year (NYT202, NYT210, WP171, AP275, G60) and was under surveillance for months before the attacks (NYT195, WP175, AP272, AP273); yet he was permitted to "consort with militant leaders" across Europe and Northern Africa (NYT210, AP288, DTT80) despite evidence of radicalism found in his apartment in 2001 (NYT207, NYT209, WP171, AP290, AP293, G60, DTT93). Collectively, the suspects appear incapable of independently executing the bombings and thus must be under the tutelage of an unidentified mastermind (AP312, AP313, AP314, DTT85); even in the case of Zougam, "leader and coordinator of the people allegedly implicated" does not "suggest that he was overall organizer of the attacks" (AP317, AP318).

It is impossible for authorities to connect such sheep-like figures with the "animal barbarism" that was "Madrid’s Guernica” (NYT191, NYT195, WP166, AP282, G47, DTT48, DTT60, R227, R229). An act of such hatred requires extraordinary resources — "an alliance with the Devil" (NYT192) — and gives rise to a new conceptualization of terrorism (NYT189, NYT195, NYT196, NYT200, WP166, WP183, AP276, DTT89, DTT94) that “alter[s] our lives forever" (NYT203, WP178, DTT91). More concerning is Western intelligence agencies' inability to prevent future massacres (WP168, G53, G61, R234, R249): even 'knowing your enemy doesn't always mean you can stop him from acting" (AP290). Not only can the authors of such attacks strike anytime, anywhere (AP280), but they will attack "whenever and however they can" (AP266). The perpetrators are impossible to appease (WP186, AP299) because they desire 
nothing less than the complete destruction of Western society (NYT210, DTT51, DTT62, DTT90).

The characterization of al Qaeda evolves relative to this new understanding of the terrorist threat with a few significant differences. First, members remain beholden to Osama bin Laden and his political vision (NYT210, WP167, WP172, AP271, AP295, G64), which seeks not the extinction of the West but rather the toppling of particular governments (WP157, WP170, AP269, AP280, DTT50, DTT59). There is further debate as to al Qaeda's organizational integrity, given the liquidation of its command structure and weakening recruiting power (WP193, AP279, G64 DTT74) despite the mutative ability that has allowed the network to survive until now (WP171, AP279). Most importantly, as compared to the general terrorist threat Western authorities have been successful in thwarting al Qaeda attacks for the past several years (R231); unfortunately, this also means that the organization cannot serve as a useful model for understanding the new "unstoppable" terrorists.

Spain's counter-terrorism credentials diminish in light of its "unequivocal" accusation of ETA (NYT190, NYT191, WP171, G48, G49, DTT55, DTT67), the product of a deceitful political class (NYT195, NYT197, NYT201, WP166, WP181, AP268, G52, DTT48, DTT76, R233) who exploits tragedy for political gain (WP174). Yet with the Aznar Government's electoral defeat, Spain's reputation as a "tough partner that fights its corner hard" (G58) in an uncompromising stand against terrorism (NYT193, WP167, WP168, WP172, DTT57, R234, R236, R239) is compromised by political naivety (NYT199, NYT211, WP182, DTT77) and terrorist appeasement (WP184, AP294, G61, G62, DTT88). What was formerly a model of free and fair 
elections was “overshadowed by terror bombings" (NYT203, NYT205, AP273, AP278, AP287) and the product of fear and anger rather than judicious deliberation (NYT215, AP277, AP286, AP287, AP294); Spain has the dubious honor of becoming the first Western power owing its political leadership to terrorists (AP293, G60, G64). The country caved more quickly than even the terrorists had anticipated, given that only one attack (rather than two or three) was required to instigate a change in policy (R244). This weakness is mirrored in a selfish citizenry, as Spaniards validate the use of terrorism and invite more violence for all nations (AP314, AP315, DTT90). Panicked, helpless, and incapable of rational judgment (NYT188, NYT191, WP167, WP170, AP264, G56, R261, R262), "the loudest, most raucous city in Europe [has grown] suddenly mute" (G47). The people's chosen leadership is the "weak link" in the Iraq coalition (DTT68), a stark contrast to Bulgaria, America, Japan, and Britain, who protect international security in defiance of danger (AP280, AP281, DTT89, R251).

Moreover, the much-vaunted Spanish intelligence apparatus failed to act on previous warnings (NYT213, AP288, AP306), raising questions over the effectiveness of intelligence efforts (NYT202, WP174, AP290). Police admit they "would be lost" without the undetonated bomb mistakenly left by the attackers (EP4). This inefficiency is pervasive and longstanding, as the country has provided a regular transit route for al Qaeda (G3) and staging ground for the September $11^{\text {th }}$ attacks (WP171).

As Spain poses a danger to its allies in its validation of terrorist strategy, the United States is similarly of questionable benefit to its international partners. Deferring to the Spanish Government's claim of ETA culpability despite evidence to the contrary (NYT190, NYT198, 
NYT200), the United States increasingly poses a danger to its friends; any ally of the United States is automatically a target (AP287, AP289), sacrificed on behalf of a nation that does not account for the wishes or interests of others (NYT190, NYT191, NYT198, WP174, WP177). The US furthermore possesses vulnerabilities which terrorists "may choose to exploit" in a similar attack (NYT187, WP165) and must now fight the perception that acts of terror against American allies can sway nations from their alliance promises (NYT193, DTT68, R241).

\section{Formal Arrest of Suspects}

In the final investigative phase, Spain and the United States are ultimately determined too dangerous for their alliance partners, particularly given their accusation and detention of innocent men and the potency of an unidentified new terrorism to which the al Qaeda is incomparable. Media sources continue to shelter suspects from accusations levied against them, as the "truly dangerous" men have either perished or are yet to be identified and detained (M25). The former category includes the operational leader (NYT217, WP194, DTT100), who had been planning another grandiose attack (NYT219, NYT222, WP194, AP325, G76, G78): their "radicalism was total (...) feelings towards the West (...) of complete and absolute rejection" (EM18). The counterparts of the departed, shadowy masterminds who are yet an enigma (AP324 AP236, AP344, AP353) are of greater concern, the "pinnacle[s]" of a bombing outfit that has not yet been apprehended (EP15, EP28); media sources continue to question "where is the real mastermind of 11 March?" (M20). In comparison, those detained are good, friendly people (WP196, EM26, EP23), model neighbors (NYT220) who have never set foot in a mosque (EM8) or engaged in suspicious activities (WP196). Hardworking and successful (NYT220, WP196) the men are "fully Westernized, keen on football, fashion, drinking and hashish and their Spanish 
girlfriends" (G76). They are foot soldiers (AP33), immigrants who were "recruited and brainwashed" (WP196, AP249, AP329) and bear childlike nicknames "like Mowgli, the boy in 'The Jungle Book'” (AP329). These are not individuals capable of felling the government of a preeminent Western nation (WP199, WP200, AP363) and committing a hellish massacre with such flourish that it "shook Spain and the rest of Europe" (NYT224, NYT236, AP353, EM16).

The possibility of continued attacks is made more significant by references to the new and inexhaustible "wave" of terrorism that is "sweeping" Europe (NYT218, NYT220 NYT230, WP208): "whenever one terrorist gets arrested, one, two, three or more men will fill his space somewhere else" (NYT218). "Enemies of freedom" (AP330, AP331, AP332), this "militant underworld" (R265) whimsically selects targets (AP349, R278) and poses a catastrophic danger to the continent (AP352, EM15, EP15). The Free World's attempts to dispel these actors are hampered by national rivalries, fragmented intelligence services, and bureaucratic obstacles, open borders, and an unwillingness to share intelligence (WP211, WP213), diminishing the likelihood of effective preventative action.

This shadowy menace stands in sharp contrast to al Qaeda, whose potency has been compromised by US retaliation (WP208, AP352). In his role as negotiator (NYT223, WP197, AP327, R268, EM19), Osama bin Laden plays on fears that Western governments' proAmerican policies place them at greater risk of attack (R267) (which does not require much reinforcement as the US is accomplishing this of its own volition). Paranoid of its own vulnerability, America has "not offered a solid piece of evidence to back its warnings" of impending doom (NYT241, AP234): it "can't see clearly anymore" the threat of terrorism 
(WP210). In its attempts to curb terrorist activity, the US has engaged in a "witch hunt" (WP201), cutting constitutional corners (NYT233) and violating individual rights (WP199, AP254) while rejecting evidence that proves suspect innocence (NYT235). Heeding an "arrest first and ask questions later" policy (NYT232, WP199, WP336, WP337, WP338) authorities detain a mild-mannered army veteran and Muslim convert who had not left America in over a decade and had never visited Spain (WP199, WP200, AP334, AP335, AP336, AP337, AP338, R273). Nor does America accept blame for its mistakes bur rather faults the "inadequate efforts" of its allies (NYT233, NYT235, WP202, WP212, AP340, AP342), despite doubts raised by said countries early in the process (NYT233, NYT234, WP200, WP202, WP212, AP341).

Spain's intelligence services are likewise willfully neglectful, as their observance of early warnings would have prevented the tragedy (NYT224, NYT226, WP207, AP347, G80, EP8). In a place where "al Qaeda operated "with ease"” and a "haven (...) for Islamic militants" (WP204, AP369), the attackers plotted under the very nose of a police force who claims to have been monitoring Islamic extremists for a decade (AP329); ironically, several of the suspects were paid police informants (EM7, EM8). Guided by "rage and impotence and fear" (NYT240, WP194) the politics of Spain have developed into emotional dictates (WP195) issued by a cowering government (NYT225, AP361) whose actions have even been chastised by the Iraqi Vice President (EP14). Unqualified and inexperienced (NYT239, WP197, AP328), the Government retreats even "more hastily than expected" (DTT106), demonstrating a "clear error of judgment" (EM12) that has cost Spain its international credibility (R266, R269, EM12). In accommodating the attackers and giving credence to the idea that terrorist violence inspires policy change, Spain has invited greater risk not only to its own society but also to the entirety of Europe. 


\section{H. Case Study: 2005 London Train Bombings}

What follows is a summary of the discourse surrounding the 2005 London train bombings. Given that a claim of responsibility (though considered incredible) was issued immediately following the attacks, the analysis commences with the "tentative claims" phase of the investigation. The resulting narrative depicts the victimization of both suspects and a hysteric public at the hands of the United Kingdom, whose human rights abuses constitute a threat as potent as that of the unknown perpetrators, who pose a danger so unprecedented that it cannot be quelled by even as experienced a government as that of Britain.

\section{Tentative Claims of Responsibility}

The media reaction immediately following the bombings details the United Kingdom, a country with one of the world's best counter-terrorism traditions and steadfast citizenry, pitted against a sophisticated evil that surpasses the known evil of Osama bin Laden's al Qaeda organization. Whether "lily whites" (locals with no police record) in the employ of "professionals from abroad," (WP231), foreign fighters (G94), a homegrown group or sleeper cell (NYT257, NYT276, WP231, AP380, AP402), or an organization such as al Qaeda (DTT136, R295), the bombing perpetrators remain at large and will kill again (NYT248, NYT263, WP221, WP223, AP386); murderers who have "such evil in their hearts" do not care who they kill (NYT247, NYT248, AP377, G97, DTT141) and have no reservations over a repeat attempt (DTT138). "Animals" deprived of "feelings or humanity" (R287), perpetrators seek to degrade the underpinning of Western society to something more uncivilized and base (NYT250, WP215, WP231, DTT117, DTT140). These persons are guilty of "slaughter irrespective of age, religion, [or] social status" (WP372, AP385, AP403, G98) and "devilish" crimes against "all nations and 
(...) civilised people everywhere" (NYT247, AP372, AP375, AP379, G92, G97, DTT120, R284, R287, R289, R290).

Despite its depravity, the refinement of the attack must be acknowledged. Painstaking, clever, and highly trained (WP231, AP383, AP404, G95, DTT129, DTT135), its authors made use of high explosives (AP401, AP402) to perpetuate explosions of such destructive magnitude the authorities have been unable to identify a single body (NYT247, AP400) from the nightmarish scenes of "blood and bodies [raining onto] the pavement" (NYT249, NYT262, WP215, WP223, WP226, WP229, G91, R282). Highly complex (NYT248, G88, DTT126, DTT127, R281), the operation was well-researched and almost certainly overseen by a trained professional (WP231, G98 AP380, R291).

Against such a threat, the British Government and public are fortunately well-experienced and prepared. The country boasts the "best antiterrorism tradition in Europe" (NYT247) and London the most "sophisticated security system in the world" (DTT123) regulated by security services that are "the envy of the policing world in relation to counter-terrorism" (WP225, DTT127). Backed by decades of experience combating IRA guerillas, their skills are finely honed and cutting-edge (NYT248, WP225, AP386, R281). Additionally, given the perceived inevitability of an attack (NYT267, DTT117, DTT121, R282), London had already rehearsed countless emergency drills that swung smoothly into action following the bombings (NYT245, NYT247, NYT249, G86, DTT118). 
Given years of domestic terrorist activity the British public took the bombing in stride (NYT247, NYT249), exhibiting an impassivity (NYT245, G89, R293) — a "British steel” (AP393, DTT119, DTT120, R283) — that could have come only from one of the world's most vigilant publics (NYT260). Londoners remain united in their determination to defend a way of life (NYT245, NYT247, AP372, AP375, G92, DTT117, DTT120) held "dear in this country and in other civilized nations throughout the world" (WP215). Past encounters with IRA bombers (NYT247, WP223, G96, DTT130) and the blitz of WWII German bombers (NYT255, WP226, AP384, AP387, AP381) have endowed the British public with a particular resilience to terror, as exhibited by the reaction of the average man and woman: "yes, you've tried it now bugger off. We're not scared, no, you won't change us. Even if we are scared, you can still bugger off...this is London. We've dealt with your sort before. Don't try and pull this on us.” (DTT133).

Moreover, the United Kingdom shares an "unshakable" strategic and cultural alliance (NYT244, WP215, WP223, AP215, DTT119, R283) with the United States as the superpower's "foremost ally" (NYT255). America is the "ultimate bulwark against world terrorism" (NYT244, WP217); an icon of liberty and freedom (NYT247, NYT251, AP215, AP373, AP378, R285), it has proven its potency by "smash[ing] up the...structure of al Qaeda pretty effectively" (DTT121). With such an ally_who has offered any assistance necessary (AP405, AP07) — to complement its own strengths, the United Kingdom cannot fail in the face of the terrorist threat.

Yet there is a key weakness in the United Kingdom's seemingly flawless defensive front. The nation's own culture of tolerance has turned it into a "Star Wars bar scene" for Islamic radicals (WP232), a breeding ground for terrorists (NYT267, WP232, AP405, DTT24) with 
"Londonistan" as its capital (DTT134, R293). Nor is the British public quite as emotionally contained as the state might wish; the backlash against British Muslims begins almost immediately despite the absence of a perpetrator identity (G86, G97), and Prime Minister Blair is required to "convince his own people of their own fortitude - and it is not yet clear whether he has succeeded" (NYT245).

One of the recognizable figures of this "bar scene" is that of Osama bin Laden, who acts as both executive and recruiter for his cause (DTT141, R297). The Saudi has persuaded dozens of youth to join the jihad (WP224) and has prevailed upon British openness to establish a political and media office in London as early as 1994 (WP232). His forces, more ruthless and cruel than known domestic terrorist organizations (G86, G93, DTT131), seek extreme policy concessions (DTT141) — nothing that the British Government could deliver "even if it wanted to" (DTT122). A charismatic leader, bin Laden enlists vulnerable citizens (WP224, AP389) into his army to mount attacks alongside his chosen lieutenants (WP224). Al Qaeda, however, is a group of questionable ability; much of its hierarchy has either been captured or killed (NYT267, WP234, DTT121), and its ability to conduct transnational attacks is diminished (WP224, AP389, G94). Unlike the IRA, al Qaeda does not provide prior warning for its attacks and thus it is more difficult to authenticate its claims (G93).

The group's ruthlessness (G86), however, pales in comparison to the threat posed by its unidentified comrades. These elusive terrorist actors are a cancer-like plague on society (NYT247, NYT266), a “scourge against humanity and against civilization” (AP378, R284, R286, R287) that must be combated by all nations. Mimicking the mutative capabilities of a 
virus, the terrorist threat in Europe has undergone a transformation (NYT267) that renders it too widespread to be quarantined (G92, DTT121, DTT141) yet no known measures can defend against its poison (WP217, AP380, AP383, DTT132, DTT136): "there will always be one that slips through the net" (R291). Capable of striking "everywhere and against everyone" (DTT19, DTT123, R287), its triumph over the West is inevitable and future attacks a case of "when, not if” (AP402, AP404).

\section{Tentative Arrest of Suspects}

Following the unimpressive arrests of mule-like suspects, British security forces are seen as failing their frantic public in combating the masterful and depraved threat posed by the perpetrators, which may prove more than the European nation can handle. Suspects detained by British security possess neither the technical nor the intellectual expertise to have autonomously instigated the bombings; they "may have blundered, blowing up the wrong target and accidentally killing [themselves]" (AP415, AP417), "mules" led to believe "they would be able to plant their devices and make their escape" (R300, R304). In comparison, perpetrators as the true "faceless killers" (G107) — ironically also referred to as the "face of evil" (WP235) — are possessed of the ingenuity, deviousness, and technical expertise (NYT269, NYT273, NYT276, R304) to conduct such an operation (NYT273, WP233, DTT147). These mystery men willfully propagated a barbaric assault on the civilized world (WP233, WP236, AP408, G101, G102, R299) that even al Qaeda supporters say "were the wrong thing to do" (AP409, DTT145), resulting in the worst attack since World War II (NYT269, NYT273), the worst ever seen by London (NYT277), and the "end of the world" (NYT280) for many. 
Faced with the extraordinary, British security forces are proving unequal to the task. Unable to identify the enemy and thus incapable of taking definitive counteractions (NYT269, NYT280), police have "desperately" made "urgent plea[s]" to the public for leads (NYT269, WP233, DTT156). The nation has sought unprecedented investigative assistance from the United States and twenty-four European allies; European officials have been "struck by how little was known" and equally stunned at the "call for help" coming from the United Kingdom, which is regarded as having "access to more and better quality intelligence" than other European nations (NYT273).

The stoicism of the British public in "just getting on with it" (NYT274) given the familiarity of terrorist violence (WP236, G105, G107, R299, R300) has deteriorated; individuals are "reeling" and anxious (NYT269, NYT276, R302), perpetuating senseless violence against British Muslims based on suspicion of Islamist involvement (NYT275). This anxiety is not entirely unjustified (though the recrimination against innocents is unwarranted) given that 3,000 British-born or British-based individuals have passed through Osama bin Laden's training camps, and approximately 200 home-grown terrorists "willing and able to slaughter innocents" reside in domestic territory (G101, G109).

As when confronted by the totalitarian ideologies of the $20^{\text {th }}$ century, the United States will stand with Britain to defeat terror using the "unstoppable power of freedom and democracy" (NYT278, WP236, R299). Yet the nature of the threat has changed; London's "model [security] system" allowed the detonation of four explosive devices within city limits (NYT271). Even al Qaeda, whose patterns of activity are well-established, has developed the ability to "change its characteristics, recruitment patterns and mode of operations more swiftly than any other terrorist 
group in history" (G145). These fungus-like terrorist cells (WP234) are not content to topple a single government but instead seek to "break the will of the world's democracies" so as to remake the world "in their own grim image of tyranny" (WP236, AP408, G105, R299).

\section{Formal Arrest/Indictment of Suspects}

The aftermath of the bombings has transformed the United Kingdom into a nervous, triggerhappy weakling who seeks vengeance on British citizens and fails to confront those forces continuing to plot Western Civilization's ruin in a new chapter of terrorism that has rendered Osama bin Laden and his al Qaeda organization irrelevant and outdated. The demise of the suspects during the conduct of the attack does not hamper attempts to displace blame for the incident, and may in face intensify such efforts. Multiple arguments are given in defense of the bombers" innocence; they are "footsoldiers" (NYT337, WP249, WP252, AP421, AP429, AP430, G130, G132, DTT163, DTT167), "at the end of some kind of a totem pole” (AP422) and receiving orders, spiritual guidance and logistical support from an outside source (NYT296, DTT184). Given their youth (NYT332, AP420, AP486), the men may have been duped (NYT332, AP471, G135) or brainwashed (NYT304, AP444, AP419, DTT156, DTT158, DTT169, R305, R324) to be a “tool...of somebody else's evil ideology" (AP445, G135); the "fragile minds" (WP296, DTT205, R331) of the youths could have belonged to "any of our children" (WP276). Under the influence of an evildoer, the young men were "perverted" and "groomed" to commit the atrocity (AP124, AP495, DTT227).

Besides lacking the intellectual fortitude to conduct such an event (NYT304, NYT346, WP243, R353), the suspects were perfectly normal, well-adjusted boys who enjoyed Elvis Presley songs 
(NYT282) and sporting events (NYT290, NYT300, WP240, G116, R373). Sweet, gentle, and loving (NYT292, DTT153, DTT154), the "suicide bombers next door” (DTT169) were welladjusted and "British to the core" (NYT281, NYT286, G237). Despite security camera evidence to the contrary, friends and relatives continue to protest the deceased's innocence: "the idea that he was involved in terrorism or extremism is ridiculous" (WP240). ${ }^{14}$

Regardless of authorship, the bombings signify an unprecedented "new chapter of terrorism" (NYT341, NYT345, G119) that will force "the outlines of life [in Europe to] change" (NYT283, R322), particularly given the novelty of suicide bombings in the region (NYT282, NYT364, WP238, WP252, AP421, G115, R305, R312). An "entirely new manifestation of terrorism" (NYT134) that has placed a strain on the "rules of engagement" (NYT295, NYT231, NYT328, G129), the meticulously planned attacks (NYT325, WP243, G211, R327) suggest experienced authors (R327) with the power to reconfigure reality (NYT339, NYT350, G212) ${ }^{15}$, thereby eliminating the aforementioned suspects. Still at large (NYT292, WP242, AP421, AP422, AP451, G124, DTT196, DTT197), the suggested perpetrator "masterminds" (WP252, G120, DTT169) upset the certainty of identification as they make it impossible to "yet say who carried out the attack" (NYT320, NYT360, WP298). There may be a "third, fourth, fifth cell" (AP444, AP463), a "fifth man, or a sixth man, a seventh man" (WP242, AP423, AP428, G122), "wouldbe killers" who move freely throughout the region (G170, G172). Given the possibility of an

${ }^{14}$ An occasional side narrative contradicts this innocence with retroactively applied evidence of radicalization, citing suspects' increasingly unsociable behavior (NYT341, NYT256), religious zeal (NYT301), outrage over the War on Terror (DTT157), and collusion with Pakistani militants (NYT329, AP430). If indeed the true culprits, the men complete a "journey from perfect son to suicide bomber" (G237).

${ }^{15}$ It is worthy to note here that a large part of these "new rules" refer to the shoot-to-kill policy, which is in fact not new but was employed against the IRA in previous years (R333). 
impending strike, it is a "race against time" for security services (WP273, WP274, DTT202)— yet British intelligence has demonstrated itself incapable of pinpointing the bombers: "where are the plotters and planners? Where is the person with the expertise to trigger it? And is the capability still out there? It could be anywhere" (G114, DTT151).

These perpetrators are the compatriots of general terrorists, those who would destroy the social fabric of European societies (NYT284, NYT334, DTT235) with their "evil ideology" (NYT295, NYT304, WP252, AP445). A “new breed” of terrorist (NYT292, NYT345) who has lost even the support of publics in Muslim countries (NYT291, WP247, AP426), they constitute "a permanent threat from which nobody is safe" (NYT311, WP244, DTT240, R331) and one that does not abide by national boundaries (NYT298, NYT303, G144). Finding such individuals is “like looking for a needle in a haystack" (R373); they constitute a unique evil (DTT183, DTT227) with the power to conquer the human soul (AP427).

It is in comparison to these minions of iniquity that the figures of al Qaeda and Osama bin Laden are evaluated, and the latter are understandably found wanting. Once the premier sponsor of terrorism and "beloved sheik” (NYT356, NYT358), bin Laden's popularity has “dropped significantly" in pivotal Muslim nations (WP247, AP426) despite the Saudi's bids to demonstrate control over his organization (WP266, R367). Bin Laden has "fallen behind younger followers worldwide" (WP85), and his influence over his empire wanes as al Qaeda leadership opts to conserve their resources (NYT283, NYT320, DTT240). Despite expectations of a clear link to the group, the possibility of al Qaeda involvement has been either inconclusive (NYT325, NYT364) or flatly negated (NYT359, WP300). 
With the involvement of the most familiar Islamist group invalidated, the United Kingdom's record of counter-terrorism accomplishments becomes extraneous (NYT284, NYT300, NYT312, R326). The self-confidence of a jittery, nerves-on-edge public (NYT314, NYT328, WP280, AP458, AP459, A460) has "seesawed between bravado and bewilderment" (NYT313) as tested countermeasures proven irrelevant by both the novelty of the atrocity and the very demographics of the British citizenry: "almost all the people voicing that sentiment ["we're children of the Blitz. This is nothing."] hadn't even been alive during World War II, much less survived the bombings" (NYT297). The exposure of British stoicism as myth is paralleled by revelations of security ineptitude over years of neglect. Despite a law enforcement body taken to be "more sophisticated than its [American] counterpart" (NYT231) and the "envy of the policing world in relation to counter-terrorism" (NYT347), and given that "no city in the Western world is better equipped to deter terrorist bombings," the fact that two attacks were conducted in London dispels the myth of invincibility (NYT318). Instead the "model" police force must rely on the goodwill of other nations (NYT292, NYT298), "pleading (...) for help” in an unprecedented manner (NYT288, NYT316, NYT333, WP251, WP261, WP272, AP422). Having looked "the wrong way for years" (DTT173, DTT174), the gap of knowledge concerning Islamist terrorism among British law enforcement is "even bigger than was previously apparent" (AP458, G205). For instance, top intelligence authorities downgraded the threat level facing the nation less than a month before the bombings (NYT303, G146, R320), while bureaucratic ineptitude (AP432, AP448, DTT166, DTT228, DT229) allowed suspicious persons to flee the country (NYT292, NYT303, DTT195, DTT196). 
The continuing possibility of attack has turned the United Kingdom into a terrifying police state, wherein law enforcement rivals its terrorist counterparts as the object of public fear. Overzealous (WP263), trigger happy (DTT186), and having crossed a "once-unthinkable line" in its antiterrorist activities (NYT313, R331), policing has become a fixture of social anxiety (NYT319, G153). Guilty of barbaric murders and “execution style” slayings (WP268, WP271, DTT187), police action could kill more innocents and even children (G174) who are in the "wrong place [at the] wrong time" (NYT324, NYT326, AP469, G154, G155). The nation as a whole no longer pays credence to human rights norms, displaying increasing irritation with European rights legislation (NYT367) and British Muslims suffering a 600 percent increase in hate crimes in the bombing aftermath (NYT321, AP421, AP447, AP480, G117, G120). London has "become Belfast or Tel Aviv" (G151), and their Muslims population "not looked on as human beings" (R309).

The general public must also fear another impending terrorist attack (NYT284, NYT314, NYT229, AP453, G178, G236, R371, R376, R377). Threatened by a yet unidentified enemy (DTT200) with attacks that are unavoidable and unstoppable (NYT285, DTT235, G212, R240, R344), the threat could come from anywhere; even Britain's own Muslim population “made clear they shared the same sense of otherness...[and] understood [the bombers'] anger" (NYT293, WP238, WP243). Despite having prevailed in previous circumstances (NYT283, G182, R323), Britain's American ally also suffers from the same risk (NYT322, NYT349) and cannot take success for granted. 


\section{The Uniqueness of the 2005 London Bombings}

Despite al Qaeda's claim of responsibility, the 2005 London bombings exhibit patterns of discourse remarkably similar to those of unclaimed attacks. This deviation from the typical "claimed case" narrative is explainable for two reasons; first, as with any act of terrorist violence, the majority of media articles are issued in the first months pending the incident, followed by a decline in later weeks as interest wanes. In looking at the 2008 Danish Embassy bombing and the 2005 Aqaba rocket attacks, both were claimed within five days of the incident. The London bombings, in turn, remained without a credible claim of responsibility until two months after the bombings; furthermore, while the al Qaeda video claim was confirmed authentic, the alternating cut-and-paste video segments by al-Zawahiri and the suicide bombers generates ambiguity over the nature and extent of al Qaeda's involvement (did the organization merely provide advisors and resources, or did it function in an active planning and participant capacity?). Consequently from July 7, 2005 until September 1, 2005, the London bombings were, de facto, an unclaimed act of violence. The discovery of unclaimed narrative patterns thus does not invalidate the distinction between claimed/unclaimed cases but rather confirms the disparity between the two types of attack. 


\section{CHAPTER 6: SUMMARY OF NARRATIVE TRENDS ACROSS CASE STUDIES}

What follows is an examination of the narrative trends evident in the unclaimed attack cases, as the element of anonymity is of primary interest; where relevant, the patterns have been contrasted against their claimed counterparts. Summarily, the tendency within unclaimed attacks to render the threatening and threatened indistinguishable destabilizes the mutually exclusive identities of civilized/barbaric, innocent/guilty, attacked/attacker that generally populate terrorist narratives, while at the same time confirming and reinforcing the possibility of harm. In contrast, claimed cases tend to reinforce existing identities and relationships ${ }^{16}$, validating assumptions inherent to the model of state/criminal actor confrontation. As compared to the increasingly radical tenor of unclaimed narratives, the claimed attack discourse sees little fluctuation, rendering the aforementioned relationships stable and thus of predictive value.

\section{A. Civilization vs. Barbarism}

Though the meaning of "civilization" has shifted according to the ideology of the dominant group, it has consistently represented a standard that determines the boundary of a particular, often European, community; "barbarism" is itself understood as a lack of "civilization" (Salter 1999, p.44-5). Both "barbarism" and "civilization" are defined by those characteristics attributed to "civilized" society; as "barbarism" is merely the absence of these features, the differentiation between "civilized" man and the "barbarian" relies on the continued preservation of these features, meaning that the "civilized" world is in constant peril of degeneration.

${ }^{16}$ As discussed previously, the 2005 London bombing presents an exception to otherwise consistent claimed/unclaimed attack narrative tendencies and in the majority of instances tends to reflect unclaimed patterns. 
"Barbarism" is gendered, impulsive, dishonest, dangerous, irrational and animalistic.

"Civilization" is grounded in secular rationalism, emotional and political stability, mastery of impulses, complexity in technology and science, and urban development. The world of the "civilized" further monopolizes moral and ethical superiority, the legitimacy of which forms the foundation of its institutions and systems of knowledge. Consequently, when "civilization" is undermined it is not simply a loss of trust in fellow individuals but a loss of faith in the system itself, the fundamental identity governing the social pact (Hosking, 2009, p.483). The "barbarian" thus functions as a site on which to project the "civilized" self, fashioning both a pre-temporal and inferior other. "Civilized" and "barbarous" identities are consequently mutually exclusive; the "civilized barbarian" does not exist, though there is debate over the degree of barbarism amongst "non-civilized" peoples (see Salter, 1999, p.53). We accept this duality as constant despite historical variation in standards of "civilized" and "barbaric" behavior.

As a general rule, terrorists fall into this latter category, anti-democratic hordes that wish to drag us "back into the dark ages" and are contemptuous of enlightened principles such as rule of law, the rules of war, and human rights. They perpetuate attacks against civilization, indicating they must be separate from such. The perpetrators of unclaimed attacks fit the same "barbarous" mold; animalistic, they are "snakes in the grass" (WP95), predators without feelings or humanity (WP142) that originate in vipers' nests (NYT95) and cast tentacles across the globe (NYT55, WP82, DTT18). They are irrational actors, mad savages (AP282, G15, DTT62).

This narrative calls on a historic discourse that compels the enlightened to use the full force of their civilizing power to keep barbaric forces: their well-trained and superior troops (NYT7, 
WP2, AP73, R245), force of law (DTT44), rationality and deliberation (WP12, AP3), stunning technological advancement (NYT123, WP126), worldly experience (WP122, AP349, R234, R245) and the very doctrine of freedom and liberty upon which their reputation rests (G35, R51, R162, EM1). Based upon established social doctrine, these strengths should easily overwhelm the crude savagery that is the only weapon available to the terrorist. Yet these same "barbarians" are not only animalistic but also masters of beasts. They "butcher" (G43, DTT35) and "slaughter" mindless animals (AP123, AP124), herding the unfortunate creatures through a "slaughterhouse" to their deaths (DTT43). These "dumb animals" are not lesser beings but rather "civilized man," given that it is he who is the terrorist target. Such verbiage calls to mind the killing of animals for market and consumption, implying the "barbarians" are not only masters of the "civilized" but that "civilization" can be devoured as easily as a rack of lamb. The perpetrators are at once both masters of "civilization" as well as its destroyers.

In conquering "civilized man," perpetrators are endowed not only with characteristics that have traditionally have distinguished "civilized society" but also the moral legitimacy accorded such values. Perpetrators are: (1) ingenious, using tactics unknown to "civilized man" that so overwhelm his existing resources that he is powerless against them; (2) advanced, capable of operations of a complexity and sophistication rivaling state-sponsored action; (3) deliberate and rational, with the foresight to plan coordinated, organized and rehearsed operations in a calm and calculating manner years in advance; (4) capable of utilizing sophisticated technology for intelligence gathering and bomb-making of a professional caliber; (5) dedicated, highly motivated with the discipline to undertake necessary training and follow through with the plan of attack. As these qualities embody the controlled, rational model of the "civilized" being, their 
application to the terrorist undermines their role as icons of our own civilization, which indeed the perpetrators appear to do in a very real material sense. Perpetrators "cripple" (WP114, AP163, DTT23, R159) the most advanced warship (NYT172, R135) of the world's most powerful military (AP188), mute Europe's loudest, most raucous world capital (G47), and demolish diplomatic enclaves, traditional symbols of Western power. Adding to this, in committing the worst European atrocities since 1945 (NYT185, NYT195, AP277) the perpetrators are paralleled with WWII era German society, arguably one of the most academically and technologically advanced nations at the time. Bombers are even likened to "David killing Goliath" (NYT146), casting them not only as Biblical heroes and divinely selected sovereigns but subsequently implying that the opposition (here, the United States) is a “savage, unenlightened pagan.” In a significant role reversal it is the terrorists, not the selfproclaimed guardian of global freedom, who are bringing the international community out of darkness into light.

This divinely-favored figure is fleshed out by phrases that attest to the perpetrators' ability to negotiate celestial dealings; they can bring about the "end of the world" (NYT18), strike blows beyond mortal control (WP22), and command the Devil's appearance at will (NYT192, WP48, AP55, AP84). These abilities are augmented by other "magical" talents; perpetrators "spirit" themselves out of harm's way (G35), confound investigators with their mysterious powers (AP166, AP254, DTT83, R225), and are unable to be stopped by normal security measures (AP2). These supernatural abilities endow the perpetrators with the means to force change in Western societies, as following their attacks "nothing will be like before" (DTT37); such events 
will "alter our lives forever" (WP178, DTT91) and "define our age and annotate its calendar" (G41).

In this way there is an unresolved tension between the perpetrators as pre-temporal, inferior others and perpetrators as divinely empowered superhumans. Ultimately, it is the "superior to self" other that dominates the narrative of each unclaimed attack. By casting the terrorists as not only having "civilized" characteristics but as perfecting them to an degree unattainable by “civilized man," we leave open the possibility for civilization to degenerate into barbarism, stripped of those qualities which rendered it superior. Certainly this appears to be a self-fulfilling prophecy; Western societies are portrayed as incapable of objective judgment, panicked and guided by pain, anger, fear, and helplessness that translates into real political capital (NYT184, NYT191, WP29, WP100, WP170, AP34, AP254, AP255, AP258, AP263, G47, R214). Untrustworthy and deceitful (NYT190, WP46, WP166, G11, G52, DTT76, R82, R233), cowardly (AP315, DTT68, DTT90, R244), and imprudent (NYT143, WP120, AP220), the state lashes out with gratuitous violence $(\mathrm{G} 11, \mathrm{R} 87, \mathrm{R} 96)$ that betrays the doctrine upon which rests its legitimacy as a free nation (NYT233, WP181, WP201, AP254).

Compared to the role reversal of unclaimed narratives, the perpetrators of clamed attacks are neither base animals nor divine beings but routine criminals. Certainly, an element of rumor initially circulates as to their possible mystical qualities; they are "phantoms" (AR1), able to slip past improved security measures in fortified cities (NYT178, NYT179) with a stealth that bewilders authorities (AP116). Yet as the narrative presence of the perpetrator figure extends only through the first two investigative phases (until the arrest of suspects), this speculation is 
laid to rest by revealing seemingly inexplicable feats as the product of cleverness, solid planning, and insider knowledge. The terrorists' experience in executing well-coordinated military operations (R199) is indicated by their selection of favorable attack conditions and exploitation of classified information (NYT117, NYT179, WP132, R179). Furthermore, these actors are hardly infallible; considerable emphasis is placed on errors within the conduct of the operation, despite their realization. In the case of the Danish Embassy bombings, perpetrators are highly illogical in attacking a building "merely named as an embassy with no Dane or Norwegian actually present" (N5) (staff had been previously evacuated). Those who ambushed the USS Cole "had not properly prepared for the attack" (R189) and consequently missed their targets (WP154, AP237, G37, R201).

Nor are the perpetrators, readily identified as followers of al Qaeda (NYT125, AP236, DTT27, DTT32, AR1) heroes to an earthly constituency; they instead attempt to create "a legitimate cover, to beautify [their] ugly acts" (AR1). Their actions identify them "as sinners" (AR2, AR3), just as any discussion of martyrdom (AP133, AP135, CP9) is eclipsed by references to suicide (NYT120, G27, R131, CP9, CP12). As Fierke (2009) notes, the distinction is significant because the depoliticized use of "suicide" terrorism "constitutes the agency of states vis a vis a moral deviant and an abject other who is outside politics and is thus the object of legitimate violence" rather than a "moral agent in pursuit of justice" (p.157). Consequently, rather than destabilizing assumed identities, claimed attack narratives tend to reinforce accepted understandings of good cop/bad criminal that tend to accompany popular crime discourse. 


\section{B. Attacked vs. Attacker: The Exoneration of Suspects}

In addition to the continual threat of attack from forces unknown, the attacked state is unable to win a victory on the security front even given the arrest of suspects, as accompanying discourses exonerate said individuals of responsibility. This, in turn, criminalizes the attacked state for detaining "innocents" and further problemitizes the exercise of moral authority by Western societies. The exculpation of detainees follows several models:

\section{Suspects as lacking the intelligence and capability to conduct attacks}

Unclaimed attack narratives frequently typify suspects as mentally deficient and thus requiring the assistance of some unnamed "mastermind" to conduct the operation, a tactic that introduces the possibility of a future atrocity. Suspects are naïve and simple (AP495), assisted by experts who assembled the explosive devices (WP121); perhaps duped into planting the bombs (G135), they may have accidentally caused the device to detonate (AP415, AP417). Their lack of independent agency is demonstrated in a particular case by the failure to remember to activate the pay-as-you-go mobile on an explosive that would have eliminated the trail of evidence (DTT85).

$\underline{\text { Suspects as soldiers under orders }}^{17}$

Suspects are low-ranking “foot soldiers” (NYT337, WP249, AP253, AP421, G130, DTT163) having no knowledge of "the whole plan" (AP210, AP225, AP422, R300). Infantry of a stronger power, suspects exist at the end of the chain of command and are deprived of responsibility for following orders as their position mandates. Their status confers upon them the legitimacy due

\footnotetext{
${ }^{17}$ Note that this section is exceptional that it incorporates data from the 2005 London bombings, for which this particular technique was extraordinarily well-represented (refer to Footnote 14).
} 
the armed forces as well as applicable Geneva Rights, which renders their abuse at the hands of the attacked state even more grievous. Suspects' actions are thus acts of war rather than civilian massacres, and it is the battlefield that is so often considered the scene of heroism. Indeed, the soldier in Western culture is a romantic and noble figure (particularly since the end of the Second World War) who takes suffering onto his own shoulders for the greater good. The self-sacrificing figure bears an uncomfortably close parallel to the "martyrdom" often referenced by terrorist compatriots.

\section{Suspects as originating from a position of persecution}

As if to explain their current predicament, suspects in unclaimed narratives are frequently typified as coming from backgrounds rife with discrimination. They are from religious minorities abused in countries such as Yemen (NYT168) or have been subject to torture during their detainment (WP37, WP59), the authorities overseeing which threaten not only detainees' personal security but also that of their families (WP59). It is not nations such as Pakistan or Sudan that so callously discard rights precedents but rather powers such as the United States and Spain whose very distinctiveness is based upon guarantees of freedom and liberty. Suspects are remanded even though their guilt is questionable and it is unlikely they would have been involved in planning or carrying out the attacks (WP175, AP272, AP275, AP277, G53, G54); they may be guilty only of being in the wrong place at the wrong time. 


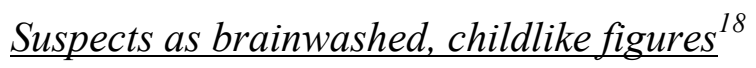

Suspects are characterized as having ingenuous characteristics, whether immaturity, gullibility, or proclivity towards brainwashing. They are young, emotional, and ignorant (AP329, AP486), “just a kid" like any other (NYT332, WP276, AP420). Even the Madrid attack, which killed 191 people and wounded over 1800, was blamed on a man bearing a nickname from a childhood fable (AP329). Befitting their adolescent tendencies, the suspects are easily tricked and manipulated into participating (NYT204, NYT332, WP196, AP329, AP471, DTT156, R324) as "tools of someone else's evil ideology" (AP445, G135). Moreover, these individuals have been "groom[ed] to carry out such evils" (WP253, AP444, AP468, AP469, DTT227). The use of terminology such as "grooming" to refer to suspects, given its frequent association with pedophilic discourse (Hoskins \& O'Loughlin, 2009, p.82), further emphasizes the maltreated suspects and their inability to be held to account

\section{Suspects as Western and morally upstanding}

The discourse of unclaimed attacks frequently portrays suspects not only as morally upstanding but also as fully Westernized. They are kind and cheerful, "not the type you'd think of as an Islamist" (G70). Quiet, model neighbors (NYT220) and devoted family men (WP66, R109), they are perfectly normal (NYT290, R373), infinitely likable and gentle individuals (NYT290, WP246, DTT153). To compound such flattering characterizations is the notion of suspects as subscribing to Western lifestyle and mannerisms. Materialistic, they are the first to embrace new fashions (DTT85) and high-end labels (R245, R246), socialites who are not "Islamic extremist[s] but (...) fun-loving figure[s] who liked discos, fast cars and drinking” (WP175, G76, DTT93).

${ }^{18}$ Refer to previous footnote. 
Attractive (G70, R246) and hardworking (NYT194, WP175, AP275), suspects are interested in the "religion" of capitalism (G70, DTT85, EM8). Either married to or dating American and British women (DTT93, DTT95), most are "charmer[s] who like to flirt" (AP418) and "eye up girls" (G70).

In the rare instance that suspicious characteristics are ascribed to the detainees, the accusations generally center around one individual (e.g. Zougam or al-Harazi). Though perhaps not as comparatively blameless, their responsibility is waived by designating such persons as "low on the totem pole"; for instance, "leader and coordinator [of the bombing squad] does not suggest he was overall organizer of the attacks" (AP317, AP318). Furthermore, blame for the attack falls upon security services who failed to prevent the bombings. Such "main plotters" had been under surveillance for months (NYT195, WP175, AP272), known to intelligence officials around the world (NYT210, G60) and yet were permitted travel without restriction or dedicated surveillance (AP210, AP288, DTT80).

Note also that the portrayal of the "Western man" is not overly flattering. What emerges is that to be "Western" and thus "civilized" is to be obsessed with a partying lifestyle (including substance abuse), materialism, physical appearance, turning a profit, and crude objectification of the female as an object of sexual liberty. In turn, the "Islamist" is understood to be unattractive, disdainful of "fun," never happy and disinclined to exhibit "neighborly" qualities. Yet to be an "Islamist" is also to possess self-restraint, a strong moral compass and a penchant to place stock not in Armani brands but in the tenacity of one's familial bonds. When measured against "civilized" 
principles, it is ironically the "Islamist"- unattractive "stick in the mud" though he may be - that embodies to a greater extent the controlled, moral actor underpinning "civilized" society.

The aforementioned depictions of suspects further destabilize the categories of terrorist/nonterrorist. Suspects are identified not by their criminal proclivities but by titles that the average individual shares - family men, children, sports lovers, Westerners. They are decent people who have been conned and otherwise taken advantage of based upon a lack of common sense and worldly experience. They are our neighbors, our children — any of us could be susceptible to such radicalism, much as anyone is susceptible to the addiction of drugs or alcohol. Consequently, attacked societies must now not only share the title of victimhood but also the possibility of blame as progenitors of the attackers.

Comparatively, suspects as detailed in claimed attacks are not exonerated of guilt but confirmed as mature criminal actors; the attacked state is thus validated as protector of the public good in preserving order and the rule of law, and its society remains unique in its victimhood. Suspects attack largely of their own initiative, demonstrating themselves cognizant and competent. Their affiliation with criminal groups such as al Qaeda (DTT31, R189, R198), in addition to extensive training and intelligence gathering (NYT180) render them skilled offenders. Despite a shared vision authored by Osama bin Laden, these actors are "in charge" of both designing and executing the attack (AP238, NYT180) and are thus morally culpable; gripped by "devilish spirit[s]," they knowingly murder innocents for their objectives (AR4). Moreover, their criminal activities are not limited to the current offense - the suspects have been previously involved in committing acts of terrorism (AP138, AP235, N9), compounding their guilt. Rather than unjust 
imprisonment, the attacked state is to be lauded in removing such individuals from the vulnerable public sphere, which functions as recipient rather than producer of terrorist violence.

\section{Attacked vs. Attacker: The Attacked State and State Foil}

In the discourse of unclaimed attacks the attacked state is often cast not as mediator but as source of risk and a danger to its own society, a contradiction further emphasized by the previously discussed typifying of suspect figures. In such instances, the characterization of the state foil follows that of its criminalized ally and reinforces both as doer of harm.

\section{The state as attacker}

More than their claimed counterparts, unclaimed attacks tend to call into question not only the attacked nation's myth of invincibility and capacity to defend its population but also its status as a member of the "civilized" world. Prior to the arrest of suspects, the attacked state constructs itself as a bastion of anti-terrorist sentiment, experienced and battle-ready. It is painfully familiar with threats of violence (NT184, NYT186, DTT45) given that its preeminent international standing solicits thousands annually (WP2, AP4). Consequently, police and intelligence apparatuses are alert and honed by years of deflecting antagonists (NYT186, DTT34); capitulation to or negotiation with such forces is unthinkable (R94, EM1). The attacked state has unrivaled power at its disposal with which to confront this new threat; in fact, it is because the country is so impregnable that its enemies were forced to use asymmetric tactics (NYT125). Bold phraseology and action-oriented verbiage reinforce the nation's willingness to employ this power and fulfill its protective obligation. Resolute, determined, and focused (WP162, AP252, G42, R217, R223), the attacked state is relentless and dismissive of compromise (DTT44, 
R209). It is swift and decisive in its strategy (NYT123, G42), leaving no doubt that a hard blow to enemy forces will restore security and normalcy (AP150, R154).

Not only is the attacked state possessed of unlimited power and the resolve to employ it in full, but it also wields superior moral/ethical authority. The United States is the guardian of global stability and peace, world superpower and a lynchpin of "civilizing" force. Its resources not only protect its own citizens but the entirety of the free world, safeguarding the existence of freedom and democracy (AP186, G35, R4). Spain's role as a democracy born of civil strife and staunch American ally confers credibility upon it in kind by extending the mantle of democratic repository.

As the singular perpetrator narrative divides into the duality of guilty perpetrator/innocent suspect, the discourse surrounding the attacked state likewise evolves. Media continues to laud the military superiority of the targeted nation, with its "stunning technological sophistication" deployed on a "barely imaginable" scale that reaches to the corners of the earth (NYT159, NYT165). The attacked state remains steadfast, unquestionable in its ability to deliver justice (NYT149, WP128, WP167, WP168, G58). However, the discourse of the "new" or "extraordinary" terrorist threat erodes these claims; if an attack is truly novel, the current skill sets of security forces may not apply, rendering boasts of superiority severely diminished in importance.

Furthermore, the nation's ability to adapt to the threat is plagued by weakness, the efficiency of its security apparatus called into question not only given the most recent attack but also due to 
repeated intelligence failures. The attacked state as a secure fortress is undermined by evidence that terrorist actors may have used it as a regular transit point or staging ground (G53, WP171) or, in the case of the USS Cole bombing, infiltrated secure areas prior to the attack (WP132). Having failed to heed others' warnings and in the absence of essential intelligence, the attacked state's attempts to "make up ground" are hasty and sloppy (WP181, DTT77).

The country's moral authority is also challenged by its response to the attacks. The retaliation of the attacked state in meting out "rough justice" (WP52) is rash and gangster-like (the very phrase repeatedly employed to describe certain politicians) (DTT12, R102). Reluctant to admit mistakes, government figures mislead populations (NYT150, WP166, G49, DTT67) as the fearful society (NYT188, AP209, AP264, G56, R258) compromises its integrity as a rational actor and allows politics to become a product of emotionality rather than calculated deliberation (NYT215, AP277). Within this environment that the terrorist actor accumulates victories, forcing policy changes with seemingly trivial effort (NYT146, R244) that humble the great power (NYT146, DTT468).

During the final investigative phase the line between attacker and attacked is comprised and the attacked state fully established as a source of threat. Mendacious and unreliable (R269), the nation is beset by accusations of imperialist ambitions, humanitarian neglect and intentional denial of aid (NYT239, AP52, AP53, AP238) that undermine its legitimacy. It is further plagued by allegations of misleading or lying to its citizenry either through a political cover-up or by intentionally voicing inaccurate threat predictions. The erosion of human rights is further perpetuated by the attacked state's repressive actions. The government is cast as the detainer of 
innocents, with the specific abuses suffered by those arrested examined in great detail: secret trials of questionable fairness (R111), collusion with torture (NYT60), issuance of baseless accusations (WP201, DTT16) and the withholding of constitutional rights including failure to explain levied criminal charges (NYT85, NYT86). In the case of Spain, the Government even comparatively legitimizes certain nationalist terrorism through continual comparisons characterizing a few organizations as "more civilized" and legitimate than Islamist groups (G47, DTT60, DTT61, DTT94). ${ }^{19}$

In the employ of an oppressive state, the military — an extension and projection of state powerbecomes a danger rather than protector. Not only does it invite greater risk to itself and others by failing to follow proper security procedure (WP138, AP229, R185) and committing severe lapses in judgment (NYT170, WP8, AP220, G80) but it strikes against innocent civilian targets (WP56, G19). More concerning, the ranks of the security forces actually produce terrorists who attack domestic targets (WP71, R125, EM7, EM8). As handler of the military, the attacked state is guided by rage, impotence, and fear (NYT240, WP194) of which consequent policy decisions are unpredictable and absurd. The trope of the attacked state as a beacon of Western enlightenment is dismantled as the country instigates humanitarian emergencies and propagates abuse against domestic and foreign populations. It is not only physical security that has been yielded to the terrorists (NYT225, EP14), but the state itself evolves into a source of cruelty that both produces and perpetuates abuse against terrorists and citizens alike, undermining the validity of its institutions, its role as victim, and its place within "civilized" society.

${ }^{19}$ This tendency is also predominates in the discourse of the 2005 London bombings. 
In the case of claimed attacks, the attacked state continues to function as a moderator of threats, in part due to the affirmed guilt of the suspects; authorities can hardly be criticized for fulfilling their legal obligations. Concerned shepherd and people's protector, the attacked state takes precautionary measures to diminish the risk facing its citizens (WP84, AP127, DTT20). Despite the reality of the catastrophe, this effort reassures the population of the government's benign commitment to make every effort in their defense, proof of which is the apprehension of the bombers themselves (WP154, AP238, R189). The attacked state is indignant and forthright in issuing its condemnation (NYT116, AP127, AP236, R128) from a position of strength and moral supremacy (G25, G26). A powerful actor, it denies "victory" to terrorists by steadfastly maintaining a normal political agenda (AP126, DTT21, CP2, CP3, CP11). Moreover, the very actions suggested as possible provocations for the attacks (e.g. the publication of the controversial Mohammed cartoons) are depicted not as foolish or inflammatory but rather in defense of basic human freedoms (DTT20, CP6, CP7). Consequently, far from undermining its reputation as a lauded member of international society, the nation has demonstrated its loyalty and commitment to the doctrine of Western liberal order even under siege.

\section{The state foil as mirror}

Interestingly, the state foil complements and to a great extent follows the characterization of the attacked state. For claimed attacks, the reputation of the attacked state as virtuous defender remains unchallenged; under such circumstances, the state foils (the United States, Jordan, and Pakistan) are portrayed as longtime (AP235, AP238, R202) and loyal allies (WP215) who supple the targeted nation with crucial support and services (R201, R204). Like their ally, the state foils are bastions of freedom and anti-terrorist mandates (NYT244, AP279, DTT33, R285) with 
established traditions of security (NYT179, JT4), stability (AP235, G38, DTT27), and extensive experience in thwarting terrorist plots (NYT181, AP243, G182, R323). Highly proficient both militarily and politically, these are nations who will stand with their allies to face down the most “murderous ideologies” (NYT178, NYT278, WP236); even Pakistan, who-though naively optimistic in its insurgent negotiations (NYT116, G26, R130)—-has successfully conducted antiterrorism operations (AP86, AP135) and proven themselves a key supporter of the War on Terror (AP133). The unwavering moral "good" of the state foil bolsters the attacked state's own authority and its ability to confront danger with due recourse to the rule of law.

This is not so in the case of unclaimed attacks, where the state foil (the United States, Kenya, Tanzania, and Yemen) also see a shift from attacked to attacker. Initial offers of friendly support and resources (NYT4, WP2, WP164, AP248, G42, R5, R223) quickly degenerate as the state foil's internal weaknesses compromise its efforts and render it a danger to the international community. The state foil is duplicitous in "assisting" the attacked state; it has obscured evidence (NYT153, AP210), hindered the investigation (NYT176), and may even have actively participated in the bombing conspiracy (WP132). Refusing to engage in supportive actions that may reveal its dishonesty, the state foil rejects blame for investigative errors (NYT235, WP212, AP342) and fails to examine suspicious persons within its own citizenry (NYT176, R188). The country furthermore musters hostile sentiment towards the attacked state; in the case of the US Embassy bombings, this resentment results in a lawsuit against the American Government, despite Kenya's continual refusals to provide requested increases in security prior to the bombings: “why should we suffer on [the Americans'] behalf?” (NYT94, NYT95). 
A growing danger to its alliance partners, the state foil is uncontrollable (WP153), unable to "see clearly" (WP210) and thus prone to vulnerabilities which "terrorists may choose to exploit" (NYT187, WP165). Consequently, its allies also become a target of terrorist actors that the state foil already harbors domestically (WP13, WP138, AP287, AP289). It cares little for the wishes or interests of its international partners (NYT198), who voice "alarm and despair" over its selfish wielding of global influence (WP174).

Finally, the state foil of the attacked state-turned-attacker is also an uncivilized nation, cutting constitutional corners (NYT233) and violating the rights of its population (WP199, AP254). A web of "bureaucracy, inefficiency, and corruption" (R45), it is prone to arbitrary torture (AP125), chaos, civil war (NYT151), lawlessness (NYT159), “witch hunts” (WP201) and an over eagerness to convict (NYT235). The state foil mirror the reputation for cruelty introduced by the attacked state's newfound pariah status and further diminishes confidence in the administration of justice.

\section{Inability to Demarcate Relevant Information}

Unclaimed attack narratives exhibit a tendency to render either too many details relevant (displaying an inability to distinguish those which are significant) or conversely to suggest the attack was so extraordinary that none of the information would be of use in apprehending the offenders. 


\section{An endless pool of potential terrorists}

Not only does the continuing presence of the perpetrator and claims of a "mastermind at large" perpetuate doubt as to the guilt of the remanded suspects in unclaimed narratives, this is further compounded by authorities' inability to typify the actor responsible. The threat may stem from a single group, a state government, a combination of terrorist groups and governments (R165), or a collaborative effort between multiple terrorist organizations (WP95) - there is no shortage of possibilities. Heavy emphasis is placed on the magnitude of annual threats received by the attacked state (WP12, AP5); the United States alone has a list of more than 200,000 individuals and 3,000 groups who wish it harm (WP1). Under such circumstances, it is impossible to determine "who is fighting who or what they are fighting for" (NYT3). Conversely, within claimed attacks the pool of actors is limited to a division between the wider field of Islamic militancy and the particularity of the al Qaeda organization, dramatically narrowing the scope investigators are forced to cover.

\section{Constituting the "extraordinary threat" via denial of the "normal" state-centered threat model}

Within claimed attack narratives, the al Qaeda organization is first and foremost understood as a product of Osama bin Laden (AP399, R297). Though "worse" than other terrorist organizations in terms of cruelty and ruthlessness (G86, G93, DTT131), the group is a failing organism; with one-third of its command staff killed in combat (NYT122, G30, G31) and the majority of its attacks committed solely for propaganda value (AP137, CP15), al Qaeda is a spent force (NYT267, WP234, AP389, DTT21). The group remains of interest only insofar as it is a bombing suspect; even the infamous Osama bin Laden is practically nonexistent except in his capacity as founder (WP266, AP239, DTT141). As his influence in pivotal Muslim countries is 
lost to younger and more technologically adept insurgents (AP246, AP247, AP285), bin Laden and his terror organization serve little function outside limiting the pool of possible antagonists.

Within unclaimed discourses the Saudi exile's narrative value is most appreciable in the 1998 US Embassy bombings when the mass public was introduced to his radical agenda. Here Osama bin Laden's presence overshadows mentions of his organization (which exists as a shadowy extension of the Saudi), in contrast to later cases where bin Laden is relevant only as al Qaeda's founder and international delegate. Bin Laden evolves from a guerrilla leader with limited geographic and demographic reach to commander of a terrorist empire, a state unto himself. Though his role becomes increasingly marginal, al Qaeda — which continues as a direct product of bin Laden's ingenuity and influence (NYT210, WP121, G64, DTT126, R97)—builds upon his statesmanlike reputation to assume the mantle of a normalized state power. Al Qaeda possesses a fully-developed network of alliances (though Iraq, Iran, and Sudan have garnered the group no favors with the international community) (NYT73, WP68, WP72, WP145, R112), led by its emir (NYT83, NYT90, WP57, WP73) and armed with a diplomatic ideologically-based agenda expressed through Islamist "ambassadors" (NYT73, WP71, AP171, AP279). This conferment of pseudo-statehood endows al Qaeda with privileges reserved for sovereign nations, such as the right to declare war (NYT176, AP222, G8) in pursuit of its policy agenda, which seeks to overthrow of nearly every Muslim government, curtail of Western influence, and suppress democratic values (NYT199, WP57, AP63, DTT70, R106). Al Qaeda attempts to achieve this goal with a combination of ruthlessness and sophistication that places it far ahead of other terrorist organizations such as ETA or IRA (WP176, G53, R244). 
The power of al Qaeda and Osama bin Laden within unclaimed attack narratives stems from their presentation as a "normal" enemy in comparison to the atypical general terrorism, which is more terrifying, strange, and forbids the attacked state from using prior experience as an interpretive lens. It is significant to note that claimed cases display an almost total lack of rumination over the characteristics of general terrorism ${ }^{20}$, excepting the occasional reference to irrational "fanatics" (NYT116, AP131, CP6). The tendency of unclaimed attacks to parallel the "normalized" bin Laden and al Qaeda threat with unspecified terrorism allows for a further estrangement of the universal danger that reemphasizes the helplessness of the attacked state, ensuring imminent harm while denying the existence of a means to handle the threat.

In contrast to al Qaeda, general terrorism is unlike any threat in existence (WP171, WP180, DTT89, DTT94); its agents will strike "whenever and however they can" (AP266), without warning (DTT62) and employing a shockingly intimate knowledge of Western intelligence services (NYT24, WP15). Given the "global terror inflation" that necessitates murder on a grander scale (G41, DTT38, R209), the average man has no defense against such violence: "there is no power on earth that can protect [him] from being bombed (...) the bomber will always get through" (AP2, DTT39, DTT40, R249). One cannot run from this ever-present threat (WP94, WP101), nor can it be mediated through law enforcement or military means (WP168, AP290). Its resources are infinite (NYT218, WP112, R164) and no concession will blunt its hatred (WP186, AP299). The attacked state and its population are thus at the mercy of a superior fighting force, whose proclivity to rage and violence will be satisfied with nothing less than the annihilation of both.

${ }^{20}$ The 2005 London bombings again present an exception for reasons discussed previously. 
Homegrown bombers: the normal made strange

Homegrown terrorist narratives exhibit a particular strategy of broadening the signals of impending aggression. The depiction of suspects as normal individuals "led astray," particularly the possibility that they could be "any one of us," denotes the idea of a "journey away from the ordinary” (Hoskins \& O’Loughlin, 2009, p.88). Within this context a morally upright individual gradually acquires certain tendencies that force him or her from the "straight path." This turn from normalcy is accompanied by the estrangement of common, everyday activities so as to retroactively impose "otherness" upon the bombers (claiming that one "missed the signs" is preferable than admitting there were none to miss). Meeting a group of friends for religious study or a sporting match becomes planning for the jihad; guiding children on a fieldtrip to London is scouting a potential attack location; declining to take part in social activities is antisocial radicalism (NYT151, WP58). Ordinary “business abroad” turns into cavorting with radical insurgents (DTT85) — even donning "blue jeans, T-shirts and running shoes [and] baseball caps" and looking for all the world like "backpackers heading off for a vacation" or a "hiking holiday" (WP251, G114, DTT151, DTT169) is taken as the uniform of a suicide bomber. In this sense, fear is not generated from a macro-level attack but from the ground-up, meaning that literally any action could be a "movement towards jihad" that has yet to be recognized as such.

\section{E. Possibility of Future Attack as Legitimizing State Action}

Within unclaimed discourses the continual possibility of a future attack legitimizes the present actions taken by the attacked state, situating the narrative consciousness in a very different temporal relationship compared to that of claimed attacks, which tend to focus on the connection 
between similar past events and current circumstances. This trend is apparent not only in the proclivity of unclaimed discourses to employ premediation but also through a statistically significant disparity in the media's choice of verbiage.

\section{Narrative instability due to the continued existence of the perpetrator}

The presence of the perpetrator figure throughout all four investigative phases despite the arrest of numerous suspects (exculpable though they may be) injects an element of narrative flux that maintains the possibility of a future attack, particularly given the aforementioned suspects' seeming incapability of autonomously executing attacks. The perpetrator destabilizes what should have been an "open and shut" criminal case by suggesting the possibility of additional conspirators, replacing assurances of justice with paranoid conjectures: "where is the real mastermind?" (EM20). As claimed narratives depict a suspect detained, guilty, and proficient in the means of attack, further speculation over other imminent dangers is rare despite the survive of the larger al Qaeda network.

Ultimate importance of the attack as herald of "new terrorism" rather than devastation wrought While it would be inaccurate to say that unclaimed attacks are not concerned with the damage caused by an act of violence, the true significance of the bombings is viewed in light of the "new era of terrorism," of which the current attack is only the beginning. This is partly achieved through the use of premediation, which refers to the "manner in which media speculatively envision possible futures so that, should any disaster emerge, publics are not shocked and normal life disrupted" (Grusin 2004, cited in Hoskins \& O'Loughlin, 2009, p.83). The realization of this pattern within unclaimed cases is actualized in three ways: the perpetrators as significant based 
upon their potential to cause harm, the means by which said perpetrators will accomplish their goals, and the attacked state as acting in the immediate present in response to a future attack that has yet to occur.

Those who conducted the terrorist attack are significant not only given the damage they wrought but also given the damage they could have rendered; the attack could have been "even more devastating" had minor deviations (such as accessing an underground parking garage as opposed to the adjacent lot) been achieved (NYT22, AP23). The new terrorism follows a "dirty-bomb of an ideology" (DTT64) and seeks to acquire biohazard materials that would produce an attack of untold devastation (R80). For example, the terrorists involved in a shoot-out during the 2004 Madrid bombing investigation posed a threat not due to their role in the rail bombings but given that they were plotting "more attacks which could have been catastrophic" (AP324, AP325, G78, DTT100).

Attacked states are very inventive in imagining the ways in which the terrorist actor will gain the upper hand, even if this may involve use of another nation's resources. Morocco, for instance, is postulated as Europe's "biggest terrorist threat (...) seething with as many as 1,000 adherents capable of suicide attacks and skilled at slipping through the continent's southern gateway" (AP248). Alarm is sounded that an attack in another major European city is "only a matter of time" (NYT236) and that the region "might become the next front in the war against terror" (AP302). Hostile elements may use vulnerabilities such as the open rail networks of a region heavily dependent on rail transport (NYT189) or they may "turn democracy into a weapon" to undermine the Western political system (NYT203, DTT70) and thus introduce a "new quality of 
threat" (NYT195, NYT196, WP171, WP180, WP183, DTT47). These scenarios even detail the collapse of the global superpower: America will "become increasingly vulnerable to hostile attack on our homeland and our military superiority will not entirely protect us," meaning that "[we are] likely to die on American soil, possibly in large numbers" (R149).

In response to an attack that has yet to occur, the attacked state and its allies engage in immediate policy changes, evident in Germany's panicked calls for an “immediate emergency gathering of officials" (NYT195, NYT196) or "huge anti-terror sweeps and arrests" in Britain, Belgium, France, Canada, and South Africa following the 2004 Madrid bombings (NYT218). Spain even withdrew its troops from Iraq on the principle that it "might get a kind of immunity from future terrorist attack by disengaging" (NYT199). In the aftermath of the 1998 Embassy bombings, the United States pursued an opposite tactic, ordering cruise missile strikes on targets in Afghanistan and Sudan to thwart "imminent plans for new attacks" (R78). The importance of these actions is that tactics of premediation narrate such catastrophes in a manner "almost indistinguishable from the way the future will be mediated when it happens" (Grusin, 2004, p.29). Consequently, premediation is "not about the future at all, but about enabling action in the present by visualizing and drawing on multiple imagined futures" (Amoore 2007, cited in de Goede, 2008, p.159).

\section{Nature of the past-present-future relationship}

The presence of an impending future atrocity does not imply, in any way, that unclaimed narratives do not recourse to past events in an attempt to contextualize or understand the damage wrought by the current attack. It is simply that unclaimed cases appear to find these events less 
helpful in making sense of the present catastrophe, limiting the applicability of historical experience as one of the "tools" in the "toolbox" to fight terrorism. Two Chi-Square tests of statistical significance were performed in order to examine the nature of the relationship between past, present, and future attacks; the first test sought to determine the nature of past-future references within the discourse, while the following test examined the relationship of the pastpresent references.

In the construction of the first Chi-Square test, claimed/unclaimed references to future attacks were compared to allusions of past attacks (such as World War II, the Lockerbie bombing, etc.). ${ }^{21}$ As indicated by the data, references to previous atrocities do significantly factor into terrorist narratives; indeed, at first glance, they appear even more numerous than references to future attacks. However, it is not insensible that in the aftermath of any act of violence comparisons will be made to previous events - it is the nature of such comparisons that is particularly relevant, and will be explored in the subsequent test. It was mentioned previously that the 2005 London bombings, though a claimed attack, exhibit unclaimed narrative characteristics given the sizable lapse between execution and claim. When the data from the London bombings is factored into the claimed cases, no significant difference is found between the tendency for claimed and unclaimed attacks to reference future or past events in their attempts to understand the present. However: when the London data is removed and the subsequent totals for claimed attacks compared to their unclaimed counterparts, a strong disparity can be observed; here claimed attacks appear to reject the forecasting of future attacks,

${ }^{21}$ See Appendix III. 
while the tendency for unclaimed attacks to do so appears almost as strong as their attempts to reference previous events.

To understand the nature of this past-present relationship, a second Chi-Square test was conducted to determine in what way past events were related to the current attack. ${ }^{22}$ Historical comparisons may be divided into two categories: (1) absolutes, which make a break with and repudiate the usefulness of the past in understanding the current situation, and (2) relatives, which establish the current situation as comparable to a past event. In the case of the former, the comparison denotes the current attack as something entirely novel; the latter denotes the current tragedy as part of an existing pattern, implying that - just as its predecessor was overcome - the management of this latest catastrophe is within the realm of possibility for government, law enforcement, and security services. Even with the inclusion of the atypical London data, a statistically significant difference is observable in the two attack types' inclination to use absolute references; unclaimed attacks characterize the present situation as something incomparable that exceeds current investigative and defense resources. Such assertions within claimed attacks are dominated by assurances of ordinary and familiar danger that allow for a more efficient response by the relevant authorities.

${ }^{22}$ See Appendix IV. 


\section{CHAPTER 7: ANALYSIS}

The previous section examined points of distinction between unclaimed and claimed terrorist attacks. Yet how do we make sense of these patterns in a way that renders them applicable to the terrorist authors of the spectacle as well as the political decision-makers who are forced to respond? The distinctions between claimed and unclaimed attacks are relevant in that they affect the relationship between the terrorist, target population, and state through the framing process inherent to political problem solving. As will be discussed below, claimed terrorist attacks tend to be cast within a framework of uncertainty, whereas unclaimed terrorist attacks are cast within a framework of ambiguity. The two concepts have very real implications for the way in which the terrorist threat is understood and confronted.

\section{A. Risk and the Notion of Risk Society}

Risk can be understood as the "unambiguous assignment of definite probability to each and every event" (Dequech, 2000, p.5). It is measurable through the use of probabilistic calculations (Knight, 1946, p.233) and acts as the dominant form of calculative reasoning in modern society (Best, 2008, p.5). Consequently, the notion of risk functions around the idea that in a given situation, the individual decision maker is able to account for every possible outcome, assign a likelihood to each based upon the probability that it will occur, and the resulting data informs the decision that can thereafter be made.

A current strand of literature holds risk to be a foundational state for civil society (Pain \& Smith 2008, p.1) and risk management as the primary mode of agreement between citizens and governments (Isin, 2004, p.219), redefining the nature of the social bond that relates a citizenry 
and its government. Theorists have suggested that state societies, whose behavior was hitherto driven by fear resulting from uncertainty of the capabilities and intentions of other states (Nelson 2010), have instead become risk societies as "subjects govern their conduct through risk and governments primarily constitute themselves as safeguarding their subjects from [transnational] risks" (see Isin, 2004, p.318). In other words, "being at risk is the way of being and ruling in the world of modernity; being at global risk is the human condition at the beginning of the twentyfirst century" (Beck, 2006, p.330).

\section{B. Why Risk is Not an Appropriate Framework for the Terrorist Attack}

Though undoubtedly of use in explaining certain decision-making situations, the notion of risk is less applicable as it pertains to the terrorist attack. First and foremost, risk assumes a continuum on a scale of zero to one hundred, thus rendering possible a situation in which there is no risk. Such a certainty does not exist in the world today, and the effort to strive for such in the face of the impossible is one of the contingencies allowing for the birth of the neurotic citizen (see Isin 2004). Moreover, within the context of decision-making or problem solving, the distinction made between the idea of risk and uncertainty is false. The principle of Knightian Uncertainty assumes that the latter is "unable to be managed through probabilistic calculations because the situation being dealt with is in a high degree unique" (Knight, 1946, p.233). However, the decision-maker never knows with absolute certainty that an objective probability distribution exists, nor does $\mathrm{s} /$ he understand the exact characteristics of this distribution. Consequently, in order to make a decision at all, the decision-maker decides on what $\mathrm{s} /$ he considers a useful representation of reality (Schrader et al., 1993, p.7) and attributes subjective probabilities to events (Dequech, 2000, p.4). 
Beck (2006) also acknowledges that risk is largely the anticipation of catastrophe, and risks are 'topical only to the extent that they are anticipated. Risks are not 'real', they are 'becoming real' (Joost van Loon). At the moment in which risks become real - for example, in the shape of a terrorist attack - they cease to be risks and become catastrophes" (p.332). If such is the case, than states are not guarding against real threats but rather possibilities; possibilities and their actualization bring the problem into the realm of the uncertain and ambiguous rather than the definitive and exact category of risk.

\section{The Distinction between Uncertainty and Ambiguity ${ }^{23}$}

Uncertainty and ambiguity refer to two related but distinct concepts. Uncertainty stems from a lack of information and refers to a situation in which the problem solver considers the structure of a problem (including the relevant variables) as given but does not have the details necessary to determine the value of said variables (Martin \& Meyerson, 1988, p.122, cited in Schrader et al., 1993, p.5). In other words, the framework of the problem is defined, the relevant variables within the problem identified, and the set of possible future outcomes understood; however, until the value of the variables and their associated probabilities are discovered, the likelihood of each outcome cannot be calculated. Uncertainty may thus be remedied by gathering more information about each variable. A mental model already demarcates the boundaries of the problem, determining what is relevant for understanding the phenomenon and identifying the specific tasks necessary with greater precision than occurs under ambiguity: a well-defined mental model “implicitly predetermines the relevant solution space for a problem" (Clement 1989, cited in

${ }^{23}$ Though scholarship offers several interpretations, the distinction utilized here is primarily that as described by Schrader et al. (1993). 
Schrader et al., 1993, p.4). Furthermore, framing a problem as one of uncertainty reduction implies that the resources necessary to solving the crisis are similar to the ones that have been used previously (Schrader et al., 1993, p.18) and thus already exist within the decision-maker's "toolbox." Given that tasks are already specified within the mental model they are also welldefined, meaning that is it possible to describe precisely the "content of specific roles that need to be fulfilled" in order to overcome the issue (Schrader et al., 1993, p.16).

In comparison, ambiguity can take one of two forms: (1) a situation in which the set of potentially relevant variables are identified but the relationships between variables and the problem structure are in need of determination, or (2) a situation in which the set of relevant variables themselves as well as their functional relationship and relationship to the problem structure are in need of further definition (Hubbard 2007; Martin \& Meyerson, 1988, p.112, cited in Schrader et al.,1993, p.4; Schrader et al., 1993, p.5). Not only does ambiguity stem from a lack of information, it also stems from a lack of clarity. Ambiguity may be introduced into a situation in multiple ways, the most common of which is the existence of seemingly conflicting and irreconcilable information (Kosnik 1986; Meyerson \& Martin 1987, cited in Schrader et al., 1993, p.12). Burns and Stalker (1966) provided evidence demonstrating how lateral (horizontal) communication networks (in comparison to vertical, top-down communication patterns) promote the communication of information outside the problem solver's direct realm of expertise and tend to introduce greater amounts of such information (Schrader et al., 1993, p.12-3); modern media communication patterns strongly favor this trend. Furthermore, problem-solving behavior is strongly influenced by past experience; challenging a model used previously for solving what appears to be a similar problem implies that the decision-maker questions its existing 
assumptions about which variables are important and their relationship to one another (Schrader et al., 1993, p.11). Finally, problem-solving under ambiguity requires not only gathering more information about the relevant variables, but first specifying the variables under consideration as well as their relationship to each other and the problem model. If the problem is framed so as to include an element of ambiguity, it is assumed that resources not been employed in the past may be required (Schrader et al., 1993, p.18) and moreover suggests that the tools currently available are not suitable for handling the issue. Problem-solving tasks within this environment can only be described in generalized terms, as it is still unclear what their content will be (Schrader et al., 1993, p.17).

\section{Claimed/Unclaimed Terrorist Attacks as Framed Under Uncertainty, Ambiguity}

Preventing or weathering an act of terrorism very much poses a problem solving dilemma for policymakers and publics alike in terms of formulating a response to the violence. This study suggests that claimed attacks tend to be framed as situations involving uncertainty, whereas unclaimed attacks are framed in terms of ambiguity.

\section{Claimed Attacks as Problems of Uncertainty}

Claimed terrorist attacks are discussed as situations of a familiar nature, with defined boundaries that demarcate the scope of the terrorist threat. The targets of violence are therefore able to understand the threat in its entirety, including the set of possible resolutions. There is no "surprise element" within a claimed attack; the perpetrator, able to upset the assured purveyance of justice within unclaimed narratives, ceases to exist in claimed narratives upon the arrest of suspects. No references are made to the possibility of an outside "coordinator" or "mastermind" 
who continues to evade investigative efforts, eliminating the potential for an unknown outcome to upset the predetermined path of the state in rendering justice and restoring normalcy. The decisive lack of premediation and speculation on future attacks further negates the possibility of an "infinite number" of possible conclusions to the terrorist act, allowing the current disaster to be understood in the singular; the attack is clearly temporally demarcated rather than compounded by the effects of a future attack realized in the present via state response.

With this definition comes an understanding of what variables are to be included or are relevant to the problem at hand. Al Qaeda and its founder are well-known criminal actors with whom law enforcement officials have an established history; yet even before al Qaeda claimed responsibility, claimed narratives narrow the pool of possible perpetrators to those practicing Islamist terrorism. More importantly, there are no ambiguous actors within such discourses; states and their allies are unquestionably endowed with ethical authority as just protectors and guardians of Western values in the face of danger; they act as a bulwark against the forces of terrorist barbarism to defend "civilized" society. Detainees are, in contrast to unclaimed narratives, mature criminal actors capable of autonomously plotting and executing skilled operations and having proven their depravity through participation in previous terrorist activities; their culpability is unquestionable and thus the moral legitimacy of the state confirmed. Even prior to the arrest of suspects, postulations of the perpetrators as superhuman are immediately dispelled by rational explanation, rendering the detainees ordinary (albeit proficient) actors able to be addressed through normal law enforcement measures. 
The implementation of a tried-and-true model of police vs. criminal implies that existing resources may be utilized in the apprehension of those responsible, which lends itself to the scripting of particular problem-solving tasks and thus investigative progress. Boasts of state power, technological superiority, and experience in the handling of insurgencies are thus applicable to the present situation, increasing public confidence in authorities' ability to fulfill their security contract. The nature of past-present comparisons in framing the current attack as the newest incarnation of an old threat implies it will be handled successfully in the manner of its predecessor.

\section{Unclaimed Attacks as Problems of Ambiguity}

Unclaimed attacks are comparatively modeled as problems of ambiguity, which is introduced both through conflicting actor identities as well as through challenging the existing model of placating the terrorist threat. First and foremost, unclaimed attacks exhibit a lack of clarity with regard to the primary actors and their associations. As Dingley (2005) notes, "if an agreement is ambiguous, it is not an agreement" (p.176); consequently, if there is not clear agreement on who is or is not a source of threat, either everyone or no one is a danger. Given that an attack has already occurred — along with the ongoing possibility of a repeat performance-everyone becomes a prospective terrorist. Actor ambiguity proceeds among several veins: confusion between "victims" and "attackers" (via the exoneration of suspects and the attacked state-asattacker through the detaining of innocents and production of terrorists), and a blurring of the "civilized" and "barbaric." This latter theme is explored through the characterization of perpetrators as masters of "civilized man" and embodying to a greater extent the principles of "civilized" behavior, as well as the moral degradation of Western society and its abandonment of 
rational principles. Attacked nations become models of "uncivilized" behavior: untrustworthy, deceitful and foolish, their use of gratuitous violence, support for torture, and unjust imprisonment undermines their identity as part of the Free World.

With the invalidation of the old framework a new model is required, yet it is impossible to demarcate the boundary of the new threat. The current security insurance paradigm in Western society is based upon "scientific calculus and group profiling" (Aradau \& Van Munster, 2007, p.103); this is impossible in an environment where estrangement of the normal provides for anything and everything as suspicious. Unclaimed attack discourses offer an endless pool of possible perpetrators whose continual presence wreaks instability despite suspects' arrest. Note that the superhuman abilities of the perpetrator and his desire to do harm are consistent and unchallenged throughout the discourse, rendering the identity_according to Hopf (2009) — among the strongest and most salient. Furthermore, the labels used to describe said suspects are indeterminate from the ones employed by the targeted population-family men, brothers, Westerners, sports lovers, charmers-implying that we are a source of threat as well as its victims. Continued references to a "mastermind" at large contribute to the inability to define the problem scope, with the statesmanlike Osama bin Laden and al Qaeda posed in stark contrast to the uncontained and virulent nature of general terrorism. Finally, the use of premediation resists any and all attempts to describe even the temporal boundaries of the danger; the importance of the terrorist act rests in its potential, with ambiguity introduced via the imagination of infinite futures (as imagination is inherently interpretive and thus always open to ambiguity) (de Goede, 2008, p.156,159; Salter, 2008, p.248, cited in Best, 2008, p.7). In turn, states are forced to react to a possible future attack, something that has not, and may not, ever occur; as such, the effects 
of a future attack in terms of policy response and popular fear have already been realized, a terrorist attack that requires absolutely nothing on the part of the terrorist. In such a way, premediation becomes the catastrophe (Countin 2008, cited in de Goede, 2009, p.171) as it mediates multiple futures in a manner indistinguishable from the way the future will be mediated when it is realized (Grusin, 2004, p.29).

This new model, indefinite as it is, requires resources outside of the state's possession. The threat is new, unique, and wrought by all-powerful, divinely favored perpetrators; boasts of military prestige and previous anti-terrorist accomplishments are irrelevant. Narrative focus is on a present that cannot be linked in any meaningful sense with previous experience, except to distinguish it as distinct from such; as Cooper (2006) notes, "if the catastrophe befalls us, it is from a future without chronological continuity with the past...no mass of information will help us pin-point the precise when, where and how of the coming havoc. We can only speculate" (p.119). What is more, problem-solving tasks towards the resolution of the threat can only be issued in general terms; consequently, states and their allies never appear to make real progress in the investigation as the true attacker, the perpetrator, is untouchable given that $\mathrm{s} / \mathrm{he}$ is a figment of our own creation. Descriptions of the attack as "extraordinary" and "unthinkable" further depoliticizes the event, as "unthinkable becomes unspeakable, and so we are excused from further enquiry" (Edkins, 2003, p.176, cited in de Goede, 2009, p.167). Consequently, there is no one to be held accountable for the security threat posed not only by the terrorists, but by the state and society itself. 


\section{E. Ambiguity as Applied to Claim Scholarship}

Given the tendency of the unclaimed attack to employ an element of ambiguity, it is beneficial to review scholarly explanations surrounding claims of responsibility so as to determine those that appear applicable in rendering a terrorist advantage.

\section{The New Religious Character of Terrorism}

Al Qaeda, through generally propagated as an exemplar of the "new religious terrorism," is presented within the case studies as a primarily political actor in that its ultimate goal is realizing the downfall of Western governments and pro-Western regimes in the Middle East. Moreover, a vast proportion of the accompanying commentary issued by al Qaeda (or its leader) exhorts young men to commit acts of terrorism on its behalf. Consequently it would be hasty to assume that terrorist groups utilizing religious verbiage to accomplish political outcomes are not targeting an earthly population; the fact that al Qaeda has conducted both claimed and unclaimed attacks indicates that there is utility to be found in both strategies.

\section{Media Coverage and the Establishment of Legitimacy}

Both claimed and unclaimed attacks without question cast the act of terrorist violence as illegitimate and without possible rational justification. However, whereas the terrorist actor is also criminalized in the case of claimed attacks, unclaimed attacks construct a duality between guilty perpetrator/innocent suspect that exonerates the arrested individuals of responsibility. In addition, though culpable, perpetrators are ultimately viewed as a "superior other" who ironically embodies to a greater extent the values of "civilized" society, particularly given the state's demotion from protector of freedoms to illegitimate actor and source of threat. Thus, 
while the terrorist act itself may never be justified, the insurgent organization is able to make use of a lawful, superior "other" while simultaneously bringing into question the moral authority of state in determining the bounds of legitimacy.

\section{Interpretive Power of Audience}

Given the misattribution of responsibility for the terrorist act in the case of the 2004 Madrid bombings, the inability to determine either actor or motivation in the 1998 US Embassy bombings, and the reality that in both cases determination of the culpable group was made only by luck or chance, it is unlikely that in the current globalized environment where a terrorist attack could originate from any number of transnational actors, a group would fail to claim an act of violence based solely on the assumption that the audience will understand the desired message.

\section{Embarrassment of Failure}

Considering that the 2005 Aqaba attacks were claimed despite the terrorists' failure to hit US Navy targets and in light of the fact that the failed July 21 London bombings served to heighten public anxiety and reinforce a psychology of vulnerability, failed attacks appear to serve a purpose in the terrorist arsenal. Failure to claim credit simply based upon success of outcome thus does not appear to be a significant consideration of terrorist organizations.

\section{Fear of Retaliation by Authorities}

It is important to note that al Qaeda was the subject of counter-terrorism measures regardless of claim status; for instance, America launched retaliatory rocket attacks following the 1998 US 
Embassy bombing despite Osama bin Laden's denial of authorship. Certainly, a delay in credit claiming to allow one's compatriots to escape from harm's reach (as occurred in the 2005 Aqaba rocket attacks) is strategically understandable; ultimately, however, an attempt to claim credit was made by the perpetrating organization. The plentiful pool of false claims made for each attack furthermore assumes a certain utility of having one's name attacked to an attack regardless of the possibility of state recrimination.

\section{Public Relations Maintenance}

As mentioned in the preceding paragraph, the plethora of false claims attached to each case study assumes the existence of a certain advantage in associating one's name with an attack. The fact that al Qaeda claimed the 2005 London bombings, the most atrocious of all cases in terms of death toll as well as shock value, perhaps also indicates a lack of concern for an "overly bloody" reputation.

\section{Greater Fear-Inciting Potential}

Of the possible explanations offered by current literature (with the exception of establishing actor legitimacy), the disparity noted between unclaimed/claimed attacks appears to support the fear hypothesis. Schmid and Jongman (1988) concede that terrorist groups are rarely capable of keeping a whole population in a permanent state of fear (Rapin, 2009, p.167); Horgan (2005) notes that terror will not be achieved unless we, personally, are the subjects of an attack (p.14), and even then that the duration of this fear is limited (Rapin 2009). This lends itself to the conundrum that terrorists desire to propagate fear amongst the target population, but: (1) it is 
limited to the subjects of attack (2) it fades rapidly after an attack (3) continual attacks result in mass desensitization and adaptation to violence.

As Norman Cousins points out in his Modern Man Is Obsolete, "where man can find no answer, he will find fear"; likewise, "where man has already found fear, he will find answers" (Overstreet, 1951, p.105). The unclaimed attack offers a solution in that it opens new narrative space in which the terrorist actor can perpetuate the reach and lasting effects of his attack; response by the government to a future attack affects the entirety of the population, and given that the location of a future attack remains unspecified, everyone is a potential victim. By destabilizing mutually-exclusive categories of "attacker" and "victim," the terrorist creates new sources of fear (e.g. the government, neighbors, family), violating the most intimate levels of trust while reinforcing the surety of the coming attack. Consequently, society suffers from an inability to identify the attacker while at the same time convinced of its impending annihilation at the hands of said attacker. The type of fear perpetuated by the unclaimed attack also differs from its claimed counterpart; rather than a "hierarchical fear" built by a national-level event and subject to top-down distribution (most intense at the site of the attack with a "trickle-down" effect as it radiates out) (Pain \& Smith, 2008, p.8), unclaimed attacks create a web of "grassroots fear" built from the ground up in which fear is perpetuated among all members of the population and found in the conduct of everyday life; new sources of fear are identified and reinforced daily, compounding and broadening the impact of the original attack. 


\section{Impact of Environmental Characteristics}

Despite a wide variety of geographic locations for the attacks, the cultural heritage of the targeted audiences (the United States, Denmark, Spain, and the United Kingdom) is not radically diverse. Consequently, the impact of the target nation's socio-demographic characteristics on claim utility cannot be evaluated. However, the setting in which the attack is conducted does not appear to exercise a significant influence over the claiming of responsibility, as both claimed and unclaimed attacks occurred in Europe, the Middle East, and post-colonial societies alike. 


\section{CHAPTER 8: IMPORTANCE OF FINDINGS AND SUGGESTIONS FOR FUTURE RESEARCH}

The framing of terrorist attacks is of note primarily because, given that the nature of the problem and the identities of the actors are constructed, defined, and understood through the narrative selections identified by the decision maker, it stands to reason that politicians and their media counterparts can recast the unclaimed attack narrative in order to minimize the fear-provoking and legitimizing effects offered the terrorist by the discourse's destabilization of mutually exclusive categories and prompting of grassroots fear mechanisms.

Future research might expand the number of terrorist groups included in the study to determine if the patterns identified here hold true for a variety of religiously motivated insurgent groups; one might also broaden the range of targeted nations to include those not considered part of Western society and not beholden to the strict human rights norms that bind such countries. Given the shift of claiming patterns over the past half-century, later studies might benefit from examining if such narrative discrepancies existed during the height of terrorist claiming in the 1970 s, or if the disparity is a product of changing media tactics and the evolving media-public relationship. The application of positivist methodologies such as process-tracing may also be useful in determining if the selection of problem framing consistently manifests itself in the choice of particular political measures that would strengthen the terrorist cause. Most importantly, this study suggests that the length of time between execution of a terrorist act and the claim of responsibility be treated as a variable of interest, given its perceived influence on frame choice. 


\section{References}

Abrahms, M. (2006). Why terrorism does not work. International Security, 31(2), 42-78.

Alexander, Y. \& Pluchinsky, D. (1992). Europe's red terrorists: The fighting communist organizations. London, UK: Frank Cass Publishers.

Altheide, D. L. (1987). Format and symbols in TV coverage of terrorism in the United States and Great Britain. International Studies Quarterly, 31(2), 161-176.

Anonymous. (1998). To reveal or not to reveal: A theoretical model of anonymous communication. Communication Theory, 8(4), 381-407.

Apter, D. E. (1997). Political violence in analytical perspective. In D. E. Apter (Ed.), The legitimization of violence (pp. 10-32). New York, NY: New York UP.

Aradau, C., \& Van Munster, R. (2007). Governing terrorism through risk: Taking precautions, (un)knowing the future. European Journal of International Relations, 13(89), 89-115.

Baader-Meinhof/Red Army Faction. (1977). Texte: der RAF. Lund, Sweden: Verlag Bo Cavefors.

Beck, U. (2006). Living in the world risk society. Economy and Society, 35(3), 329-345.

Best, J. (2008). Ambiguity, uncertainty and risk: Rethinking indeterminacy. International Political Sociology, 2(4), 355-374.

Bjorgo, T. (2009). Processes of disengagement from violent groups of the extreme right. In T. Bjorgo \& J. Horgan (Eds.), Leaving terrorism behind: Individual and collective disengagement (pp. 30-48). USA \& Canada: Routledge.

Blanchard, C. M. (2007). Al Qaeda: Statements and evolving ideology. Congressional Research Service. Retrieved from Federation of American Scientists website: http://www.fas.org/ sgp/crs/terror/RL32759.pdf 
Bockstette, C. (2008). Jihadist terrorist use of strategic communication management techniques. Germany: George C. Marshall European Center for Security Studies. Retrieved from http://www.marshallcenter.org/mcpublicweb/

Brannan, D. W., Esler, P. F., \& Strindberg, N. T. A. (2010). Talking to "terrorists": Towards an independent analytical framework for the study of violence and substate activism. Studies in conflict and terrorism, 24, 3-24.

Burns, T., \& Stalker, G. M. (1966). The management of innovation. London, UK: Tavistock Press.

Chermak, S. M. \& Gruenewald, J. (2006). The media's coverage of domestic terrorism. Justice Quarterly, 23(4), 428-461.

Cooper, M. (2006). Pre-empting emergence: The biological turn in the war on terror. Theory, Culture \& Society, 23(4), 113-135.

Cordes, B. (1987). When terrorists do the talking: Reflections on terrorist literature. Santa Monica, CA: The Rand Corporation. Retrieved from http://www.rand.org/ pubs/papers/P7365.html

Cordes, B., Jenkins, B. M., \& Kellen, K. (1985). A conceptual framework for analyzing terrorist groups. Santa Monica, CA: The Rand Corporation. Retrieved from http://www.rand.org/pubs/reports/2005/R3151.pdf

Crelinsten, R. D. (1989a). Terrorism as political communication: The relationship between the controller and the controlled. In P. Wilkinson \& A. M. Stewart (Eds.), Contemporary research on terrorism ( $2^{\text {nd }}$ ed.) (pp. 3-23). Aberdeen, UK: Aberdeen UP. 
Crelinsten, R. D. (1989b). Power and meaning: Terrorism as a struggle over access to the communication structure. In P. Wilkinson \& A. M. Stewart (Eds.), Contemporary research on terrorism ( $2^{\text {nd }}$ ed.) (pp. 419-450). Aberdeen, UK: Aberdeen UP.

Crenshaw, M. (1992). Decisions to use terrorism: Psychological constraints on instrumental reasoning. International Social Movement Research, 4, 29-42.

Crenshaw, M. (1995). Thoughts on relating terrorism to historical contexts. In M. Crenshaw (Ed.), Terrorism in context (pp. 3-24). USA: Pennsylvania State UP.

Crenshaw, M. (1996). Why violence is rejected or renounced: A case study of oppositional terrorism. In T. Gregor (Ed.), A natural history of peace (pp. 249-272). Nashville, USA \& London, UK: Vanderbilt UP.

Crenshaw, M. (2001). Theories of terrorism: Instrumental and organizational approaches. In D. C. Rapoport (Ed.), Inside terrorist organizations (2 ${ }^{\text {nd }}$ ed.) (pp. 13-31). Great Britain: Frank Cass Publishers.

Creswell, J. W. (2007). Qualitative inquiry and research design: Choosing among five approaches. Thousand Oaks, CA: Sage Publications.

Davis, J. (2005). Terms of inquiry: On the theory and practice of political science. USA: Johns Hopkins UP.

Decker, W. \& Rainey, D. (1980, Nov. 13-16). Terrorism as communication. Paper presented at the Annual Meeting of the Speech Communication Association, New York, NY. Retrieved from http://www.eric.ed.gov:80/PDFS/ED196091.pdf

DeGhetto, T. H. (1994). Precipitating the decline of terrorist groups: A systems analysis thesis (Unpublished masters dissertation). Naval Postgraduate School, Monterey, CA. 
De Goede, M. (2008). Beyond risk: Premediation and the post-9/11 security imagination. Security Dialogue, 39(2/3), 155-176.

De Mesquita, B. (2005). The quality of terror. American Journal of Political Science, 49(3), 515 530.

Dequech, D. (2000). Fundamental uncertainty and ambiguity. Eastern Economic Journal, 26(1), $40-60$.

Dingley, J. (2005). "Constructive ambiguity” and the peace process in Northern Ireland. In L. Germani \& D. Kaarthikeyan (Eds.), Pathways out of terrorism and insurgency (pp. 173200). USA: New Dawn Press Group.

Enders, W., \& Sandler, T. (2000). Is transnational terrorism becoming more threatening? A timeseries investigation. Journal of Conflict Resolution, 44(3), 307-332.

Fierke, K. M. (2003). Breaking the silence: Language and method in international relations. In F. Debrix (Ed.), Language, agency, and politics in a constructed world (pp. 66-86). New York, NY: M.E. Sharpe.

Fierke, K. M. (2009). Agents of death: The structural logic of suicide terrorism and martyrdom. International Theory, 1(1), 155-184.

Fierke, K. M. (2010). Constructivism. In Dunne, T., Kurki, M., \& Smith, S. (Eds.), International relations theories: Discipline and diversity (pp. 177-194). New York, NY: Oxford UP.

Fleming, P. A., Stohl, M., \& Schmid, A. P. (1988). The theoretical utility of typologies of terrorism: Lessons and opportunities. In M. Stohl (Ed.), The politics of terrorism (pp. 153-196). New York, NY: Marcel Dekker Inc.

Frey, B. S. (2004). Dealing with terrorism - stick or carrot? Cheltenham \& Northampton, UK: Edward Elgar Publishing. 
Garrison, A. H. (2003). Terrorism: The nature of its history. Criminal Justice Studies, 16(1), 3952.

Gearson, J. (2002). The nature of modern terrorism. In L. Freedman (Ed.), Superterrorism: Policy responses (pp. 7-24). USA: Blackwell Publishing.

George, A. L. (1979). The causal nexus between cognitive beliefs and decision-making behavior: The "operational code" belief system. In L. S. Falkowski (Ed.), Psychological models in international politics (pp. 95-124). Boulder, CO: Westview Press, Inc.

George, A. L. \& Bennett, A. (2004). Case studies and theory development in the social sciences. Cambridge, MA: MIT Press.

Grusin, R. (2004). Premediation. Criticism, 46(1), 17-39.

Hermann, M. G. (1980). Assessing the personalities of Soviet Politburo members. Personality and Social Psychology Bulletin, 6, 332-352.

Hewitt, C. (1990). Terrorism and public opinion: A five country comparison. Terrorism and Political Violence, 2(2), 145-170.

Hoffman, A. M. (2010). Voice and silence: Why groups take credit for acts of terror. Journal of Peace Research, 47(5), 615-626.

Hoffman, B. (1996, August 18). A new kind of terrorism: Silence is deadlier. Los Angeles Times, p. M1.

Hoffman, B. (1997). Why terrorists don’t claim credit. Terrorism and Political Violence, 9(1), 1-6.

Hoffman, B. (1999). Terrorism trends and prospects. In I. O. Lesser et al. (Eds.), Countering the new terrorism (pp. 7-38). Santa Monica, CA: The Rand Corporation.

Hoffman, B. (2006). Inside terrorism ( $2^{\text {nd }}$ ed.). New York, NY: Columbia UP. 
Hogg, C. (2010, August 17). Facebook, media outlets discuss social media's news revolution. Digital Journal. Retrieved from http://digitaljournal.com/article/295970

Hopf, T. (2009). Identity relations and the Sino-Soviet split. In R. Abdelal, Y. Herrera, A. Johnston, \& R. McDermott (Eds.), Measuring identity: A guide for social scientists (pp. 279-315). USA: Cambridge UP.

Horgan, J. (2004). The case for firsthand research. In A. Silke (Ed.), Research on terrorism: Trends, achievements and failures (pp. 30-56). Great Britain: Frank Cass.

Horgan, J. (2005). Militant Irish republicanism: An overview of the historical and strategic development of the Provisional IRA. In L. Germani \& D. Kaarthikeyan (Eds.), Pathways out of terrorism and insurgency (pp. 201-236). USA: New Dawn Press Group.

Horowitz, I. L. (1983). The routinization of terrorism and its unanticipated consequences. In M. Crenshaw (Ed.), Terrorism, legitimacy, and power: The consequences of political violence (pp. 38-51). Middletown: Wesleyan UP.

Hosking, G. (2009). Terrorism and trust. Critical Studies on Terrorism, 2(3), 482-496.

Hoskins, A., \& O’Loughlin, B. (2009). Pre-mediating guilt: radicalisation and mediality in British news. Critical Studies on Terrorism, 2(1), 81-93.

Hubbard, D. W. (2007). How to measure anything: Finding the value of intangibles in business. New York, NY: John Wiley \& Sons Inc.

Hulsse, R., \& Spencer, A. (2008). The metaphor of terror: Terrorism studies and the constructivist turn. Security Dialogue, 39, 571-592.

Isbell, L. M., Ottati, V. C., \& Burns, K. C. (2006). Affect and politics: Effects on judgment, processing, and information seeking. In D. P. Redlawsk (Ed.), Feeling politics: Emotion in political information processing (pp. 57-86). New York, NY: Palgrave Macmillan. 
Isin, E. (2004). The neurotic citizen. Citizenship Studies, 8(3), 217-235.

Jenkins, B. M. (1981). The psychological implications of media-covered terrorism. Santa Monica, CA: The Rand Corporation. Retrieved from http://www.rand.org/ pubs/papers/P6627.html

Johnston, D. (1995, April 20). Clues are lacking. New York Times, p. A1.

Kellen, K. (1982). On terrorists and terrorism. Santa Monica, CA: The Rand Corporation. Retrieved from http://www.rand.org/pubs/notes/N1942.html

Kiras, J. D. (2009). Irregular warfare: Terrorism and insurgency. In J. Baylis, J. J. Wirtz, \& C. S. Gray (Eds.), Strategy in the contemporary world: An introduction to strategic studies $\left(3^{\text {rd }}\right.$ ed.) (pp. 185-207). United Kingdom: Oxford UP.

Klotz, A. \& Lynch, C. (2007). Strategies for research in constructivist international relations. USA: M.E. Sharpe, Inc.

Klotz, A., \& Prakash, D. (2009). Qualitative methods in international relations: A pluralist guide. USA: Palgrave Macmillan.

Knight, F. (1946). Risk, uncertainty and profit. Boston, MA: Houghton Mifflin Company.

Knutson, J. N. (1980). The terrorists' dilemmas: Some implicit rules of the game. Terrorism, $4(1), 195-222$.

Kosnik, T. J. (1986). Flexibility seeking and delay: The effects of ambiguity of preference on selecting a short list. Working Paper. Harvard business school, Boston, MA.

LaFree, G., \& Dugan, L. (2004). How does studying terrorism compare to studying crime? In M. Deflem (Ed.), Terrorism and counter-terrorism: Criminological perspectives, vol. 5 (pp. 53-74). Amsterdam, The Netherlands: JAI Press. 
LaFree, G,. \& Dugan, L. (2008). Global terrorism database II, 1998-2004: Codebook and data documentation. ICPSR codebook no. 22600.

Lijphart, A. (1971). Comparative politics and the comparative method. The American Political Science Review, 65(3), 682-693.

Lin, A. (1998). Bridging positivist and interpretivist approaches to qualitative methods. Policy Studies Journal, 26(1), 162-180.

Lockett, C. E. (1995). We bomb, therefore we are: The evolution of terrorist group life cycles (Unpublished masters dissertation). Naval Postgraduate School, Monterey, CA.

Lupovici, A. (2007, February). Methodologizing constructivism: modifying methods and criteria. Paper presented at the International Studies Association Annual Meeting, Chicago, IL.

Marris, P. (1996). Politics of uncertainty: Attachment in private and public life. London, UK: Routledge.

Marx, G. (1999). What's in a name? Some reflections on the sociology of anonymity. Information Society, 15, 99-112.

Mulaj, K. (2010). Violent non-state actors in world politics. New York, NY: Columbia UP.

Nacos, B. L. (2002). Mass-mediated terrorism: The central role of the media in terrorism and counterterrorism. Lanham, MD: Rowman and Littlefield Publishers, Inc.

Nacos, B. L. (2009). Revisiting the contagion hypothesis: Terrorism, news coverage, and copycat attacks. Perspectives on Terrorism, 3(3), 3-13.

Nelson, A. (2010). Taming ambiguity: Understanding uncertainty in foreign policy decisionmaking and negotiation. [Abstract]. Social Science Research Network. Retrieved from http://papers.ssrn.com/

Neumann, P. R. (2009). Old and new terrorism. Cambridge \& Malden, UK: Polity. 
Padilla, T. (2007, February 18). How easy is it to search the complete archives of the New York Times online? George Mason University's History News Network. Retrieved from http://hnn.us/articles/34785.html

Pain, R., \& Smith, S. (2008). Fear: Critical geopolitics and everyday life. Great Britain: Ashgate.

Paletz, D., \& Schmid, A. (1992). Terrorism and the media. London, UK: SAGE Publications. Pape, R. A. (2003). The strategic logic of suicide terrorism. American Political Science Review, $97,343-361$.

Passante, C. K. (2007). The complete idiot's guide to journalism. New York, NY: Alpha.

Perl, R. F. (1997). Terrorism, the media, and the government: Perspectives, trends, and options for policymakers. Retrieved from Federation of American Scientists website: http://www.fas.org/irp/crs/crs-terror.htm

Picard, R. G. (1989). Press relations of terrorist organizations. Public Relations Review, 15(4), $12-23$.

Picard, R. G. (1993). Media portrayals of terrorism: Functions and meaning of news coverage. Ames, IA: Iowa State UP.

Pluchinsky, D. A. (1997). The terrorism puzzle: Missing pieces and no boxcover. Terrorism and Political Violence, 9(1), 7-10.

Post, J. M. (1987). Rewarding fire with fire: Effects of retaliation on terrorist group dynamics. Terrorism, 10(1), 23-36.

Post, J. M. (2005). The new face of terrorism: Socio-cultural foundations of contemporary terrorism. Behavioral Sciences and the Law, 23(4), 451-465.

Post, J. M. (2007). The mind of the terrorist: The psychology of terrorism from the IRA to al- 
Qaeda. New York, NY: Palgrave Macmillan.

Project for Excellence in Journalism (The Pew Charitable Trusts). (2004). The state of the news media 2004. Retrieved from http://stateofthemedia.org/2004/

Project for Excellence in Journalism (The Pew Charitable Trusts). (2011). Principles of journalism. Retrieved from http://www.journalism.org/resources/principles

Ranstorp, M. (1996). Terrorism in the name of religion. Journal of International Affairs, 50(1), $41-62$.

Rapin, A. (2009). Does terrorism create terror? Critical Studies on Terrorism, 2(2), 165-179.

Rapoport, D. C. (1984). Fear and trembling: Terrorism in three religious traditions. The American Political Science Review, 78(3), 658-677.

Rapoport, D. C. (1996). Editorial: The media and terrorism: Implications of the Unabomber. Terrorism and Political Violence, 8(1), 7-9.

Rapoport, D. C. (1997). To claim or not to claim; that is the question-always! Terrorism and Political Violence, 9(1), 11-17.

Rapoport, D.C. (2004). Terrorism. In M. E. Hawkesworth \& M. Kogan (Eds.), The encyclopedia of government and politics (Vol. 2 pp. 1049-1077) (2 $2^{\text {nd }}$ ed.). London, UK: Routledge.

Reid, D. \& Teizeira, T. (2010, February 26). Are people ready to pay for online news? $B B C$ News. Retrieved from http://news.bbc.co.uk/2/hi/programmes/click_online/8537519.stm

Richardson, L. (2006). What terrorists want: Understanding the terrorist threat. Great Britain: John Murray.

Rorie, M. L. (2008). Communicating through violence: An application of rational choice theory to terrorist claims of responsibility (Unpublished masters dissertation). University of Maryland Graduate School, College Park, MA. 
Ross, J. I. \& Gurr, T. R. (1989). Why terrorism subsides: A comparative study of Canada and the United States. Comparative Politics, 21(4), 405-426.

Salter, M. (1999). On barbarians: The discourse of “civilization” in international theory (Unpublished doctoral dissertation). The University of British Columbia, Kelowna, Canada.

Schmid, A. P., \& Jongman, A. J. (1988) Political terrorism (2 ${ }^{\text {nd }}$ ed.). New Brunswick, NJ: Transaction Publishers.

Schrader, S., Riggs, W. M., \& Smith, R. P. (1993). Choice over uncertainty and ambiguity in technical problem solving. Retrieved from Massachusetts Institute of Technology, Cambridge, Alfred P. Sloan School of Management website: http://dspace.mit.edu/ handle/1721.1/46980

Smith, J. \& Moncourt, A. (2009). The Red Army Faction: A documentary history. Montreal, Canada: PM Press.

Sper, M. K. (1995). Towards understanding terrorism: A theoretical examination of internal cohesion in terrorist groups and the negative dynamic of violence (Unpublished masters dissertation). Naval Postgraduate School, Monterey, CA.

Staun, J. (2009). A linguistic turn of terrorism studies. Copenhagen, Denmark: Danish Institute for International Studies. Retrieved from http://www.diis.dk

Talbot, D. (2005). Terror's server. Technology Review, 46-52.

Thomson Reuters. (2011). Media. Retrieved from http://thomsonreuters.com/ United States Central Intelligence Agency. (1988, Dec. 22). Spot commentary: Pan Am 103 analysis of claims. Retrieved from http://www.foia.cia.gov/ 
United States Department of Defense. (2001, Dec. 13). Transcript of Usama Bin Laden video tape. Retrieved from US Department of Defense website: http://www.defense.gov/news/ Dec2001/d20011213ubl.pdf

United States Institute of Peace (1999, May 25). How terrorism ends. Retrieved from United States Institute of Peace website: http://www.usip.org/files/resources/sr990525.pdf

Voice of America. New Bin Laden tape calls Obama powerless to stop Afghanistan war. (2009, Sept. 14). Voice of America News. Retrieved from http://www.voanews.com/ english/news/

Wardlaw, G. (1989). Political terrorism: Theory, tactics, and counter-measures $\left(2^{\text {nd }}\right.$ ed.). Cambridge, UK: Cambridge UP.

Waugh Jr., W. L. (1983). The values in violence: Organizational and political objectives of terrorist groups. Conflict Quarterly, 3(4), 5-19.

Weimann, G. \& Winn, C. (1993). The theater of terror: Mass media and international terrorism. United Kingdom: Longman Group.

Weinberg, L., Pedahzur, A., \& Hirsch-Hoefler, S. (2004). The challenges of conceptualizing terrorism. Terrorism and Political Violence, 16(4), 777-794.

Wendt, A. (1999). Social theory of international politics. Cambridge, UK: Cambridge UP.

Williams, R. (1973). The Country and the City. New York, NY: Oxford UP.

Williams, R. (1988). Reflections on anonymity. Perceptual and Motor Skills, 67, 763-766.

Winter, D. G. (1973). The power motive. New York, NY: Free Press.

Wright, A. L. (2009). Why do terrorists claim credit? Attack-level and country-level analyses of factors influencing terrorist credit-taking behavior. Retrieved from http://www.icpsr.umich.edu/files/ICPSR/prize/Wright_Paper.pdf 
Zulaika, J. \& Douglass, W. A. (2008). The terrorist subject: Terrorism studies and the absent subjectivity. Critical Studies on Terrorism, 1(1), 27-36. 
News Reference $\mathrm{Key}^{24}$

NYT1 Shenon, P. (1998, August 8). Bombings in East Africa: In Washington; Focus on suspects in past attacks. The New York Times, p. A1.

NYT2 Agence France-Presse. (1998, August 8). Bombings in East Africa: The reaction; Around the world, leaders express outrage. The New York Times, p. A8.

NYT3 McKinley Jr., J.C. (1998 August 8). Bombings in East Africa: In Nairobi; Few triumphs for those sifting 60 feet of rubble, listening for a muffled voice. The New York Times, p. A7.

NYT4 Agence France-Presse. (1998, August 8). Bombings in East Africa: In Dar es Salaam; Without warning, a bomb in a gasoline tanker kills 7 and injures 72 . The New York Times, p. A7.

NYT5 McFadden, R.D. (1998, August 8). Bombings in East Africa: The victims; civilians and GI confirmed as killed. The New York Times, p. A8.

NYT6 Risen, J. (1998, August 8). Bombings in East Africa: The security issue; Bombed embassies did not meet toughened security standards. The New York Times, p. A1.

NYT7 McKinley Jr., J.C. (1998, August 8). Bombings in East Africa: The overview; Bombs rip apart 2 U.S. embassies in Africa; Scores killed; No firm motive or suspects. The New York Times, p. A1.

NYT8 Risen, J. (1998, August 9). Bombings in East Africa: In Washington; Rescuers and investigators sent by U.S. begin to arrive. The New York Times, p. A1, 11.

NYT9 Yardley, J. (1998, August 9). The American dead; For victims' kin, sudden bad news comes from afar. The New York Times, p. A1, 11.

NYT10 McKinley Jr., K.C. (1998, August 9). The overview; Bombing toll rises; Rescue effort in Nairobi intensifies. The New York Times, p. A1, 11

NYT11 Shenon, P. (1998, August 10). The security; Now, a push to shore up ramparts at embassies. The New York Times, p. A6.

NYT12 Bonner, R. (1998, August 10). The scene; Caprice of terror: Who dies, who lives. The New York Times, p. A6.

NYT13 McKinley Jr., J.C. (1998, August 10). As 155 Kenyans lives ended, many more changed forever. The New York Times, p. A1. ${ }^{24}$ Note that any gap in numbering is intention and a product of the elimination of sources based
upon the stated methodology following the collection and evaluation of the media articles. 
NYT14 Perlez, J. (1998, August 10). Investigators in Tanzania study videocamera and water truck belonging to the embassy. The New York Times, p. A8.

NYT15 Weiner, T. (1998, August 10). Experts starting search for clues in Kenya bombing. The New York Times, p. A1.

NYT16 Bonner, R., Dao, J. (1998, August 10). The consul general; The last hope of one family is extinguished. The New York Times, p. A1.

NYT17 McFadden, R.D. (1998, August 10). The American dead; Their quiet lives, rendered stark and bold by the manner of their deaths. The New York Times, $\mathrm{p}$. A7.

NYT18 Shenon, P., and McKinley Jr., J.C. (1998, August 11). The witnesses; Kenyan guard at gate says he halted bomber's truck. The New York Times, p. A8.

NYT19 Bonner, R. (1998, August 11). The search: As rescuers' final hopes fade, investigators' toil begins. The New York Times, p. A8.

NYT20 Weiner, T. (1998, August 11). The investigation; Reward is offered and clues studied in African blasts. The New York Times, p. A1.

NYT21 Perlez, J. (1998, August 12). Roof camera at embassy didn't have videotape. The New York Times, p. A8.

NYT22 McKinley Jr., J.C. (1998, August 12). FBI sifts vehicles' scraps from debris for blast clues. The New York Times, p. A8.

NYT23 Shenon, P. (1998, August 12). The security issue; U.S. closes down some operations in foreign posts. The New York Times, p. A1.

NYT24 Weiner, T. (1998, August 13). Sophisticated terrorists pose daunting obstacle. The New York Times, p. A8.

NYT25 Bonner, R. (1998, August 13). Envoy rejects accusations Americans acted selfishly. The New York Times, p. A9.

NYT26 McKinley Jr., J.C. (1998. August 13). The American ambassador; The 'devastated' envoy now faces Kenyans' ire. The New York Times, p. A9.

NYT27 Whitney, C.R. (1998, August 13). The American dead; From Germany, Albright escorts home the bodies of "10 brave Americans". The New York Times, p. A8.

NYT28 Shenon, P. (1998, August 13). The security costs; Envoy's requests for safer building refused, U.S. says. The New York Times, p. A1.

NYT29 Perlez, J. (1998, August 14). Water truck discounted as carrier of explosive. The New York Times, p. A10. 
NYT30 Kifner, J. (1998, August 14). The suspect; Wealthy force behind murky militant group. The New York Times, p. A11.

NYT31 Weiner, T., Bonner, R. (1998, August 14). The investigation in Kenya; FBI reports finding pieces of bomb truck. The New York Times, p. A1.

NYT32 Seelye, K.Q. (1998, August 14). The American dead; Clinton tearfully receives 10 bodies, praising lives that "nothing can erase". The New York Times, p. A10.

NYT33 Shenon, P. (1998, August 15). U.S. halts business at embassy in Albania. The New York Times, p. A6.

NYT34 Weiner, T. (1998, August 15). Devastation from explosion permeates Kenyans' lives. The New York Times, p. A6.

NYT35 Seelye, K.Q. (1998, August 16). New burials at Arlingotn raise issues of fairness. The New York Times, p. A1, 29.

NYT36 Johnston, D. (1998, August 16). Suspect in embassy blasts being taken to Kenya. The New York Times, p. A1.

NYT37 Johnston, D. (1998, August 17). U.S. hopes arrest in embassy blasts will break case. The New York Times, p. A1.

NYT38 Johnston, D. (1998, August 18). U.S. says suspect does not admit role in bombings or ties to Saudi. The New York Times, p. A7.

NYT39 Shenon, P. (1998, August 19). U.S. pressing Kabul to oust Saudi linked to bombings. The New York Times, p. A6.

NYT40 Bonner, R. (1998, August 19). Pakistan arrests two new suspects in embassy blasts. The New York Times, p. A1.

NYT41 McKinley Jr., J.C. (1998, August 20). Hotel janitors don't recall bomb materials in Kenya. The New York Times, p. A6.

NYT42 Bonner, R. (1998, August 20). U.S. warns non-Muslims to leave Afghanistan. The New York Times, p. A6.

NYT43 Risen, J. (1998, August 20). U.S. seeks means to bring suspect from Afghanistan. The New York Times, p. A1.

NYT44 Risen, J. (1998, August 21). U.S. fury on 2 continents; The intelligence; U.S. says it has strong evidence of threat justifying retaliation. The New York Times, p. A1.

NYT45 Bennett, J. (1998, August 21). U.S. cruise missiles strike Sudan and Afghan targets tied to terrorist network. The New York Times, p. A1. 
NYT46 Weiner, T. (1998, August 21). Man with mission takes on the U.S. at far-flung sites. The New York Times, p. A1.

NYT47 Erlanger, S. (1998, August 21). A new worldwide warning for Americans to be cautious. The New York Times, p. A13.

NYT48 Schmitt, E. (1998, August 22). Two Senators say evidence of plotting is compelling. The New York Times, p. A7.

NYT49 McKinley Jr., J.C. (1998, August 22). New suspect held in Kenya, and Islamic agency searched. The New York Times, p. A7.

NYT50 Bonner, R. (1998, August 22). Muted criticism and marches in Pakistan. The New York Times, p. A7.

NYT51 Myers, S.L. (1998, August 22). U.S. says raids worked and may stall terror attacks. The New York Times, p. A1.

NYT52 Shenon, P. (1998, August 23). Hitting home: America takes on a struggle with domestic costs. The New York Times, p. D1.

NYT53 Erlanger, S. (1998, August 23). The diplomacy; Missile strikes are seen as new strategy for U.S. The New York Times, p. A10.

NYT54 Myers, S.L. (1998, August 23). President swears to use "all tools" against terrorism. The New York Times, p. A1.

NYT55 McKinley Jr., J.C. (1998, August 24). In Kenya: On Nairobi’s front pages, a war of rumors. The New York Times, p. A6.

NYT56 McKinley Jr., J.C. (1998, August 26). In Kenya: In-laws say bomb suspect led a quiet, religious life. The New York Times, p. A8.

NYT57 Johnston, D. (1998, August 28). Blast suspect held in U.S. and is said to admit role. The New York Times, p. A1.

NYT58 (1998, August 28). Excerpts from court charges; To terrorists, "it was proper to kill Americans." The New York Times, p. A6.

NYT59 McKinley Jr., J.C. (1998, August 29). The suspect; A man stern on Islam, reticent about his past. The New York Times, p. A4.

NYT60 Weiser, B. (1998, September 5). Bombing defendant said to claim coercion. The New York Times, p. A4.

NYT61 Risen, J. (1998, September 6). Militant leader was a U.S. target since the spring. The New York Times, p. A1. 
NYT62 McKinley Jr., J.C. (1998, September 7). Progress in investigation of embassy blasts, officials say. The New York Times, p. A3.

NYT63 Shenon, P. (1998, September 8). Security experts assessing U.S. embassies. The New York Times, p. A6.

NYT64 McKinley Jr., J.C. (1998, September 9). Security flaws left embassy in Nairobi open to attack. The New York Times, p. A6.

NYT65 Shenon, P. (1998, September 13). Travel advisory: Correspondent's report; Bombings cast a shadow on East Africa tourism. The New York Times, p. E3.

NYT66 Weiser, B. (1998, September 18). 2 new suspects linked by U.S. to terror case. The New York Times, p. A1.

NYT67 Lyman, R. (1998, September 20). Texans call terror suspect apolitical. The New York Times, p. A2,6.

NYT68 Weiser, B. (1998, September 22). Texan charged with Bin Laden link. The New York Times, p. A6.

NYT69 Schmitt, E. (1998, September 22). Administration to ask 1.8 billion for embassy security. The New York Times, p. A6.

NYT70 Bonner, R. (1998, September 22). Tanzania charges two in bombing of American embassy. The New York Times, p. A6.

NYT71 Risen J. (1998, September 25). U.S. directs international drive on Bin Laden networks. The New York Times, p. A3.

NYT72 Bonner, R. (1998, September 26). FBI focusing bomb search on house near Nairobi. The New York Times, p. A3.

NYT73 Weiser, B. (1998, September 26). U.S. says Bin Laden aide tried to get nuclear material. The New York Times, p. A3.

NYT74 Bonner, R. (1998, September 27). Public face of terror suspect: Low-key family man. The New York Times, p. A1, 6.

NYT75 Weiser, B. (1998, September 29). U.S. asks British to deliver suspected Bin Laden aide. The New York Times, p. A10.

NYT76 Risen, J. (1998, October 4). New evidence ties Sudanese to Bin Laden, U.S. asserts. The New York Times, p. A1, 11.

NYT77 McNeil Jr., D.G. (1998, October 6). Assets of a bombing suspect: Keen wit, religious soul, angry temper. The New York Times, p. A6. 
NYT78 Weiser, B. (1998, October 8). U.S. closer to tying Bin Laden to embassy bombings. The New York Times, p. A3.

NYT79 Miller, J., Risen, J. (1998, October 18). Backed by U.S., Saudis seek Afghan ouster of Bin Laden. The New York Times, p. A1, 6.

NYT80 Weiser, B., Sachs, S., Kocieniewski, D. (1998, October 22). U.S. sees Brooklyn link to world terror network. The New York Times, p. A1.

NYT81 Bonner, R., Risen, J. (1998, October 23). Nairobi embassy received warning of coming attack. The New York Times, p. A1.

NYT82 Weiser, B. (1998, October 30). U.S. ex-sergeant linked to Bin Laden conspiracy. The New York Times, p. A1.

NYT83 (1998, November 5). U.S. indictment: Detonated an explosive device. The New York Times, p. A8.

NYT84 Weiser, B. (1998, November 5). Saudi is indicted in bomb attacks on U.S. embassies. The New York Times, p. A1.

NYT85 Weiser, B. (1998, November 10). Lawyers for bombing suspects say jail rules violate rights. The New York Times, p. B4.

NYT86 Weiser, B. (1998, November 11). Judge to hear complaints on jail rights. The New York Times, p. B3.

NYT87 Risen, J. (1998, November 14). Bin Laden was target of Afghan raid, U.S. confirms. The New York Times, p. A3.

NYT88 Weiser, B. (1998, November 19). Judge won't ease jail restrictions on men held in bombings of U.S. embassies. The New York Times, p. B9.

NYT89 Weiner, T. (1998, November 21). Taliban proclaim Bin Laden innocent in embassy attacks. The New York Times, p. A6.

NYT90 Weiser, B. (1998, December 2). A Bin Laden agent left angry record of gripes and fears. The New York Times, p. A1.

NYT91 Bonner, R. (1998, December 5). Seeking bombs? No, a wife, Arab suspect tells the FBI. The New York Times, p. A4.

NYT92 Weiser, B. (1998, December 17). Details given, and 5 more charged, in Tanzania bombing. The New York Times, p. A10.

NYT93 Shenon, P. (1999, January 8). Many flaws blamed in embassy attacks. The New York Times, p. A6. 
NYT94 Shenon, P. (1999, January 9). Report on security suggests closing some U.S. embassies. The New York Times, p. A7.

NYT95 Risen, J., Weiser, B. (1999, January 9). Unheeded warnings: A special report: Before bombings, omens and fears. The New York Times, p. A1.

NYT96 Johnston, D. (1999, January 25). Administration to seek \$3 billion to protect embassies abroad. The New York Times, p. A9.

NYT97 Risen, J. (1999, February 5). Embassy security budget is far less than panel urged. The New York Times, p. A3.

NYT98 Weiser, B. (1999, February 9). Judge denies bail for suspect in embassy bombing inquiry. The New York Times, p. B5.

NYT99 Shenon, P. (1999, February 19). Spending to avert embassy attacks assailed as timid. The New York Times, p. A1.

NYT100 Weiner, T. (1999, March 4). Terror suspect said to anger Afghan hosts. The New York Times, p. A1.

NYT101 Weiser, B. (1999, March 6). U.S. unfairly tying imam to terror suspect, lawyer says. The New York Times, p. B4.

NYT102 Fisher, I. (1999, March 28). Doctors tackle scars of Nairobi blast. The New York Times, p. A1, 11.

NYT103 Weiner, T. (1999, April 13). U.S. hard put to find proof Bin Laden directed attacks. The New York Times, p. A1.

NYT104 Weiser, B. (1999, May 18). Terror suspect's indictment to be sought as talks fail. The New York Times, p. A14.

NYT105 Weiser, B. (1999, May 20). U.S. charges ex-soldier, calling him plotter with Bin Laden. The New York Times, p. A12.

NYT106 Jacobs, A. (1999, June 17). U.S. indicts 2 more men in bombing of embassies. The New York Times, p. A17.

NYT107 Weiser, B. (1999, June 22). No freedom for man staying silent in terrorism inquiry. The New York Times, p. B4.

NYT108 Weiser, B. (1999, June 22). No freedom for man staying silent in terrorism inquiry. The New York Times, p. B4.

NYT109 Weiser, B. (1999, June 23). Terrorism suspect charges toward judge, but is tackled. The New York Times, p. B6. 
NYT110 Weiser, B. (1999, June 25). Suspect in embassy bombings avows innocence in letters to relatives. The New York Times, p. B5.

NYT111 Shenon, P. (1999, June 26). 6 U.S. embassies in Africa temporarily closed. The New York Times, p. A3.

NYT112 Weiser, B. (1999, July 1). Bomb suspects' lawyers to need security checks. The New York Times, p. B5.

NYT113 Rohde, D. (1999, July 13). U.S. says it has fingerprints of embassy bombing suspects. The New York Times, p. A6.

NYT114 Weiser, B. (1999, August 6). Judge won't free terrorism case witnesses. The New York Times, p. B3.

NYT115 Fisher, Ian. (1999, August 7). Nairobi embassy blast survivors still struggling. The New York Times, p. A3.

NYT116 Perlez, J., Shah, P.Z (2008, June 3). 8 are killed in bombing in Pakistan. The New York Times, p. A6.

NYT117 Perlez, J., Shah, P.Z. (2009, June 4). Pakistan calls embassy blast suicide attack. The New York Times, p. A11.

NYT118 Perlez, J. (2008, June 5). Proposals would curtail power of Pakistan leader. The New York Times, p. A10.

NYT119 Shah, P.Z., Cowell, A. (2008, June 7). Police say they foiled bomb plot in Pakistan. The New York Times, p. A6.

NYT120 Reuters. (2008, June 14). Denmark: Police warn of threat by al Qaeda after embassy attack. The New York Times, p. A6.

NYT121 Tagliabue, J. (2008, August 19). Making a caricature of a nation's fears. The New York Times, p. A9.

NYT122 Reuters. (2008, November 6). Al Qaeda repeats threat to Danes. The New York Times, p. A6.

NYT123 Burns, J.F., Myers, S.L. (2000, October 13). The warship explosion: The overview: Blast kills sailors on US ship in Yemen. The New York Times. Retrieved from http://www.nytimes.com/

NYT124 Kleinfield, N.R. (2000, October 14). The victims: Explosion claimed 17 mostly young lives, cutting short careers and aspirations. The New York Times. Retrieved from http://www.nytimes.com/ 
NYT125 Gordon, M.R. (2000, October 14). Superpower suddenly finds itself threatened by sophisticated terrorists. The New York Times. Retrieved from http://www.nytimes.com/

NYT126 Myers, S.L. (2000, October 14). Whose holy land? US officials tell of getting warning last month, but say it was too vague. The New York Times. Retrieved from http://www.nytimes.com/

NYT127 Burns, J.F. (2000, October 14). Toll rises to 17 in ship blast, as US hunts suspects. The New York Times. Retrieved from http://www.nytimes.com/

NYT128 Clines, F.X. (2000, October 15). The family; Navy mother mourns, as does a navy town. The New York Times. Retrieved from http://www.nytimes.com/

NYT129 Schmitt, E. (2000, October 15). The nation: Preventing terrorism after the Cole bombing. The New York Times. Retrieved from http://www.nytimes.com/

NYT130 Wald, M.L. (2000, October 17). Seamen recall a day when quiet turned to chaos. The New York Times. Retrieved from http://www.nytimes.com/

NYT131 Burns, J.F. (2000, October 17). Yemenis now say that ship blast was criminal act. The New York Times. Retrieved from http://www.nytimes.com/

NYT132 Burrns, J.F., Myers, S.L. (2000, October 18). US says Yemen has found "leads" in bombing. The New York Times. Retrieved from http://www.nytimes.com/

NYT133 Myers, S.L. (2000, October 19). Clinton leads tribute to the Cole's crew. The New York Times. Retrieved from http://www.nytimes.com/

NYT134 Burns, J.F. (2000, October 19). Ship bomb inquiry focuses on safe houses and deserted car. The New York Times. Retrieved from http://www.nytimes.com/

NYT135 Myers, S.L. (2000, October 20). Possible lapses in security at Yemen port investigated. The New York Times. Retrieved from http://www.nytimes.com/

NYT136 Burns, J.F. (2000, October 20). Yemenis link bomb inquiry to border region and a Somali. The New York Times. Retrieved from http://www.nytimes.com/

NYT137 Miller, J., MacFarquhar, N. (2000, October 20). US says it was warned on Egyptian Islamic group. The New York Times. Retrieved from http://www.nytimes.com/

NYT138 Myers, S.L., Johnston, D. (2000, October 21). Skiff that bombed US destroyer now said to have moved in alone. The New York Times. Retrieved from http://www.nytimes.com/

NYT139 Burns, J.F. (2000, October 21). Yemen, an edgy place, faces flood of Americans. The New York Times. Retrieved from http://www.nytimes.com/ 
NYT140 Burns, J.F. (2000, October 22). Yemeni and US teams focus on boat used to attack Cole. The New York Times. Retrieved from http://www.nytimes.com/

NYT141 Burns, J.F. (2000, October 23). Investigators discouraging speculation in Cole attack. The New York Times. Retrieved from http://www.nytimes.com/

NYT142 Burns, J.F. (2000, October 24). Yemeni supply firm emerges as a focus of inquiry into ship attack. The New York Times. Retrieved from http://www.nytimes.com/

NYT143 Burns, J.F. (2000, October 25). No special alert for Cole before bombing. The New York Times. Retrieved from http://www.nytimes.com/

NYT144 Burns, J.F. (2000, October 26). Yemen reports arrests of foreign-born Arabs in Cole attack. The New York Times. Retrieved from http://www.nytimes.com/

NYT145 Becker, E., Myers, S.L. (2000, October 26). Pentagon aide quits; Warnings ignored, he says. The New York Times. Retrieved from http://www.nytimes.com/

NYT146 Burns, J.F. (2000 October 28). How a mighty power was humbled by a little skiff. The New York Times. Retrieved from http://www.nytimes.com/

NYT147 Nagourney, A., Murphy, D.E. (2000, October 29). Attack on Cole is raised as issue in New York race. The New York Times. Retrieved from http://www.nytimes.com/

NYT148 Burns, J.F. (2000, October 29). Yemen restricting FBI access to suspects in Cole bombing. The New York Times. Retrieved from http://www.nytimes.com/

NYT149 Johnston, D., Myers, S.L. (2000, October 30). Investigation of attack on US destroyer moving slowly. The New York Times. Retrieved from http://www.nytimes.com/

NYT150 Burns, J.F. (2000, October 30). A maimed destroyer Cole starts for home. The New York Times. Retrieved from http://www.nytimes.com/

NYT151 Burns, J.F. (2000, October 31). Ship attack suspects seemed out of place. The New York Times. Retrieved from http://www.nytimes.com/

NYT152 Murphy, D.E. (2000, November 1). Clinton and Lazio turn negative on campaign use of Cole attack. The New York Times. Retrieved from http://www.nytimes.com/

NYT153 Burns, J.F. (2000, November 1). US aides say the Yemenis seem to hinder Cole inquiry. The New York Times. Retrieved from http://www.nytimes.com/

NYT154 Becker, E., Myers, S.L. (2000, November 1). Destroyer may not have fulfilled security rules. The New York Times. Retrieved from http://www.nytimes.com/ 
NYT155 Burns, J.F. (2000, November 2). FBI and Yemen said to be near an agreement on the investigation of the Cole blast. The New York Times. Retrieved from http://www.nytimes.com/

NYT156 Archibold, R.C. (2000, November 3). Pataki says GOP calls were "wrong." The New York Times. Retrieved from http://www.nytimes.com/

NYT157 Archibold, R.C., Nagourney, A. (2000, November 4). Lazio and Clinton swap charges on Mideast. The New York Times. Retrieved from http://www.nytimes.com/

NYT158 Becker, E. (2000, November 4). Destroyer's sailors fly home to a hero's welcome. The New York Times. Retrieved from http://www.nytimes.com/

NYT159 Burns, J.F. (2000, November 5). Remote Yemen may be key to terrorist's past and future. The New York Times. Retrieved from http://www.nytimes.com/

NYT160 Burns, J.F. (2000, November 9). US remains at impasse with Yemenis over Cole investigation. The New York Times. Retrieved from http://www.nytimes.com/

NYT161 Myers, S.L. (2000, November 10). Failed plan to bomb a US ship is reported. The New York Times. Retrieved from http://www.nytimes.com/

NYT162 Burns, J.F. (2000, November 12). Cole inquiry provokes bitter US dispute. The New York Times. Retrieved from http://www.nytimes.com/

NYT163 Burns, J.F. (2000, November 23). Yemeni cites Cole suspects seen as linked to bin Laden. The New York Times. Retrieved from http://www.nytimes.com/

NYT164 Burns, J.F. (2000, November 26). Yemen links to bin Laden gnaw at FBI in Cole inquiry. The New York Times. Retrieved from http://www.nytimes.com/

NYT165 Myers, S.L. (2000, December 6). America to press security in distant ports. The New York Times. Retrieved from http://www.nytimes.com/

NYT166 Miller, J., Burns, J.F. (2000, December 8). Two primary figures emerge in bombing of the Cole. The New York Times. Retrieved from http://www.nytimes.com/

NYT167 Myers, S.L. (2000, December 9) Inquiry faults the Cole's captain and crew. The New York Times. Retrieved from http://www.nytimes.com/

NYT168 Burns, J.F. (2000, December 13). Yemenis say Saudi man is top suspect in Cole attack. The New York Times. Retrieved from http:/www.nytimes.com/

NYT169 Burns, J.F. (2000, December 15). Yemen on delicate path in bin Laden hunt. The New York Times. Retrieved from http://www.nytimes.com/ 
NYT170 Myers, S.L. (2001, January 2). Pentagon finds ongoing lapses in Gulf security. The New York Times. Retrieved from http://www.nytimes.com/

NYT171 Myers, S.L. (2001, January 6). Cohen to order broader review of Cole attack. The New York Times. Retrieved from http://www.nytimes.com/

NYT172 Myers, S.L. (2001, January 8). Navy inquiry on Cole urges no punishment of captain or crew. The New York Times. Retrieved from http://www.nytimes.com/

NYT173 Myers, S.L. (2001, January 10). Panel on Cole attack urges increased spending on intelligence. The New York Times. Retrieved from http:/www.nytimes.com/

NYT174 Burns, J.F. (2001, February 1). The Cole investigation proves frustrating. The New York Times. Retrieved from http://www.nytimes.com/

NYT175 Dao, J. (2001, May 4). Senators question handling of Cole case. The New York Times. Retrieved from http://www.nytimes.com/

NYT176 Burns, J.F. (2001, August 21). FBI's inquiry in Cole attack is nearing halt. The New York Times. Retrieved from http://www.nytimes.com/

NYT177 Gerth, J., Van Natta Jr., D. (2001, October 6). A nation challenged: The investigation: US traces path of hijacker to other attacks. The New York Times. Retrieved from http:/www.nytimes.com/

NYT178 Fattah, H.M., Wong, E. (2005, August 20). US ships target of rocket attack in Jordan's port. The New York Times, p. A1.

NYT179 Fattah, H.M. (2005, August 21). Search continues for clues and suspects in rocket attack in Jordan. The New York Times, p. A1.

NYT180 Fattah, H.M. (2005, August 23). Jordan arrests key suspect in rocket attack on US warships; Link to Iraqi insurgents is seen. The New York Times, p. A1.

NYT181 Associated Press. (2005, August 24). Zarqawi's group claims Jordan attack. The New York Times, p. A4.

NYT182 Glanz, J. (2005, November 13). In Jordan, methodical madness. The New York Times, p. D1.

NYT183 Filkins, D., Shane, S., Shanker, T. (2006, March 25). Top insurgent in Iraq adopts lower profile. The New York Times, p. A5.

NYT184 Sciolino, E., Carvajal, D., Alvarez, L. (2004, March 12). Spain struggles to cope as the equation of terror changes in an instant. The New York Times, p. A1.

NYT185 Sciolion, E., Fuchs, D. (2004, March 12). 10 bombs shatter trains in Madrid, killing 192. The New York Times, p. A1, 5. 
NYT186 Golden, T., Van Natta Jr., D. Carnage yields conflicting clues as officials search for culprits. The New York Times, p. A1, 5.

NYT187 Lichtblau, E., Kershaw, S. (2004, March 13). Bombings lead US to raise security for trains. The New York Times, p. A1, 3.

NYT188 Sciolion, E. (2004, March 13). Grieving crowds in Spain seethe at train attacks. The New York Times, p. A1, 6.

NYT189 Tyler, P.E., Van Natta Jr., D. (2004, March 13). Europe adds new security measures to its well-traveled rail system. The New York Times, p. A1, 6.

NYT190 Golden, T. (2004, March 13). Spanish officials divided on whom to blame for train attacks: Basques or Islamists. The New York Times, p. A1, 7.

NYT191 Sciolino, E., Alvarez, L. (2004, March 14). Video claims al Qaeda set blasts in Spain; Officials arrest 3 Moroccans and 2 Indians. The New York Times, p. A1.

NYT192 Alvarez, L. (2004, March 15). Deep unease over the future gnaws at Moroccans in Spain. The New York Times, p. A5, 13.

NYT193 Sanger, D.E. (2004, March 15). Blow to Bush: Ally rejected. The New York Times, p. A1, 5.

NYT194 Golden, T. (2004, March 15). Moroccan suspect has ties to 9/11 figure, files show. The New York Times, p. A5, 12.

NYT195 Sciolino, E. (2005, March 15). Following attacks, Spain's governing party is beaten. The New York Times, p. A1, 6.

NYT196 Bernstein, R. (2004, March 15). A shocking confrontation with terror on home turf. The New York Times, p. A1, 13.

NYT197 Alvarez, L. (2004, March 15). In his startling leap to high office, socialist takes strong stand against "an unjust war". The New York Times, p. A1, 12.

NYT198 Sciolion, E. (2004, March 16). Spain will loosen its alliance with US, premierelect says. The New York Times, p. A1.

NYT199 Bernstein, R. (2004, March 16). Nations with troops in Iraq make no move to join Spain. The New York Times, p. A1, 16.

NYT200 Golden, T., Johnston, D. (2004, March 16). Officials tending to blame Qaeda for Madrid attack. The New York Times, p. A1, 17.

NYT201 Sciolino, E. (2004, March 16). Many in Europe suspect Spain misled them about attackers. The New York Times, p. A3, 17. 
NYT202 Golden, T., Van Natta Jr., D. (2004, March 17). Madrid suspect under scrutiny in 3 countries. The New York Times, p. A1.

NYT203 Alvarez, L., Sciolino, E. (2004, March 17). Spain grapples with notion that terrorism trumped democracy. The New York Times, p. A1, 12.

NYT204 Santora, M. (2004, March 17). Iraq politics and rawer nerves accompany Albany terror debate. The New York Times, p. B1, 2.

NYT205 Sanger, D.E., Johnston, D. (2004, March 18). US official says Spanish government "mishandled" reports on bombing. The New York Times, p. A1, 10.

NYT206 Alvarez, L. (2004, March 18). Spain's losing party plans to sue movie director for slander over a "coup" accusation. The New York Times, p. A1, 10.

NYT207 Golden, T., Smith, C.S. (2004, March 19). Spain arrests 5 more suspects in Madrid bomb attacks. The New York Times, p. A1, 12.

NYT208 Alvaarez, L., Sciolino, E. (2004, March 19). Spanish government seeks to document that it did not lie about suspects. The New York Times, p. A1, 12.

NYT209 Golden, T. (2004, March 20). Spanish judge holds 3 Moroccans on murder charges. The New York Times, p. A1, 7.

NYT210 Golden, T., Butler, D., Van Natta Jr., D. (2004, March 22). As Europe hunts for terrorists, the hunted press advantages. The New York Times, p. A1.

NYT211 Sciolino, E. (2004, March 22). Spain's new leader blows both hot and cold toward US. The New York Times, p. A1, 3.

NYT212 Sciolion, E. (2004, March 25). World leaders converge in Spain to mourn bomb victims. The New York Times, p. A1, 3.

NYT213 Smith, C.S., Golden, T. (2004, March 27). Spain says it holds half of group that bombed trains. The New York Times, p. A2, 3.

NYT214 Smith, C.S. (2004, March 28). A long fuse links Tangier to bombings in Madrid. The New York Times, p. A1, 20.

NYT215 Fuchs, D. (2004, March 30). Investigation of Madrid bombings shows no link to Basque group, Spanish minister says. The New York Times, p. A1, 6.

NYT216 Fuchs, D. (2004, April 4). Blast in Madrid kills 3 suspects in train attack. The New York Times, p. A1.

NYT217 Bennhold, K. (2004, April 5). Main suspect in Spain blasts among dead. The New York Times, p. A1, 3. 
NYT218 Tyler, P.E. (2004, April 7). Europe trying to act first against terrorist networks. The New York Times, p. A5, 12.

NYT219 Sciolino, E., Daly, E. (2004, April 9). Blast suspects in Madrid had new plot, officials say. The New York Times, p. A1, 6.

NYT220 Sciolino, E. (2004, April 12). Complex web of Madrid plot still entangled. The New York Times, p. A1.

NYT221 Sciolino, E., Daly, E. (2004, April 13). 3 more Moroccans arrested in Madrid train bombings. The New York Times, p. A3, 8.

NYT222 Sciolino, E. (2004, April 14). Terrorists in Spain said to eye Jewish sites. The New York Times, p. A4, 6.

NYT223 Bernstein, R. (2004, April 16). Tape, probably bin Laden's, offers "truce" to Europe. (2004, April 16). The New York Times, p. A1, 3.

NYT224 Simons, M. (2004, April 17). Spain says it has arrested 3 more suspects in train bombings. The New York Times, p. A1, 3.

NYT225 Simons, M. (2004, April 19). Spanish premier orders soldiers home from Iraq. The New York Times, p. A1, 6.

NYT226 Simons, M. (2005, April 25). Spain's new premier pays visit to Morocco. The New York Times, p. A8, 14.

NYT227 Kershaw, S., Lichtblau, E. (2004, May 7). US lawyer arrested in Madrid bombing inquiry. A1, 3.

NYT228 Sciolino, E. (2004, May 7). Spanish premier says troops will not return to Iraq. The New York Times, p. A1, 3.

NYT229 Kershaw, S., Johnston, D. (2004, May 8). Arrest in bombing inquiry was rushed, officials say. The New York Times, p. A5, 12.

NYT230 Sciolino, E. (2004, May 16). Morocco connection is emerging as sleeper threat in terror war. The New York Times, p. A1, 4.

NYT231 Kershaw, S. (2004, May 21). Lawyer linked to bombings is released. The New York Times, p. A1, 14.

NYT232 Kershaw, S., Lichtblau, E. (2004, May 22). Questions about evidence in US arrest in bombing. The New York Times, p. A5, 14.

NYT233 Kershaw, S., Lichtblau, E. (2004, May 25). Bomb case against lawyer is rejected. The New York Times, p. A1, 16. 
NYT234 Kershaw, S., Lichtblau, E. (2004, May 26). Spain had doubts before US held lawyer in blast. The New York Times, p. A1.

NYT235 Kershaw, S., Lichtblau, E., Fuchs, D., Bergman, L. (2004, June 5). Spain and US at odds on mistaken terror arrest. The New York Times, p. A1, 3.

NYT236 Baker, A. (2004, June 9). Italy arrests two as terrorist suspects. The New York Times, p. A1, 10.

NYT237 Sciolino, E. (2004, June 11). Terror suspect in Italy linked to more plots. The New York Times, p. A1, 9.

NYT238 Sciolino, E., Horowitz, J. (2004, June 12). The talkative terrorist on tape: The Madrid plot "was my project." The New York Times, p. A1, 2.

NYT239 McLean, R. (2004, October 17). Old friends US and Spain weather a time of tension. The New York Times, p. A5, 11.

NYT240 Simons, M. (2004, October 24). Spain is seeking to integrate growing Muslim population. The New York Times, p. A5, 18.

NYT241 Johnston, D., Van Natta Jr., D. (2004, October 24). Little evidence of Qaeda plot timed to vote. The New York Times, p. A1, 29.

NYT242 McLean, R. (2004, October 31). Spanish prisons provide pool of recruits for radical Islam. The New York Times, p. A5, 18.

NYT243 Sciolino, E., McLean, R. (2005, March 11). Spain is riven by the sorrows of March. The New York Times, p. A3, 4.

NYT244 Vitello, P. (2005, July 8). In Americans, lurking fears rise to surface. The New York Times, p. A3.

NYT245 Cowell, A. (2005, July 8). 4 Blasts, and Blair's rising star runs into a treacherous future. The New York Times, p. A5.

NYT246 Story, L. (2005, July 8). Witnesses post instant photos on the web to capture drama. The New York Times, p. A5.

NYT247 Cowell, A. (2005, July 8). Subway and bus blasts in London kill at least 37. The New York Times, p. A6.

NYT248 Van Natta Jr., D., Sciolino, E. (2005, July 8). Timers used in blasts, police say; Parallels to Madrid are found. The New York Times, p. A4.

NYT249 Lyall, S. (2005, July 8). An umbrella in a shower of a million bits that had been a bus. The New York Times, p. A1. 
NYT250 Lipton, E. (2005, July 8). Authorities step up security on American transit systems. The New York Times, p. A5.

NYT251 Stevenson, R. (2005, July 8). Bombings rewrite agenda for world leaders in Scotland. The New York Times, p. A1.

NYT252 Elliott, C. (2005, July 8). Bomb attacks may threaten lucrative fares in Europe. The New York Times, p. A6.

NYT253 Chan, S. (2005, July 8). In added security measure, officers are riding the rails. The New York Times, p. A1.

NYT254 Landler, M., Fuerbringer, J. (2005, July 8). Initial panic selling followed by a numbing business as usual. The New York Times, p. C2.

NYT255 Cowell, A. (2005, July 9). First details of bombs emerge; Toll reaches 49 and some bodies aren't yet recovered. The New York Times, p. A1.

NYT256 Boxer S. (2005, July 9). On the web, photos strain to connect 7/7 and 9/11. The New York Times, p. B1.

NYT257 Van Natta Jr., D., Johnston, D. (2005, July 9). London bombs seen as crude; Death toll rises to 49. The New York Times, p. A6.

NYT258 Rosenthal, E. (2005, July 9). Italians fear they'll face next attack by terrorists. The New York Times, p. A6.

NYT259 Bernstein, R. (2005, July 9). Despite terror, Europeans seem determined to maintain civil liberties. The New York Times, p. A1.

NYT260 Chan, S. (2005, July 9). MTA slow to spend money on transit security. The New York Times, p. A3.

NYT261 Smith, C.S. (2005, July 9). At mosque that recruited radicals, new imam calls for help in catching bombers. The New York Times, p. A1.

NYT262 Lyall, S. (2005, July 9). Overslept? You lived. In a big hurry to catch the bus? You died. The New York Times, p. A1.

NYT263 Cowell, A. (2005, July 10). British police revise time span of subway bombs; 3 blasts within 50 seconds. The New York Times, p. A1.

NYT264 Alvarez, L. (2005, July 10). Photos plead; Have you seen this person? The New York Times, p. A1, 3.

NYT265 Kilgannon, C. (2005, July 10). Tourists still flock to the sights, terror worries or not. The New York Times, p. A1. 
NYT266 Fattah, H.M. (2005, July 10). Longtime haven for Arabs now must ask: Why us? The New York Times, p. A1.

NYT267 Sciolino, E., Van Natta Jr., D. (2005, July 10). For a decade, London thrived as a busy crossroads of terror. The New York Times, p. A4.

NYT268 McFadden, R.D. (2005, July 10). Bronx man among missing after London bomb blasts. The New York Times, p. A5.

NYT269 Cowell, A. (2005, July 11). Show of resolve as religious leaders try to cool tensions. The New York Times, p. A3.

NYT270 Pfanner, E. (2005, July 11). British news media reacted to bombings with a measure of caution. The New York Times, p. C4.

NYT271 Lipton, E., Revkin, A.C. (2005, July 11). High-tech antiterror tolls: A costly, long-range goal. The New York Times, p. A1.

NYT272 Hernandez, R. (200, July 11). Congress urged to extend help after attacks. The New York Times, p. B5.

NYT273 Sciolino, E., Van Natta Jr., D. (2005, July 11). With no leads, British consult allies on blasts. The New York Times, p. A1.

NYT274 Lyall, S. (2005, July 11). Londoners, remembering crises old and new, just "get on with it." The New York Times, p. A1.

NYT275 Alvarez, L. (2005, July 12). Revenge attacks and vandalism unnerve Muslims in Britain. The New York Times, p. A1.

NYT276 Van Natta Jr., D., Sciolino, E. (2005, July 12). Bombs in London are now called military quality. The New York Times, p. A1.

NYT277 Smith, C.S. (2005, July 12). Usually volatile mayor wins praise for low-key presence. The New York Times, p. A5.

NYT278 Sanger, D.S. (2005, July 12). Bush vows to fight until terrorists' defeat. The New York Times, p. A1.

NYT279 Timmons, H. (2005, July 12). Attacks create only a brief pause in the tourist swarm to London. The New York Times, p. C1.

NYT280 Cowell, A. .(2005, July 12). Transit officials now concede they did not see terrorism in the initial confusion. The New York Times, p. A1.

NYT281 Cowell, A., Van Natta Jr., D. (2005, July 13). 4 from Britain carried out terror blasts, police say. The New York Times, p. A6 
NYT282 Fattah, H.M. (2005, July 13). In a neighborhood in Leeds, tolerance tempers the hard economic times. The New York Times, p. A1.

NYT283 Jehl, D. (200, July 13). Experts fear suicide bomb is spreading into the West. The New York Times, p. A6.

NYT284 Cowell, A. (2005, July 14). British seeking $5^{\text {th }}$ man, thought to be ringleader. The New York Times, p. A6.

NYT285 Sciolino, E., Van Natta Jr., D. (2005, July 14). 2004 British raid sounded alert on Pakistani militants. The New York Times, p. A5.

NYT286 Alvarez, L. (2005, July 14). Lives of three men offer little to explain attacks. The New York Times, p. A1.

NYT287 Chan, S. (2005, July 14). US transit agencies turn to cameras in terror fight, but systems vary in effectiveness. The New York Times, p. A1.

NYT288 Cowell, A., Jehl, D. (2005, July 15). Police ask public to help trace a bomber, homemade explosive is now hinted. The New York Times, p. A1.

NYT289 Lipton, E. (2005, July 15). Senators clash over where to spend for homeland security. The New York Times, p. A1.

NYT290 Alvarez, L. (2005, July 15). Suspects' neighbors say there was no hint of evil. The New York Times, p. A1.

NYT291 Bernstein, R. (2005, July 15). Muslim approval of terrorism declines, a global poll finds. The New York Times, p. A1.

NYT292 Van Natta Jr., D., Sciolino, E. (2005, July 16). Egyptian biochemist is arrested in Cairo and questioned in the London bombings. The New York Times, p. A1.

NYT293 Fattah, H.M. (2005, July 16). Anger burns on the fringe of Britain's Muslims. The New York Times, p. A3.

NYT294 MacFarquhar, N. (2005, July 16). In Cairo suburb, man in bombing inquiry is described as committed to his studies. The New York Times, p. A1.

NYT295 Cowell, A. (2005, July 17). Blair says "evil ideology" must be faced directly. The New York Times, p. A6.

NYT296 Timmons, H. (2005, July 17). A black market for bomb materials is said to flourish in Europe. The New York Times, p. A1.

NYT297 Emmrich, S. (2005, July 17). London after the bombings; Life goes on. The New York Times, p. E1. 
NYT298 Sciolino, E. (2005, July 17). Politics intrudes in bombing inquiry, deepening the French-British rift. The New York Times, p. A1.

NYT299 Lyall, S. (2005, July 17). Lost in bombings, diverse and promising lives. The New York Times, p. A3.

NYT300 Cowell, A. (2005, July 18). British seek new laws to confront terror. The New York Times, p. A1.

NYT301 Alvarez, L. (2005, July 18). New Muslim at 15, terror suspect at 19. The New York Times, p. A4.

NYT302 Van Natta Jr., D., Grey, S. (2005, July 18). Investigators are clear who carried bombs, but have far to go to explain more. The New York Times, p. A1.

NYT303 Sciolino, E., Van Natta Jr., D. (2005, July 19). June report led Britain to lower its terror alert. The New York Times, p. A6.

NYT304 Cowell, A. (2005, July 19). Britain assails critical report on role in Iraq. The New York Times, p. A6.

NYT305 Cowell, A. (2005, July 20). Seeking moderate support, Blair meets Muslim leaders. The New York Times, p. A1.

NYT306 Chan, S. (2005, July 20). Since London bombings, New York has guarded underwater subway tubes full times. The New York Times, p. B2.

NYT307 Sengupta, S., Rohde, D. (2005, July 20). TO many, talk of a crackdown in Pakistan seems hollow. The New York Times, p. A3.

NYT308 Van Natta Jr., D. (2005, July 21). British seeking cleric's top aide in July 7 attack. The New York Times, p. A1.

NYT309 Cowell, A. (2005, July 21). Britain and Jordan agree on expulsion of terror suspects. The New York Times, p. A1.

NYT310 Cowell, A. (2005, July 22). Bombs set at 4 London sites, but fail to explode. The New York Times, p. A3.

NYT311 Van Natta Jr., D., Sciolino, E. (2005, July 22). Two Thursdays: Echoes and theories but no solid links. The New York Times, p. A1.

NYT312 Lyall, S. (2005, July 22). A calm response in a city shocked 2 weeks earlier. The New York Times, p. A1.

NYT313 Cowell, A. (2005, July 23). 5 shots in a train car leave Londoners shaken. The New York Times, p. A2. 
NYT314 Van Natta Jr., D., Sciolino, E. (2005, July 13). Subway suspect is shot to death by London police. The New York Times, p. A1.

NYT315 Fattah, H.M. (2005, July 23). New incidents heighten tensions among British Muslims. The New York Times, p. A3.

NYT316 Van Natta Jr., D. (2005, July 24). Scotland Yard challenged by missteps in bombing inquiry. The New York Times, p. A3.

NYT317 Fahim, J. (2005, July 24). After London, time is right for bag searches in New York, police commissioner says. The New York Times, p. A1.

NYT318 Lipton, E. (2005, July 24). To fight terror, New York tries London’s “ring of steel". The New York Times, p. D1.

NYT319 Cowell, A., Van Natta Jr., D. (2005, July 24). Britain says man killed by police had no bomb tie. The New York Times, p. A6.

NYT320 Jehl D. (2005, July 24). Many bombs but links are unclear. The New York Times, p. A6.

NYT321 Cowell, A. (2005, July 25). A fleeing man and a burst of gunfire; Britons look into their collective conscience. The New York Times, p. A1

NYT322 Kershaw, S. (2005, July 25). Suicide bombings bring urgency to police in US. The New York Times, p. A5.

NYT323 Myer, G., El-Naggar, M. (2005, July 25). It's too soon to assign responsibility for bombings, authorities in Egypt content. The New York Times, p. A1.

NYT324 Sciolino, E. (2005, July 25). Regrets, but no apology, in London subway shooting. The New York Times, p. A1.

NYT325 Sciolino, E., Van Natta Jr., D. (2005, July 25). Searching for footprints. The New York Times, p. A1.

NYT326 Lyall, S. (2005, July 25). Relatives and friends remember a busy, hopeful man, and discover a new fear. The New York Times, p. A1.

NYT327 Cowell, A. (2005, July 26). Police name 2 of 4 men linked to bomb attempts. The New York Times, p. A1.

NYT328 Lyall, S. (2005, July 26). Londoners grappling with pervasive new foes; Fear and suspicion. The New York Times, p. A1.

NYT329 Jamal, A., Sengupta, S. (2005, July 26). Two militants place suspect at a camp in Pakistan. The New York Times, p. A6.

NYT330 Sciolino, E., Van Natta Jr., D. (2005, July 27). The New York Times, p. A1. 
NYT331 LYall, S. (2005, July 27). 3 main British parties to back tougher antiterrorism laws. The New York Times, p. A5.

NYT332 Sciolino, E., Van Natta Jr., D. (2005, July 27). Police debate if London plotters were suicide bombers, or dupes. The New York Times, p. A4.

NYT333 Landler, M., Sciolino, E. (2005, July 28). Police in Britain hold Somali man in $2^{\text {nd }}$ bomb plot. The New York Times, p. A1.

NYT334 Lyall, S. (2005, July 28). In Britain, migrants took a new path: To terrorism. The New York Times, p. A5.

NYT335 Broder, J.M. (2005, July 29). Police chiefs moving to share terror data. The New York Times, p. A1.

NYT336 Bowley, G. (2005, July 29). Family of man slain by London police challenges official account. The New York Times, p. A2.

NYT337 Rashbaum, W.K., Bonner, R. (2005, July 29). As 3 nations consulted, terror suspect eluded arrest. The New York Times, p. A1.

NYT338 Cowell, A. (2005, July 30). Police in London and Rome arrest 4 bomb suspects. The New York Times, p. A6.

NYT339 Fisher, I., Cowell, A. (2005, July 31). Suspect held in Italy said to admit carrying bomb in train. The New York Times, p. A3.

NYT340 Bonner, R., Stephen, G., Van Natta Jr., D. (2005, July 31). British inquiry shifts away from foreign aid for plots. The New York Times, p. A1.

NYT341 Waldman, A. (2005, July 31). Seething unease shaped British bombers' newfound zeal. The New York Times, p. A1.

NYT342 Rosenthal, E. (2005, August 1). Muslims in Italy unsettled over increased scrutiny. The New York Times, p. A1.

NYT343 Cowell, A. (2005, August 1). 8 are detained in Britain in a wider search for suspects. The New York Times, p. A3.

NYT344 Lichtblau, E., Lipton, E. (2005, August 1). After bombings, few signs of similar attacks in US. The New York Times, p. A5.

NYT345 Sciolino, E. (2005, August 1). Europe confronts changing face of terrorism. The New York Times, p. A2.

NYT346 Fisher, I. (2005, August 2). Italians say London suspect lacks wide terrorist ties. The New York Times, p. A1. 
NYT347 Cowell, A. (2005, August 4). For London's police chief, plaudits, and barbs, in bombings' wake. The New York Times, p. A1.

NYT348 Van Natta Jr., D. (2005, August 5). Britain goes on high alert, spurred by hint of attack. The New York Times, p. A5.

NYT349 Lichtblau, E. (2005, August 5). Assessments find threat of suicide attacks in US. The New York Times, p. A5.

NYT350 Cowell, A. (2005, August 6). Blair is seeking to curb radicals who preach hate. The New York Times, p. A6.

NYT351 Cowell, A., Van Natta Jr., D. (2005, August 7). British indict a main suspect in the failed bomb attempts. The New York Times, p. A1.

NYT352 Cowell, A. (2005, August 8). Zambia deports terror suspect sough in US; Britain files formal charges in attacks. The New York Times, p. A1.

NYT353 Slackman, M. (2005, August 10). Egypt releases chemist question about London bombings. The New York Times, p. A1.

NYT354 Cowell, A. (2005, August 10). Britain considers lengthening time for holding terror suspects. The New York Times, p. A1.

NYT355 Fattah, H.M. (2005, August 11). Britain's Muslims take tough line on militants. The New York Times, p. A4.

NYT356 Cowell, A., Bonner, R. (2005, August 15). Changes in investigation of bombing attacks in London leave major questions unanswered. The New York Times, p. A1.

NYT357 Cowell, A. (2005, August 23). London police facing pressure over killing of Brazilian. The New York Times, p. A1

NYT358 Cowell, A. (2005, September 2). Al Jazeera video links London bombings to al Qaeda. The New York Times, p. A1.

NYT359 Cowell, A., Van Natta Jr., D. (2005, September 3). Top Muslims in Britain reject call to violence. The New York Times, p. A1.

NYT360 Lyall, S. (2005, September 21). London bombers visited earlier, apparently on practice run. The New York Times, p. A1.

NYT361 Cowell, A. (2005, December 31). Diplomat says Britain used data gotten by torture. The New York Times, p. A1.

NYT362 Van Natta Jr., D. (2006, February 8). Cleric convicted of stirring hate. The New York Times, p. A1. 
NYT363 Lyall, S. (2006, March 23). Briton tried to buy A-bomb, prosecution in trial contends. The New York Times, p. A5.

NYT364 Cowell, A. (2006, May 12). Panels say Britain underrated threat before July attacks. The New York Times, p. A3.

NYT365 Cowell, A. (2006, June 3). Man shot in counterterrorism raid in London. The New York Times, p. A1.

NYT366 Lyall, S. (2006, June 6). Report faults rescue effort after attacks in London. The New York Times, p. A6.

NYT367 Cowell, A. (2006, June 29). British court rejects tactic used in cases of terrorism. The New York Times, p. A1.

NYT368 Cowell, A. (2006, July 4). Britain grapples with terror challenges. The New York Times, p. A1.

NYT369 Cowell, A. (2006, July 6). A year later, homegrown terror still baffles Britons. The New York Times, p. A1.

NYT370 Rampe, D. (2006, July 7). Poll shows bright view of Muslim integration. The New York Times, p. A1.

NYT371 Cowell, A. (2006, July 7). One year later, video shows warning by a London bomber. The New York Times, p. A1.

WP1 Gellman, B. (1998, August 8). In Washington, emotional echoes and the start of a hunt: Investigators' focus goes beyond Africa. The Washington Post, p. A01.

WP2 Claiborne, W. (1998, August 8). Bombs at 2 U.S. Embassies in Africa kill 81: 8 Americans among the dead. The Washington Post, p. A01.

WP3 Montgomery, D. (1998, August 8). At State Department, grieving for colleagues. The Washington Post, p. A01.

WP4 Lippman, T.W. (1998, August 8). Compounds can never be fully protected, specialists say. The Washington Post, p. A16.

WP5 Lippman, T.W. (1998, August 9). Terrorists will not prevail, Clinton pledges. The Washington Post, p. A25.

WP6 Reid, T.R. (1998, August 9). Tanzania embassy’s security low-key; Government says bomb was put on truck. The Washington Post, p. A24.

WP7 Vick, K. (1998, August 9). In Nairobi, a trail of mateless shoes; City strangely quiet as rescuers search doggedly for signs of life. The Washington Post, p. A01. 
WP8 Vick, K. (1998, August 9). 149 confirmed dead in embassy blasts. The Washington Post, p. A01.

WP9 Reid, A., Weil, M., Ordonez, J. (1998, August 9). For families, a mixture of anger, grief; Bombing victims recalled fondly. The Washington Post, p. A01.

WP10 Buckley, S. (1998, August 10). Bomb vehicle was turned away; Nairobi guards sent driver to rear door. The Washington Post, p. A01.

WP11 Vick, K., Reid, T.R. (1998, August 10). An ordinary day, then horror; for explosion survivors in Kenya and Tanzania, life nearly ended on a morning like any other. The Washington Post, p. A01.

WP12 Loeb, V. (1998, August 10). Albright defends security efforts; State officials say more funding needed. The Washington Post, p. A13.

WP13 Locy, T., Lee, J. (1998, August 10). Family loses two in Nairobi blast. The Washington Post, p. A01.

WP14 Gellman, B. (1998, August 11). U.S. sets \$2 million bounty for 'cowards'; Albright vows to find, punish the bombers. The Washington Post, p. A15.

WP15 Pincus, W., Loeb, V. (1998, August 11). CIA blocked two attacks last year. The Washington Post, p. A16.

WP16 Reid, T.R. (1998, August 11). Several arrested in Tanzania bombing; Officials say little on investigation. The Washington Post, p. A16.

WP17 Slevin, P. (1998, August 11). In real life, no glamour for working diplomats. The Washington Post, p. A15.

WP18 Vick, K., Buckley, S. (1998, August 11). Agents dig for clues in African bombings; $\$ 2$ million offered to help solve case. The Washington Post, p. A01.

WP19 Buckley, S. (1998, August 11). After the explosion, silence; A survivor's 36 hours with the missing and the dead. The Washington Post, p. A01.

WP20 Smith, R.J. (1998, August 12). U.S. probes blasts' possible Mideast ties; Alleged terrorists investigated in Albania. The Washington Post, p. A19.

WP21 Vick, K., Reid, T.R. (1998, August 12). FBI teams inundate bomb sites; Embassy camera wasn't set to tape. The Washington Post, p. A19.

WP22 Boustany, N. (1998, August 12). Horrifying home thoughts from abroad. The Washington Post, p. A18.

WP23 Buckley, S. (1998, August 12). Losing a loved one - and a livelihood; Kenyan bomb victims supported network of poor relatives. The Washington Post, p. A01. 
WP24 Loeb, V., Pincus, W. (1998, August 13). Bomb suspect has been a target; Aides say Bin Laden had motive, means to attack embassies. The Washington Post, $\mathrm{p}$. A01.

WP25 Buckley, S., Vick, K. (1998, August 13). Search for survivors ends; Suspect questioned in Kenya. The Washington Post, p. A25.

WP26 Reid, T.R. (1998, August 13). Tanzanian police seek embassy driver's aide; Man usually rode in truck that carried bomb. The Washington Post, p. A27.

WP27 Vick, K., Buckley, S. (1998, August 13). 'Base! base! terrorism! terrorism!'; Gate guard in Nairobi blocked bombers. The Washington Post, p. A01.

WP28 Lippman, T.W. (1998, August 13). U.S. envoy’s pleas rebuffed; Ambassador twice sought more secure embassy for Nairobi. The Washington Post, p. A01.

WP29 Hockstader, L. (1998, August 14). U.S. embassy is fortress on a hill; Regal isolation is the price of safety at Amman mission. The Washington Post, p. A27.

WP30 Ruane, M.E., Vogel, S. (1998, August 14). At Andrews, sorrow and pride; Families, strangers alike salute bombing victims. The Washington Post, p. A01.

WP31 Buckley, S., Reid, T.R. (1998, August 14). Investigators find parts of bombing vehicle in Nairobi. The Washington Post, p. A30.

WP32 Boustany, N. (1998, August 14). The elusive face of modern terrorism. The Washington Post, p. A29.

WP33 Smith, R.J. (1998, August 14). U.S. embassy threatened in Albania; Warning against Americans follows crackdown on extremists. The Washington Post, $\mathrm{p}$. A11.

WP34 Grunwald, M. (1998, August 15). Africa bombings provide big test for FBI unit; Revamped explosives group has chance to redeem itself after critical 1997 review. The Washington Post, p. A14.

WP35 Lippman, T.W. (1998, August 15). Symbolism, safety clash at Berlin embassy; State Department reviews plans for a building that won't meet security standards. The Washington Post, p. A15.

WP36 Buckley, S. (1998, August 16). Bombing brings divided Kenyans together. The Washington Post, p. A34.

WP37 Grunwald, M., Loeb, V. (1998, August 16). Bombing suspect flown to Kenya from Pakistan. The Washington Post, p. A01. 
WP38 Constable, P., Khan, K. (1998, August 17). Suspect links embassy blast to Saudi exile; Pakistanis are told U.S. foe organized Nairobi bombing. The Washington Post, p. A01.

WP39 Loeb, V. (1998, August 17). U.S. staff, citizens told to leave Pakistan. The Washington Post, p. A12.

WP40 Vick, K. (1998, August 18). U.S. criticized as 'out of touch' with Kenyans after Nairobi blast. The Washington Post, p. A16.

WP41 Constable, P., Khan, K. (1998, August 18). U.S. cuts diplomatic staff in Pakistan; Officials cite heightened security threat following embassy bombings in Africa. The Washington Post, p. A16.

WP42 Khan, K., Constable, P. (1998, August 19). Bomb suspect details anti-U.S. terror force; Muslim radical said to lead thousands. The Washington Post, p. A01.

WP43 Lippman, T.W. (1998, August 19). Albright chides Afghan rulers; U.S. favor linked to Taliban's denial of aid to terrorists. The Washington Post, p. A24.

WP44 Abse, N. (1998, August 20). A gift of time for victims of terrorism; Program will let U.S. workers donate leave to those affected by bombings. The Washington Post, p. A13.

WP45 Vick, K. (1998, August 20). FBI, police search hotel for clues in Kenya blast. The Washington Post, p. A17.

WP46 Gellman, B., Priest, D. (1998, August 21). U.S. strikes terrorist-linked sites in Afghanistan, factory in Sudan. The Washington Post, p. A01.

WP47 Constable, P. (1998, August 21). Terrorist leader 'safe,' Afghan hosts declare. The Washington Post, p. A01.

WP48 Vick, K. (1998, August 21). Six more die in Kenya, raising death toll in Africa bombings to 263. The Washington Post, p. A20.

WP49 Loeb, V., Grunwald, M. (1998, August 21). Officials won't detail evidence on Bin Laden. The Washington Post, p. A19.

WP50 Gugliotta, G., Eilperin, J. (1998, August 21). Tough response appeals to critics of President; Several question Clinton's timing of raids. The Washington Post, $\mathrm{p}$. A17

WP51 Robinson, E., Priest, D. (1998, August 22). Reports of U.S. strikes' destruction vary; Afghanistan damage 'moderate to heavy'; Sudan plant leveled. The Washington Post, p. A01. 
WP52 Vick, K. (1998, August 22). Nairobi charity office raided; FBI chief cuts visit short. The Washington Post, p. A14.

WP53 Pae, P., Broadway, B. (1998, August 22). Muslim residents doubt, decry American action; U.S. lacked evidence to support retaliation, many say. The Washington Post, p. A15.

WP54 Loeb, V. (1998, August 23). A global, pan-Islamic network; Terrorism entrepreneur unifies groups financially, politically. The Washington Post, p. A01.

WP55 Grunwald, M. (1998, August 28). Africa blast suspects to stand trial in U.S.; 1 arraigned in New York; $2^{\text {nd }}$ to follow. The Washington Post, p. A01.

WP56 Graham, B. (1998, August 29). Bin Laden was at camp just before U.S. attack. The Washington Post, p. A01.

WP57 Grunwald, M. (1998, August 29). U.S. complaint links Bin Laden to bombing. The Washington Post, p. A01.

WP58 Vick, K. (1998, August 31). Odeh: A mystery to his in-laws; Bomb suspect stood out in village as secretive, dogmatic. The Washington Post, p. A17.

WP59 Grunwald, M. (1998, September 4). Bombing suspect alleges he was bullied into confession. The Washington Post, p. A08.

WP60 Grunwald, M. (1998, September 6). Tanzania detains 2 bombing suspects; Momentum grows in probe of attacks on U.S. embassies. The Washington Post, p. A01.

WP61 Reid, T.R. (1998, September 10). Probers focus on Tanzania business; Truck shop may be key to embassy blast. The Washington Post, p. A23.

WP62 Vick, K. (1998, September 17). FBI trails embassy bombing suspect; Investigators find clues to double life. The Washington Post, p. A01.

WP63 Grunwald, M. (1998, September 18). Ex-aide to Bin Laden held in bomb probe; U.S. details links to terror group, fugitive. The Washington Post, p. A01.

WP64 Grunwald, M., Loeb, V. (1998, September 19). German police arrest an aide to Bin Laden; U.S. files charges. The Washington Post, p. A06.

WP65 Grunwald, M., Loeb, V. (1998, September 20). U.S. is unraveling Bin Laden network; End of terrorists' thread is unknown. The Washington Post, p. A10.

WP66 Grunwald, M. (1998, September 22). Bin Laden associate indicted for perjury; New details on network are revealed. The Washington Post, p. A12. 
WP67 Grunwald, M., Reid, T.R. (1998, September 24). U.S. tries to link N.Y., Africa bombs; Prosecutors say Bin Laden aide got guns for Trade Center plotter. The Washington Post, p. A29.

WP68 Grunwald, M. (1998, September 26). U.S. says Bin Laden sought nuclear arms; Complaint cites alliance with Sudan, Iran. The Washington Post, p. A19.

WP69 Vick, K. (1998, October 6). Embassy in Uganda may have been a target; Two bombing plots alleged, including one on day of blasts in Kenya, Tanzania. The Washington Post, p. A18.

WP70 Grunwald, M. (1998, October 8). 4 followers of Bin Laden indicted in plot to kill Americans. The Washington Post, p. A02.

WP71 Grunwald, M., Mintz, J. (1998, October 31). Ex-sergeant charged in bomb plot; Former Army instructor accused of training Bin Laden disciples. The Washington Post, p. A08.

WP72 Grunwald, M., Loeb, V. (1998, November 5). Charges filed against Bin Laden; Saudi exile accused of masterminding embassy bombings. The Washington Post, p. A17.

WP73 Vick, K. (1998, November 23). Assault on a U.S. embassy; A plot both wide and deep. The Washington Post, p. A01.

WP74 Grunwald, M. (1998, December 4). Bin Laden aide pleads guilty to terrorism; Secret informant agrees to help build case against embassy bombing suspects. The Washington Post, p. A08.

WP75 Mintz, J. (1998, December 17). 5 fugitives indicted in embassy bombings; State Department announces reward of $\$ 5$ million for capture of Bin Laden allies. The Washington Post, p. A10.

WP76 Vick, K. (1999, January 3). Bombing dramatically increased Kenya's blind population. The Washington Post, p. A27.

WP77 Mintz, J. (1999, January 8). Panel cites U.S. failures on security for embassies. The Washington Post, p. A01.

WP78 Lippman, T.W. (1999, January 9). Report on terrorism suggests closing some U.S. embassies. The Washington Post, p. A14.

WP79 Loeb, V. (1999, February 17). Has the U.S. blunted Bin Laden? Yes and no, terrorist fighters say, describing an invisible war. The Washington Post, p. A04.

WP80 Rupert, J. (1999, June 26). U.S. and Britain close 10 embassies in Africa; Move prompted by reported fears of attack similar to ' 98 bombings in Kenya, Tanzania. The Washington Post, p. A13. 
WP81 Loeb, V. (1999, July 29). Bin Laden still seen as threat; U.S. harassment campaign may backfire, boosting fugitive's image. The Washington Post, p. A03.

WP82 Lynch, C., Loeb, V. (1999, August 1). Bin Laden's network: Terror conspiracy or loose alliance? The Washington Post, p. A01.

WP83 Lippman, T.W. (1999, August 4). Vulnerable embassies still a problem for U.S. The Washington Post, p. A15.

WP84 Rondeaux, C. (2008, June 3). Car bomb hits Danish mission in Islamabad; Attack in capital of Pakistan leaves as many as eight dead. The Washington Post, p. A08.

WP85 Associated Press. (2008, June 4). Al-Qaeda suspected in Pakistan bombing. The Washington Post, p. A16.

WP86 (2008, June 7). Around the world. The Washington Post, p. A16.

WP87 Hussain, S., Constable, P. (2008, September 21). Blast kills dozens in Pakistan; At least 250 hurt as suicide bomber detonates truck outside Islamabad hotel. The Washington Post, p. A01.

WP88 Connolly, C., Allen, M. (2000, October 13). Crises take precedence with the candidates. The Washington Post, p. A30.

WP89 Ricks, T.E. (2000, October 13). Officers say ship was easy mark; no way to prevent blast from a "friendly" boat. The Washington Post, p. A28.

WP90 Vise, D.A., Loeb, V. (2000, October 13). Attack carefully planned, experts say. The Washington Post, p. A29.

WP91 Vogel, S. (2000, October 13). Va. Navy town wonders, worries; Attack mutes celebration at ship's home port as families await news. The Washington Post, p. A29.

WP92 Harris, J.F., Nakashima, E. (2000, October 13). Clinton's day of crisis; Planned respite falls victim to Mideast violence. The Washington Post, p. A01.

WP93 Allen, M., Connolly, C. (2000, October 14). Candidates use Mideast to frame issues. The Washington Post, p. A11.

WP94 Ricks, T.E., Priest, D. (2000, October 14). Security duties in dispute; Defense Department points to embassy State Department points back. The Washington Post, p. A18.

WP95 Vise, D.A., Loeb, V. (2000, October 14). US team may face difficulties in probe; Yemeni government's cooperation uncertain. The Washington Post, p. A18. 
WP96 Schneider, H., Suro, R. (2000, October 14). Death toll put at 17 in USS Cole blast; Some doubt Yemenis will aid in probe. The Washington Post, p. A01.

WP97 Slevin, P., Shaver, K. (2000, October 14). Blossoming lives ended in an instant; blast leaves trail of grief across US. The Washington Post, p. A01.

WP98 Vogel, S. (2000, October 14). In Norfolk, sense of loss is shared; Relieved families comfort those mourning loved ones. The Washington Post, p. A19.

WP99 Balz, D. (2000, October 15). Gore struggles to regain his voice in tight race. The Washington Post, p. A01.

WP100 Reid, T.R. (2000, October 15). Cole sailors reach hospital in Germany; wounds both emotional and physical. The Washington Post, p. A23.

WP101 Ricks, T.E. (2000, October 15). Persian Gulf, US danger zone; Military has been committed to hot spot despite risk. The Washington Post, p. A01.

WP102 Schneider, H., Suro, R. (2000, October 15). In Yemen, a search for clues; Navy team dispatched to free trapped bodies. The Washington Post, p. A01.

WP103 Vogel, S. (2000, October 16). USS Cole's wounded return to Va.; Cheering of crowd, families' reunion mix joy with grief over attack. The Washington Post, p. A22.

WP104 Ricks, T.E., Schneider, H. (2000, October 16). Sailors keep the Cole afloat; Crew mans pumps and mourns losses. The Washington Post, p. A01.

WP105 Vogel, S. (2000, October 17). Blast "blew everything," injured sailor says. The Washington Post, p. A28.

WP106 Sipress, A. (2000, October 17). Yemeni leader now calls ship blast "criminal". The Washington Post, p. A01.

WP107 Sipress, A., Vise, D.A. (2000, October 18). Bomb material found in Yemen. The Washington Post, p. A25.

WP108 Hull, A. (2000, October 18). A sailor's mourners; Family and community left behind to hold a Cole victim tightly in death. The Washington Post, p. A01.

WP109 Vogel, S. (2000, October 19). New statue-and timely dedication-honor sacrifice of the Navy family. The Washington Post, p. J08.

Wp110 Shapiro, L. (2000, October 19). Players to honor those killed in USS Cole attack. The Washington Post, p. D07.

WP111 Hull, A., Vogel, S. (2000, October 19). "Give them their meaning"; Cole families, survivors and Clinton grieve at Norfolk service. The Washington Post, p. A01. 
WP112 Vise, D.A. (2000, October 20). General defense decision to refuel in Yemen. The Washington Post, p. A26.

WP113 Boustany, N. (2000, October 20). Mideast violence strains Arabs' outreach. The Washington Post, p. A29.

WP114 Sipress, A., Vise, D.A. (2000, October 20). Aden's wary welcome; Despite moves to reassure Yemenis, US military influx raises suspicions. The Washington Post, p. A01.

WP115 Vogel, S. (2000, October 21). Family pride helps dry tears; USS Cole sailor's noble spirit recalled at funeral service. The Washington Post, p. B01.

WP116 Suro, R., Sipress, A. (2000, October 21). Navy revises initial account of bombing; Cole was moored, refueling before attack, officials say. The Washington Post, $\mathrm{p}$. A01.

WP117 Ricks, T.E., Vogel, S. (2000, October 23). "Killed in action": Is gender an issue?; Lack of specific outcry over Cole women's deaths splits experts. The Washington Post, p. A03.

WP118 Sipress, A. (2000, October 24). For Yemen, an evolving US relationship; As both seek to improve ties, sanctions against Iraq remain a point of division. The Washington Post, p. A19.

WP119 Sipress, A. (2000, October 25). Cole probe focuses on three locations; apartment apparently used as lookout. The Washington Post, p. A22.

WP120 Suro, R., Loeb, V. (2000, October 26). US had hints of possible attack before Cole was hit. The Washington Post, p. A32.

WP121 (2000, October 26). Cole blast probe drawing closer to Bin Laden. The Washington Post, p. A01.

WP122 (2000, October 28). "I just didn't want to die on the ship"; As USS Cole shook, sailors fought to save themselves, crew mates and vessel. The Washington Post, p. A01.

WP123 Vogel, S. (2000, October 29). "Torn between Navy and family"; USS Cole bombing took one southern Maryland son; Another was saved. The Washington Post, p. M01.

WP124 Loeb, V. (2000, October 29). Warnings of terror attack were broad, vague; No specific threat of imminent strike preceded USS Cole blast in Yemeni port. The Washington Post, p. A34.

WP125 Vise, D.A. (2000, October 29). New global role puts FBI in unsavory company. The Washington Post, p. A01. 
WP126 Sipress, A. (2000, October 29). Limited witness access hinders FBI Cole probe; Relationship with Yemenis strained as focus shifts toward interrogation. The Washington Post, p. A32.

WP127 Vogel, S. (2000, October 29). A sailor's sacrifice honored at Antietam; USS Cole fireman joins revered soldiers. The Washington Post, p. C01.

WP128 Sipress, A. (2000, October 30). USS Cole departs "proudly," with help; Relief is felt in Yemen; As probe continues, question about policy and security remain. The Washington Post, p. A21.

WP129 Sipress, A. (2000, November 1). Outside Aden, clues and "Afghan Arabs"; Cole probe examines role of government employees, ties to '93 hotel bombings. The Washington Post, p. A26.

WP130 Vise, D.A. (2000, November 2). Critical talks underway on US role in probe of Cole blast. The Washington Post, p. A16.

WP131 Vise, D.A., Ricks, T.E. (2000, November 3). FBI probes source of explosives in attack; Investigators hope analysis could help identify who aided bombing of USS Cole. The Washington Post, p. A08.

WP132 Ricks, T.E., Vogel, S. (2000, November 14). USS Cole guards told not to fire first shot; Defense rules kept weapons unloaded. The Washington Post, p. A01.

WP133 Vise, D.A. (2000, November 16). US cites cooperation by Yemen; Deal reached in handling interrogations in bomb probe. The Washington Post, p. A40.

WP134 Vick, K. (2000, November 17). Cole bombers identified as veterans of Afghan war; Yemeni premier says help from outside still unknown. The Washington Post, p. A30.

WP135 Ricks, T.E. (2000, November 22). USS Cole retaliation possible; Joint chiefs chairman won't disclose method, possible targets. The Washington Post, p. A08.

WP136 Vise, D.A. (2000, November 22). Cole, embassy bombings linked. The Washington Post, p. A08.

WP137 Loeb, V. (2000, December 3). US considers array of actions against Bin Laden. The Washington Post, p. A03.

WP138 Ricks, T.E., Loeb, V. (2000, December 9). Cole security lapses found; Some precautions not taken when ship was hit by bomb. The Washington Post, p. A14.

WP139 (2000, December 10). Yemen's president, naming names. The Washington Post, p. B01. 
WP140 Mufson, S. (2000, December 10). US aides look for a reason to be hopeful. The Washington Post, p. A47.

WP141 Ricks, T.E. (2001, January 7). Cole lapses may go unpunished; Investigation finds 30 "force protection" steps not taken before ship was bombed. The Washington Post, p. A2.

WP142 Suro, R. (2001, January 20). Pentagon avoids individual punishment in Cole attack. The Washington Post, p. A1.

WP143 Vise, D.A., Eggen, D. (2001, January 27). FBI widens Cole probe as Yemen cooperates. The Washington Post, p. A14.

WP144 Lancaster, J., Sipress, A. (2001, February 1). A muted victory against terror. The Washington Post, p. A01.

WP145 Lynch, C. (2001, February 7). Witness tells how Bin Laden group works; Embassy bombing trial hears from defector. The Washington Post, p. A01.

WP146 Vogel, S. (2001, March 18). Deadly blast haunts battleship's skipper. The Washington Post, p. C01.

WP147 Loeb, V. (2001, June 19). Nine alleged plotters held in Yemen; FBI's Cole investigators are withdrawn due to threat. The Washington Post, p. A14.

WP148 Loeb, V. (2001, June 26). US has Bin Laden “on the run,” Senator Shelby says. The Washington Post, p. A15.

WP149 Constable, P. (2001, July 8). In Bin Laden's lair, small talk and a warning. The Washington Post, p. A16.

WP150 Loeb, V. (2001, September 4). FBI agents resume Cole probe in Yemen; More cooperation, security pledged. The Washington Post, p. A12.

WP151 Dobbs, M. (2001, September 11). Inside the mind of Osama bin Laden; Strategy mixes long preparation, powerful message aimed at dispossessed. The Washington Post, p. A01.

WP152 Powell, M. (2001, September 27). Bin Laden recruits with graphic video. The Washington Post, p. A19.

WP153 Vick, K. (2001, November 29). Yemen walks tightrope in terrorism stance. The Washington Post, p. A20.

WP154 Mattar, S. (2005, August 20). US ship attacked in Jordan port; Rockets miss mark; No sailors injured. The Washington Post, p. A11. 
WP155 Mattar, S. (2005, August 21). Jordan holds suspects in strike on US ship; Rocket launcher found as hunt widens. The Washington Post, p. A21.

WP156 (2005, August 23). World in brief. The Washington Post, p. A11.

WP157 (2005, August 24). World in brief. The Washington Post, p. A12.

WP158 Finer, J., Mehdawi, N. (2005, November 10). Bombings kill over 50 at 3 hotels in Jordan; Coordinated attack in Amman linked to Zarqawi's network. The Washington Post, p. A01.

WP159 Finer, J., Whitlock, C. (2005, November 11). Zarqawi's network asserts it launched attacks in Amman. The Washington Post, p. A21.

WP160 Finer, J., Mehdawi, N. (2005, November 12). Hotel bombings in Jordan fuel anger at exiles; Internet posting describes attackers in Amman as Iraqis. The Washington Post, p. A17.

WP161 Masters, B.A., (2004, March 12). Stocks plummet after attacks; Major indicators lose 2004's gain. The Washington Post, p. E01.

WP162 Eggen, D., Pincus, W. (2004, March 12). Bombing clues point to Islamist terrorists; But officials say it's too soon to know. The Washington Post, p. A15.

WP163 Richburg, K.B. (2004, March 12). A catastrophe "like the twin towers"; Witnesses describe scenes of chaos. The Washington Post, p. A01.

WP164 Richburg, K.B. (2004, March 12). Madrid train blasts kill at least 190; 10 bombs detonate almost at once; Nearly 1500 hurt. The Washington Post, p. A01.

WP165 Mintz, J. (2004, March 13). US passenger trains vulnerable to terror attacks, bulletin warns. The Washington Post, p. A15.

WP166 Frankel, G. (2004, March 13). For Basques, sorrow and outrage mixed with anxiety. The Washington Post, p. A15.

WP167 Richburg, K.B. (2004, March 13). Millions in Spain decry attacks; Marchers jam streets; Government still focused on Basque separatists. The Washington Post, p. A01.

WP168 Granke, G. (2004, March 14). Affinity for ETA runs deep in stronghold. The Washington Post, p. A23.

WP169 Rolfe, P. (2004, March 14). Spaniards bury the dead, console the living. The Washington Post, p. A25.

WP170 Richburg, K.B. (2004, March 14). Five held in Madrid blasts; Tape asserts al Qaeda responsibility. The Washington Post, p. A01. 
WP171 Frankel, G., Finn, P., Richburg, K.B. (2004, March 15). Al Qaeda implicated in Madrid bombings. The Washington Post, p. A01.

WP172 Richburg, K.B. (2004, March 15). Spanish socialists oust party of US war ally; Voters cite train attacks in poll upset. The Washington Post, p. A01.

WP173 Day, K. (2004, March 16). Terror fears push markets to new lows for the year; Investors show concern about economy, attacks. The Washington Post, p. E01.

WP174 Franke, G. (2004, March 16). Madrid bombs shook voters; Distrust of government, anger at US fueled upset. The Washington Post, p. A01.

WP175 Richburg, K.B. (2004, March 16). New leader in Spain calls Iraq “disaster”; Incoming premier affirms vow on troop withdrawal. The Washington Post, p. A01.

WP176 Priest, D., Pincus, W. (2004, March 16). Similar tactics, different names; Al Qaeda-like groups scrutinized. The Washington Post, p. A16.

WP177 Milbank, D. (2004, March 17). Opinion of US abroad is falling, survey finds; Majorities doubt war in Iraq is quelling terrorism. The Washington Post, p. A22.

WP178 Boustany, N. (2004, March 17). At Spanish embassy, coping with tragedy. The Washington Post, p. A22.

WP179 Richburg, K.B. (2004, March 17). Spain seeking 5 Moroccans tied to Islamic terror cell. The Washington Post, p. A20.

WP180 Burgess, J. (2004, March 17). Tighter security on Europe's rails; Riders weigh risks as officials concede they can make no guarantees. The Washington Post, p. A20.

WP181 Richburg, K.B. (2004, March 17). Spain campaigned to pin blame on ETA; Despite evidence t contrary, Basque group was focus in blasts. The Washington Post, p. A01.

WP182 Richburg, K.B. (2004, March 18). Spain's next prime minister says US should dump Bush. The Washington Post, p. A23.

WP183 Richburg, K.B. (2004, March 19). Another 5 arrested in Madrid attacks. The Washington Post, p. A16.

WP184 Slevin, P. (2004, March 19). US aims to calm allies apprehensive about Iraq. The Washington Post, p. A16.

WP185 Martinez, M.J. (2004, March 20). Markets fall for a second week; Terrorism fears contribute to loss. The Washington Post, p. E01. 
WP186 Milbank, D. (2004, March 20). Bush asks allies for unity on Iraq; No nation exempt from terrorism, president says on war anniversary. The Washington Post, p. A01.

WP187 Finn, P., Richburg, K.B. (2004, March 20). Madrid probe turns to Islamic cell in Morocco; Member met with suspect jailed in Spain and al Qaeda operative, officials say. The Washington Post, p. A01.

WP188 Sottili, C. (2004, March 21). Madrid aftermath; Staying safe abroad. The Washington Post, p. P01.

WP189 Hsu, S.S., Layton, L. (2004, March 22). Spain blast prompts demands for funds; Transit agencies seek to improve rail safety. The Washington Post, p. B01.

WP190 Rolfe, P., Wright, R. (2004, March 25). Powell confers with Spain's new leader. The Washington Post, p. A17.

WP191 Frankel, G. (2004, March 28). Europe, US diverge on how to fight terrorism. The Washington Post, p. A15.

WP192 Rolfe, P. (2004, April 4). Blast rocks Madrid suburb; 3 suspected in train attacks detonate explosives, killing themselves. The Washington Post, p. A01.

WP193 Pincus, W. (2004, April 4). Spread of bin Laden ideology cited; Iraq invasion said to alter dynamics of local militants. The Washington Post, p. A13.

WP194 Rolfe, P. (2004, April 5). Spain says blast killed head of terror cell; Four dead believed to be group's core. The Washington Post, p. A01.

WP195 Richburg, K.B. (2004, April 6). Spain arrests another in train bombings; Islamic group threatens more attacks. The Washington Post, p. A14.

WP196 Richburg, K.B. (2004, April 12). Plot leader in Madrid sought help of al Qaeda; Spain says suspect met with operative. The Washington Post, p. A01.

WP197 Burgess, J. (2004, April 16). Europeans reject bin Laden “Truce”; Tape attributed to al Qaeda leader seeks withdrawal of troops in Muslim countries. The Washington Post, p. A01.

WP198 Mintz, J. (2004, April 20). Precautions raised for preelection terrorism; Al Qaeda intends to strike, officials say. The Washington Post, p. A03.

WP199 Schmidt, S. (2004, May 7). American held in Madrid bombings. The Washington Post, p. A01.

WP200 Schmidt, S., Harden, B. (2004, May 8). Lawyer's fingerprint linked to bombing; Bag, detonators found in stolen van in Spain. The Washington Post, p. A03. 
WP201 Schmidt, S., Harden, B. (2004, May 21). US frees Oregon lawyer jailed in Madrid bombings. The Washington Post, p. A06.

WP202 Schmidt, S., Harden, B. (2004, May 25). Lawyer is cleared of ties to bombings; FBI apologizes for fingerprint error. The Washington Post, p. A02.

WP203 Schmidt, S., Mintz, J. (2004, May 27). FBI seeks tips on 7 linked to al Qaeda; Officials convinced attack on US is being planned. The Washington Post, p. A01.

WP204 Richburg, K.B. (2004, June 9). Madrid suspect arrested in Italy; Seventeen detained in 4-nation coordinated raids in Europe. The Washington Post, p. A15.

WP205 Richburg, K.B. (2004, June 12). Spain seeks custody of bombing suspect; Man held in Italy called key to train attack. The Washington Post, p. A10.

WP206 Richburg, K.B. (2004, June 16). Spanish judge ties suspects to 9/11; Formal charges against 15 likely. The Washington Post, p. A18.

WP207 Richburg, K.B., Rolfe, P. (2004, June 25). Politics intrude on inquiry into Madrid train attacks. The Washington Post, p. A24.

WP208 Eggen, D., Lancaster, J. (2004, August 14). Al Qaeda showing new life; US surprised by signs of regrouping. The Washington Post, p. A01.

WP209 Richburg, K.B. (2004, October 17). Madrid attacks may have targeted election; Wiretaps bolster theory that blasts were timed to hurt chances of leader who backed Iraq war. The Washington Post, p. A16.

WP210 Eggen, D., Gellman, B. (2004, October 23). No direct evidence of plot to attack around elections. The Washington Post, p. A01.

WP211 Whitlock. C. (2004, November 14). In Europe, a radical as elusive as smoke; "Mohamed the Egyptian" implicated in Madrid attacks, used border weaknesses to escape discovery." The Washington Post, p. A01.

WP212 Harden, B. (2004, November 16). FBI faulted in arrest of Oregon Lawyer; Study by forensic experts cites mistakes in fingerprint identification. The Washington Post, p. A02.

WP213 Rolfe, P. (2005, March 11). A year after Madrid attacks, Europe stalled in terror fight; National rivalries, fragmented intelligence activities thwart progress. The Washington Post, p. A12.

WP214 Noguchi, Y. (2005, July 8). Camera phones lend immediacy to images of disaster. The Washington Post, p. A16.

WP215 Vandehei, J. (2005, July 8). Blush, Blair renew bonds forged by terror. The Washington Post, p. A18. 
WP216 Henderson, N. (2005, July 8). Responses to shock of 9/11 aided rebound. The Washington Post, p. C1.

WP217 Haygood, W. (2005, July 8). Shaken, not deterred; Metro riders absorb the shock and hold their stations. The Washington Post, p. D1.

WP218 Goo, S.K., Eggen, D. (2005, July 8). US increases threat level for mass transit; But Chertoff says there is no sign of imminent attack. The Washington Post, p. A18.

WP219 Kinzie, S. (2005, July 8). Close calls, confusion remembered in aftermath; Gathering relives a surreal day. The Washington Post, p. A18.

WP220 Green, J. (2005, July 8). London attacks spur empathy, alerts in Spain; '04 train bombings in Madrid recalled; Nations condemn terror, boost security. The Washington Post, p. A19.

WP221 Whitlock. C. (2005, July 8). Probers note similarities with Madrid attacks. The Washington Post, p. A15.

WP222 Layton, L., Ginsberg, S. (2005, July 8). Patrols on mass transit intensified but scattered. The Washington Post, p. A1.

WP223 Frankel, G. (2005, July 8). Bombers strike London at rush hour; At least 37 killed on trains, bus. The Washington Post, p. A01.

WP224 Coll, S., Glasser, S.B. (2005, July 8). Attacks bear earmarks of evolving al Qaeda; Targets, timing both familiar. The Washington Post, p. A01.

WP225 Frankel, G. (2005, July 9). Londoners warily resume their lives; Toll in bombings rises to 49, with bodies yet uncounted; Officials urge vigilance. The Washington Post, p. A01.

WP226 Knickmeyer, E. (2005, July 9). Indomitable Londoners get back on buses. The Washington Post, p. A09.

WP227 Whitlock, C. (2005, July 9). Investigators explore link to Madrid attacks; Timing devices used; No suspects named. The Washington Post, p. A09.

WP228 Weiss, E.M. (2005, July 10). DC defers text alert on London bombings. The Washington Post, Metro.

WP229 Frankel, G. (2005, July 10). Londoners warily resuming their lives. The Washington Post, p. A17.

WP230 Whitlock, C. (2005, July 10). Madrid links being explored; Cell phones used; No suspects named. The Washington Post, p. A01. 
WP231 Frankel, G. (2005, July 10). London subway blasts almost simultaneous, investigators conclude; Timing devices, high explosives used. The Washington Post, p. A19.

WP232 Coll, S., Glasser, S.B. (2005, July 10). In London, Islamic radicals found a haven. The Washington Post, p. A01.

WP233 Frankel, G. (2005, July 11). Britain appeals to public for help; Police seek witnesses to train, bus attacks. The Washington Post, p. A10.

WP234 Whitlock, C. (2005, July 1). Terror probes find "the hands, but not the brains"; Attackers often caught as masterminds flee. The Washington Post, p. A10.

WP235 Frankel, G. (2005, July 12). British politicians unite behind Blair; Friend and foe praise prime minister for response to London attacks. The Washington Post, p. A14.

WP236 Vandehei, J. (2005, July 12). Bush defends strategy against terrorist attacks; London bombs meant to scare US, President says. The Washington Post, p. A03.

WP237 Knickmeyer, E. (2005, July 12). A multinational list of missing in London; Young Muslim woman becomes a symbol. The Washington Post, p. A14.

WP238 Frankel, G. (2005, July 13). Four Britons tied to London blasts; Police say men of Pakistani descent may have been suicide attackers. The Washington Post, p. A01.

WP239 Coates, S. (2005, July 13). Tea and solidarity for British expatriates; Englishthemed businesses become area gathering places after bombings. The Washington Post, p. B02.

WP240 Whitlock, C. (2005, July 13). Police raids shock neighbors of alleged bombers; Suspects from northern city apparently kept a low profile, avoiding attention of intelligence officials. The Washington Post, p. A17.

WP241 Weiss, E.M. (2005, July 14). DC might add cameras for police; London bombings renew debate. The Washington Post, p. B01.

WP242 Whitlock, C., Linzer, D. (2005, July 14). Police widen probe of London bombings; Fifth conspirator sought as suspected organizer. The Washington Post, p. A17.

WP243 Frankel, G., Knickmeyer, E. (2005, July 14). For Britain's Muslims, a fear realized. The Washington Post, p. A17.

WP244 Duggan, P., Layton, L. (2005, July 14). Transit security seen and unseen; Most commuters not riding scared. The Washington Post, p. A01. 
WP245 Frankel, G. (2005, July 15). British seek Egyptian-born chemist in connection with London attacks; Leeds resident missing for two weeks is wanted for questioning; Death toll at 54. The Washington Post, p. A20.

WP246 Whitlock, C. (2005, July 15). Trail from London to Leeds yields portraits of 3 bombers; Identities are revealed, but motives still a mystery. The Washington Post, p. A01.

WP247 Wright, R. (2005, July 15). Support for bin Laden, violence down among Muslims, poll says. The Washington Post, p. A13.

WP248 Jones, T. (2005, July 16). Anxious Muslims pray in Leeds; Faithful gather near alleged site of bombmaking. The Washington Post, p. A14.

WP249 Frankel, G., Whitlock, C. (2005, July 16). London probe extends abroad; Egyptian arrested; Pakistani sought. The Washington Post, p. A01.

WP250 Shadid, A. (200, July 16). Egyptian linked to attackers held for questioning in Cairo; Biochemist thought to have helped rent Leeds townhouse. The Washington Post, p. A14.

WP251 Frankel, G. (2005, July 17). Seeking public's help, British police release image of bombing suspects. The Washington Post, p. A16.

WP252 Eggen, D., Wilson, S. (2005, July 17). Suicide bombs potent tools of terrorists; Deadly attacks have been increasing and spreading since September 11, 2001. The Washington Post, p. A01.

WP253 Frankel, G. (2005, July 18) Ties to US made Britain vulnerable, report says. The Washington Post, p. A10.

WP254 Whitlock, C., Khan, K. (2005, July 19). Suspected London bomber traveled to Israel. The Washington Post, p. A17.

WP255 Horwitz, S., Layton, L. (2005, July 19). So far, dogs are still best detectors of bombs. The Washington Post, p. A17.

WP256 Frankel, G. (2005, July 20). Muslim leaders in Britain pledge solidarity despite divisions; Religious moderates meet with Blair to address attacks. The Washington Post, p. A14.

WP257 Jones, T. (2005, July 20). Among the young of multiethnic Leeds, a hardening hatred; Radical resentment, lack of opportunity are shaping a generation, experts fear. The Washington Post, p. A14.

WP258 Frankel, G. (2005, July 21). Britain will act to bar terrorist sympathizers; New measures also intended to expand deportations. The Washington Post, p. A18. 
WP259 Linzer, D., Raghavan, S. (2005, July 22). Authorities probe Pakistani linked to plot in Oregon; Records show calls from July 7 bombers. The Washington Post, p. A17.

WP260 Frankel, G. (2005, July 22). London hit again with explosions; Small blasts on 3 trains and a bus reminiscent of deadly July 7 attacks. The Washington Post, p. A01.

WP261 Frankel, G., Gillan, A. (2005, July 23). British police kill man on train; link to abortive attacks is cited. The Washington Post, p. A01.

WP262 Layton, L. (2005, July 23). Metro's response to alert delayed; Riders say backpack slow to be removed. The Washington Post, p. B01.

WP263 Frankel, G. (2005, July 24). Man shot dead by British police was innocent Brazilian citizen; Bystander mistaken for suspect in failed bomb attacks. The Washington Post, p. A24.

WP264 Shadid, A. (2005, July 24). Egyptians investigate link to 2004 bombings; Death toll in Sharm el-Sheikh attack rises to 88. The Washington Post, p. A21.

WP265 Jones, T. (2005, July 24). A London victim is laid to rest; Nigerian eulogized as citizen of the world. The Washington Post, p. A23.

WP266 Whitlock, C. (2005, July 24). Al Qaeda leaders seen in control; Experts say radicals in London, Egypt may have followed orders. The Washington Post, p. A01.

WP267 Eggen, D. (2005, July 25). Pakistani American aiding London probe; Man in US custody has ties to al Qaeda. The Washington Post, p. A14.

WP268 Frankel, G. (2005, July 25). British pursue link between 2 sets of bombers; Police apologize for mistaken killing. The Washington Post, p. A01.

WP269 Frankel, G. (2005, July 26). Police in Britain release names of two suspects; Authorities raid North London apartment. The Washington Post, p. A13.

WP270 Whitlock, C. (2005, July 27). 2 British suspects came from Africa; One got housing subsidy, officials say. The Washington Post, p. A18.

WP271 Frankel, G., Jones, T. (2005, July 27). In Britain, a divide over radial profiling; Mistaken killing by police sets off debate. The Washington Post, p. A01.

WP272 Frankel, G. (2005, July 28). British arrest man wanted in transit attacks; Suspect subdued by stun gun in raid. The Washington Post, p. A20.

WP273 Eggen, D. (2005, July 29). 9 more held in second London subway attacks. The Washington Post, p. A16. 
WP274 Frankel, G. (2005, July 30). All four bombing suspects in custody; British raid nets two; Another held in Rome. The Washington Post, p. A01.

WP275 Frankel, G. (2005, July 31). Suspect says London attack aimed to scare but not kill; Analysts wary of account of man arrested in abortive plot. The Washington Post, p. A13.

WP276 Raghavan, S. (2005, July 31). Muslims in Britain start to take harder look at their young; Leeds community fears pull of extremism. The Washington Post, p. A14.

WP277 Finn, P., Cooper, G. (2005, July 31). Londoners are asking: "is it really over?”; Arrests of suspects in failed attacks stun residents and elicit concerns. The Washington Post, p. A14.

WP278 Finn, P., Frankel, G. (2005, August 1). Al Qaeda link to attacks in London probed; Information sought on contacts between group's leaders in Saudi Arabia, callers in Britain. The Washington Post, p. A10.

WP279 Stewart, P., Chambers, M. (2005, August 2). London suspect likely part of ad hoc group, Italians say. The Washington Post, p. A14.

WP280 Sullivan, K. (2005, August 4). From refugee to thug to suspect in London plot; Accused leader in abortive bombings reportedly found radical Islam while incarcerated. The Washington Post, p. A10.

WP281 Horwitz, S. (2005, August 4). Police chiefs group bolsters policy on suicide bombers. The Washington Post, p. A02.

WP282 Sullivan, K. (2005, August 5). Al Qaeda's no. 2 blames Blair, issues warning; Security high for London commuters. The Washington Post, p. A01.

WP283 Sullivan, K., Jordan, M. (2005, August 6). Blair acts against Muslim "fringe"; Some see measures as threat to rights. The Washington Post, p. A01.

WP284 Eggen, D. (2005, August 6). US keeps security response to London attacks lowkey; No intelligence suggests such bombings are planned. The Washington Post, p. A16.

WP285 Coll, S., Glasser, S.B. (2005, August 7). Terrorists turn to the web as base of operations. The Washington Post, p. A01.

WP286 Jordan, M., Sullivan, K. (2005, August 9). Masses try other forms of transit; In London, fearful commuters turn to bikes, skateboards. The Washington Post, p. A11.

WP287 Sullivan, K. (2005, August 9). Attempted murder charges brought in London attack; Prominent radical cleric flees Britain in the face of crackdown. The Washington Post, p. A11. 
WP288 Sullivan, K. (2005, August 11). Poll: Britons support multiculturalism; Public sentiment gauged in wake of attacks. The Washington Post, p. A18.

WP289 Sullivan, K. (2005, August 12). Britain arrests 10 and seeks to deport them; Detained cleric's case tests new anti-terror powers. The Washington Post, p. A15.

WP290 Sullivan, K. (2005, August 13). British government bars return of radical Islamic cleric. The Washington Post, p. A18.

WP291 Hsu, S.S., Eggen, D. (2005, August 13). Terrorism alert level lowered for transit. The Washington Post, p. B01. .

WP292 Jordan, M. (2005, August 19). London police stalled probe into shooting. The Washington Post, p. A13.

WP293 Jordan, M. (2005, August 26). In London neighborhood, a feeling of being watched; Minority residents say police harassment on rise. The Washington Post, p. A15.

WP294 Sullivan, K. (2005, August 29). Denmark tries to act against terrorism as mood in Europe shifts; Law raises concerns of civil libertarians. The Washington Post, p. A09.

WP295 Sullivan, K. (2005, September 23). Italians turn over suspect in failed London attack. The Washington Post, p. A15.

WP296 Sullivan, K. (2005, September 24). London bomber's mind was twisted by radicals. The Washington Post, p. A19.

WP297 Jordan, M. (2005, October 13). Blair's proposed anti-terror law divides Britons. The Washington Post, p. A20.

WP298 Sullivan, K. (2006, May 12). No proof of al Qaeda in 2005 London transit blasts; Two government reports find evidence of contact, not aid. The Washington Post, p. A14.

WP299 Jordan, M. (2006, June 4). London police question brothers after big raid. The Washington Post, p. A19.

WP300 Sullivan, K. (2006, July 7). Video broadcast warns Britons of more attacks. The Washington Post, p. A10.

AP2 Myers, L. (1998, August 7). Barriers, metal detectors, guards not always enough. The Associated Press.

AP3 Davies, K. (1998, August 7). Bomb blasts rock U.S. embassies in Tanzania, Kenya; More than 81 killed. The Associated Press. 
AP4 Gedda, G. (1998, August 7). Clinton vows justice for terrorists in Africa. The Associated Press.

AP5 Hunt, T. (1998, August 7). Clinton vows to find embassy bombers "no matter what or how long it takes". The Associated Press.

AP6 Davies, K. (1998, August 8). Witnesses describe carnage at bombings of U.S. embassies. The Associated Press.

AP7 Knutson, L.L. (1998, August 8). Rescue crews prepare for tragedy, head for bombing sites. The Associated Press.

AP8 Schafer, S.M. (1998, August 8). International terrorists often take years to find and punish. The Associated Press.

AP9 (1998, August 8). Search for bombing clues begins as rescue dogs join effort. The Associated Press.

AP10 Gedda, G. (1998, August 8). Clinton promises terrorists won't force U.S. retreat. The Associated Press.

AP11 Sniffen, M.J. (1998, August 8). FBI agents rushed to Africa in echo of Saudi bombing. The Associated Press.

AP12 Davies, K. (1998, August 8). Rescuers dig for survivors of bombings at U.S. embassies in Africa. The Associated Press.

AP13 Gedda, G. (1998, August 8). Clinton vows to find and punish bombers, not to give in to terror. The Associated Press.

AP14 Kallestad, B. (1998, August 8). Families mourn those killed in Kenyan bombing. The Associated Press.

AP15 Joshi, V. (1998, August 9). Solid construction may have kept toll lower in Tanzania bombing. The Associated Press.

AP16 (1998, August 9). Bombings: Encouraging trapped survivors and praying for the dead. The Associated Press.

AP17 Myers, L. (1998, August 9). U.S. promises to hit back if any government involved in bombings. The Associated Press.

AP18 (1998, August 9). Mother and son rescued as death toll in bombings rises to 198. The Associated Press.

AP19 Hughes, C. (1998, August 10). Out front; Survivor never doubted help would come. The Associated Press. 
AP20 Schweid, B. (1998, August 10). Reward offered, Clinton says U.S. can't run away from terrorism. The Associated Press.

AP21 Hughes, C. (1998, August 10). Tapping raises hopes as investigators turn to solving mystery. The Associated Press.

AP22 Myers, L. (1998, August 10). Police detain about a dozen for questioning in Tanzania. The Associated Press.

AP23 (1998, August 10). Several suspects detained as rescuers race to find survivors. The Associated Press.

AP24 (1998, August 11). FBI sweep up traces of explosives as search intensified for survivors. The Associated Press.

AP25 Schweid, B. (1998, August 11). Half dozen embassies suspend operations, some to be relocated. The Associated Press.

AP26 Hughes, C. (1998, August 11). Death toll reaches 234 in bombings, arrests made in Tanzania. The Associated Press.

AP27 (1998, August 11). The morgue; Some relatives find loved ones, others keep searching. The Associated Press.

AP28 Myers, L. (1998, August 11). Tanzanian envoy suspects may have had a hand in embassy bombing. The Associated Press.

AP29 Schweid, B. (1998, August 11). Half dozen embassies suspend operations, enw threats made. The Associated Press.

AP30 Hughes, C. (1998, August 12). Detentions announced in embassy bombings; search for survivors end. The Associated Press.

AP31 Davies, K. (1998, August 12). Out front; Woman whose cries for help inspired rescuers found dead in rubble. The Associated Press.

AP32 Myers, L. (1998, August 12). Embassy staffs trained to assess terrorist threats. The Associated Press.

AP33 Schweid, B. (1998, August 12). Bombing suspects detained in Kenya, ambassador sought new embassy. The Associated Press.

AP34 Davies, K. (1998, August 12). Search for survivors in Nairobi called off; Rose found dead. The Associated Press.

AP35 Alt Powell, E. (1998, August 12). Mideast, African embassies tighten security after bombings. The Associated Press. 
AP36 Schweid, B. (1998, August 12). Some U.S. embassies will be relocated to counter terrorism. The Associated Press.

AP37 Hughes, C. (1998, August 13). Detentions announced in embassy bombings; FBI may have found parts of bomb vehicle. The Associated Press.

AP38 Schweid, B. (1998, August 13). Ambassador in Nairobi had warned of security. The Associated Press.

AP39 (1998, August 13). FBI: Parts of vehicle carrying Kenyan embassy bomb identified. The Associated Press.

AP40 Myers, L. (1998, August 13). Clinton honors returned Americans killed in embassy bombing. The Associated Press.

AP41 Davies, K. (1998, August 14). Families look for relatives, investigators look for clues. The Associated Press.

AP42 Sniffen, M.J. (1998, August 14). FBI lab will examine evidence from African bombings. The Associated Press.

AP43 Davies, K. (1998, August 15). Kenyans bury dead, FBI seeks clues to unmask embassy bombers. The Associated Press.

AP44 (1998, August 15). Chaos, smoke, fire, cries for help - and the silence of the dead. The Associated Press.

AP45 Carpenter, D. (1998, August 16). Pakistan returns bombing suspect to Nairobi. The Associated Press.

AP46 Carpenter, D. (1998, August 17). FBI, Kenyan police question bombing suspect in Nairobi. The Associated Press.

AP47 Myers, L. (1998, August 18). Surveying embassy wreckage, Albright says: “It's a war". The Associated Press.

AP48 Hughes, C. (1998, August 18). Suspect in embassy bombings: Hot lead or false trail? The Associated Press.

AP49 Myers, L. (1998, August 18). Albright pledges justice for embassy bombers. The Associated Press.

AP50 Mbitiru, C. (1998, August 18). FBI raids hotel in Nairobi where bomb believed to have been made. The Associated Press.

AP51 Raum, T. (1998, August 19). Administration working on a multibillion embassy security bill. The Associated Press. 
AP52 Gedda, G. (1998, August 19). Many U.S. embassies affected by threats, upheaval. The Associated Press.

AP53 Davies, K. (1998, August 19). Out front; $12^{\text {th }}$ U.S. victim of bombing to be buried on Kenyan farm. The Associated Press.

AP54 Mbitiru, C. (1998, August 19). FBI agents raid Nairobi hotel, Islamic groups warn of more strikes. The Associated Press.

AP55 Davies, K. (1998, August 20). FBI chief tours wrecked embassy; bomber linked to Saudi terrorist. The Associated Press.

AP56 Shadid, A. (1998, August 20). Out front; "Islamic International" now in sights of a superpower. The Associated Press.

AP57 Hussain, Z. (1998, August 20). Suspect reportedly says hired hands left behind to carry out bombings. The Associated Press.

AP58 Mroue, B. (1998, August 20). Sudanese take over U.S. embassy in Khartoum after attack. The Associated Press.

AP59 Raum, T. (1998, August 20). Embassy security bill could touch off partisan wrangling. The Associated Press.

AP60 Benac, N. (1998, August 20). Clinton orders strikes on Afghan, Sudanese terrorist sties. The Associated Press.

AP61 Abrams, J. (1998, August 20) Some in Congress question Clinton's motives. The Associated Press.

AP62 Mroue, B. (1998, August 20). Sudanese storm empty U.S. Embassy complex in Khartoum after attack. The Associated Press.

AP63 Burns, R. (1998, August 20). U.S. forces hit targets suspected in embassy bombings. The Associated Press.

AP64 Halaby, J. (1998, August 21). Sudan withdraws diplomats, calls on U.N. to investigate. The Associated Press.

AP65 Myers, L. (1998, August 21). U.S. calls target of American missiles a "terrorist university". The Associated Press.

AP66 Davies, K. (1998, August 21). FBI director shortens trip; charity office raided. The Associated Press.

AP67 Diamond, J. (1998, August 21). U.S. cites "moderate to heavy" damage, Cohen says more strikes possible. The Associated Press. 
AP68 Diamond, J. (1998, August 21). Strikes only partly successful, reports suggest. The Associated Press.

AP69 Diamond, J. (1998, August 22). Tomahawk has become weapon of choice against terrorists. The Associated Press.

AP70 King, L. (1998, August 22). Report: Three confess bin Laden links, detail attack preparation. The Associated Press.

AP71 Schoffner, C. (1998, August 22). ISU runner felt Kenyan blast first hand. The Associated Press.

AP72 Abu-Nasr, D. (1998, August 22). U.S. inherits former Soviet nemesis as chief terrorist threat. The Associated Press.

AP73 Ross, S. (1998, August 22). Clinton acts to cut bin Laden's financial pipeline. The Associated Press.

AP74 Riaz, M. (1998, August 22). Witnesses describe U.S. missile strike on Afghanistan. The Associated Press.

AP75 Gedda, G. (1998, August 23). Antecedents to U.S. missile strikes date back a long way. The Associated Press.

AP76 Halaby, J. (1998, August 23). Sudan seeks an apology from the Untied States along with U.N. probe. The Associated Press.

AP77 Abrams, J. (1998, August 23). Officials promise aggressive battle against bin Laden. The Associated Press.

AP78 Gedda, G. (1998, August 24). U.S., Britain propose Libyan suspects be tried in Netherlands. The Associated Press.

AP79 Halaby, J. (1998, August 24). Sudanese president: Clinton "War criminal" for missile strike. The Associated Press.

AP80 King, L. (1998, August 24). Urban breadwinners' deaths in bombing impoverish rural families. The Associated Press.

AP81 Halaby, J. (1998, August 24). Sudanese president: U.S. seeks cooperation, doesn't target government. The Associated Press.

AP82 Abrams, J. (1998, August 24). Administration moves against terrorism, Republicans show support. The Associated Press.

AP83 Diamond, J. (1998, August 25). U.S. intelligence cites Iraqi tie to Sudan plant. The Associated Press. 
AP84 Shadid, A. (1998, August 25). Sudan's ideologue says relations with U.S. will improve. The Associated Press.

AP85 Neumeister, L. (1998, August 27). Two suspects in Kenyan embassy bombing flown to U.S. for trial. The Associated Press.

AP86 Neumeister, L. (1998, August 28). FBi: Bin Laden sought deaths of Americans worldwide; $2^{\text {nd }}$ suspect in U.S. The Associated Press.

AP87 Gedda, G. (1998, August 28). Firepower in Gulf upgraded, U.S. says. The Associated Press.

AP88 King, L. (1998, September 1). Kenya struggles to cope with dozens blinded form embassy bomb. The Associated Press.

AP89 Myers, L. (1998, September 2). War against terrorism fraught with uncertainties. The Associated Press.

AP90 Diamond, J. (1998, September 2). Administration officials detail missile strike strategy. The Associated Press.

AP91 Diamond, J. (1998, September 3). Senators question FBI director about legality of assassination. The Associated Press.

AP92 Gannon, K. (1998, September 8). Taliban not ready to hand over Osama bin Laden to U.S. The Associated Press.

AP93 Neumeister, L. (1998, September 18). FBI boss: Expect more arrests in agency's largest overseas probe yet. The Associated Press.

AP94 Winfield, N. (1998, September 19). Threat of terrorism is evident inside halls of General Assembly. The Associated Press.

AP95 Burns, R. (1998, September 21). President calls terrorism "threat to all humankind." The Associated Press.

AP96 Gedda, G. (1998, September 23). Following East Africa bombings, security concerns mount. The Associated Press.

AP97 Gedda, G. (1998, September 23). After East Africa bombings, diplomats' security concerns mount. The Associated Press.

AP98 Davies, K. (1998, October 2). In aftermath of embassy bombing, many Kenyans left needy. The Associated Press.

AP99 Schuman, J. (1998, October 26). Americans abroad taking counterterrorism steps. The Associated Press. 
AP100 Neumeister, L. (1998, November 5). Record reward offered for capture of Osama bin Laden. The Associated Press.

AP101 Gannon, K. (1998, November 20). Afghanistan's Taliban rulers clear bin Laden of terrorist charges. The Associated Press.

AP102 Davies, K. (1998, December 15). Donors make dreams possible in aftermath of U.S. embassy bombings. The Associated Press.

AP103 Pyle, Richard. (1999, January 3). Alleged terrorist sends mixed messages on embassy bombing role. The Associated Press.

AP104 Cahn, D. (1999, January 9). Marine is awarded Purple Heart for heroism in Kenya bombing. The Associated Press.

AP105 Raum, T. (1999, February 4). Albright, Reno say U.S. still vulnerable to terrorism. The Associated Press.

AP106 Diamond, J. (1999, February 7). U.S. asserts right to bomb regimes that harbor terrorists. The Associated Press.

AP107 Burns, R. (1999, February 9). U.S. wants closer ties but wary of military involvement in Africa. The Associated Press.

AP108 Kole, W.J. (1999, February 22). Disfigured bodies and minds getting mended in Nairobi. The Associated Press.

AP109 Gannon, K. (1999, March 2). Taliban helped bin Laden “disappear”. The Associated Press.

AP110 Myers, L. (1999, March 9). U.S. says Taliban lie about bin Laden's disappearance. The Associated Press.

AP111 Gedda, G. (1999, March 11). Security program derided as inadequate. The Associated Press.

AP112 Schweid, B. (1999, April 30). Terrorism toll hits record high. The Associated Press.

AP113 Linnee, S. (1999, May 5). U.S. ambassador wounded in bombing ends tour in Kenya. The Associated Press.

AP114 Boorstein, M. (1999, June 1). After embassy bombing, Kenya's coastal woes become U.S. woes. The Associated Press.

AP115 Gannon, K. (1999, June 8). Bin Laden, now one of America's Most Wanted, seen by many as hero. The Associated Press. 
AP116 Pandolfi, A. (1999, June 26). Closed embassies already received security upgrades. The Associated Press.

AP117 Gedda, G. (1999, July 9). Sanctions against Taliban buck trend. The Associated Press.

AP118 Leeman, S. (1999, July 12). Authorities say fingerprints link two men to African embassy bombings. The Associated Press.

AP119 Briscoe, D. (1999, July 21). Terrorism fear prompts House vote to boost embassy security The Associated Press.

AP120 Davies, K. (1999, July 31). Many African victims still suffering year after embassy attacks. The Associated Press.

AP121 Neumeister, L. (1999, July 31). U.S. prosecutors pursue legal assault on terrorists. The Associated Press.

AP122 Briscoe, D. (1999, August 5). State Department warns Americans on bombing anniversary. The Associated Press.

AP123 Nelson, C. (1999, August 6). Quarrel flares over commemoration of U.S. embassy bombing. The Associated Press.

AP124 Nelson, C. (1999, August 7). Kenyans mark anniversary of bombing of U.S. embassy in Nairobi. The Associated Press.

AP125 Nelson, C. (1999, August 7). Survivors, victims remember U.S. embassy terrorist bombing. The Associated Press.

AP125 Toosi, N. (2008, June 2). 6 die in blast outside Danish embassy in Pakistan. The Associated Press.

AP126 Shahzad, A. (2008, June 2). Bomb explodes outside Danish embassy in Pakistan. The Associated Press.

AP127 Olsen, J.M. (2008, June 2). Denmark deplores deadly embassy attack in Pakistan's capital. The Associated Press.

AP128 (2008, June 2). Pakistan blast kills embassy worker, injures 3. The Associated Press.

AP129 (2008, June 2). Explosion in Pakistan's capital, at least 3 killed. The Associated Press.

AP130 (2008, June 2). Explosion in Pakistan's capital, casualties reported. The Associated Press. 
AP131 Shahzad, A. (2008, June 3). Denmark: Al-Qaida likely behind bomb in Pakistan. The Associated Press.

AP132 Pennington, M. (2008, June 5). Al-Qaida claims Danish embassy blast. The Associated Press.

AP133 Ahmad, M. (2008, June 8). Pakistani authorities arrest 3, seize explosives. The Associated Press.

AP134 Ahmad, M. (2008, June 8). Pakistani police say they foiled major terrorist plot. The Associated Press.

AP135 Ahmad, M. (2008, July 22). Senior al-Qaida leader gives interview, urges Pakistanis to help Afghans fight US. The Associated Press.

AP136 Kratovac, K. (2008, September 5). Purported bomber warns Denmark of more attacks. The Associated Press.

AP137 Olsen, J. M. (2008, November 13). Agency: Terror threat against Denmark considerable. The Associated Press.

AP138 Graham, S. (2009, January 29). Pakistan seizes suspects in Danish embassy attack. The Associated Press.

AP139 Burns, R. (2000, October 12). US ship hit in apparent terrorist bombing, at least give killed. The Associated Press.

AP140 Geller, A. (2000, October 12). Attack on US Navy ship, escalation at West Bank, send oil prices soaring. The Associated Press.

AP141 Bauder, D. (2000, October 12). Pentagon asks networks not to air Yemen footage. The Associated Press.

AP142 Burns, R. (2000, October 12). Apparent suicide bombing of US ship kills sailors. The Associated Press.

AP143 Hunt, T. (2000, October 12). Clinton urges immediate Mideast cease-fire. The Associated Press.

AP144 Al-Haj, A. (2000, October 12). Yemeni port rocked by US ship explosion. The Associated Press.

AP145 Gearan, A. (2000, October 12). US investigators seek clues to explosives. The Associated Press.

AP146 Jeliek, P. (2000, October 13). Navy considers options for repairing Cole. The Associated Press. 
AP147 Nasrawi, S. (2000, October 13). 17 US sailors presumed dead in Yemen blast; injured evacuated. The Associated Press.

AP148 Herbert, H.J. (2000, October 13). Many questions, few answers in attack on US warship. The Associated Press.

AP149 Divito, N.P. (2000, October 13). Agonizing wait for relatives of attacked Navy ship's crew. The Associated Press.

AP150 Schweid, B. (2000, October 13). Clinton: Ship's attackers will be held accountable. The Associated Press.

AP151 Burns, R. (2000, October 13). Pentagon to review Navy ships' security in foreign ports. The Associated Press.

AP152 Jelinek, P. (2000, October 13). Day after attack, investigators look for clues. The Associated Press.

AP153 (2000, October 13). A look at the victims aboard the Cole. The Associated Press.

AP154 Nasrawi, S. (2000, October 13). US says 17 presumed dead in Yemen blast. The Associated Press.

AP155 Schweid, B. (2000, October 13). Suspicion centers on bin Laden, two groups in Yemen. The Associated Press.

AP156 Crary, D. (2000, October 13). From small towns, from military families: The victims of the Cole. The Associated Press.

AP157 Jelinek, P. (2000, October 14). Pentagon says it will repair ship, review security. The Associated Press.

AP158 Murphy, B. (2000, October 14). Team investigating USS Cole explosion in Yemen grows. The Associated Press.

AP159 Burns, R. (2000, October 14). For ill-fated ship, nothing seemed unusual until the blast. The Associated Press.

AP160 Olsen, J.F. (2000, October 14). Stunned and exhausted, US sailors wounded in attack on Navy ship arrive in Germany. The Associated Press.

AP161 Murphy, B. (2000, October 14). Yemen's Islamic cells spawned from US-backed Cold War militias. The Associated Press.

AP162 Murphy, B. (2000, October 15). Specialists scour crippled destroyer for clues to deadly blast. The Associated Press.

AP163 Murphy, B. (2000, October 15). Officials: USS Cole blast turned attack boat into "confetti". The Associated Press. 
AP164 Sanminiatelli, M. (2000, October 15). Families welcome injured USS Cole survivors home. The Associated Press.

AP165 Jelinek, P. (2000, October 15). US officials defend use of Yemen port, promise to catch attackers. The Associated Press.

AP166 Murphy, B. (2000, October 16). Divers search the USS Cole as sailors work to stabilize ship. The Associated Press.

AP167 Murphy, B. (2000, October 16). Conditions improve for survivors abroad USS Cole. The Associated Press.

AP168 Murphy, B. (2000, October 16). Supply agent for Navy under scrutiny in bombing probe. The Associated Press.

AP169 Burns, R. (2000, October 17). Searchers remove six more bodies from Cole. The Associated Press.

AP170 (2000, October 17). AP news in brief; Yemeni security finds bomber leads; Four injured arrive in Virginia. The Associated Press.

AP171 Murphy, B. (2000, October 17). Yemeni security officials say two attackers traced. The Associated Press.

AP172 Murphy, B. (2000, October 17). Yemeni security sees bomb equipment links to suicide attack on ship. The Associated Press.

AP173 Murphy, B. (2000, October 17). Divers struggle to retrieve bodies from bombed ship in Yemen. The Associated Press.

AP174 Murphy, B. (2000, October 17). Yemeni security finds bomber leads; US sees "quantum leap" in probe. The Associated Press.

AP175 Ross, S. (2000, October 18). Clinton hails the fallen, vows retribution against the "hate-filled terrorists". The Associated Press.

AP176 Murphy, B. (2000, October 18). Police question two people in Yemen blast. The Associated Press.

AP177 Burns, R. (2000, October 18). If the perpetrator can be fingered, will Clinton order military retaliation? The Associated Press.

AP178 Gedda, G. (2000, October 18). US blocks, then approves VOA editorial on terrorism. The Associated Press.

AP179 Nasrawi, S. (2000, October 18). Police probe Islamic activists in ship attack. The Associated Press. 
AP180 Nasrawi, S. (2000, October 19). 12-year-old provides a lead in Cole inquiry. The Associated Press.

AP181 Nasrawi, S. (2000, October 19). Police probe Islamic activists in Navy ship attack in Yemen. The Associated Press.

AP182 Burns, R. (2000, October 19). Former commander says Aden was acceptable security risk for Navy. The Associated Press.

AP183 Gedda, G. (2000, October 19). US blames "glitch" for memo attacking antiterrorist editorial. The Associated Press.

AP184 Burns, R. (2000, October 19). Retired admiral and general to investigate Cole. The Associated Press.

AP185 Malik, A. (2000, October 20). USS Cole focus shifts to repairs, investigation. The Associated Press.

AP186 White, J. (2000, October 20). Shared mourning for Cole victims. The Associated Press.

AP187 Burns, R. (2000, October 20). Navy revises key detail in sequence of events preceding the Cole attack. The Associated Press.

AP188 Burns, R. (2000, October 21). Navy revises timeline of events preceding the Cole attack. The Associated Press.

AP189 Burns, R. (2000, October 25). US troops in Turkey, Baharain, Qatar on heightened alert. The Associated Press.

AP190 Burns, R. (2000, October 25). US military won't retreat from Gulf, admiral tells Congress. The Associated Press.

AP191 Burns, R. (2000, October 25). Analyst quits, saying Gulf threat reports unheeded. The Associated Press.

AP192 Burns, R. (2000, October 25). US commanders prepare against new terrorist threats. The Associated Press.

AP193 Burns, R. (2000, October 25). Intelligence analyst says warning of possible terrorism was ignored. The Associated Press.

AP194 Abu-Nasr, D. (2000, October 25). One of suspected Cole bombers was Egyptian, Yemen's president says. The Associated Press.

AP195 Burns, R. (2000, October 26). Rules required USS Cole to scan small boats in Aden harbor. The Associated Press. 
AP196 Abu-Nasr, D. (2000, October 26). FBI wraps up evidence gathering in Cole blast. The Associated Press.

AP197 Abu-Nasr, D. (2000, October 26). Bomb threat made against FBI investigators into Cole blast. The Associated Press.

AP198 Burns, R. (2000, October 27). Bomb probe seeking links to exiled Osama bin Laden. The Associated Press.

AP199 Burns, R. (2000, October 27). US investigators seek Cole bombing links to Osama bin Laden. The Associated Press.

AP200 Burns, R. (2000, October 28). Suspected terrorist mastermind is focus of Cole bombing probe. The Associated Press.

AP201 Abu-Nasr, D. (2000, October 29). Crippled Cole begins journey home. The Associated Press.

AP202 Pyle, R. (2000, October 30). USS Cole second US warship to ride home on other ship's deck. The Associated Press.

AP203 Hunt, T. (2000, October 30). Clinton asks Yemen to cooperate more in Cole investigation. The Associated Press.

AP204 Schweid, B. (2000, October 31). Navy ships avoiding Suez Canal out of terrorism concerns. The Associated Press.

AP205 Abu-Nasr, D. (2000, October 31). Two detained in the bombing of Cole also linked to hotel bombings. The Associated Press.

AP206 Abu-Nasr, D. (2000, October 31). Cole investigation focusing on four suspects; links to militants explored. The Associated Press.

AP207 Abu-Nasr, D. (2000, October 31). Cole investigation focusing on four suspects; Links to militants explored. The Associated Press.

AP208 Sniffen, M.J. (2000, November 2). Agreement near for FBI agents to observe Yemeni questioning. The Associated Press.

AP209 Burns, R. (2000, November 3). Officers to probe security for US troops in transit. The Associated Press.

AP210 Abu-Nasr, D. (2000, November 4). The Cole has sailed, leaving many questions behind. The Associated Press.

AP211 Mellgren, D. (2000, November 6). When superpowers get in trouble, Norwegian ships respond. The Associated Press. 
AP212 Gannon, K. (2000, November 13). After warship bombing, Afghans feel they're in the cross-hairs again. The Associated Press.

AP213 Sniffen, M.J. (2000, November 17). FBI: Progress in Cole probe allows more agents to come home. The Associated Press.

AP214 Margasak, L. (2000, November 18). Cohen tells troops that Mideast violence could spread. The Associated Press.

AP215 Al-Haj, A. (2000, November 19). Sources say six key accomplices held in Cole attack. The Associated Press.

AP216 Bryson, D. (2000, December 4). Yemen says USS Cole attack was work of international terrorism. The Associated Press.

AP217 Bryson, D. (2000, December 6). At least three Yemenis to be tried in attack on US warship. The Associated Press.

AP218 Bryson, D. (2000, December 13). Six suspects named; All fought in Afghanistan. The Associated Press.

AP219 Schweid, B. (2000, December 13). US counterterrorism expert thinks Cole bombers in Afghanistan. The Associated Press.

AP220 Burns, R. (2001, January 2). Study says poor intelligence risks more Cole-like attacks. The Associated Press.

AP221 Al-Haj, A. (2001, January 6). Security tightens ahead of USS Cole trial in Yemen. The Associated Press.

AP222 Al-Haj, A. (2001, January 8). Sources: Suspect in Cole attack says he believes orders came from bin Laden. The Associated Press.

AP223 Burns, R. (2001, January 9). Navy chief decides against punishing Cole's captain or crew. The Associated Press.

AP224 Burns, R. (2001, January 9). Panel says US military should change anti-terrorism approach. The Associated Press.

AP225 Sevareid, S. (2001, January 10). Yemeni lawyer: Key suspect unlikely to get fair trial. The Associated Press.

AP226 Sevareid, S. (2001, January 11). Fears of attacks on Western targets grow in Yemen. The Associated Press.

AP227 Sevareid, S. (2001, January 12). Report: Yemen seeks US details on Cole's voyage before deadly blast. The Associated Press. 
AP228 Sevareid, S. (2001, January 13). Sources: United States, Yemen disagree on trial for three Cole suspects. The Associated Press.

AP229 Jelinek, P. (2001, January 19). Cohen sees no negligence in failures that led to Cole bombing. The Associated Press.

AP230 Jelinek, P. (2001, January 20). Pentagon sees "collective responsibility" for Cole bombing. The Associated Press.

AP231 King, L. (2001, February 21). Bin Laden links probed amid series of arrests of Islamic militants. The Associated Press.

AP232 Al-Haj, A. (2001, March 1). Osama bin Laden applauds the bombing of the USS Cole in Aden harbor. The Associated Press.

AP233 Shah, A. (2001, June 24). Taliban reject US concerns on bin Laden's threat. The Associated Press.

AP234 Pincus, W. (2001, October 12). One year later, US Yemen clash over Cole bombing investigation. The Associated Press.

AP235 Mattar, S. (2005, August 19). Jordan's only sea outlet comes under rocket attack because US naval ships were present. The Associated Press.

AP236 Lumpkin, J.J. (2005, August 19). Administration trying to learn more about incident involving US warship. The Associated Press.

AP237 Halaby, J. (2005, August 19). Rockets fired from Jordan at US Navy ship, airport; Jordanian soldier killed. The Associated Press.

AP238 Halaby, J. (2005, August 22). Jordan arrests prime suspect in rocket attack on Navy ship, says Iraqi group involved. The Associated Press.

AP239 Halaby, J. (2005, August 23). Al-Zarqawi claims attack that narrowly missed US ship, Jordan arrests prime suspect. The Associated Press.

AP240 Halaby, J. (2005, August 23). Jordan arrests suspect in rocket attack on US ship, says Iraqi group involved. The Associated Press.

AP241 Gavlak, D. (2005, August 27). Jordan says it will ask Iraq to arrest the perpetrators of Aqaba rocket attack. The Associated Press.

AP242 Mattar, S. (2005, August 29). Jordan plans $\$ 85$ million for better controls at Iraq border crossing. The Associated Press.

AP243 Halaby, J., Buzbee, S. (2005, November 9). Jordan's capital, gateway to Iraq, long viewed as prime terror target. The Associated Press. 
AP244 Halaby, J. (2005, November 9). Suicide attackers strike hotels in Jordanian capital, killing 57 and wounding hundreds. The Associated Press.

AP245 Halaby, J. (2005, November 10). Jordanian protest condemns al-Zarqawi after alQaida says it bombed hotels; 1 American killed. The Associated Press.

AP246 (2006, April 26). Jordan begins trial of 12 charged in Aqaba blasts. The Associated Press.

AP247 Halaby, J. (2006, August 3). Jordan's military prosecutor demands death for 7 men charged with attacking US warships. The Associated Press.

AP248 Roman, M. (2004, March 11). Bombs kill more than 170 in Spanish train system ahead of weekend election. The Associated Press.

AP249 Barr, R. (2004, March 11). World leaders condemn terrorist bombings in Spain. The Associated Press.

AP250 McCullough, E. (2004, March 11). Basque extremist group has repeatedly confounded predictions of its demise. The Associated Press.

AP251 Linzer, D., Sampson, P. (2004, March 11). In country with homegrown terror, investigators struggle to sort out who's behind Spanish attack. The Associated Press.

AP252 Guggenheim, K. (2004, March 11). Bush calls Aznar to express solidarity after terrorist attack. The Associated Press.

AP253 Miller, L. (2004, March 11). Homeland security officials keep wary eye on Spain. The Associated Press.

AP254 Roman, M. (2004, March 12). Terrorist bombs kill more than 190 on trains in rush-hour attack in Madrid. The Associated Press.

AP255 Roman, M. (2004, March 12). A day after bombings, tears and silence at Madrid's Atocha station. The Associated Press.

AP256 Woolls, D. (2004, March 12). Spain hunts for bombers as death toll in train attacks increases to 198. The Associated Press.

AP257 Woolls, D. (2004, March 12). Spain halts for silent tribute to victims of terrorist bombings. The Associated Press.

AP258 Roman, M. (2004, March 12). Normally boisterous Madrid engulfed in grief after bombings. The Associated Press.

AP259 Giles, C. (2004, March 12). Madrid bombings expected to play decisive role in Sunday's general elections in Spain. The Associated Press. 
AP260 Surman, M. (2004, March 12). Madrid terrorist attacks raises fears that European tourism won't rebound. The Associated Press.

AP261 Gatopoulos, D., McDonough, M. (2004, March 12). Madrid attacks sound terror alarm for Olympics, world transport networks. The Associated Press.

AP262 Selsky, A. (2004, March 12). Millions rally across Spain in defiance of terrorist attacks. The Associated Press.

AP263 Lumpkin, J.J. (2004, March 12). Bush remembers Madrid victims; Investigators unsure who is responsible. The Associated Press.

AP264 Giles, C. (2004, March 13). Grief-striken Spaniards gird for Sunday’s general election. The Associated Press.

AP265 Giles, C. (2004, March 13). Police search for three suspects in Spanish bombings; Spaniards prepare for elections. The Associated Press.

AP266 McDonough, M. (2004, March 13). Prepare against terrorists, Blair warns, as countries boost security in wake of Madrid attacks. The Associated Press.

AP267 Giles, C. (2004, March 13). Police search for three suspects in Spanish bombings; No evidence so far of suicide bombings. The Associated Press.

AP268 Giles, C. (2004, March 13). Spain arrests five suspects in Madrid bombings three Moroccans possibly linked to extremists. The Associated Press.

AP269 Leicester, J. (2004, March 13). Purported al-Qaida videotape claims responsibility for Madrid bombings; Five people arrested. The Associated Press.

AP270 McCullough, E. (2004, March 14). Spain votes in elections overshadowed by alQaida claim of responsibility for Madrid bombings. The Associated Press.

AP271 McCullough, E. (2004, March 14). High election turnout following terrorist train bomb. The Associated Press.

AP272 Moulson, G. (2004, March 14). European intelligence agencies seek identity of purported al-Qaida operative on videotape. The Associated Press.

AP273 McCullough, E. (2004, March 14). Spain's ruling party losing ground in elections after terror attacks. The Associated Press.

AP274 McCullough, E. (2004, March 14). Spain's ruling party ousted from power after terror attack. The Associated Press.

AP275 Selsky, A. (2004, March 14). Suspect in Madrid bombing is tied to September 11 suspects. The Associated Press. 
AP276 Gardiner, B. (2004, March 14). After Madrid, Europe takes another look at security, intelligence efforts. The Associated Press.

AP277 Selsky, A. (2004 March 15). Suspect in Spain bomb attacks on train was named months earlier in terror investigation. The Associated Press.

AP278 McCullough, E. (2004, March 15). Socialist leader vows to bring Spanish troops home from Iraq. The Associated Press.

AP279 Nasrawi, S. (2004, March 15). Web of Islamic militants who share bin Laden's ideology grew out of al-Qaida recruiting drive. The Associated Press.

AP280 Johnson, E. (2004, March 15). US allies in Iraq refuse to waver in wake of Madrid rail bombings. The Associated Press.

AP281 Hunt, T. (2004, March 15). After Spain, questions about how a new attack on US would affect November election. The Associated Press.

AP282 Selsky, A., Marmie, N. (2004, March 15). Authorities investigate possible ties between Madrid attacks, Casablanca bombings. The Associated Press.

AP283 Pfleger Shrader, K. (2004, March 15). Bush congratulates Spain's prime ministerelect; Evidence points to Muslim extremists role in attacks. The Associated Press.

AP284 Leicester, J. (004, March 16). Madrid bombing probe sharpens focus on al-Qaida connection amid reports of five Moroccan suspects. The Associated Press.

AP285 Krane, J. (2004, March 16). US says attacks on missionaries, withdrawal of Spain won't undermine coalition in Iraq. The Associated Press.

AP286 Leicester, J. (2004, March 16). Police detain Algerian, death toll rises to 201 in Spain bombing. The Associated Press.

AP287 Scislowska, M. (2004, March 16) Fear of terrorist attack grows in countries involved in Iraq after Madrid strike. The Associated Press.

AP288 Sampson, P. (2004, March 16). Evidence shows authorities knew since 2001 that key Madrid bombing suspect had contact with accused terrorists. The Associated Press.

AP289 Loven, J. (2004, March 16). White House says allies must remain resolute, not let terrorists think they affect elections. The Associated Press.

AP290 Leicester, J. (2004, March 17). Madrid suspects were known to authorities years ago. The Associated Press.

AP291 Doland, A. (2004, March 17). Interior minister: Threat letter does not bear typical signs of Islamic extremism. The Associated Press. 
AP292 Selsky, A. (2004, March 17). Algerian who allegedly threatened mass bloodshed in Madrid brought before court. The Associated Press.

AP293 Selsky, A. (2004, March 17). Spain's new leader says he won't reconsider pledge to withdraw troops from Iraq. The Associated Press.

AP294 Schweid, B. (2004, March 17). Administration official faults defeated government for "mishandling" terror attack. The Associated Press.

AP295 Marmie, N. (2004, March 17). Moroccan authorities suspect Islamic extremist group linked to al-Qaida was behind Madrid bombing. The Associated Press.

AP296 McCullough, E. (2004, March 18). Spanish leader and US politicians spar over Iraq and fight against terrorism. The Associated Press.

AP297 Prades, M.J. (2004, March 18). Spanish police arrest four more suspects, one week after Madrid bombings. The Associated Press.

AP298 Anderson, C. (2004, March 18). US officials say they're puzzled about Spain's reluctance to let FBI assist in bomb probe. The Associated Press.

AP299 Hunt, T. (2004, March 18). Bush cites Madrid bombing, says nations can't live trying to appease terrorists. The Associated Press.

AP300 Prades, M.J. (2004, March 19). Three Moroccans, Two Indians charged in bomb attacks on Madrid trains, ordered held for up to two years. The Associated Press.

AP301 Woolls, D. (2004, March 20). Report: Spaniard led four Moroccans to mine to steal dynamite used in Madrid bombings. The Associated Press.

AP302 Roman, M. (2004, March 22). Four more suspects in Madrid bombings arrested; European intelligence officials gather. The Associated Press.

AP303 Woolls, D. (2004, March 23). Spain seeks bombing suspects who ma have fled; Police lower death toll to 190. The Associated Press.

AP304 Miller, L. (2004, March 23). Attention turns to rail security after deadly Madrid bombings. The Associated Press.

AP305 Letona, A. (2004, March 23). Basque group ETA seen pondering new cease-fire. The Associated Press.

AP306 Woolls, D. (2004, March 24). Spain and Morocco put aside differences to team up in Madrid terror probe. The Associated Press.

AP307 McCullough, E. (2004, March 24). New Spanish leader stand by to pledge of troop pullout from Iraq. The Associated Press. 
AP308 Roman, M. (2004, March 24). World leaders join Spain at state funeral for Madrid bombing victims. The Associated Press.

AP309 Roman, M. (2004, March 24). Spanish royals weep at state funeral for Madrid bombing victims. The Associated Press.

AP310 Ganley, E. (2003, March 25). Letters by mysterious group announce suspension of bomb threats while improving its means. The Associated Press.

AP311 Prades, M.J. (2004, March 26). Another Moroccan charged in March 11 train bombings in Spain. The Associated Press.

AP312 Woolls, D. (2004, April 26). Terror suspect linked to al-Qaida suspected of being behind Madrid bombs, investigator says. The Associated Press.

AP313 Ritter, K. (2004, March 27). Search of rural Spain house yields fingerprints of prime suspects in Madrid bombings. The Associated Press.

AP314 Prades, M.K. (2004, March 29). Five bombing suspects in Spanish court as media reports another death; Government will double Afghan force. The Associated Press.

AP315 Prades, M.J. (2004, March 30). Spanish judge charges two more suspects in Madrid terror bombings. The Associated Press.

AP316 Prades, M.J. (2004, March 30). Spain says focus of bombing probe is Moroccan extremist group. The Associated Press.

AP317 Woods, A. (2004, April 1). Arrest warrant says Tunisian was leader of Madrid bombing suspects. The Associated Press.

AP318 Prades, M.J. (2004, April 2). Spanish judge frees three arrested in Madrid train bombings. The Associated Press.

AP319 Woolls, D. (2004, April 2). Bomb found under tracks of high-speed rail line in Spain. The Associated Press.

AP320 Woolls, D. (2004, April 2). Bomb found under tracks of high-speed rail line in Spain; May be same explosive used in Madrid attacks. The Associated Press.

AP321 Roman, M. (2004, April 3). Three suspected terrorists blow themselves up as Spanish police prepare to raid building, one agent killed. The Associated Press.

AP322 Roman, M. (2004, April 4). Official: Madrid attacks ringleader among suicide bombers, more assaults were planned. The Associated Press.

AP323 Roman, M. (2004, April 5). Security stepped up as police search for more bombing suspects. The Associated Press. 
AP324 Giles, C. (2004, April 5). Spain makes another arrest in Madrid bombings; Newspaper says al-Qaida group threatens more violence. The Associated Press.

AP325 Prades, M.J. (2004, April 7). Suicide terrorists planned second attack in Madrid, court officials say. The Associated Press.

AP326 Roman, M. (2004, April 14). Madrid bombers financed themselves with drug sales, Spain says. The Associated Press.

AP327 Khalifa, M. (2004, April 15). Man claiming to be bin Laden offers "truce" with Europe $\mathrm{n}$ audio recording. The Associated Press.

AP328 McCullough, E. (2004, April 16). Socialist leader Zapatero voted in as Spain's prime minister. The Associated Press.

AP329 Woolls, D. (2004, April 16). Young, angry, and lucky, Madrid bombers attacked their adopted homeland. The Associated Press.

AP330 McCullough, E. (2004, April 19). Foreign minister: Spain's long-term ties with us won't suffer over troop withdrawal. The Associated Press.

AP331 Roman, M. (2004, April 19). Spain plans Iraq troop pullout within 6 weeks. The Associated Press.

AP332 Hunt, T. (2004, April 19). Bush criticizes Spain's new prime minister on Iraq pullout. The Associated Press.

AP333 Prades, M.J. (2004, April 28). Judge indicts Madrid terror suspect on charges of planning September 11 attacks. The Associated Press.

AP334 Callimachi, R. (2004, May 6). Spain bombings probe leads to arrest of Oregon lawyer. The Associated Press.

AP333 Callimachi, R. (2004, May 7). Oregon lawyer arrested as material witness in Madrid train bombings that killed 191. The Associated Press.

AP336 Woolls, D. (2004, May 7). American's fingerprints found on bag containing detonators, Spain says. The Associated Press.

AP337 Callimachi, R. (2004, May 7). Two different pictures emerge of Portland lawyer arrested in Madrid bombing. The Associated Press.

AP338 Callimachi, R. (2004, May 8). Family says Oregon lawyer has no connection to Madrid bombing. The Associated Press.

AP339 Roman, M. (2004, May 12). Rescuers and victims seek reunion after Madrid terror bombings. The Associated Press. 
AP340 Kramer, A. (2004, May 24). Court dismisses case against American lawyer arrested in connection with Spanish bombings. The Associated Press.

AP341 Kramer, A. (2004, May 25). FBI apologizes to American lawyer wrongly arrested in connection with Spanish bombings. The Associated Press.

AP342 Anderson, C. (2004, May 25). Lawyer's arrest on bad fingerprint match illustrates post-9/11 flaws, critics say. The Associated Press.

AP343 Rizzo, A. (2004, June 8). Police in Italy and Belgium arrest 17, including an alleged organizer of Madrid bombings. The Associated Press.

AP344 Woolls, D. (2004, July 2). Months after terror attack, Spain still in search of masterminds. The Associated Press.

AP345 Woolls, D. (2004, July 6). Parliament's investigation of Madrid train bombings gets under way. The Associated Press.

AP346 Woolls, D. (2004, July 7). Hearing examines Spanish government's erroneous blame of Basque rebels for train bombings. The Associated Press.

AP347 Woolls, D. (2004, July 14). Spain ignored mosque where train bombing suspects prayed because of Saudi Arabia link, expert says. The Associated Press.

AP348 Woolls, D. (2004, July 15). Morocco has up to 1,000 al-Qaida supporters, Spain's Judge Garzon says. The Associated Press.

AP349 McCullough, E. (2004, July 28). Spain's former interior minister defends initial blame of ETA for Madrid bombings. The Associated Press.

AP350 Roman, M. (2004, July 29). Socialist accuses Spain's former government of lying about train bombing perpetrators. The Associated Press.

AP351 McCullough, E. (2004, August 7). Spaniards find little succor in politicized parliamentary inquiry into Madrid bombings. The Associated Press.

AP352 Abu-Nasr, D. (2004, August 9). Al-Qaida's smaller "Franchise" followers pose serious threat to the West, experts say. The Associated Press.

AP353 Roman, M. (2004, September 11). Veneer of normality masks pain of recovery six months after Madrid train bombings. The Associated Press.

AP354 Anderson, C. (2004, September 13). Justice investigates mistaken detention of lawyer over fingerprint. The Associated Press.

AP355 Roman, M. (2004, October 19). Spanish station airs footage of March 11 bombings; Alleged plot to blow up courthouse foiled. The Associated Press. 
AP356 Roman, M. (2004, October 20). Suspected Muslim militant planned suicide attack on court to kill judges, destroy terrorism case files and deal Spain its' "biggest blow of its history." The Associated Press.

AP357 Woolls, D. (2004, October 21). Three inmates seen as close to suspected Madrid train bombing ringleader questioned over new terror plot in Spain. The Associated Press.

AP358 Prades, M.J. (2004, October 23). Spanish judge files terrorism charges against 17 suspects for alleged plot to attack court. The Associated Press.

AP359 McCullough, E. (2004, November 29). Former Spanish prime minister defends handling of Madrid train bombings, says attack meant to undermine his party. The Associated Press.

AP360 Woolls, D. (2004, December 6). Small bombs explode in seven Spanish cities after warnings from Basque group. The Associated Press.

AP361 Woolls, D. (2004, December 13). Spain's prime minister alleges his predecessor's government erased computer records after March 11 bombings. The Associated Press.

AP362 Giles, C. (2005, January 17). Spanish judge indicts eight on terror charges and links with September 11 suspects. The Associated Press.

AP363 Pfleger Shrader, K. (2005, January 22). Militant logistics coordinator may link September 11, Madrid attacks. The Associated Press.

AP364 McCullough, E. (2005, February 9). Car bomb explodes in Madrid; Basque separatists purportedly claim responsibility. The Associated Press.

AP365 Woolls, D. (2005, February 14). Spanish prosecutor plans to seek more than 74,000 years in prison for three September 11 suspects. The Associated Press.

AP366 Woolls, D. (2005, March 2). Madrid bombing suspect had sketch of New York rail terminal. The Associated Press.

AP367 Woolls, D. (2005, March 3). Counterterrorism chief says Madrid bombers plotted to follow up with suicide attacks. The Associated Press.

AP368 McCullough, E. (2005, March 9). Last year's bombing, election paired inseparably, to country's detriment. The Associated Press.

AP369 Woolls, D. (2005, March 9). A year after the Madrid bombing, Spaniards realize their country has long been a haven for Islamic militants. The Associated Press.

AP370 Roman, M. (2005, March 10). Madrid bombing survivors nurse physical and psychological wounds on anniversary of attack. The Associated Press. 
AP371 Roman, M. (200, March 11). Tears, bells and moment of silence as Spain mourns on first anniversary of train bombings. The Associated Press.

AP372 Wardell, J. (2005, July 7). Explosions rock double-decker bus, London subway, injuring 190. The Associated Press.

AP373 Crutsinger, M. (2005, July 7). Blair says deadly explosions will not halt the work at world leader summit. The Associated Press.

AP374 Sherman, M. (2005, July 7). Homeland security asks major cities to be vigilant on transit systems. The Associated Press.

AP375 Wardell, J. (2005, July 7). Three blasts rock subway, at least 40 killed and more than 350 wounded. The Associated Press.

AP376 Milton, P. (2005, July 7). US cities on heightened alert following London attacks; Subway riders told to be vigilant. The Associated Press.

AP377 Crutsinger, M. (2005, July 7). World leaders respond to London bombing with vow to terrorists: "We shall prevail." The Associated Press.

AP378 Jordan, L.J. (2005, July 7). US raises terror alert to code orange for transit. The Associated Press.

AP379 Wardell, J. (2005, July 7). Four blasts rock London, killing at least 40 people in the worst attacks since World War II. The Associated Press.

AP380 Abou El Magd, N. (2005, July 7). London attacks bear the fingerprints of al Qaeda, experts say. The Associated Press.

AP381 Bryson, D. (2005, July 7). Doctors, police, ordinary people fill streets to help after London attacks. The Associated Press.

AP382 Lawless, J. (2005, July 7). Londoners take pride in stoic "blitz spirit" in wake of deadly bombs. The Associated Press.

AP383 Linton, L. (2005, July 7). Sprawling transport system like London's vulnerable to attack, experts say. The Associated Press.

AP384 Barr, R. (2005, July 7). At least 37 dead in terror strike on London transit; Blair blames Islamic extremists. The Associated Press.

AP385 Lawless, J. (2005, July 7). In wake of terror, Blair shows resolve, appeals for unity. The Associated Press.

AP386 Gardiner, B. (2005, July 7). Despite expertise from past IRA bombings, British investigators face arduous task. The Associated Press. 
AP387 Barr, R. (2005, July 8). At least 37 dead in terror strike on London transit; Al Qaeda is implicated. The Associated Press.

AP388 Dodds, P. (2005, July 8). Scared Londoners return to underground; Investigators combing through evidence. The Associated Press.

AP389 Shrader, K. (2005, July 8). Officials looking into claim that little-known al-Qaida group pulled off London bombings. The Associated Press.

AP390 Crutsinger, M. (2005, July 8) Summit shaken by London bombings reaches compromises on African and Palestinian aid. The Associated Press.

AP391 Gardiner, B. (2005, July 8). Less than 10 pounds of explosives used in each London bomb, police say. The Associated Press.

AP392 Dodds, P. (2005, July 8). Official death toll at 49 and expected to rise. The Associated Press.

AP393 Kole, W.J. (2005, July 8). Tears for the missing, flowers for the dead as Londoners cope with attacks. The Associated Press.

AP394 Dodds, P. (2005, July 8). As death toll mounts, Londoners try to bring healing, search for missing relatives. The Associated Press.

AP395 Keath, L. (2005, July 8). Amid condemnations of the London bombings, Arabs debate where to place the blame. The Associated Press.

AP396 Gardiner, B. (2005, July 8). London attackers likely used simple, homemade bomb, plastic explosives. The Associated Press.

AP397 Ross, E. (2005, July 8). Terrorist bombings unlikely to leave psychological scars for most Londoners. The Associated Press.

AP398 Jordan, L.J. (2005, July 8). Transit alert level could be dropped within days, officials say. The Associated Press.

AP399 Murphy, B. (2005, July 9). Muslims pray for bombing victims but urge West to heed roots of anger. The Associated Press.

AP400 Moore, M. (2005, July 9). Three bombs that hit London subway exploded within less than a minute of each other, police say. The Associated Press.

AP401 Gardiner, B. (2005, July 9). Simultaneity of London blasts suggests bombers used timers. The Associated Press.

AP402 Dodds, P. (2005, July 9). Clues emerging in London bomb blasts as crews hunt for missing and bodies. The Associated Press. 
AP403 Sakurai, J. (2005, July 9). London's bulldog spirit shines through as euphoria gives way to grief. The Associated Press.

AP404 Moore, M. (2005, July 10). Searchers still trying to reach bodies; Three arrests made at London's airport. The Associated Press.

AP405 Barr, R. (2005, July 10). London police arrest three as search for London bombers looks abroad and at home. The Associated Press.

AP406 Moore, M. (2005, July 10). Bomb investigators, rescuers fight horrendous conditions to find bodies and clues. The Associated Press.

AP407 Barr, R. (2005, July 10). Britons gather to mourn victims of bombings while police sort through tips. The Associated Press.

AP408 Pickler, N. (2005, July 11). London bombings give new urgency to Bush's war on terrorism. The Associated Press.

AP409 Faramarzi, S. (2005, July 11). London bombings may be turning Muslim activists against al Qaeda. The Associated Press.

AP410 Faramarzi, S. (2005, July 11). Moroccan mentioned as possible suspect in London bombings denies involvement. The Associated Press.

AP411 Wagner, T. (2005, July 11). London police comb through closed-circuit TV tapes. The Associated Press.

AP412 Moore, M. (2005, July 12). Families of missing agonize over uncertainty; Blair says justice will be done. The Associated Press.

AP413 Moore, M. (2005, July 12). Police raid residences as investigation spreads to northern England. The Associated Press.

AP414 Wagner, T. (2005, July 12). Police raid houses in northern England; Media reports bombers died in London blasts. The Associated Press.

AP415 Wagner, T. (2005, July 12). Police investigating whether four attackers died in London bombings. The Associated Press.

AP416 Kole, W.J. (2005, July 12). Five days after London bombings, families give up hope of finding loved ones alive. The Associated Press.

AP417 Wager, T. (2005, July 12). Evidence indicates four suicide attackers carried out London bombings. The Associated Press.

AP418 Faramarzi, S. (2005, July 13). London bombing suspects: Young men who may have had dual lives. The Associated Press. 
AP419 Dodds, P. (2005, July 13). Muslims agonize over bombing attacks as Tony Blair calls for calm in Britain. The Associated Press.

AP420 Faramarzi, S. (2005, July 13). English neighborhood tries to understand why several of its sons became suicide bombers. The Associated Press.

AP421 Kirka, D. (2005, July 13). British police seek a possible mastermind of London terror attacks. The Associated Press.

AP422 McDonough, M. (2005, July 14). Investigation continues as Britons mark one week since London bombings. The Associated Press.

AP423 Gardiner, B. (2005, July 14). Police chief: Authorities have identified all four suicide bombers responsible for London attacks. The Associated Press.

AP424 Associated Press. (2005, July 14). Profiles of men suspected in the London bombings and others tied to the investigation. The Associated Press.

AP425 Rizzo, A. (2005, July 14). From Rome to Copenhagen, officials scramble to protect Europe after London attacks. The Associated Press.

AP426 Lester, W. (2005, July 14). Support for bin Laden, suicide bombers falling in some heavily Muslims countries. The Associated Press.

AP427 Murphy, B. (2005, July 14). Britain seeks Muslim help to battle "intellectual strength" of radical Islam. The Associated Press.

AP428 Gardiner, B. (2005, July 14). FBI agents and Jamaican authorities join London bomb investigation, searching for plotters. The Associated Press.

AP429 Haven, P. (2005, July 15). Pakistani authorities looking into possible links between London bomber and militant group. The Associated Press.

AP430 Haven, P. (2005, July 15). Pakistani authorities see links between militant groups, London bomber. The Associated Press.

AP431 Michael, M. (2005, July 15). Chemist arrested in connection with London bombings came from poor family. The Associated Press.

AP432 Murphy, B., Faramarzi, S. (2005, July 15). Egyptian biochemist jailed in London bombings; Police raid bookstore. The Associated Press.

AP433 Haven, P. (2005, July 16). Pakistani authorities question school officials over possible links to London bomber. The Associated Press.

AP444 Kole, W.J. (2005, July 16). Search for evidence in London attacks widens as Blair warns of "evil ideology". The Associated Press. 
AP445 Murphy, B. (2005, July 17). Britain's largest Sunni group condemns London bombings, probe continues. The Associated Press.

AP446 Johnson, E. (2005, July 18). Investigators pursue clues to London bombings in Leeds, Pakistan. The Associated Press.

AP447 Kole, W.J. (2005, July 18). Rage mingles with grief as please mount not to blame Muslims for attacks. The Associated Press.

AP448 Gardiner, B. (2005, July 18). British government draws criticism for not keeping tabs on suspect. The Associated Press.

AP449 Gardiner, B. (2005, July 19). Pakistan police arrest militants with possible links to London; Blair meets Muslim leaders. The Associated Press.

AP450 Kole, W.J. (2005, July 19). Credit cards, bills, receipts; Investigators focusing on bombers' finances. The Associated Press.

AP451 Wagner, T. (2005, July 19). London bombings: Blair asks Muslim leaders to combat terror. The Associated Press.

AP452 Wagner, T. (2005, July 20). Even in Britain, moderate Muslims don't always agree that suicide bombing is wrong. The Associated Press.

AP453 Wagner, T. (2005, July 20). Pakistan arrests "important" suspect: British police removed subway carriage. The Associated Press.

AP454 Johnson, E. (2005, July 21). Britain plans laws to keep out Islamic radicals who glorify terror. The Associated Press.

AP455 Barr, R. (2005, July 21). Four explosions in London underground, bus two weeks after deadly blasts. The Associated Press.

AP456 Johnson, E. (2005, July 21). Second assault on London transit system stirs worries over security in Britain and abroad. The Associated Press.

AP457 Jordan, L.J. (2005, July 21). Homeland security had eyed lowering terror alert before latest London attacks. The Associated Press.

AP458 Kirka, D. (2005, July 21). Explosions again hit subways, bus in London; One arrested. The Associated Press.

AP459 Barr, R. (2005, July 22). Witnesses say suspects fled the scenes of London attacks. The Associated Press.

AP460 Barr, R. (2005, July 22). Police kill man at subway station a day after second wave of transit attacks. The Associated Press. 
AP461 Dolnick, S. (2005, July 22). New York police launch random checks of bags entering subway. The Associated Press.

AP462 Barr, R. (2005, July 22). Police kill man at London subway station, link it to previous attacks; Two men arrested. The Associated Press.

AP463 Gardiner, B. (2005, July 22). Expert says bomb analysis should reveal whether London attacks linked. The Associated Press.

AP464 Lawless, J. (2005, July 23). British police arrest second suspect in bombings amid massive manhunt. The Associated Press.

AP465 Lawless, J. (2005, July 23). London police say man they fatally shot on subway car unrelated to bombings. The Associated Press.

AP466 Lawless, J. (2005, July 23). Police killing of terrorism suspect sparks worry in Britain. The Associated Press.

AP467 Johnson, E. (2005, July 24). Third man arrested in connection with failed attack on London transit, al-Qaida suspected. The Associated Press.

AP468 Quinn, P. (2005, July 25). Police hold three suspects arrested after failed bomb attacks in London. The Associated Press.

AP469 Quinn, P. (2005, July 25). Police release names of two suspects in failed transit bombings; Brazilian was shot. The Associated Press.

AP470 Gardiner, B. (2005, July 25). Police storm home in Birmingham, reportedly arrest suspected July 21 bomber. The Associated Press.

AP471 Rising, D. (2005, July 27). Evidence has intelligence community asking if bombers knew they would die. The Associated Press.

AP472 Gardiner, G. (2005, July 27). British police investigating failed London bombings arrest four men. The Associated Press.

AP473 Johnson, E. (2005, July 28). Police arrest nine more men in connection with failed London bombings. The Associated Press.

AP474 Lawless, J. (2005, July 29). All four suspects in failed July 21 bombings reported to be in custody. The Associated Press.

AP475 D'Emilio, F. (2005, July 29). Italy traces cell phone calls to arrest fourth suspect in London bombings. The Associated Press.

AP476 D’Emilio, F. (2005, July 30). Bombing suspect arrested in Rome left London by train five days after attacks. The Associated Press. 
AP477 McAloon, C. (2005, July 31). Police question London bomb suspects, investigate their ties to Saudi Arabia, Italy. The Associated Press.

AP478 Gardiner, B. (2005, August 3). British police charge first suspect in London bombing investigations. The Associated Press.

AP479 Youssef, M. (2005, August 4). Al-Qaida's deputy leader threatens more attacks in Britain, according to videotape. The Associated Press.

AP480 McDonough, M. (2005, August 4). British Muslims see sharp increase in hate crimes in wake of London bombings. The Associated Press.

AP481 Hurst, S. (2005, August 4). Al-Qaida deputy leader threatens more attacks in Britain. The Associated Press.

AP482 Johnson, E. (2005, August 6). British authorities charge first of London bombings suspects. The Associated Press.

AP483 Tomlinson, C. (2005, August 8). London suspects have ties to East Africa, where al-Qaida-linked groups may be growing. The Associated Press.

AP484 Johnson, E. (2005, August 8). London bombing suspects charged with attempted murder. The Associated Press.

AP485 Ballaby, M.D. (2005, August 9). Britain may set up secretive courts to help prosecute terror suspects. The Associated Press.

AP486 El Magd, N.A. (2005, August 9). Egyptian chemist says he knew two of the London attackers. The Associated Press.

AP487 Weissenstein, M. (2005, August 9). Potential “lone wolf” attackers a law enforcement concern. The Associated Press.

AP488 Wagner, T. (2005, August 22). Brazilian officials meet London police about killing of man mistaken for suicide bomber. The Associated Press.

AP489 Buzbee, S. (2005, September 1). Al-Qaida no. 2 claims responsibility for the London bombings. The Associated Press.

AP490 Buzbee, S. (2005, September 1). Al-Qaida claims responsibility for London bombings; Video shows final statement of suicide attacker. The Associated Press.

AP491 Buzbee, S. (2005, September 1). London suicide bomber appears in farewell tape along with al-Qaida no. 2. The Associated Press.

AP492 Wagner, T., Solomon, J. (2005, September 1). Saudis told British, US last December about threat against London. The Associated Press. 
AP493 Barr, R. (2005, September 2). British Muslims shocked, dismayed by video of London bomber. The Associated Press.

AP494 Gardiner, B. (2005, September 20). Closed-circuit TV footage shows London bombers on practice run. The Associated Press.

AP495 Haven, P. (2005, September 23). Suspected bomber appears in London court after extradition from Italy. The Associated Press.

AP496 Gardiner, B. (2005, September 26). London bombing compensation payments too slow, victims say. The Associated Press.

AP497 Gardiner, B. (2006, January 6). Investigation stalled six months after London bombings. The Associated Press.

AP498 Keath, L. (2006, January 20). New tape from bin Laden says al-Qaida preparing new attacks in US. The Associated Press.

AP499 Jordan, L.J. (2006, January 21). Analysts seeking date, language of bin Laden tape for clues to threat. The Associated Press.

AP500 Stringer, D. (2006, May 11). Investigators missed changes to thwart transit attacks. The Associated Press.

AP501 Stringer, D. (2006, May 11). Few clues London bombers were turning to extremism, investigators report. The Associated Press.

AP502 Stringer, D. (2006, May 11). Police missed chances to identify two bombers before attacks, official says. The Associated Press.

AP503 Stringer, D. (2006, May 11). Legislative panel finds no intelligence failures in lead up to London transit bombings. The Associated Press.

AP504 Quinn, J. (2006, July 6). London bomber says in video that attacks were "only the beginning." The Associated Press.

AP505 Panja, T. (2006, July 6). Community that produced London bombers tires of reminders of the attacks. The Associated Press.

AP506 Mortimer, J. (2006, July 7). Al Qaida deputy leader says two London bombers spent time at an al-Qaida camp. The Associated Press.

G1 Younge, G., Hannan, L. (1998, August 8). Carnage at the embassies; U.S. vows to bring bombers to justice after scores die in East Africa attacks. The Guardian, p. 1. 
G2 Gough, D. (1998, August 8). "This is horror. Nobody knows what to do"; Much of the rescue effort fell to ordinary people lacking leaders or plans. The Guardian, p. 1.

G3 Younge, G. (1998, August 8). "We do not forgive. We do not forget. We will leave no stone unturned"; U.S. fury. The Guardian, p. 4.

McGreal, C., Hirst, D. (1998, August 8). West scents the hand of Islamists behind outrages. The Guardian, p. 5.

G5 Hannan, L. (1998, August 8). Kenyan doctors face "deluge" of the injured; Victims/volunteers rush to hospitals overwhelmed by unidentified casualties. The Guardian, p. 5.

Younge, G. (1998, August 10). Hard search ahead for the suspects. The Guardian, p. 10.

Younge, G. (1998, August 13). Multiple threats put missions on alert: Washington accused of ignoring advice as "unprecedented" bomb warning close embassies around the world. The Guardian, p. 13.

G8 Goldenberg, S., Borger, J. (1998, August 17). Bomb suspect extradited; Man detained by Pakistan confesses to helping build the devices that tore the embassies apart. The Guardian, p. 12.

G9 Younge, G., Vulliamy, E., Kettle, M. (1998, August 21). Clinton takes revenge; U.S. missile raids on "terror camps" in Afghanistan and Sudan. The Guardian, p. 1.

G10 Younge, G., Vulliamy, E. (1998, August 21). Terror bases were targets. The Guardian, p. 3.

G11 Borger, J. (1998, August 21). Sudan prepares to make complaint to the UN. The Guardian, p. 3.

G12 Hirst, D. (1998, August 22). The Politics: Why our drugs factory? Why not the arsenal? The Guardian, p. 3.

G13 Norton-Taylor, R. (1998, August 22). Terrorist made by the USA; Arch-Suspect. The Guardian, p. 4.

G14 Borger, J. (1998, August 22). Terrorist made by the USA; The gamble. The Guardian, p. 4.

G15 Benn, T. (1998, August 24). With "enemies" like these, Clinton needs candid friends like us. The Guardian, p.16. 
G16 Hopkins, N., Vulliamy, E., Hooper, J. (1998, August 24). Terror threat to U.S. and Israeli plans; America is put on its guard as the defence secretary warns citizens: "Be on heightened alert". The Guardian, p. 2.

G17 Younge, G. (1998, August 26). Bin Laden allegedly planned to kill Clinton; FBI trail leads to Saudi millionaire terrorist. The Guardian, p. 10.

G18 Beresford, D. (1998, August 27). Hitting back at America; South Africans united by bomb. The Guardian, p. 14.

G19 Younge, G., Norton-Taylor, R., Campbell, D. (1998, August 28). Kenya bomb suspects face U.S. trial; Scotland Yard admits Britain could be target in terrorist war as diplomatic staff are sent home from Sudan in retaliation for air strike. The Guardian, p. 2.

G20 Black, I. (1998, September 22). "Terror is the world's problem"; Clinton at the UN: Speech tries to counter the worry that Washington is too preoccupied to focus on big global problems. The Guardian, p. 7.

G21 Campbell, D., Norton-Taylor, R., Pallister, D. (1998, September 24). Seven held in terror swoop. The Guardian, p. 1.

G22 Galpin, R. (1999, July 31). Bin Laden "to abandon haven in Afghanistan" The Guardian, p. 15.

G23 Gough, David. (1999, August 7). Scars of Nairobi bomb linger in minds and bodies; As Americans go on alert for the anniversary today of the embassy explosion, victims relive their trauma. The Guardian, p. 12.

G24 (2008, June 2). Blast kills four outside Danish embassy in Pakistan. The Guardian Unlimited.

G25 (2008, June 2). Blast kills six outside Danish embassy in Pakistan. The Guardian Unlimited.

G26 Walsh, D. (2008, June 3). Bomb at Danish embassy kills six in Pakistan. The Guardian, p. 16.

G27 (2008, June 6). Guardian Weekly: World roundup: Asia/Pacific: Suicide bomb kills six. The Guardian Weekly, p. 2, 47.

G28 Black, I., Norton-Taylor, R. (2008, June 11). International: Counter-terrorism: Experts fear new front with al-Qaida as terror group switches focus from Iraq. The Guardian, p. 23.

G29 Shah, S. (2008, July 7). International: Pakistan: Deadly suicide bombing marks Red Mosque anniversary. The Guardian, p. 20. 
G30 Shah, S. (2008, August 13). Al-Qaida's number three killed after fighting on Pakistan border. The Guardian, p.20.

G31 Shah, D. (2008, August 13). Leading al-Qaida militant killed after days of fighting in Pakistan. The Guardian, p.16.

G32 (2008, August 22). World roundup: Asia/Pacific: Al-Qaida no 3 killed. The Guardian Weekly, p. 2.

G33 Walsh, D. (2009, April 18). International: Fortress Islamabad in frontline of war with Islamic militants. The Guardian, p. 23.

G34 Kettle, M., Whitaker, B. (2000, October 13). Yemen blast: Seventeen feared dead in attack on US destroyer. The Guardian, p. 6.

G35 Borger, J. (2000, October 19). USS Cole: Iraq-Bin Laden boat bomb link: 17 dead mourned as experts piece together attack. The Guardian, p. 4.

G36 Whitaker, B. (2000, November 10). Arab suspects linked to big operation against US. The Guardian, p. 17.

G37 (2005, August 19). Missiles narrowly miss US warship. The Guardian Unlimited.

G38 Whitaker, B. (2005, August 20). Rockets target US warships in Jordan. The Guardian, p. 14.

G39 Whitaker, B. (2005, August 20). Rocket strike targets US in Jordan. The Guardian, p. 2.

G40 (2005, August 26). International news; US warships attacked in Red Sea port. The Guardian Weekly, International news.

G41 (2004, March 12). Spanish bombs: To die in Madrid. The Guardian, p.27.

G42 Tremlett, G. (2004, March 12). Massacre in Madrid: ETA or al-Qaida? 192 killed, and 14,000 injured in train bombings. The Guardian, p. 1.

G43 Tremlett, G., Hooper, J., Walker, J., Bowcott, O., Jones, S. (2004, March 12). “It looked like the platform of death. I've never seen anything like it. "The Guardian, p. 1.

G44 Tremlett, G., Bowcott, O. (2004, March 12). Terror in Madrid: A new - and bloody - style of attack: If ETA is behind the attacks, it would point to a deadly change of tactics. The Guardian, p. 3.

G45 Allison, R. (2004, March 12). Britain: Blair pledges to continue fight against terrorism. The Guardian, p. 4. 
G46 MacAskill, E., Norton-Taylor, R. (2004, March 12). From Bali to Madrid, attackers seek to inflict ever-greater casualties. The Guardian, p. 5.

G47 Chrisafis, A. (2004, March 13). Sick, afraid, defiant, they marched in the millions. The Guardian, p. 1.

G48 Tremlett, G. (2004, March 13). ETA still main suspect despite denials. The Guardian, p.

G49 Tremlett, G., MacAskill, E., Norton-Taylor, R. (2004, March 13). Who’s to blame? The long search for clues to blasts begins: Conflicting evidence keeps both terror groups in frame. The Guardian, p. 3.

G50 Hooper, J. (2004, March 13). Basque country's relief at ETA denial is tinged with skepticism; Some see cynical motive behind statement. The Guardian, p. 4.

G51 Tremlett, G. (2004, March 13). Mourning: Commuter town hit hardest where everyone knew a victim. The Guardian, p. 5.

G52 Tremlett, G. (2004, March 15). Furious voters oust Spanish government: Socialists gain power as Aznar is punished for bloodshed. The Guardian, p. 1.

G53 MacAskill, E., Norton-Taylor, R., Tremlett, G., Black, I. (2004, march 15). Tape find that casts doubt on West's spy network: Intelligence sources say their monitoring gave no reason to suspect an al-Qaida attack in Europe was imminent. The Guardian, p. 3.

G54 Tremlett, G. (2004, March 15). Bombing suspects have police records, says interior minister. The Guardian, p. 3.

G55 Cowan, R., Clark, A., Norton-Taylor, R. (2004, March 15). Top police officer ready to put troops on street; UK security transport police warn that they are short of stagg. The Guardian, p. 4.

G56 Chrisafis, A. (2004, March 15). Angry voters demand to know the trust behind carnage. The Guardian, p. 5.

G57 Tremlett, G. (2004, March 15). US sends special forces into North Africa: AlQaida Pentagon fears growth of terrorist haven. The Guardian, p. 5.

G58 Tremlett, G. (2004, March 15). New PM promises realignment in Europe: Zapatero signals move away from US. The Guardian, p. 5.

G59 Hooper, J. (2004, March 15). Basques vote as shooting raises tension. The Guardian, p. 5. pull troops out of Iraq as row over election result escalates. The Guardian, p. 1. 
G61 Tisdall, S. (2004, March 16). Power balance blown apart: World briefing. The Guardian, p. 4.

G62

G63 Tremlett, G. (2004, March 16). Bombings suspect has terror link. The Guardian, p. 5.

G64 MacAskill, E., Smith, H., Tremlett, G. (2004, March 16). Political fallout likely to embolden al Qaida. The Guardian, p. 5.

G65 Anthony, A. (2004, March 16). Why did we shed more tears for 9/11? The Guardian, p. 5.

G66 Tremlett, G., Bowcott, O, Black, I, Arie, S. (2004, March 1). Spain accused of easing up on terror watch; Madrid aftermath signs emerge of serious intelligence and security failures before bombings. The Guardian, p. 11.

G67 Bowcott, O., Tremlett, G., Arie, S., Norton-Taylor, R. (2004, March 18). Alleged leader of Islamist group linked to Madrid bomb lives in UK. The Guardian, p. 3.

G68 Tremlett, G. (2004, March 18). Kofi Annan calls Aznar author of his own defeat. The Guardian, p. 9.

G69 Tremlett, G. (2004, March 19). Spanish police arrest five more suspects over train bombings: Madrid investigators focus on links with Morocco. The Guardian, p. 18.

G70 Bowcott, O., Tremlett, G. (2004, March 20). In Morocco's gateway to Europe, disbelief greets arrests over Madrid bombings. The Guardian, p. 19.

G71 Tremlett, G. (2004, March 23). Explosives theft linked to Madrid bomb: Intelligence officers gather for anti terror summit. The Guardian, p. 12.

G72 Watt, N., Tremlett, G. (2004, March 25). Zapatero holds firm over Iraqi pullout. The Guardian, p. 17.

G73 Morris, S. (2004, March 26). Terror suspect claims he has been smeared: Moroccan denies claims he was linked with bombings. The Guardian, p. 13.

G74 Tremlett, G. (2004, March 29). ETA tempted to call ceasefire. The Guardian, p. 13.

G75 Tremlett, G. (2004, April 3). Spanish police foil new railway bomb attack. The Guardian, p. 1.

G76 Tremlett, G. (2004, April 5). Cornered, they blew themselves up - but others are still on the run. The Guardian, p. 1. 
G77 Tremlett, G., Norton-Taylor, R. (2004, April 6). Madrid seeks bomb fugitives: Spanish police begin to patrol bus and underground networks while France arrests 13 suspected Islamist militants in Paris suburbs. The Guardian, p. 12.

G78 Tremlett, G. (2004, April 9). Madrid bombers planned more attacks: Video found in flat of dead terrorists gave ultimatum. The Guardian, p. 14.

G79 Tremlett, G., Hooper, J. (2004, June 9). Madrid bomb leader held in Italy. The Guardian, p. 2.

G80 Tremlett, G. (2004, June 14). Vital clues missed by Spanish police: three months on, failings are blamed for letting bombers strike. The Guardian, p. 13.

G81 Tremlett, G. (2004, July 2). Madrid school used by British on bombers' list. The Guardian, p. 15.

G82 Tremlett, G. (2004, November 30). Aznar asserts ties between ETA and Islamists over Madrid terror attack. The Guardian, p. 12.

G83 Tremlett, G. (2004, December 7). ETA bombs keep up pressure on national holiday. The Guardian, p. 14.

G84 Tremlett, G. (2005, December 14). Aznar "wiped files on Madrid bombings": All computer records in PM's office destroyed, says Zapatero. The Guardian, p. 11.

G85 Campbell, D. (2005, March 11). A year on from train bombs, pain is still etched on streets of Madrid. The Guardian, p. 3.

G86 Muir, H., Cowan, R., Borger, J. (2005, July 8). Attack on London; Four bombs in 50 minutes. The Guardian, p. 2.

G87

Burkeman, O. (2005, July 8). From Olympic jubilation to bafflement and horror: First the shock and then a strange, quiet kind of chaos took over London streets. The Guardian, p. 2.

G88 (2005, July 8). Aldgate: Stunned silence, darkness, panic, then calm. The Guardian.

G89

(2005, July 8). Tavistock square: "You could hear screams and small cordite". The Guardian, p. 5.

G90 Jones, S. (2005, July 8). As mark of respect, the shows won't go on. The Guardian, p. 7.

G91 Travis, A. (2005, July 8). Emergency powers help tackle chaos; Services ministers take charge of response teams. The Guardian, p. 8. 
G92 Wintour, P. (2005, July 8). Blair's careful plans end in painful dilemma. The Guardian, p. 9.

G93 Campbell, D., Norton-Taylor, R., Urguart, C. (2005, July 8). The targets: “They say why attack a tiger when there are so many sheep?” The Guardian, p. 10.

G94 Norton-Taylor, R., Campbell, D., Dodd, V. (2005, July 8). Intelligence officials were braced for an offensive - but lowered threat levels. The Guardian, p. 10.

G95 Morris, S. (2005, July 8). Attack on London: Tackling terror 800 arrests, 17 convictions. The Guardian, p. 10.

G96 Elliott, L. (2005, July 8). High street was already struggling and now shoppers will think twice. The Guardian, p.

G97

Dodd, V., Taylor, M., Branigan, T. (2005, July 8). Backlash: Muslims fear hate attacks in the wake of bombings as threats pour into Islamic organizations. The Guardian, p. 13.

G98 Kelso, P. (2005, July 8). London games safe, IOC insists, as bid team's delight turns to sadness. The Guardian, p. 14.

G99 Mackay, D. (2005, July 8). Olympics 2010; Spectre that stalks the games. The Guardian, p. 30.

G100 Warner, E. (2005, July 11). The inside view: Callous? No - the City simply kept its nerve. Business as usual is the right response to bombing. The Guardian, p. 24.

G101 Cowan, R., Campbell, D., Norton-Taylor, R., Tremlett, G. (2005, July 11). Bus bomb clues may hold key to terror attack. The Guardian, p. 1.

G102 Travis, A. (2005, July 11). Clarke wants to track email and phone messages: Data check critics warn of huge task to sift through records. The Guardian, p. 2.

G103 Gillian, A. (2005, July 11). The missing family prepares for the worst after no sign of charity worker. The Guardian, p.

G104 Lavilla, S. (2005, July 11). Distraught families near end of their search. The Guardian, p. 3.

G105 Bates, S. (2005, July 11). In the shadow of terrorism, veterans enjoy tribute to resilience, humour and courage. The Guardian, p. 9.

G106 Gillian, A., Bowcott, O. (2005, July 12). Families feel pain of name delay; First victim is identified but frustration grows among those waiting to hear fate of the missing. The Guardian, p. 1. 
G107 White, M. (2005, July 12). Howard praises "calm and resolute" Blair. The Guardian, p. 2.

G108 Muir, H., Honigsbaum, M. (2005, July 12). Sombre but united capital shows depth of grief and strength of will. The Guardian, p. 3.

G109 Norton-Taylor, R., Campbell, D. (2005, July 12). Terror cell "capable of further attacks". The Guardian, p. 4.

G110 Cowan, R. (2005, July 12). Tapes CCTV seizures raise hopes of quick identification of suspects. The Guardian, p. 4.

G111 Muir, H. (2005, July 12). Back to work: Wary commuters return to routine. The Guardian, p. 5.

G112 Muir, H., Booth, R. (2005, July 12). US bans military staff from travelling to London. The Guardian, p. 5.

G113 Honigsbaum, M. (2005, July 12). The face of the woman in the mask. The Guardian, p. 5.

G114 Campbell, D., Laville, S. (2005, July 13). British suicide bombers carried out London attacks, say police. The Guardian, p. 1.

G115 Norton-Taylor, R. (2005, July 13). Security services face worst scenario. The Guardian, p. 2.

G116 Laville, S., Ward, D., Cobain, I. (2005, July 13). How parents' frantic hunt ended in disbelief. The Guardian, p. 2.

G117 Dodd, V. (2005, July 13). Calls for calm as fear of severe backlash grows. The Guardian, p. 5.

G118 Benjamin, A., Andalo, D. (2005, July 13). Meetings with destiny. The Guardian, p. 8.

G119 Johnson, B., Cross, M. (2005, July 13). Technology to the rescue: After the London bombings, hi-tech help was at hand to coordinate the response. The Guardian, p. 23.

(2005, July 13). The need for calm: Aftermath of terror. The Guardian, p. 25.

G121 Gillian, A. (2005, July 14). The victim cashier at bank had all to live for. The Guardian, p. 1.

G122 White, M., Travis, A., Campbell, D. (2005, July 14). Blair: Uproot this ideology of evil. The Guardian, p. 1. 
G123 Dodd, V. (2005, July 14). Terror hits home in alarmed communities: Dewsbury. The Guardian, p. 2.

G124 (2005, July 14). Deep-rooted problems, Muslim MPs warn: The way ahead. The Guardian, p. 4.

G125 Campbell, D., Norton-Taylor, R., Travis, A. (2005, July 14). Hunt for bombers' support network. The Guardian, p. 5

G126 Muir, H. (2005, July 14). Internet concern: Police scrutinise extremist Islamist websites. The Guardian, p. 5.

G127 Smith L. (2005, July 14). Victims: Coroner warns that some families may have to wait weeks for confirmation. The Guardian, p. 5.

G128 Jones, S. (2005, July 14). Police raid Aylesbury: House is searched in effort to find associates. The Guardian, p. 5.

G129 MacAskill, E. (200, July 14). The suicide bombers it he smartest of smart bombs. The Guardian, p. 6.

G130 Campbell, D., Norton-Taylor, R. (2005, July 16). London bomb net widens: Leeds biochemist questioned in Egypt. The Guardian, p. 1.

G131 Gillan, A., Cobain, I., Muir, H. (2005, July 16). Jamaican-born convert to Islam "coordinated fellow bombers". The Guardian, p. 4.

G132 (2005, July 16). Speculation and hypotheses as investigators search for answers. The Guardian, p. 5.

G133 Barkham, P. (2005, July 16). Journey through Britain's Muslim divide. The Guardian, p. 6.

G134 Harding, L. (2005, July 16). Madrasas mix football with support for jihad. The Guardian, p. 7.

G135 (2005, July 18). The loving boy and murderous terrorist: Personal testimony. The Guardian, p. 4.

G136 Smith, L., Eddison, M., Brown, A., Muntean, A. (2005, July 18). Ordinary lives: Tributes to two young women killed in the bombings. The Guardian, p. 5.

G137 MacAskill, E., Harding, L. (2005, July 18). Ambassador denies Pakistan linked to bombings. The Guardian, p. 5.

G138 Bowcott, O. (2005, July 18). Tourist fears after bus bombing: Uneasy calm as British visitors return to the beaches. The Guardian, p. 6. 
G139 Seager, A., Moore, C., Long, H. (2005, July 19). Amid fears for consumer confidence, it seems Britain can absorb such shocks: Economy expected to hold fast. The Guardian, p. 18.

G140 Tomlinson, H. (2005, July 19). Behind the trendy bars, poorer areas in Leeds fear a backlash. The Guardian, p. 18.

G141 Harding, L., Cowan, R. (2005, July 19). Pakistan militants linked to London attacks: Two bombers travelled together, documents show. The Guardian, p. 1.

G142 Sample, I., Taylor, M., Curtis, P. (2005, July 19). Foreign scientists barred amid terror fears. The Guardian, p. 1.

G143 Norton-Taylor, R. (2005, July 19). Plea bargaining urged to help gain information. The Guardian, p. 4.

G144 Glover, J. (2005, July 19). Two-thirds believe London bombings are linked to Iraq war. The Guardian, p. 5.

G145 (2005, July 20). London bombings: The Iraq connection. The Guardian, p. 23.

G146 Norton-Taylor, R., Dodd, V., Muir, H. (2005, July 20). Ministers warned of Iraq link to UK terror. The Guardian, p. 8.

G147 Dodd, V., White, M. (2005, July 20). Muslims agree network to fight extremists. The Guardian, p. 9.

G148 Cobain, I., Cowan, R., Norton-Taylor, R. (2005, July 23). Faces of the suspects: Police chase ends with man shot dead on tube. The Guardian, p. 1.

G149 Dodd, V. (2005, July 23). Seconds to decide if suspect is suicide threat: Shoot to kill. The Guardian, p. 2.

G150 Barkham, P. (2005, July 23). "The main thing we feel is fear, 24/7": Muslim communities. The Guardian, p. 4.

G151 Lawson, M. (2005, July 23). On the tube the dread felt deeper...there was the grim feeling of a pattern taking shape. The Guardian, p. 5.

G152 MacAskill, E., O’Riordan, B., Harding, L. (2005, July 23). Italy and Australia move to toughen terror laws. The Guardian, p. 6.

G153 Burkeman, O., Bellos, A., Philips, T., Chrisadis, A., Branigan, T. (2005, July 25). Short walk and the no. 2 bus - a very ordinary journey to death. The Guardian, p. 1.

G154 Cowan, R., Dodd, V., Norton-Taylor, R. (2005, July 25). Met chief warns more could be shot. The Guardian, p. 1. 
G155 Cowan, R. (2005, July 25). Inquiries must establish why innocent man was targeted. The Guardian, p. 4.

G156 Carter, H. (2005, July 25). Inquiry: Bombers could have been on same rafting trip. The Guardian, p. 6.

G157 Carter, H. (2005, July 25). Police fear fifth bomber at large. The Guardian, p. 6.

G158 Campbell, D., Cowan, R., Cobain, I., Gillan, A. (2005, July 26). Police name bomb suspects: Man's father held for interview. The Guardian.

G159 Honigsbaum, M., Dodd, V. (2005, July 26). Brazilian was shot eight times, inquest told. The Guardian, p. 4.

G160 Cowan, R. (2005, July 26). How bomb suspects got away. The Guardian, p. 5.

G161 Cowan, R., Cobain, I., Gillan, A., Kirkham, S. (2005, July 27). They are capable of killing again - we must find them. The Guardian, p. 1.

G162 Travis, A. (2005, July 27). Police likely to be able to hold suspects longer. The Guardian, p. 4.

G163 White, M. (2005, July 27) Public mood has hardened over terror cases, Blair tells judges. The Guardian, p. 4.

G164 Cowan, R., Campbell, D. (2005, July 27). On the run - but where did they run to?: Suspects could stay hidden in capital despite huge manhunt. The Guardian, p. 5.

G165 Campbell, D., Cowan, R., Morris, S., Ward, D. (2005, July 28). Net closes on bomb suspects. The Guardian, p. 1.

G166 Travis, A., Gillan, A. (2005, July 28). Bomb suspect "became a militant" in prison. The Guardian, p. 4.

G167 Morris, S., Ward, D. (2005, July 28). Big bangs and a flash as streets wake up to arrests. The Guardian, p. 5.

G168 Campbell, D., Norton-Taylor, R. (2005, July 28). 14-day clock is ticking as interrogation gets under way. The Guardian, p. 5.

G169 (2005, July 28). Fearful Europe steps up security. The Guardian, p. 7.

G170 Laville, S., Kirkham, S. (2005, July 29). Day of high alert for wary commuters as 6,000 police seek to deter and reassure. The Guardian, p. 10.

G171 Campbell, D., Cowan, R. (2005, July 29). The Guardian profile: Peter Clarke. The Guardian, p. 13. 
G172 Cobain, I., Cowan, R., Norton-Taylor, R. (2005, July 30). Suspects caught: Entire alleged bomb ring held after raids in London and Rome. The Guardian, p. 1.

G173 Hooper, J., Laville, S. (2005, July 30). Fourth suspect tracked across Europe. The Guardian, p. 4.

G174 Dodd, V., Kirkham, S., Taylor, M., Campbell, D., Dowling, T., Norton-Taylor, R. (2005, July 30). Guns, gas, then three suspects are taken. The Guardian, p. 4.

G175 Laville, S. (2005, July 30). CCTV to aid fatal shooting inquiry. The Guardian, p. 6.

G176 Kirkham, S. (2005, July 30). Bomb fears hit hotels, shops, and restaurants. The Guardian, p. 7.

G177 Campbell, D., Hooper, J. (2005, August 1). Second bomb suspect was seen in Rome. The Guardian, p. 1.

G178 Hooper, J., Campbell, D., Gillan, A. (2005, August 2). Yard fears wrangle over suspect. The Guardian, p. 1.

G179 Norton-Taylor, R., Campbell, D. (2005, August 2). The inquiry so far: Is there a mastermind, and are the two bomb groups linked? The Guardian, p. 5.

G180 Ward, D. (2005, August 3). Muslims tell Blair of price they're paying, their anger - and fears. The Guardian, p. 9.

G181 Laville, S. (2005, August 4). Victim of terror crackdown blames bombers for robbing him of freedom. The Guardian, p. 7.

G182 Whitaker, B., Campbell, D., Cowan, R. (2005, August 5). A chilling message to Britons: Al-Qaida blames Blair and threatens more attacks. The Guardian, p. 1.

G183 Campbell, D., Cowan, R. (2005, August 5). Met denies rift as US leaks details of bombs. The Guardian, p. 5.

G184 Muir, H. (2005, August 5). Numbers using tube down by up to $30 \%$. The Guardian, p. 5.

G185 Wintour, P. (2005, August 6). Blair vows to root out extremism: Lawyers and Muslim groups alarmed. The Guardian, p. 1.

G186 Norton-Taylor, R., Laville, S. (2005, August 6). Terror measures: Who will be deported and who decides? The Guardian, p. 4.

G187 Vulliamy, E. (2005, August 6). He has made us the problem. The Guardian, p. 5.

G188 Cowan, R., Hooper, J. (2005, August 6). Bank accounts of suspects frozen. The Guardian, p. 6. 
G189 Cowan, R. (2005, August 9). Big security ring for bomb hearing. The Guardian, p. 1.

G190 Laville, S., Levinson, C. (2005, August 10). Freed biochemist says he knew suicide bombers. The Guardian, p. 1.

G191 Travis, A., Norton-Taylor, R. (2005, August 16). Clarke threatens to expel more "preachers of hate". The Guardian, p. 2.

G192 Cowan, R., Campbell, D., Dodd, V. (2005, August 17). The death of Jean Charles de Menezes: He made no attempt to run away. The Guardian, p. 1.

G193 Campbell, D., Cowan, R., Dodd, V., Honigsbaum, M. (2005, August 17). Key questions over de Menezes shooting. The Guardian, p. 6.

G194 Cowan, R., Dodd, V., Norton-Taylor, R. (2005, August 18). Met chief tried to stop shooting inquiry. The Guardian, p. 1.

G195 Dodd, V., Cowan, R. (2005, August 19). Police chief faces new claims: Doubts surfaced before statement. The Guardian, p. 1.

G196 Cowan, R., Dodd, V. (2005, August 19). Met police back chief but admit Menezes issue will not go away. The Guardian, p. 8.

G197 Dodd, V. (2005, August 20). Police rethink shoot-to-kill policy. The Guardian, p. 1.

G198 Honigsbaum, M. (2005, August 20). After the bombings: Allies at odds over tube death blunder. The Guardian, p. 10.

G199 Cowan, R. (2005, August 22). No. 10 backs Met chief over killing. The Guardian, p. 1.

G200 Cowan, R., Phillips, T. (2005, August 23). Brazilian officials in UK for answers on killing. The Guardian, p. 8.

G201 Dodd, V., Cowan, R. (2005, August 24). Suicide bombs breakthrough gives police vital clues. The Guardian, p. 1.

G202 MacAskill, E., Glover, J., Dodd, V. (2005, August 25). Expulsions illegal, UN tells Clarke. The Guardian, p. 1.

G203 Cowan, R., Gillan, A. (2005, August 25). Met chief faces enemy within: Blair under pressure from disgruntled officers at Yard. The Guardian, p. 6.

G204 Dodd, V., Muir, H. (2005, August 26). De Menzes "shot for 30 seconds". The Guardian, p. 2. 
G205 Dodd, V., Norton-Taylor, R. (2005, September 2). Video of 7/7 ringleader blames foreign policy. The Guardian, p. 1.

G206 Jones, S., Norton-Taylor, R., Dodd, V. (2005, September 2). A1-Qaida link to 7/7 plot under scrutiny fuels fear, but is it genuine? The Guardian, p. 11.

G207 Laville, S. (2005, September 3). Friends claim Khan's statement was faked; Old and young refuse to accept youth worker's role in attack. The Guardian, p. 10.

G208 Laville, S. (2005, September 7). Explosives traces “found in suspect's luggage”. The Guardian, p. 7.

G209 Laville, S., Dodd, V. (2005, September 10). UK to sign extradition deal with Pakistan: Pact could pave way for arrest of suspects linked to July 7 bombs. The Guardian, p. 2.

G210 Travis, A. (2005, September 14). Relatives of dead Brazilian spurn Met chief's offer of talks. The Guardian, p. 4.

G211 Cowan, R. (2005, September 21). CCTV captures July 7 terrorists staging dry run before attacks. The Guardian, p. 9.

G212 Cowan, R. (2005, September 29). "The threat is real. London is an iconic site for another attack". The Guardian, p. 6.

G213 Laville, S. (2005, November 1). Angry families threaten to boycott remembrance service at St Paul's. The Guardian, p. 11.

G214 Lawson, M. (2005, November 2). July 7 memorial service: Many shades of mourning. The Guardian, p. 6.

G215 Travis, A. (2005, November 11). Terror laws: Muslim taskforce produces ambitious action plan to tackle extremism. The Guardian, p. 9.

G216 Kettle, M. (2005, November 16). Met chief tells politicians: You are putting us in an impossible position. The Guardian, p. 1.

G217 Dodd, V. (2005, December 24). Surge in stop and search of Asian people after July 7. The Guardian, p. 7.

G218 Katz, I., Dodd, V. (2006, January 30). Met chief admits mishandling shooting. The Guardian, p. 1.

G219 Travis, A., Wintour, P. (2006, February 16). Extremist Muslim groups to be banned. The Guardian, p. 1.

G220 Dodd, V., Cowan, R. (2006, March 17). Met chief to be quizzed under caution. The Guardian, p. 1. 
G221 Cowan, R. (2006, March 23). Terror trial: British suspects considered blowing up London club, court told. The Guardian, p. 3.

G222 Norton-Taylor, R., Burkeman, O. (2006, April 17). US-style terror alerts for UK. The Guardian, p. 1.

G223 Dodd, V. (2006, April 18). Shooting inquiry witness on a collision course. The Guardian, p. 4.

G224 Whitaker, B. (2006, April 24). New bin Laden tape issues threat to civilians. The Guardian, p. 1.

G225 (2006, May 12). July 7 bombings: Face up to the failures. The Guardian, p. 34.

G226 Travis, A., Cowan, R. (2006, May 12). Bombs in the bath: How gang plotted attacks. The Guardian, p. 2.

G227 Cobain, I., Norton-Taylor, R., Cowan, R. (2006, May 12). Bomber slipped through net of watching M15. The Guardian, p. 4.

G228 Norton-Taylor, R., Cowan, R. (2006, May 12). July 7 reports: Extremist: Britishborn terror shocked police. The Guardian, p. 5.

G229 Cobain, I., Norton-Taylor, R., Woodward, W. (2006, May 13). Intelligence bungles in build-up to 77 attacks. The Guardian, p. 7.

G230 (2006, June 6). Fighting terror: Intelligence needed. The Guardian, p. 34.

G231 Dodd, V., Laville, S., Norton-Taylor, R. (2006, June 6). Intelligence behind raid was wrong, officials say. The Guardian, p. 1.

G232 Muir, H. (2006, June 6). Pictures of chaos after blasts triggers calls for public inquiry. The Guardian, p. 6.

G233 Norton-Taylor, R. (2006, June 20). An intelligence failure. An explosive exclusive. But was it the wrong Khan? The Guardian, p. 3.

G234 Woodward, W. (2006, June 27). Police have no right to rush into action on dubious intelligence, say most Muslims in poll. The Guardian, p. 4.

G235 Laville, S. (2006, July 1). I keep asking myself, when does it become normal? Is this normal now? The Guardian, p. 12.

G236 Laville, S., Dodd, V. (2006, July 7). One year on, a London bomber issues a threat from the dead. The Guardian, p. 1.

G237 Laville, S., Dodd, V. (2006, July 7). From cricket and cars to plots and bombs. The Guardian, p. 6. 
G238 Addley, E., Mackay, D. (2006, July 7). Relatives and survivors: Families say video will not overshadow their day as Jowell reveals Olympic memorial plan. The Guardian, p. 7.

DTT1 Orr, D. (1998, August 8). US embassy bombers kill 80. The Times, Overseas news.

DTT2 (1998, August 8). Target America. The Times, Features.

DTT3 Ungoed-Thomas, J., Orr, D. (1998, August 9). Terror blast blamed on suicide bomb. The Sunday Times, Overseas news.

DTT4 Ungoed-Thomas, J., Orr, D. (1998, August 9). Africa’s Bloody Friday that rocked the world. The Sunday Times, Overseas news.

DTT5 Gilmore, I. (1998, August 10). Embassies tackle aftermath of attacks. The Times, Overseas news.

DTT6 Gamini, G., Orr, D., Evans, M. (1998, August 13). FBI investigates Iran envoy connection. The Times, Overseas news.

DTT7 Colvin, M. (1998, August 16). Holy warrior with US in his sights. The Sunday Times, Overseas news.

DTT8 Ungoed-Thomas, J., Gilmore, I. (1998, August 16). Countdown to bombings. The Sunday Times, Overseas news.

DTT9 Hussain, Z., Thomas, C. (1998, August 18). US pulls its embassy staff out of Pakistan in security alert. The Times, Overseas news.

DTT10 Evans, M. (1998, August 22). Tomahawks pack deadly firepower. The Times, Overseas news.

DTT11 (1998, August 23). Balance of terror. The Sunday Times, Features.

DTT12 Colvin, M., Grey, S., Campbell, M., Allen-Mills, T. (1998, August 23). Clinton gambles all on revenge. The Sunday Times, Overseas news.

DTT13 Johnson, R.W. (1998, August 27). Cape Muslims recruited to fundamentalist ranks by drugs war. The Times, Overseas news.

DTT14 Gilmore, I., Brodie, I. (1998, August 27). South African bomb suspect caught on video. The Times, Overseas news.

DTT15 Grey, S., Campbell, M. (1998, August 30). Did America hit mosques? The Sunday Times, Overseas news.

DTT16 Bawdon, F. (1998, October 20). The lawyer the media turned into a terrorist. The Times, Features. 
DTT17 Walker, T. (1998, November 26). US alarmed as mujahidin join Kosovo rebels. The Times, Overseas news.

DTT18 Leppard, D., Hastings, C., Berry, J., Colvin, M., Goni, U. (1999, February 7). The global terrorist. The Sunday Times, Features.

DTT19 Colvin, M. (1999, February 14). Bin Laden flees Afghan hideout. The Sunday Times, Overseas news.

DTT20 Wilkinson, I. (2008, June 3). Eight die in Danish embassy bombing. The Daily Telegraph, p. 18.

DTT21 Hussain, Z. (2008, June 3). Six die in last at Danish embassy. The Times, p. 29.

DTT22 Maddox, B. (2008, June 3). Emboldened militants' head-on attack on the west. The Times, p. 30.

DTT23 Brodie, I., Theodoulou, M., Cobain, I. (2000, October 13). Suicide bombers gave salute as they died. The Times, Overseas news.

DTT24 (2000, October 16). Shock waves. The Times, Features.

DTT25 Brodie, I. (2000, October 23). US crew waved as suicide bomb boat drew near. The Times, Overseas news.

DTT26 Beeston, R. (2001, June 22). Bin Laden video brags of attack on US ship. The Times, Overseas news.

DTT27 Sabbagh-Gargour, R. (2005, August 20). One dead in al-Qaeda rocket attack on ships. The Times, p. 38.

DTT28 Butcher, T. (2005, August 20). Missile shot across the bow of US ship in Jordanian Red Sea port. The Daily Telegraph.

DTT29 Litterick, D. (2005, August 20). Rockets and protests push up oil prices. The Daily Telegraph.

DTT30 Walker, T. (2005, August 21). Jordan hunts ship attackers. The Sunday Times, p. 22.

DTT31 Beeston, R. (2005, September 16). Al-Zarqawi's dark forces riding high on a tide of blood. The Times, p. 37.

DTT32 Sabbagh-Gargour, R., Beeston, R. (2005, November 10). A1-Qaeda exports its terror to an oasis of peace in region of blood. The Times, p. 37.

DTT33 Colvin, M., Mahnaimi, U. (2005, November 13). Jordanian soldiers seduced by al-Qaeda "aided" suicide attacks. The Sunday Times, p. 22. 
DTT34 Wilkinson, I. (2004, March 12). 192 die as bombs hit commuter trains in Madrid. The Daily Telegraph, p. 01.

DTT35 Broughton, P.D. (2004, March 12). I shook like a cigarette paper. The sky seemed to be crashing in on our heads. The Daily Telegraph, p. 2.

DTT36 Blair, D., Wilkinson, I. (2004, March 12). Van with detonators points to an Islamic link. The Daily Telegraph, p. 4.

DTT37 Wilkinson, I. (2004, March 12). Nation plunged back into darkest days. The Daily Telegraph, p. 4.

DTT38 La Guardia, A. (2004, March 12). Terrorists learn the lessons of al-Qa'eda. The Daily Telegraph, p. 5.

DTT39 Bishop, P. (2004, March 12). The bomber will always get through, be he ETA or al-Qae'da. The Daily Telegraph, p. 26.

DTT40 Tendler, S., Webster, B., Evans, M. (2004, March 12). Security officials ask: Could it happen in Britain? The Times, p. 7.

DTT41 Maddox, B. (2004, March 12). The new terrorism comes to Europe. The Times, p. 8.

DTT42 Sharrock, D. (2004, March 12). Madrid's horror as ten bombs explode on rushhour trains. The Times, p. 2.

DTT43 Owen, E., McGrory, D. (2004, March 12). Twisted steel, broken bodies: Spain reels at butchery on brutal scale. The Times, p. 3.

DTT44 Woodworth, P. (2004, March 12). Was it ETA or a strike by al-Qaeda? The Times, p. 4.

DTT45 Sage, A. (2004, March 12). Basques gather in horror to denounce an outrage too far. The Times, p. 4.

DTT46 Owen, E., McGrory, D. (2004, March 12). Tide of grief and revulsion sweeps nation. The Times, p. 5.

DTT47 Wilkinson, I., La Guardia, A. (2004, March 13). Millions rally in anger at Madrid bombers. The Daily Telegraph, p. 1.

DTT48 Connolly, K. (2004, March 13). Brutality of a modern Guernica shocks and angers the Basques. The Daily Telegraph, p. 04.

DTT49 Wilkinson, I., Broughton, P.D., Connolly, K. (2004, March 13). A nation marches to defy terrorists. The Daily Telegraph, p. 04. 
DTT50 Wilkinson, I. (2004, March 13). History points finger at revenge for lose Moor kingdom. The Daily Telegraph, p. 06.

DTT51 Brogan, B. (2004, March 13). Busy Blair sends Prescott to bombing rally. The Daily Telegraph, p. 06.

DTT52 (2004, March 13). Spaniards proudly defiant in the face of terror. The Daily Telegraph, p. 25.

DTT53 McGrory, D., Owen, E. (2004, March 13). Death line open again, but there are so many empty seats. The Times, p. 16.

DTT54 McGrory, D., Owen, E. (2004, March 13). Silenced by grief, Spain's anger grows. The Times, p. 17

DTT55 Woodworth, P. (2004, March 13). The new axis of evil? The Times, p. 18.

DTT56 Sage, A. (2004, March 13). 15 minutes of silence and despair in Basque capital. The Times, p. 18.

DTT57 Sharrock, D. (2004, March 13). How terrorists can influence poll outcome. The Times, p. 19.

DTT58 MacIntyre, B. (2004, March 13). Was Madrid a barbarous revenge for the lost paradise of al Andalus? The Times, p. 30.

DTT59 Campbell, M., Toomey, C. (2004, March 14). Muslims held over Madrid massacre. The Times, p. 1.

DTT60 Campbell, M., Toomey, C., Hawkey, I. (2004 March 14). Death at dawn. The Times, p. 15.

DTT61 Ungoed-Thomas, J., Fielding, N. (2004, March 14). Spain in grip of bloody whodunit. The Times, p. 18.

DTT62 (2004, March 14). A message for us all. The Times, p. 20.

DTT63 Portillo, M. (2004, March 14). Every country must learn the lesson of this new Guernica. The Times, p. 21.

DTT64 McCartney, J. (2004, March 14). Even if it was ETA, this was an al-Qaeda victory: Global terror spells doom for nationalist groups. The Daily Telegraph, $\mathrm{p}$. 24.

DTT65 McElroy, D. (2004, March 14). Al-Qaeda: We were behind the massacre in Madrid: Five suspects detained after police find vital clues in unexploded backpack bomb. The Daily Telegraph, p. 01. 
DTT66 McElroy, D., Harrison, D. (2004, March 14). Private grief, public outrage: The victims of last week's atrocity are now being buried. But who did it, and why? The Daily Telegraph, p. 20.

DTT67 Coughlin, C. (2004, March 14). Basques or Muslims? Aznar really hoped that ETA were the ones to blame. The Daily Telegraph, p. 20.

DTT68 Wilkinson, I. (2004, March 15). Election blow to Bush's war on terror: Socialists win in Spain and promise to pull out of Iraq. The Daily Telegraph, p. 01.

DTT69 Connolly, K. (2004, March 15). Shooting hardens feelings among ETA's supporters the Basques. The Daily Telegraph, p. 04.

DTT70 Blair, D. (2004, March 15). Were the attacks a plot to hijack democracy? The Daily Telegraph, p. 05.

DTT71 Russell, A. (2004, March 15). Don't flinch in fight on terror, warns White House America. The Daily Telegraph, p. 05.

DTT72 Sharrock, D. (2004, March 15). Bombers turn Spanish poll upside down. The Times, p. 1

DTT73 Ford, R., Pierce, A. (2004, March 15). Europe in silent salute to Madrid victims. The Times, p. 1.

DTT74 Maddox, B. (2004, March 15). Has the War on Terror made us all targets? The Times, p. 4.

DTT75 Evans, M. (2004, March 15). Intelligence chiefs had no hint of al-Qaeda bomb plot. The Times, p. 4.

DTT76 Owen, E., McGrory, D. (2004, March 15). Socialists' victory celebrations are muted by grief. The Times, p. 5.

DTT77 Wilkinson, I., La Guardia, A. (2004, March 16). Spain quits the war alliance: New PM attacks Bush and Blair over Iraq "lies". The Daily Telegraph, p. 01.

DTT78 Sharrock, D., Webster, P., Watson, R. (2004, March 16). Fight to stop collapse of Iraq coalition. The Times, p. 1.

DTT79 Maddox, B. (2004, March 16). Polls give terrorists plenty of new targets. The Times, p. 14.

DTT80 McGrory, D. (2004, March 16). Police examine why suspect went missing. The Times, p. 17.

DTT81 Owen, E., McGrory, D. (2004, March 16). Bereaved seek previous keepsakes. The Times, p. 17. 
DTT82 Jones, G. (2004, March 17). Pubs, buses and trains are targets for bombers: Attack “inevitable," says Met chief. The Daily Telegraph, p. 01.

DTT83 Wilkinson, I. (2004, March 17). Police hunt gang of five Moroccans for Madrid bombings. The Daily Telegraph, p. 04.

DTT84 Evans, M., McGrory, D., Sharrock, D. (2004, March 17). Buses, clubs and pubs put on backpack bomb alert. The Daily Telegraph, p. 1.

DTT85 McGrory, D., Owen, E. (2004, March 17). The phone wizard no one suspected. The Times, p. 4.

DTT86 Evans, M., Webster, B. (2004, March 17). Race to protect Achilles' heel of London. The Times, p. 5.

DTT87 Rennie, D. (2004, March 19). Appeasement will not halt terror, Bush tells Spain. The Daily Telegraph, p. 16.

DTT88 Reid, T. (2004, March 19). Spain and America in bitter exchange. The Times, p. 19.

DTT89 LaGuardia, A., Helm, T. (2004, March 20). "We should have hit al-Qa'eda sooner": Jack Straw believes it was a mistake to let bin Laden wage his campaign of terror unchecked for so long. The Daily Telegraph, p. 11.

DTT90 Rennie, D. (2004, March 20). Bush strives to stiffen wavering allies. The Daily Telegraph, p. 14.

DTT91 Sharrock, D. (2004, March 20). Empty streets in a nation ripped asunder. The Times, p. 20.

DTT92 Koenig, P. (2004, March 21). Madrid bombs fail to derail markets. The Daily Telegraph, p. 7.

DTT93 Campbell, M., Jaber, H. (2004, March 21). Hunting down the Madrid bombers. The Daily Telegraph, p. 14.

DTT94 Portillo, M. (2004, March 21). The terrorists' other outrage was to make Spain shrink. The Times, p. 19.

DTT95 McElroy, D. (2004, March 21). Wealthy Moroccan identified as Madrid bombings mastermind: Terrorist leader comes from merchant family. The Daily Telegraph, p. 28.

DTT96 Webster, P., Sharrock, D. (2004, March 24). Blair to mend fences with Spain's new leader. The Times, p. 12. 
DTT97 Campbell, M. (2004, March 28). Accidental premier sets out to heal Spain. The Times, p. 23.

DTT98 Payne, S. (2004, April 1). Well-educated extremists target disaffected youth. The Daily Telegraph, p. 03.

DTT99 La Guardia, A., Wilkinson, I. (2004, April 3). Plot to blow up Madrid express foiled bomb on the track. The Daily Telegraph, p. 01.

DTT100 Wilkinson, I., La Guardia, A. (2004, April 5). Madrid bomb mastermind blows himself up as police raid hideout. The Daily Telegraph, p. 01.

DTT101 Wilkinson, I., La Guardia, A. (2004, April 5). Allah is great and we are doing to die killing, shouted one of the terrorists. The Daily Telegraph, p. 04.

DTT102 Owen, E. (2004, April 5). Return to terror suspects' flat of death. The Times, p. 13.

DTT103 Campbell, M. (2004, April 11). Suffering of Spain's terror survivors The Times, p. 25.

DTT104 Blair, D. (2004, April 16). Bin Laden's truce offer rejected as “absurd.” The Daily Telegraph, p. 01.

DTT105 Wilkinson, I. (2004, April 17). Fearsome dilemma of Spain's Muslims: The country's south provides a sinister inspiration to Osama bin Laden and his followers. The Daily Telegraph, p. 13.

DTT106 Sharrock, D., Farrell, S. (2004, April 19). Coalition splinters as Spain starts pullout. The Times, p. 1..

DTT107 Sharrock, S. (2004, April 20). Spanish troops begin Iraq pull-out. The Times, p 12.

DTT108 Sharrock, D. (2004, April 24). Madrid victims log on to find their saviours. The Times, p. 20.

DTT109 Campbell, M. (2004, May 16). Chilling last hours of Madrid bombers. The Times, p. 28.

DTT110 Sharrock, D. (2004, June 2). Letters suggest ETA link with Islamic terror. The Times, p. 16.

DTT111 Hussain, Z., McGrory, D. (2004, August 12). Bin Laden's hit squads preparing wave of attacks on politicians. The Times, p. 1.

DTT112 Sharrock, D. (2004, October 6). Spain seeks answers in its Arab past. The Times, p. 39. 
DTT113 Sharrock, D. (2004, December 14). Aznar accused of destroying Madrid bomb evidence and deceiving public. The Times, p. 25.

DTT114 Owen, E., McGrory, D. (2005, March 5). Madrid mastermind may plan UK attack. The Times, p. 46.

DTT115 Owen, E., McGrory, D. (2005, March 5). One year on and the spectre of terror still haunts Europe. The Times, p. 47.

DTT116 O’Neill, S., McGrory, D. (2005, March 11) Free, the man accused of inspiring Madrid bomb. The Times, p. 7.

DTT117 Fenton, B., Pook, S. Gardham, D., Rozenberg, J., Davies, H., Murray-West, R. ... Devlin, K. (2005, July 8). The Daily Telegraph, p. 02.

DTT118 Hall, C. (2005, July 8). Hospital: Hundreds taken for treatment by ambulance and double-deckers. The Daily Telegraph, p. 010.

DTT119 Samuel, H., Russell, A. (2005, July 8). World view: We're all Londoners now. The Daily Telegraph, p. 013.

DTT120 Jones, G. (2005, July 8). Politics: Britain will not be cowed by terrorists. The Daily Telegraph, p. 15.

DTT121 Bishop, P. (2005, July 8). Remember that normality is the only civilized response to terror. The Daily Telegraph, p. 21.

DTT122 Utley, T. (2005, July 8). We must accept that the terrorist threat is here to stay. The Daily Telegraph, p. 22.

DTT123 Bose, M. (2005, July 8). Olympic team “devastated” by terror attack. The Daily Telegraph, p. 01.

DTT124 Johnston, P. (2005, July 8). Terror groups: Al-Qa'eda link hides multitude of suspects. The Daily Telegraph, p. 25.

DTT125 Baldwin, T. (2005, July 8). Britain "Defiant" as bombers kill 52 in attack on the heart of London. The Times, p. 2.

DTT126 O’Neill, S., McGrory, D. (2005, July 8). Was it work of al-Qaeda sleeper cell or home-grown terrorists? The Times, p. 10.

DTT127 Evans, M. (2005, July 8). Terror alert downgraded, then attacks came out of the blue. The Times, p. 11.

DTT128 Waller, M., Merrell, C., Butler, S. (2005, July 8). Amid chaos and confusion, the city keeps on working. The Times, p. 52. 
DTT129 O’Neill, S., McGrory, D., Baldwin, T., Tendler, S. (2005, July 9). Police give warning that bombers may strike again. The Times, p. 2.

DTT130 Hamilton, A. (2005, July 9). Terrorists will not change our way of life, says Queen. The Times, p. 7.

DTT131 Wilkinson, P. (2005, July 9). We can beat the al-Qaeda hydra. The Times, p. 27.

DTT132 Toolis, K. (2005, July 9). The grim signs that say suicide bomb. The Times, p. 12.

DTT133 (2005, July 9). I'm proud of Londoners who came through this nightmare. No one can break the will of this city. The Times, p. 20.

DTT134 Taher, A., Gadher, D. (2005, July 10). Radical cleric warned of a "big operation." The Times, p. 4.

DTT135 Winnett Whitehall, R. (2005, July 10). Bombers may be British born. The Times, p. 4.

DTT136 Cracknell, D., Leppard, D. (2005, July 10). Clarke moves to tighten security controls. The Times, p. 5.

DTT137 Fielding, N., Walsh, G. (2005, July 10). Mastermind of Madrid is key figure. The Times, p. 5.

DTT138 Leppard, D., Winnett Whitehall, R. (2005, July 10). Bombing death toll could reach 70 . The Times, p. 1.

DTT139 Winnett Whitehall, R., Leppard, D. (2005, July 10). Leaked no. 10 dossier reveals al-Qaeda's British recruits. The Times, p. 1.

DTT140 Downey, G. (2005, July 10). Tories hope London bombs will put pressure on IRA. The Times, p. 5.

DTT141 (2005, July 10). Attack is the best defense against terror. The Daily Telegraph, p. 22.

DTT142 D'Ancona, M. (2005, July 10). Blair proves equal to the long-dreaded day. The Daily Telegraph, p. 23.

DTT143 Henness, P., Harrison, D., Foggo, D. (2005, July 10). Foreign terrorist cell was behind London bombings. The Daily Telegraph, p. 1.

DTT144 Harnden, T. (2005, July 10). Londoners are made of particularly tough stuff. The Daily Telegraph, p. 19.

DTT145 Rashid, A. (2005, July 11). New terror groups pay homage to bin Laden but work alone. The Daily Telegraph, p. 4. 
DTT146 Steele, J. (2005, July 11). Detectives trawl CCTV in hunt for killers. The Daily Telegraph, p. 4.

DTT147 Evans, M., O’Neill, S., McGrory, D., Tendler, S. (2005, July 11). Terror alert highest ever as police fear new attack. The Times, p. 1.

DTT148 Ford, R., Bennett, R. (2005, July 11). Emergency summit to discuss gaps in phone intelligence. The Times, p. 12.

DTT149 Jones, G., Steele, J., Davies, C. (2005, July 12). Crackdown on Muslim clerics who preach hate. The Daily Telegraph, p. 1.

DTT150 Rozenberg, J. (2005, July 12). Why identification is taking so long. The Daily Telegraph, p. 4.

DTT151 Steele, J. (2005, July 13). Rucksack gang filmed at King's Cross "looked like the infantry going to war." The Daily Telegraph, p. 4.

DTT152 Midgley, C. (2005, July 13). A suburb wakes up to the horror of having bombers in its midst. The Times, p. 2.

DTT153 Norfolk, A., Jenkins, R. (2005, July 13). A laughing lad from the chippie and his wild mates. The Times, p. 4.

DTT154 Jones, G., Britten, N., Stokes, P. (2005, July 14). Blair vows to expel foreign extremists. The Daily Telegraph, p. 1.

DTT155 Britten, N., Stokes, P. (2005, July 14). Police extend search of houses and community projects. The Daily Telegraph, p. 2.

DTT156 Midgley, C. (2005, July 14). Grief of bomber's family honoured by the Queen. The Times, p. 4.

DTT157 Petre, J., Britten, N., Stokes, P. (2005, July 15). Where terrorists hatched their plot. The Daily Telegraph, p. 5.

DTT158 Foster, P. (2005, July 15). West is to blame for bombers, says mullahs. The Daily Telegraph, p. 6.

DTT159 Webster, P., Ford, R. (2005, July 15). Law to ban religious extremists will be tightened. The Times, p. 4.

DTT160 Fresco, A., O’Neill, S., Tendler, S. (2005, July 15). Jamaican-born bomber from the suburbs of middle England. The Times, p. 6.

DTT161 La Guardia, A., Giannangeli, M., Stokes, P., Miles, H. (2005, July 16). The pious and clever young chemistry student who left Cairo's slums behind. The Daily Telegraph, p. 4. 
DTT162 Foster, P. (2005, July 16). We do not teach any terrorism in this place. The Daily Telegraph, p. 6.

DTT163 O’Neill, S., Ford, R. (2005, July 16). London terror suspect arrested. The Times, p. 1 .

DTT164 McGrory, D., Hussein, Z., El-Amrani, I. (2005, July 16). Egyptian chemist and head of Pakistani religious school held. The Times, p. 4.

DTT165 O’Neill, S., Ford, R. (2005, July 16). Cleric who defended suicide bombers allowed into Britain. The Times, p. 6.

DTT166 McGrory, D., Hussein, Z., El-Amrani, I. (2005, July 16). Extent of terrorism networks suggests intelligence failure. The Times, p. 4.

DTT167 Leppard, D. (2005, July 17). M15 judged bomber "no threat". The Times, p. 1.

DTT168 Fielding, N., Gadher, D. (2005, July 17). London-based radical salutes bombs "victory". The Times, p. 2.

DTT169 Leppard, D., Calvert, J. (2005, July 17). The web of terror. The Times, p. 11.

DTT170 Lamb, C. (2005, July 17). The Pakistan connection. The Times, p. 14.

DTT171 Rayment, S., Harrison, D. (2005, July 17). M15: We did not receive a warning. The Daily Telegraph, p. 17.

DTT172 Rayment, S. (2005, July 17). M15 denies lapses and defends record of foiling plots. The Daily Telegraph, p. 17.

DTT173 Steele, J. (2005, July 18). Police seek killers' mobiles in wreckage. The Daily Telegraph, p. 4.

DTT174 Charter, D. (2005, July 18). M15 "was looking for the wrong kind of terrorists". The Times, p. 8.

DTT175 Foster, P., Malick, N. (2005, July 19). Suicide bombers flew to Pakistan together. The Daily Telegraph, p. 4.

DTT176 McGrory, D., Hussain, Z. (2005, July 19). Bombers "met chief plotter” in Karachi. The Times, p. 8.

DTT177 Baldwin, T., Webster, P. (2005, July 19). Blair appeals for Muslim backing as parties agree to fast-track terror laws. The Times, p. 8.

DTT178 Jones, G. (2005, July 20). Muslim leaders promise to tackle radicals. The Daily Telegraph, p. 4. 
DTT179 Johnston, P. (2005, July 21). Imams who praise terrorism to face deportation. The Daily Telegraph, p. 1.

DTT180 Fenton, B., Steele, J. (2005, July 22). London hit again: Four bombers on the run as copycat suicide attack fails. The Daily Telegraph, p. 1.

DTT181 Fenton, B., Steele, J. (2005, July 23). Faces of the four bombers: Suspect shot dead by pursuing police in tube. The Daily Telegraph, p. 1.

DTT182 Burleigh, J., Fenton, B. (2005, July 23). Bomb suspect gunned down on Tube after frantic chase with armed police. The Daily Telegraph, p. 2.

DTT183 Calvert, J., Leppard, D. (2005, July 24). Police shot wrong man. The Daily Telegraph, p. 1.

DTT184 Calvert, J., Leppard, D. (2005, July 24) Police: We shot wrong man. The Daily Telegraph, p. 1.

DTT185 Alderson, A., Edwardes, C., Harrison, D. (2005, July 24). Police admit "tragic" error: The man we shot on the Tube was no terrorist. The Daily Telegraph, p. 1.

DTT186 Harrison, D. (2005, July 24). Muslims back "shoot to kill” despite an innocent man's death. The Daily Telegraph, p. 5.

DTT187 Fenton, B. (2005, July 25). He was law-abiding. We blame the government for his death. The Daily Telegraph, p. 3.

DTT188 Steele, J., Rozenberg, J. (2005, July 25). "Shoot to kill” policy at heart of inquiry into how an innocent man lost his life. The Daily Telegraph, p. 3.

DTT189 Gardham, D., Johnston, P. (2005, July 27). Terror suspect is a convicted mugger. The Daily Telegraph, p. 1.

DTT190 Britten, N. (2005, July 28). In a quiet suburban street, a suspect is cornered and captured by police. The Daily Telegraph, p. 4.

DTT191 O’Neill, S., McGrory, D. (2005, July 28). Bombs find shows outrages on 7/7 and 21/7 were linked. The Times, p. 4.

DTT192 Steele, J. Gardham, D., Britten, N. (2005, July 29). Police flood trains with 6,000 officers. The Daily Telegraph, p. 4.

DTT193 Tendler, S., O’Neill, S., McGrory, D. (2005, July 29). 21/7 bombers made just one mistake, police chief warns. The Times, p. 6.

DTT194 O’Neill, S., McGrory, D. (2005, July 29). Bombs suspect “arrested in Africa”. The Times, p. 9. 
DTT195 Tendler, S., McGrory, D., O’Neill, S. (2005, July 30). Bomb suspects all captured - now for the terror leaders. The Times, p. 2.

DTT196 McGrory, D., Tendler, S., O’Neill, S. (2005, July 30). Bomb suspects seized in London and Rome. The Times, p. 1.

DTT197 Woods, R., Leppard, D., Smith, M. (2005, July 31). Tangled web that still leaves worrying loose ends. The Times, p. 15.

DTT198 Cracknell, D. (2005, July 31). How can we stop this happening again? The Times, p. 17.

DTT199 (2005, July 31). The source of terror. The Times, p. 20.

DTT200 Alderson, A., Harrison, D., Johnston, B. (2005, July 31). Police investigate Saudi link to London attacks. The Daily Telegraph, p. 1.

DTT201 Harrison, D., Alderson, A., Johnston, B. (2005, July 31). Forceful, persistent, patient: Unraveling the bombing plot. The Daily Telegraph, p. 13.

DTT202 Steele, J. (2005, August 2). Two more men arrested in south London over failed attacks. The Daily Telegraph, p. 4.

DTT203 Johnston, B. (2005, August 2). Terror suspects very probably amateurs, say Italian police. The Daily Telegraph, p. 4.

DTT204 McGrory, D. (2005, August 3). Did alleged leader of 21/7 meet 7/7 bombers in Pakistan. The Times, p. 6.

DTT205 Butcher, T. (2005, August 5). Al-Zawahiri: "More destruction will come to London, God willing”. The Daily Telegraph, p. 1.

DTT206 O’Neill, S., McGrory, D., Beeston, R. (2005, August 5). Al-Qaeda surfaces to hail 7/7 atrocities. The Times, p. 1.

DTT207 Beeston, R. (2005, August 5). The deadly game of cat and mouse from al-Qaeda's no. 2. The Times, p. 6.

DTT208 McGrory, D. (2005, August 5). All roads lead to Pakistan for team hunting bombers. The Times, p. 7.

DTT209 Beeston, R., Binyon, M. (2005, August 10). Blair "repeatedly failed to tackle radical Muslims in his backyard". The Times, p. 8.

DTT210 Leppard, D. (2005, August 14). US warns of new attacks on London. The Times, p. 1.

DTT211 Baxter, S. (2005, August 14). Bush "losing way" in war on terror. The Times, p. 22. 
DTT212 McGrory, D. (2005, August 22). No one woke Met chief to tell him his team had killed the wrong man. The Times, p. 7.

DTT213 Pook, S., Martin, N. (2005, August 23). Crucifying the police will achieve nothing. The Daily Telegraph, p. 4.

DTT214 Hurst, G. (2005, August 29). Blair warned of extremist threat from his police on Middle East. The Times, p. 7.

DTT215 Calvert, J., Fielding, N. (2005, September 4). Tape links al-Qaeda to London. The Daily Telegraph, p. 11.

DTT216 Rayment, S., Alderson, A. (2005, September 4). London bombers "recorded video in Pakistan" with help of al-Qaeda. The Daily Telegraph, p. 8.

DTT217 Evans, M. (2005, September 10). Defeating terror may mean giving up rights, M15 warns. The Times, p. 2.

DTT218 Ford, R. (2005, September 14). M15 has hundreds of terror suspects under surveillance, Clarke tells MPs. The Times, p. 6.

DTT219 Johnston, P. (2005, September 16). Clarke bungle reveals his doubts over terror law. The Daily Telegraph, p. 1.

DTT220 Sanderson, D. (2005, September 23). Bomber's widow says extremists twisted his mind. The Times, p. 2.

DTT221 Foster, P., Ali, I. (2005, October 5). I'm not link to London attacks, says Briton held in Pakistan, wants change to prove his innocence. The Daily Telegraph, p. 14.

DTT222 McGrory, D. (2005, October 8). Pakistani who instructed 7/7 cell eludes detectives. The Times, p. 27.

DTT223 McGrory, D., Tendler, S. (2005, October 10). Ten arrested in raids against groups linked to al-Zarqawi. The Times, p. 4.

DTT224 Sylvester, R., Thomson, A. (2005, November 7). Fund for victims of terrorism ruled out by Clarke. The Daily Telegraph, p. 1.

DTT225 Bale, J., Evans, M. (2005, November 14). Al-Qaeda threat to Queen tightens cenotaph security. The Times, p. 6 .

DTT226 Leppard, D. (2005, December 18). Spies warned of tube attack. The Times, p. 1.

DTT227 O’Neill, S., McGrory, D. (2005, December 28). Detectives draw up new brief in hunt for radicals. The Times, p. 7. 
DTT228 Leppard, D. (2006, January 29). M15 admits: We've run out of leads on bombers. The Times, p. 1.

DTT229 Leppard, D. (2006, February 26). M15 rebels expose tube bomb cover-up. The Times, p. 1.

DTT230 Aldernson, A., Hastings, C. (2006, April 9). July 7 bombs were a "demo" not terrorism, claims professor. The Daily Telegraph, p. 4.

DTT231 Norfolk, A. (2006, April 28). July suicide bomber “is an invisible poster boy". The Times, p. 35.

DTT232 Harris, F., Gardham, D. (2006, May 4). Life in London made my boy a terrorist. The Daily Telegraph, p. 6.

DTT233 Hamilton, A., Tendler, S. (2006, May 12). They aroused no suspicion. They were hugging and happy - but had bombs. The Times, p. 6.

DTT234 Johnston, P. (2006, May 13). Suicide attacks "unlikely", experts said. The Daily Telegraph, p. 6.

DTT235 Palmer, A. (2006, May 14). M15: Mission impossible. The Daily Telegraph, p. 19.

DTT236 Tendler, S. (2006, May 17). Police chief savaged by his own junior officers. The Times, p. 11.

DTT237 McGrory, D. (206, June 19). US “issued alert” on 7/7 bomber in 2003. The Times, p. 1.

DTT238 McGrory, D. (2006, June 20). British agents trace 7/7 terror links to smalltown America. The Times, p. 8.

DTT239 McGrory, D. (2006, June 24). Terror leader in our sights before 7/7, says US police. The Times, p. 4.

DTT240 Rayment, S. (2006, June 25). Islamists will set off dirty bomb, spy bosses believe. (2006, June 25). The Daily Telegraph, p. 4.

DTT241 Helm, T. (2006, July 3). Risk from al-Qa'eda is greater than ever, warn MPs. The Daily Telegraph, p. 4.

DTT242 Frean, A., Syal, R. (2006, July 4). Muslim Britain spit over "martyrs" of 7/7. The Times, p. 1.

DTT243 Steele, J. (2006, July 7). Suicide bomber's video won't frighten us, say July 7 families. The Daily Telegraph, p. 1. 
DTT244 O’Neill, S., McGrory, D. (2006, July 7). I blame war in Iraq and Afghanistan, 7/7 bomber says in video. The Times, p. 4.

DTT245 McGrory, D. (2006, July 7). California dropout masterminded the tapes for alQaeda. The Times, p. 5.

R1 (1998, August 7). Chronology of attacks on US targets. Reuters News. Retrieved from http://global.factiva.com/

R2 Fox, D. (1998, August 7). Focus - 80 feared dead, 1000 hurt in Africa blasts. Reuters News. Retrieved from http:/global.factiva.com/

R3 (1998, August 7). Corrected - Scores feared dead as US African embassies bombed. Reuters News. Retrieved from http:/global.factiva.com/

R4 (1998, August 7). Corrected - No lack of candidates for embassy bombings experts. Reuters News. Retrieved from http://global.factiva.com/

R5 Bigg, M. (1998, August 7). Car bombs blast US African missions, up to 80 dead. Reuters News. Retrieved from http://global.factiva.com/

R6 Thoennes, T. (1998, August 7). Focus - US plane leaves for Kenya to help victims. Reuters News. Retrieved from http://global.factiva.com/

R7 Fox, M. (1998, August 7). Bomb blasts hard to defend against, US experts say. Reuters News. Retrieved from http://global.factiva.com/

R8 Holland, S. (1998, August 7). Clinton vows to catch Africa embassy bombers. Reuters News.

R9 (1998, August 7). World leaders condemn blasts in Kenya, Tanzania. Reuters News. Retrieved from http://global.factiva.com/

R10 Holland, S. (1998, August 7). Grim Clinton vows to catch "cowardly" bombers. Reuters News. Retrieved from http://global.factiva.com/

R11 Chege, W. (1998, August 7). Bomb devastates Tanzania's diplomatic quarter. Reuters News. Retrieved from http:/global.factiva.com/

R12 Zabarenko, D. (1998, August 7). Africa bombings eclipse White House scandal. Reuters News. Retrieved from http://global.factiva.com/

R13 Heller, J. (1998, August 7). Africa an anti-terrorism blindspot for US. Reuters News. Retrieved from http://global.factiva.com/

R14 Fox, M. (1998, August 7). Muslim extremists main suspects in embassy bombings. Reuters News. Retrieved from http://global.factiva.com/ 
R15 Fox, D. (1998, August 7). Focus - Rescuers dig through night for bomb survivors. Reuters News. Retrieved from http://global.factiva.com/

R16 Holland, S. (1998, August 7). Clinton vows all means to bring bombers to justice. Reuters News. Retrieved from http://global.factiva.com/

R17 Bigg, M. (1998, August 8). US to launch inquiry into Africa bomb blasts. Reuters News. Retrieved from http://global.factiva.com/

R18 Wilson, P. (1998, August 8). US hunts for bombers, Clinton offers consolation. Reuters News. Retrieved from http:/global.factiva.com/

R19 Fox, D. (1998, August 8). Sense of order returns to scene of Kenya bomb blast. Reuters News. Retrieved from http://global.factiva.com/

R20 (1998, August 8). Islamic group claims anti-US attacks, vows more. Reuters News. Retrieved from http://global.factiva.com/

R21 Russell, R. (1998, August 8). Focus - Rescue team hauls Kenya bomb victim to safety. Reuters News. Retrieved from http://global.factiva.com/

R22 (1998, August 8). Clinton leads global outrage over East Africa bombings. Reuters News. Retrieved from http://global.factiva.com/

R23 Richardson, P. (1998, August 8). US ambassador to Kenya recounts horror blast. Reuters News. Retrieved from http://global.factiva.com/

R24 Holland, S. (1998, August 8). Clinton vows will "never give up" bomber search. Reuters News. Retrieved from http://global.factiva.com/

R25 Fox, D. (1998, August 9). Focus - East African blasts probe swings into gear. Reuters News. Retrieved from http://global.factiva.com/

R26 Holland, S. (1998, August 9). Clinton vows justice in African embassy bombings. Reuters News. Retrieved from http://global.factiva.com/

R27 Russell, R. (1998, August 9). Hopes fade for survivors in Kenya bomb rescue. Reuters News. Retrieved from http:/global.factiva.com/

R28 Whitesides, J. (1998, August 9). US officials warn of long East Africa bomb probe. Reuters News. Retrieved from http://global.factiva.com/

R29 May, B. (1998, August 9). Bombing suspect vowed "holy war" on Americans. Reuters News. Retrieved from http://global.factiva.com/

R30 Gray, A. (1998, August 9). Focus - Blast wounded flown to Germany for treatment. Reuters News. Retrieved from http://global.factiva.com/ 
R31 Fox, D. (1998, August 9). Kenya buries its dead as blast probe widens. Reuters News. Retrieved from http://global.factiva.com/

R32 Fox, D. (1998, August 9). Witnesses give conflicting accounts of the Kenya blast. Reuters News. Retrieved from http://global.factiva.com/

R33 Denyer, S. (1998, August 10). Investigators follow leads into Africa bombings. Reuters News. Retrieved from http://global.factiva.com/

R34 Bigg, M. (1998, August 10). Focus - US experts examine Tanzania blast victims. Reuters News. Retrieved from http:/global.factiva.com/

R35 Tudor, G. (1998, August 10). Bombs fail to shake African markets. Reuters News. Retrieved from http://global.factiva.com/

R36 Denyer, S. (1998, August 10). Focus - Police probe embassy bombs, rescuers work on. Reuters News. Retrieved from http:/global.factiva.com/

R37 Fox, D. (1998, August 10). Focus - Tanzania police hold embassy bombing suspects. Reuters News. Retrieved from http:/global.factiva.com/

R38 Giacomo, C. (1998, August 10). Diplomats question Albright on bombings. Reuters News. Retrieved from http://global.factiva.com/

R39 Worsnip, P. (1998, August 10). US offers \$2 million reward in embassy bombings. Reuters News. Retrieved from http://global.factiva.com/

R40 Fox, D. (1998, August 10). Arrests made in embassy bombing, US offers reward. Reuters News. Retrieved from http://global.factiva.com/

R41 Gray, A. (1998, August 11). Focus - Kenyans treated at US hospital in Germany. Reuters News. Retrieved from http://global.factiva.com/

R42 Giacomo, C. (1998, August 11). US said lagging in embassy security upgrades. Reuters News. Retrieved from http://global.factiva.com/

R43 Bigg, M. (1998, August 11). Focus - Tanzania police hold 14 in embassy bomb probe. Reuters News. Retrieved from http://global.factiva.com/

R44 Denyer, S. (1998, August 11). Bomb dashes hopes for Kenyan economic recovery. Reuters News. Retrieved from http://global.factiva.com/

R45 Fox, D. (1998, August 11). Bomb investigators face web of African bureaucracy. Reuters News. Retrieved from http://global.factiva.com/

R46 Worsnip, P. (1998, August 11). US hails cooperation in hunt for embassy bombers. Reuters News. Retrieved from http://global.factiva.com/ 
R47 O'Callaghan, J. (1998, August 12). Spotlight on Africa bomb probe as rescue hopes fade. Reuters News. Retrieved from http://global.factiva.com/

R48 Russell, R. (1998, August 11). Rescue hopes fade at Kenya bomb site. Reuters News. Retrieved from http://global.factiva.com/

R49 O’Callaghan, J. (1998, August 12). Focus - Spotlight now on East Africa bombings probe. Reuters News. Retrieved from http://global.factiva.com/

R50 Worsnip, P. (1998, August 12). Kenya blast adds new names to State Dept plaque. Reuters News. Retrieved from http:/global.factiva.com/

R51 Gray, A. (1998, August 12). Focus - Albright vows US will not be bowed. Reuters News. Retrieved from http://global.factiva.com/

R52 McQuillan, L. (1998, August 12). Clinton orders safety assessment of US embassies. Reuters News. Retrieved from http:/global.factiva.com/

R53 Fox, D. (1998, August 12). FBI to detail bomb probe after arrests in Kenya. Reuters News. Retrieved from http://global.factiva.com/

R54 Giacomo, C. (1998, August 13). US said mulling huge increase in security funds. Reuters News. Retrieved from http://global.factiva.com/

R55 Fox, D. (1998, August 12). US struggles to shake bias accusations after bomb. Reuters News. Retrieved from http://global.factiva.com/

R56 Richardson, P. (1998, August 12). Focus - Multinational rescue team ends Kenya mission. Reuters News. Retrieved from http://global.factiva.com/

R57 Fox, D. (1998, August 12). Focus - Kenya holds suspects, criticism of US mounts. Reuters News. Retrieved from http://global.factiva.com/

R58 McQuillan, L. (1998, August 13). Clinton orders report on safety of US embassies. Reuters News. Retrieved from http://global.factiva.com/

R59 Giacomo, C. (1998, August 13). Pre-bombing request for new Kenya embassy was rejected. Reuters News. Retrieved from http://global.factiva.com/

R60 Fox, D. (1998, August 13). FBI to speak on Nairobi bomb probe. Reuters News. Retrieved from http://global.factiva.com/

R61 Richardson, P. (1998, August 13). Focus - Five suspects held after Kenya bomb attack. Reuters News. Retrieved from http://global.factiva.com/

R62 Gray, A. (1998, August 13). Focus - Albright leaves Germany with bomb dead. Reuters News. Retrieved from http://global.factiva.com/ 
R63 Iredale, P. (1998, August 13). Albania expelled Luxor suspects before US bombings. Reuters News. Retrieved from http:/global.factiva.com/

R64 Goller, H. (1998, August 13). Israeli rescue team returns to heroes' welcome. Reuters News. Retrieved from http://global.factiva.com/

R65 Giacomo, C. (1998, August 13). Can US vow of justice for bombers be trusted? Reuters News. Retrieved from http://global.factiva.com/

R66 Mikkelsen, R. (1998, August 13). Grief, remembrance at service for US bomb victims. Reuters News. Retrieved from http://global.factiva.com/

R67 Duncan, S. (1998, August 13). FBI scales back search for US bombing fugitive. Reuters News. Retrieved from http://global.factiva.com/

R68 Richardson, P. (1998, August 13). Focus - Five suspects held after Kenya bomb attack. Reuters News. Retrieved from http://global.factiva.com/

R69 (1998, August 14). Investigators gather embassy bombing clues. Reuters News. Retrieved from http:/global.factiva.com/

R70 O'Callaghan, J. (1998, August 14). Focus - Africa probe steps up, US lifts warnings. Reuters News. Retrieved from http://global.factiva.com/

R71 Iredale, P. (1998, August 14). Focus - US shuts Albania embassy on Islamic threat. Reuters News. Retrieved from http://global.factiva.com/

R72 O'Callaghan, J. (1998, August 15). Tanzanian suspects are freed as bomb probes continue. Reuters News. Retrieved from http://global.factiva.com/

R73 Harrison, C. (1998, August 16). Focus - Kenya buries bomb victims, suspect deported. Reuters News. Retrieved from http://global.factiva.com/

R74 Worsnip, P. (1998, August 18). Focus - Albright likens Kenya bomb to London blitz. Reuters News. Retrieved from http://global.factiva.com/

R75 Bigg, M. (1998, August 18). Focus - Albright says bombs murder, not politics. Reuters News. Retrieved from http://global.factiva.com/

R76 Stoddard, E. (1998, August 19). Focus - FBI, Kenya confirm hotel search over bombing. Reuters News. Retrieved from http://global.factiva.com/

R77 Lyon, A. (1998, August 19). Islamic group threatens more anti-US attacks. Reuters News. Retrieved from http://global.factiva.com/

R78 McQuillan, L. (1998, August 20). US attacks sites it links to terrorist bombings. Reuters News. Retrieved from http://global.factiva.com/ 
R79 Aldinger, C. (1998, August 20). No sanctuary safe for terrorists, says Cohen. Reuters News. Retrieved from http://global.factiva.com/

R80 (1998, August 20). US launches military raids on Sudan, Afghanistan. Reuters News. Retrieved from http://global.factiva.com/

R81 Green, M. (1998, August 20). At least seven wounded in US raid on Sudan. Reuters News. Retrieved from http://global.factiva.com/

R82 Mohammed, A. (1998, August 21). Life seems to imitate art with US military strikes. Reuters News. Retrieved from http://global.factiva.com/

R83 Taban, A. (1998, August 21). Focus - Sudan wants UN to investigate US raid. Reuters News. Retrieved from http://global.factiva.com/

R84 Cameron-Moore, S. (1998, August 21). US air strikes unsettle Pakistan's balancing act. Reuters News. Retrieved from http://global.factiva.com/

R85 Asghar, R. (1998, August 21). Focus - Pakistan voices outrage at US air strikes. Reuters News. Retrieved from http://global.factiva.com/

R86 Shlal-Esa, A. (1998, August 21). US strikes shift focus to Clinton foreign policy. Reuters News. Retrieved from http://global.factiva.com/

R87 Wilson, P. (1998, August 21). US on edge after strikes on "terrorist" sites. Reuters News. Retrieved from http://global.factiva.com/

R88 Kirschbaum, E. (1998, August 21). Focus - Kohl backs US strikes against “terrorists". Reuters News. Retrieved from http://global.factiva.com/

R89 Hauser, C. (1998, August 21). Sudan factory takes brunt of US revenge bombing. Reuters News. Retrieved from http://global.factiva.com/

R90 (1998, August 21). Focus - Muslim backlash underway after US strikes. Reuters News. Retrieved from http://global.factiva.com/

R91 Leopold, E. (1998, August 21). US tells UN strikes were self-defense. Reuters News. Retrieved from http://global.factiva.com/

R92 (1998, August 21). US cruise missiles strike in Afghanistan, Sudan. Reuters News. Retrieved from http:/global.factiva.com/

R93 McQuillan, L. (1998, August 21). US says attacks aimed at stopping new bombings. Reuters News. Retrieved from http://global.factiva.com/

R94 McQuillan, L. (1998, August 21). US mum on assessing success of missile strikes. Reuters News. Retrieved from http:/global.factiva.com/ 
R95 Worsnip, P. (1998, August 21). US raid could harm deal with Taleban - analysts. Reuters News. Retrieved from http://global.factiva.com/

R96 McQuillan, L. (1998, August 21). Focus - US readies plans for new missile strikes. Reuters News. Retrieved from http://global.factiva.com/

R97 McQuillan, L. (1998, august 21). Focus - Missile damage "moderate to severe" US. Reuters News. Retrieved from http://global.factiva.com/

R98 (1998, August 22). Bin Laden quoted as threatening further attacks. Reuters News. Retrieved from http://global.factiva.com/

R99 (1998, August 22). More US strikes possible, Bin Laden vows revenge. Reuters News. Retrieved from http://global.factiva.com/

R100 Holland, S. (1998, August 23). Clinton opens new front in war on Bin Laden. Reuters News. Retrieved from http://global.factiva.com/

R101 Smith, D. (1998, August 23). US assesses success of missile strikes. Reuters News. Retrieved from http://global.factiva.com/

R102 Aaser, G.H. (1998, August 24). Focus - Bin Laden far away when missiles hit Taleban. Reuters News. Retrieved from http:/global.factiva.com/

R103 Subhani, O. (1998, August 24). US enemy Bin Laden a hero to many Pakistanis. Reuters News. Retrieved from http://global.factiva.com/

R104 Maclean, W. (1998, August 25). Interview - US may turn Bin Laden into hero Saudi. Reuters News. Retrieved from http://global.factiva.com/

R105 Stoddard, E. (998, August 27). Focus - Kenya embassy bomb suspect said sent to US. Reuters News. Retrieved from http://global.factiva.com/

R106 Appleson, G. (1998, August 28). Focus - Nairobi bombing suspect charged with murder. Reuters News. Retrieved from http://global.factiva.com/

R107 Appleson, G. (1998, August 28). Second man charged in US embassy bombing. Reuters News. Retrieved from http://global.factiva.com/

R108 Ryan, T. (1998, September 11). Clinton honors Americans killed in embassy attacks. Reuters News. Retrieved from http://global.factiva.com/

R109 Appleson, G. (1998, September 17). Nairobi bombing suspect charged in New York. Reuters News. Retrieved from http:/global.factiva.com/

R110 Worsnip, P. (1998, October 13). Cohen says US strikes “went after” Bin Laden. Reuters News. Retrieved from http://global.factiva.com/ 
R111 (1998, October 30). Ex-soldier linked to Bin Laden - NY Times. Reuters News. Retrieved from http:/global.factiva.com/

R112 Appleson, G. (1998, November 4). Bin Laden indicted, US offers \$5 million reward. Reuters News. Retrieved from http://global.factiva.com/

R113 Hill, A. (1998, December 6). Taleban silent on reports of Bin Laden murder bid. Reuters News. Retrieved from http://global.factiva.com/

R114 Giacomo, C. (1998, December 17). US temporarily closes embassies in Africa. Reuters News. Retrieved from http://global.factiva.com/

R115 (1998, December 25). Bin Laden wants attacks on US, UK citizens - paper. Reuters News. Retrieved from http://global.factiva.com/

R116 Russell, R. (1999, January 1). Feature - Scars left by Kenya bombing yet to heal. Reuters News. Retrieved from http://global.factiva.com/

R117 Hill, A. (1999, January 26). Corrected - Interview - Taleban assure UN on Bin Laden. Reuters News. Retrieved from http://global.factiva.com/

R118 Salahuddin, S. (1999, February 13). Focus - Afghan Taleban say Bin Laden missing. Reuters News. Retrieved from http://global.factiva.com/

R119 Salahuddin, S. (1999, July 14). Focus - Afghan Taleban denies asking Bin Laden to leave. Reuters News. Retrieved from http://global.factiva.com/

R120 Mageria, D. (1999, May 3). Bomb-hit Kenyan businesses struggle to recover. Reuters News. Retrieved from http://global.factiva.com/

R121 Zakaria, T. (1999, June 17). US accuses Bin Laden of preparing to attack. Reuters News. Retrieved from http://global.factiva.com/

R122 (1999, June 17). US indicts two more in Africa embassy bombings. Reuters News. Retrieved from http:/global.factiva.com/

R123 Cornwell, S. (1999, June 24). Focus - Saudi man linked to Bin Laden - UK lawyer. Reuters News. Retrieved from http:/global.factiva.com/

R124 Russell, R. (1999, August 3). Feature - Kenya bomb survivors struggle one year on. Reuters News. Retrieved from http://global.factiva.com/

R125 Wold, J. (1999, August 3). US steps up security before bomb anniversary. Reuters News. Retrieved from http://global.factiva.com/

R126 (1999, August 4). Corrected - US still has much work to do on securing embassies. Reuters News. Retrieved from http://global.factiva.com/ 
R127 Wolf, J. (1999, August 5). US fights extremists with new tactics. Reuters News. Retrieved from http:/global.factiva.com/

R128 Haider, K. (2008, June 2). Bomb kills 6 at Danish embassy in Pakistan. Reuters News. Retrieved from http://global.factiva.com/

R129 Sulugiuc, G. (2008, June 2). Denmark condemns embassy attack. Reuters News. Retrieved from http:/global.factiva.com/

R130 Anthony, A. (2008, June 3). Deadly embassy bomb raises security fears. Reuters News. Retrieved from http://global.factiva.com/

R131 (2008, June 5). Al Qaeda claims attack on Danish embassy. Reuters News. Retrieved from http:/global.factiva.com/

R132 Anthony, A. (2008, June 5). Danes working with Pakistanis investigating blast. Reuters News. Retrieved from http:/global.factiva.com/

R133 (2008, July 22). Danish embassy bomber reportedly "from Mecca". Reuters News. Retrieved from http:/global.factiva.com/

R134 Sedarat, F. (2008, September 5). Al Qaeda video vows more Denmark attacks. Reuters News. Retrieved from http://global.factiva.com/

R135 Abeidoh, R. (2000, October 12). US warship attacked in Aden, five sailors dead. Reuters News. Retrieved from http://global.factiva.com/

R136 Pleming, S. (2000, October 12). US horrified by attack on Navy destroyer. Reuters News. Retrieved from http://global.factiva.com/

R137 Abeidoh, R. (2000, October 12). US warship hit by "suicide bombers" off Yemen. Reuters News. Retrieved from http://global.factiva.com/

R138 Aldinger, C. (2000, October 12). Pentagon says warship attack "apparent terrorism.” Reuters News. Retrieved from http:/global.factiva.com/

R139 Mohammed, A. (2000, October 13). Clinton deplores attack, urges Mideast ceasefire. Reuters News. Retrieved from http://global.factiva.com/

R140 Aldinger, C. (2000, October 13). US probes Aden blast, identifies victims. Reuters News. Retrieved from http://global.factiva.com/

R141 Pleming, S. (2000, October 13). Death toll rises in Yemen warship blast.

R142 Abeidoh, R. (2000, October 13). US warship attacked in Yemen, six sailors dead. Reuters News. Retrieved from http://global.factiva.com/

R143 Sudam, M. (2000, October 13). US starts investigating Yemen ship blast. Reuters News. Retrieved from http://global.factiva.com/ 
R144 Pleming, S. (2000, October 13). Clues sought worldwide in USS Cole bombing. Reuters News. Retrieved from http://global.factiva.com/

R145 (2000, October 13). Conflicting claims, suspicions over Yemen attack. Reuters News. Retrieved from http://global.factiva.com/

R146 Pleming, S. (2000, October 13). US outraged by Navy destroyer attack. Reuters News. Retrieved from http://global.factiva.com/

R147 Millership, P. (2000, October 13). World press shudders at specter of Mideast war. Reuters News. Retrieved from http://global.factiva.com/

R148 Sudam, M. (2000, October 13). US starts probe into deadly Yemen warship blast. Reuters News. Retrieved from http://global.factiva.com/

R149 Giacomo, C. (2000, October 14). Aden attack underscores US "homeland defense". Reuters News. Retrieved from http://global.factiva.com/

R150 Doughty, S. (2000, October 14). US hunts for clues to Yemen ship bombings. Reuters News. Retrieved from http:/global.factiva.com/

R151 Sudam, M. (2000, October 14). US experts to look for clues in Aden ship blast. Reuters News. Retrieved from http://global.factiva.com/

R152 Sudam, M. (2000, October 14). US looks for clues in Aden ship blast. Reuters News. Retrieved from http://global.factiva.com/

R153 Blair, E. (2000, October 14). US ship blast puts unruly Yemen in spotlight. Reuters News. Retrieved from http://global.factiva.com/

R154 Pierpoint, J. (2000, October 14). US crew sent to Yemen to recover remaining victims. Reuters News. Retrieved from http://global.factiva.com/

R155 Sudam, M. (2000, October 14). US looks for clues in Aden ship blast. Reuters News. Retrieved from http://global.factiva.com/

R156 Santos, L. (2000, October 15). Cohen - investigation of US ship bombing continues. Reuters News. Retrieved from http://global.factiva.com/

R157 Blair, E. (2000, October 15). USS Cole blast in Aden had the force of a missile. Reuters News. Retrieved from http://global.factiva.com/

R158 Blair, E. (2000, October 15). US probes Aden bombing, Yemen rounds up suspects. Reuters News. Retrieved from http://global.factiva.com/

R159 Zakaria, T. (2000, October 17). Mideast a factor in any US response to Cole attack. Reuters News. Retrieved from http://global.factiva.com/ 
R160 Blair, E. (2000, October 17). US, Yemen probe ship blast, bodies recovered. Reuters News. Retrieved from http://global.factiva.com/

R161 Blair, E. (2000, October 18). Progress made in probe into US warship blast. Reuters News. Retrieved from http://global.factiva.com/

R162 Mikkelsen, R. (2000, October 18). Clinton to Cole bombers - We will find you. Reuters News. Retrieved from http://global.factiva.com/

R163 Blair, E. (2000, October 19). FBI chief says no word on who bombed USS Cole. Reuters News. Retrieved from http://global.factiva.com/

R164 Pleming, S. (2000, October 19). US general defends using Aden, warns more attacks. Reuters News. Retrieved from http:/global.factiva.com/

R165 Zakaria, T. (2000, October 21). US Cole investigators looking at likely suspects. Reuters News. Retrieved from http://global.factiva.com/

R166 Blair, E. (2000, October 22). Yemenis unsettled by US presence in Aden. Reuters News. Retrieved from http://global.factiva.com/

R167 (2000, October 24). US says crippled USS Cole ready to be moved. Reuters News. Retrieved from http://global.factiva.com/

R168 Aldinger, C. (2000, October 24). Highest alert for some US Gulf forces - official. Reuters News. Retrieved from http://global.factiva.com/

R169 Aldinger, C. (2000, October 24). US forces in Bahrain and Qatar put on top alert. Reuters News. Retrieved from http://global.factiva.com/

R170 Zakaria, T. (2000, October 26). US intelligence analyst quits over Cole attack. Reuters News. Retrieved from http://global.factiva.com/

R171 Aldinger, C. (2000, October 26). US military reviewing security worldwide Pentagon. Reuters News. Retrieved from http://global.factiva.com/

R172 Monaghan, E. (2000, October 28). US seeks access to Yemen bombing suspects. Reuters News. Retrieved from http://global.factiva.com/

R173 Aboudi, S. (2000, October 29). Search for bomb backers strengthens US-Yemen ties. Reuters News. Retrieved from http://global.factiva.com/

R174 Zakaria, T. (2000, October 30). Interview - CIA official says will hunt Cole attackers. Reuters News. Retrieved from http://global.factiva.com/

R175 Charles, D. (2000, October 31). Clinton urges joint investigation in Yemen. Reuters News. Retrieved from http://global.factiva.com/ 
R176 Aldinger, C. (2000, November 10). US officials cite plan to attack $2^{\text {nd }}$ US destroyer. Reuters News. Retrieved from http://global.factiva.com/

R177 Aldinger, C. (2000, November 10). Major progress in Cole bombing probe - US officials. Reuters News. Retrieved from http://global.factiva.com/

R178 Charles, D. (2000, November 11). Clinton pays tribute to Cole, Vietnam soldiers. Reuters News. Retrieved from http://global.factiva.com/

R179 (2000, November 14). USS Cole guards told not to fire first shot - Post. Reuters News. Retrieved from http://global.factiva.com/

R180 (2000, December 12). Yemen says looking for more suspects in Cole attack. Reuters News. Retrieved from http://global.factiva.com/

R181 Taylor, P. (2000, December 19). Mideast bid may stay Clinton's hand on bin Laden. Reuters News. Retrieved from http://global.factiva.com/

R182 Aldinger, C. (2001, January 6). Pentagon plans broader look at Cole attack. Reuters News. Retrieved from http://global.factiva.com/

R183 Aldinger, C. (2001, January 9). Pentagon urged to raise guard against "terrorists." Reuters News. Retrieved from http://global.factiva.com/

R184 Zakaria, T. (2001, January 10). US reports detail proliferation concerns. Reuters News. Retrieved from http://global.factiva.com/

R185 Aldinger, C. (2001, January 19). Cohen faults self US command in Cole bombing. Reuters News. Retrieved from http://global.factiva.com/

R186 Appleson, G. (2001, February 3). Bin Laden focus of US embassy bombing trial in New York. Reuters News. Retrieved from http://global.factiva.com/

R187 Monaghan, E. (2001, June 19). US working to get FBI team back into Yemen. Reuters News. Retrieved from http://global.factiva.com/

R188 Shalal-Esa, A. (2001, August 21). US says FBI team may return to Yemen for Cole probe. Reuters News. Retrieved from http:/global.factiva.com/

R189 (2005, August 19). Rockets narrowly miss US warships in Jordan. Reuters News. Retrieved from http://global.factiva.com/

(2005, August 19). Rocket hits Israel after Jordan blast - radios. Reuters News. Retrieved from http:/global.factiva.com/

R191 (2005, August 19). Rocket fired near US ship in Aqaba - US official. Reuters News. Retrieved from http://global.factiva.com/ 
R192 (2005, August 19). Israel says cooperating with Jordan after rockets. Reuters News. Retrieved from http://global.factiva.com/

R193 (2005, August 19). US ships leave Jordan port after missile attack. Reuters News. Retrieved from http://global.factiva.com/

R194 (2005, August 19). Mofaz; Strikes on Israel, Jordan were coordinated. Reuters News. Retrieved from http://global.factiva.com/

R195 (2005, August 19). Jordanian soldier killed in Aqaba rocket attack. Reuters News. Retrieved from http:/global.factiva.com/

R196 (2005, August 19). Jordan hunting Syrian, 2 Iraqis after rocket attack. Reuters News. Retrieved from http://global.factiva.com/

R197 (2005, August 19). "Qaeda” group claims rocket attack on US ships. Reuters News. Retrieved from http://global.factiva.com/

R198 McBride, J. (2005, August 19). Oil jumps after attack on US ships, Ecuador halt. Reuters News. Retrieved from http://global.factiva.com/

R199 Al-Khalidi, S. (2005, August 21). Aqaba attack may signal new Zarqawi front in Jordan. Reuters News. Retrieved from http://global.factiva.com/

R200 Al-Khalidi, S. (2005, August 21). Jordan questions Arabs over Aqaba rocket attack. Reuters News. Retrieved from http://global.factiva.com/

R201 Al-Khalidi, S. (2005, August 22). Jordan says Iraq-based group behind rocket attack. Reuters News. Retrieved from http://global.factiva.com/

R202 (2005, August 23). Iraq Qaeda claims rocket attack in Jordan port - web. Reuters News. Retrieved from http://global.factiva.com/

R203 Al-Khalidi, S. (2005, August 23). Jordan says Syrian militants behind rocket attack. Reuters News. Retrieved from http:/global.factiva.com/

R204 Al-Khalidi, S. (2005, October 1). Jordan and Iraq bolster security cooperation. Reuters News. Retrieved from http:/global.factiva.com/

R205 (2006, April 26). Corrected - Syrians, Jordanian on trial over Aqaba rocket attack. Reuters News. Retrieved from http://global.factiva.com/

R206 Trotta, D. (2004, March 11). Madrid bombs kill 192 - purported al Qaeda claim. Reuters News. Retrieved from http:/global.factiva.com/

R207 (2004, March 11). Chronology - ETA's history and major attacks. Reuters News. Retrieved from http://global.factiva.com/ 
R208 Trotta, D. (2004, March 11). Madrid train blasts kill 131 ahead of election. Reuters News. Retrieved from http://global.factiva.com/

R209 Flynn, D. (2004, March 11). Bombs may be new chapter in deadly ETA separatism. Reuters News. Retrieved from http://global.factiva.com/

R210 Trevelyan, M. (2004, March 11). Terror experts see "9/11 factor" in Madrid bombings. Reuters News. Retrieved from http://global.factiva.com/

R211 Neely, J. (2004, March 11). Europe's travel sector rattled by Madrid bombings. Reuters News. Retrieved from http://global.factiva.com/

R212 Sedarat, F. (2004, March 11). Purported Qaeda letter claims Spain bombings paper. Reuters News. Retrieved from http://global.factiva.com/

R213 Croft, A. (2004, March 12). Spain mourns 192 dead, probes al Qaeda bomb claim. Reuters News. Retrieved from http://global.factiva.com/

R214 Cawthorne, A. (2004, March 12). Responsibility for bombs crucial to Spain election. Reuters News. Retrieved from http://global.factiva.com/

R215 Maeda, R. (2004, March 12). Nikkei falls for third day, hit by Spain bombings. Reuters News. Retrieved from http://global.factiva.com/

R216 Maitre, M. (2004, March 12). Eurostocks slip as attack fears hit travel, insurers. Reuters News. Retrieved from http://global.factiva.com/

R217 Trevelyan, M. (2004, March 12). Terror experts say jury out on Qaeda Madrid role. Reuters News. Retrieved from http://global.factiva.com/

R218 Cawthorne, A. (2004, March 12). Aznar vows to pursue all lines in Madrid bomber hunt. Reuters News. Retrieved from http://global.factiva.com/

R219 Di Giorgio, M. (2004, March 12). Pro-US countries boost security after Madrid bombs. Reuters News. Retrieved from http://global.factiva.com/

R220 Feast, L. (2004, March 12). Madrid blasts rock stocks but recovery seen quick. Reuters News. Retrieved from http://global.factiva.com/

R221 Ross-Thomas, E., Lifshitz, A. (2004, March 12). Spain blast relatives await news, identify dead. Reuters News. Retrieved from http://global.factiva.com/

R222 Graff, P. (2004, March 12). Basques still main suspects in Spain blasts. Reuters News. Retrieved from http://global.factiva.com/

R223 Entous, A. (2004, March 12). "Wouldn't rule anybody out" in Spain blast - Bush. Reuters News. Retrieved from http://global.factiva.com/ 
R224 Cawthorne, A. (2004, March 12). Millions protest over Spain bombs, ETA denies blame. Reuters News. Retrieved from http://global.factiva.com/

R225 Croft, A. (2004, March 13). Millions mourn in Spain as bomb mystery deepens. Reuters News. Retrieved from http://global.factiva.com/

R226 Cawthorne, A. (2004, March 13). Spain told envoys to point finger at ETA paper. Reuters News. Retrieved from http://global.factiva.com/

R227 Trotta, D. (2004, March 13). Spain's spies see Islamic group behind attack radio. Reuters News. Retrieved from http:/global.factiva.com/

R228 Flynn, D. (2004, March 13). Madrid bombs could signal death blow to ETA. Reuters News. Retrieved from http://global.factiva.com/

R229 O’Leary, E. (2004, March 13). Spain arrests five in bomb probe breakthrough. Reuters News. Retrieved from http://global.factiva.com/

R230 O'Leary, E. (2004, March 13). Madrid Muslims fearful if al Qaeda behind blast. Reuters News. Retrieved from http://global.factiva.com/

R231 Ross-Thomas, E. (2004, March 14). Spain says tape claims al Qaeda behind attacks. Reuters News. Retrieved from http:/global.factiva.com/

R232 O'Leary, E. (2004, March 14). Rancour grows as Spain votes after "Qaeda” bombs. Reuters News. Retrieved from http:/global.factiva.com/

R233 Croft, A. (2004, March 14). Socialists score spectacular Spanish election win. Reuters News. Retrieved from http://global.factiva.com/

R234 Graff, P. (2004, March 14). Authorities have no clear response for Madrid. Reuters News. Retrieved from http://global.factiva.com/

R235 Flynn, D. (2004, March 14). Spain's “war on terror” role may have made it target. Reuters News. Retrieved from http://global.factiva.com/

R236 Blenkinsop, P. (2004, March 14). Germany urges urgent EU talks as Qaeda fears mount. Reuters News. Retrieved from http:/global.factiva.com/

R237 Flynn, D. (2004, March 14). Spain's Zapatero, a man of peace for wounded Spain. Reuters News. Retrieved from http://global.factiva.com/

R238 Croft, A. (2004, March 15). Spaniards vote out government over Iraq, bombings. Reuters News. Retrieved from http://global.factiva.com/

R239 Croft, A. (2004, March 15). Anger over attack put Spain's Socialists in power. Reuters News. Retrieved from http://global.factiva.com/ 
R240 Flynn, D. (2004, March 15). Spanish Socialists may pull troops from Iraq. Reuters News. Retrieved from http://global.factiva.com/

R241 Sieg, L. (2004, March 15). US Asian allies seen nervous after Spain election. Reuters News. Retrieved from http://global.factiva.com/

R242 Boyle, J. (2004, March 15). Europe-wide rail, metro alert after Madrid blasts. Reuters News. Retrieved from http://global.factiva.com/

R243 Alison, S. (2004, March 15). Europeans honour Madrid dead in silent vigil. Reuters News. Retrieved from http://global.factiva.com/

R244 Graf, P. (2004, March 15). Experts fear Spain election will encourage attacks. Reuters News. Retrieved from http://global.factiva.com/

R245 Trotta, D. (2004, March 16). Spain pursues Moroccan link to train bombs. Reuters News. Retrieved from http://global.factiva.com/

R246 Baldwin, K. (2004, March 16). Moroccan bomb suspect in Spain is "modern" Muslim. Reuters News. Retrieved from http://global.factiva.com/

R247 Cawthorne, A. (2004, March 17). World shudders at Spain's attack fallout. Reuters News. Retrieved from http://global.factiva.com/

R248 Flynn, D. (2004, March 17). Spain's Zapatero brands Iraq occupation a fiasco. Reuters News. Retrieved from http://global.factiva.com/

R249 Clothier, M. (2004, March 17). Europe defiant, on alert in face of attack threat. Reuters News. Retrieved from http://global.factiva.com/

R250 Allen, V. (2004, March 18). US lawmakers blame Spain, battle over Iraq. Reuters News. Retrieved from http://global.factiva.com/

R251 Kitano, M> (2004, March 18). Japan steadfast after purported al Qaeda threat. Reuters News. Retrieved from http://global.factiva.com/

R252 Baldwin, K. (2004, March 19). Spanish judge to rule on first five bomb suspects. Reuters News. Retrieved from http://global.factiva.com/

R253 Trevelyan, M. (2004, March 19). Spanish intelligence files fail to dispel doubts. Reuters News. Retrieved from http://global.factiva.com/

R254 Baldwin, K. (2004, March 20). "Bring troops home!” shout protesting Spaniards. Reuters News. Retrieved from http:/global.factiva.com/

R255 Baldwin, K. (2004, March 23). Battle begins to keep Spain in Iraq alliance. Reuters News. Retrieved from http://global.factiva.com/ 
R256 Trotta, D., Hudson, S. (2004, March 24). New Spanish leader resists pressure over Iraq troops. Reuters News. Retrieved from http://global.factiva.com/

R257 Trotta, D. (2004, March 24). Madrid bomb investigators hunt for mastermind. Reuters News. Retrieved from http://global.factiva.com/

R258 Shirbon, E. (2004, April 2). Spain finds bomb on high-speed rail, calls in army. Reuters News. Retrieved from http://global.factiva.com/

R259 Croft, A. (2004, April 3). Islamic militants suspected in Spain bomb - reports. Reuters News. Retrieved from http://global.factiva.com/

R260 (2004, April 3). Policeman, three suspects dead in Madrid blast. Reuters News. Retrieved from http:/global.factiva.com/

R261 Flynn, D. (2004, April 4). Madrid bomb suspects blow up themselves, policeman. Reuters News. Retrieved from http://global.factiva.com/

R262 Shirbon, E. (2004, April 4). Suicide blast rattles peaceful Madrid suburb. Reuters News. Retrieved from http://global.factiva.com/

R263 Shirbon, E. (2004, April 4). Madrid bomb ringleader cornered, killed in blast. Reuters News. Retrieved from http://global.factiva.com/

R264 Parsons, C. (2004, April 6). Spaniards blame Iraq war but Qaeda aim seen wider. Reuters News. Retrieved from http://global.factiva.com/

R265 Graf, P., Boyle, J. (2004, April 6). French trial links Madrid and Casablanca bombs. Reuters News. Retrieved from http://global.factiva.com/

R266 (2004, April 7). US Asia allies say no Iraq pull-out for now. Reuters News. Retrieved from http://global.factiva.com/

R267 Trevelyan, M. (2004, April 15). Bin Laden bids to split West, targets Iraq allies. Reuters News. Retrieved from http:/global.factiva.com/

R268 Zakaria, T. (2004, April 15). Bin Laden message may suggest attacks planned. Reuters News. Retrieved from http:/global.factiva.com/

R269 Lifschitz, A., Ross-Thomas, E. (2004, April 18). Zapatero orders Spanish pullout from Iraq. Reuters News. Retrieved from http://global.factiva.com/

R270 Marshall, A. (2004, April 19). Spain pulls troops from Iraq, 10 US troops killed. Reuters News. Retrieved from http://global.factiva.com/

R271 Sieg, L. (2004, April 19). Iraq dilemma stirs Japanese resentment of US ties. Reuters News. Retrieved from http://global.factiva.com/ 
R272 Trevelyan, M. (2004, April 26). Skepticism as G7 acts against terror cash couriers. Reuters News. Retrieved from http://global.factiva.com/

R273 Stetkiewicz, C. (2004, May 8). Family has no word on American linked to bombing. Reuters News. Retrieved from http://global.factiva.com/

R274 Parodi, E., Ferreira-Marques, C. (2004, June 8). Italy, Belgium seize suspected militants in raids. Reuters News. Retrieved from http://global.factiva.com/

R275 Flynn, D. (2004, December 22). Madrid bomb probe poisons Spain's political waters. Reuters News. Retrieved from http:/global.factiva.com/

R276 Baldwin, K. (2005, February 24). Terrorism climbs up UK election agenda. Reuters News. Retrieved from http://global.factiva.com/

R277 Trotta, D. (2005, March 8). Madrid dreading anniversary of train bombings. Reuters News. Retrieved from http://global.factiva.com/

R278 Flynn, D., Ross-Thomas, E. (2005, March 8). Victims demand answers before March 11 anniversary. Reuters News. Retrieved from http:/global.factiva.com/

R279 Flynn, D. (2005, March 10). Tough tests lie ahead for Spain's Zapatero. Reuters News. Retrieved from http://global.factiva.com/

R280 Ross-Thomas, E. (2005, March 11). Spain marks March 11 attacks with silence, sorrow. Reuters News. Retrieved from http:/global.factiva.com/

R281 Trevelyan, M. (2005, July 7). London blasts fit al Qaeda pattern -analysts. Reuters News. Retrieved from http://global.factiva.com/

R282 Harding, B. (2005, July 7). Blasts sow shock, confusion in dumbstruck London. Reuters News. Retrieved from http://global.factiva.com/

R283 (2005, July 7). US raises alert level after London bombs. Reuters News. Retrieved from http://global.factiva.com/

R284 (2005, July 7). Factbox - World reaction to London attacks. Reuters News. Retrieved from http://global.factiva.com/

R285 (2005, July 7). Bush orders US vigilance after London blasts. Reuters News. Retrieved from http://global.factiva.com/

R286 Stewart, P. (2005, July 7). Europe tightens security after blasts hit London. Reuters News. Retrieved from http:/global.factiva.com/

R287 Lyon, A. (2005, July 7). London bombings evoke sympathy in Middle East. Reuters News. Retrieved from http://global.factiva.com/ 
R288 (2005, July 7). U.S. safer but still vulnerable - experts. Reuters News. Retrieved from http://global.factiva.com/

R289 Balmer, C. (2005, July 7). Shocked G8 leaders rally around after London blasts. Reuters News. Retrieved from http://global.factiva.com/

R290 Millership, P. (2005, July 7). World recoils in horror at London attacks. Reuters News. Retrieved from http://global.factiva.com/

R291 Trevelyan, M. (2005, July 8). UK intelligence in spotlight over London bombers. Reuters News. Retrieved from http://global.factiva.com/

R292 Heritage, T. (2005, July 8). Britain sees hallmarks of al Qaeda in attacks. Reuters News. Retrieved from http://global.factiva.com/

R293 (2005, July 8). After London attack, who's next? world press asks. Reuters News. Retrieved from http:/global.factiva.com/

R294 Desai, S., Strohecker, K. (2005, July 8). Consumers bounce back after London blasts. Reuters News. Retrieved from http://global.factiva.com/

R295 Nakhoul, S. (2005, July 8). London blasts reflect classic al Qaeda style. Reuters News. Retrieved from http://global.factiva.com/

R296 Strohecker, K., Robbins, M. (2005, July 8). Show goes on for London's theaters and restaurants. Reuters News. Retrieved from http://global.factiva.com/

R297 (2005, July 8). US official sees Zarqawi spectre in London attacks. Reuters News. Retrieved from http:/global.factiva.com/

R298 Ibrahim, W. (2005, July 10). Iraqis blame US, Britain over London bombings. Reuters News. Retrieved from http://global.factiva.com/

R299 Wilson, P. (2005, July 11). Bush: London attacks targeted civilized world. Reuters News. Retrieved from http://global.factiva.com/

R300 Holden, M. (2005, July 12). Suicide bombing feared in London attacks. Reuters News. Retrieved from http://global.factiva.com/

R301 (2005, July 12). Britain pleads for time to identify bomb victims. Reuters News. Retrieved from http://global.factiva.com/

R302 Trevelyan, M. (2005, July 12). After bombings, some say “Londinistan" bears blame. Reuters News. Retrieved from http:/global.factiva.com/

R303 Pullella, P. (2005, July 12). Terrorism "knocking on our door - Italy minister." Reuters News. Retrieved from http://global.factiva.com/ 
R304 Treelyan, M., Holden, M. (2005, July 12). Suicide blasts would break new ground in Western Europe. Reuters News. Retrieved from http://global.factiva.com/

R305 Holton, K., Baroumy, Y. (2005, July 13). Northern England shocked at homegrown bombers. Reuters News. Retrieved from http://global.factiva.com/

R306 Haider, Z. (2005, July 13). Pakistan says helped thwart UK attack before polls Reuters News. Retrieved from http://global.factiva.com/

R307 Holden, M. (2005, July 13). Police seek London bombing mastermind. Reuters News. Retrieved from http://global.factiva.com/

R308 Trevelyan, M. (2005, July 13). “Cleanskin” homegrown bombers emerge as new threat. Reuters News. Retrieved from http://global.factiva.com/

R309 Abbas, M. (2005, July 13). London Muslims point to anger behind bomb attacks. Reuters News. Retrieved from http://global.factiva.com/

R310 Haider, Z. (2005, July 15). UK bomber met Islamabad church bomber in $2003-$ source. Reuters News. Retrieved from http:/global.factiva.com/

R311 Holden, M. (2005, July 15). UK bomb probe widens to Egypt, Pakistan. Reuters News. Retrieved from http://global.factiva.com/

R312 Trevelyan, M. (2005, July 16). Blair urges "battle of ideas" to beat al Qaeda. Reuters News. Retrieved from http://global.factiva.com/

R313 Khursheed, M. (2005, July 16). Pakistan detains four more suspects in London probe. Reuters News. Retrieved from http://global.factiva.com/

R314 (2005, July 17). Pakistani madrassahs fear London bombs backlash. Reuters News. Retrieved from http://global.factiva.com/

R315 Peacock, M. (2005, July 17). Hunt for London bombing network fans out across globe. Reuters News. Retrieved from http:/global.factiva.com/

R316 Eaton, D. (2005, July 18). London blasts seen as lesson for Southeast Asia.

Reuters News. Retrieved from http://global.factiva.com/

R317 Peacock, M. (2005, July 18). UK rejects Iraq link to London bombs, seeks new law. Reuters News. Retrieved from http://global.factiva.com/

R318 (2005, July 18). Pakistan points finger at militants, madrassahs. Reuters News. Retrieved from http:/global.factiva.com/

R319 Aziz, F. (2005, July 18). London bombs reverberate in Pakistani madrassahs. Reuters News. Retrieved from http://global.factiva.com/ 
R320 Trevelyan, M. (2005, July 19). Pre-attack memo raises pressure on UK intelligence. Reuters News. Retrieved from http://global.factiva.com/

R321 Haider, Z. (2005, July 20). Pakistan arrests London bombing suspects - sources. Reuters News. Retrieved from http://global.factiva.com/

R322 Trevelyan, M. (2005, July 20). Europe gropes for joint anti-terrorism response. Reuters News. Retrieved from http://global.factiva.com/

R323 Bohan, C. (2005, July 20). Bush vows to safeguard US transit against attack. Reuters News. Retrieved from http://global.factiva.com/

R324 Tanveer, A. (2005, July 21). Pakistani relatives recall bomber's jihadi dreams. Reuters News. Retrieved from http://global.factiva.com/

R325 Meares, R., Wynn, G. (2005, July 21). Bombs hit London two weeks after deadly blasts. Reuters News. Retrieved from http://global.factiva.com/

R326 Peacock, M. (2005, July 21). London bombings fail to damage Blair...yet. Reuters News. Retrieved from http://global.factiva.com/

R327 Trevelyan, M. (2005, July 21). UK bombs meant as carbon-copy, may be same group. Reuters News. Retrieved from http://global.factiva.com/

R328 Jones, M., Lovell, J. (2005, July 21). British police admit shooting wrong man in bomb hunt. Reuters News. Retrieved from http://global.factiva.com/

R329 Baldwin, K. (2005, July 22). Londoners flee as police kill bombing suspect. Reuters News. Retrieved from http://global.factiva.com/

R330 Long, G. (2005, July 22). Attacks on UK will continue, radical cleric. Reuters News. Retrieved from http://global.factiva.com/

R331 Balmer, C. (2005, July 22). Italy and France boost measures to fight terrorism. Reuters News. Retrieved from http://global.factiva.com/

R332 (2005, July 22). NY police begin random bag searches on subways. Reuters News. Retrieved from http://global.factiva.com/

R333 Lovell, J. (2005, July 23). UK agonises over police "shoot-to-kill" tactics. Reuters News. Retrieved from http://global.factiva.com/

R334 Gray, A. (2005, July 24). Police arrest man over London bombs, defend tactics. Reuters News. Retrieved from http://global.factiva.com/

R335 Holden, M. (2005, July 23). British police name two suspects in bombing probe. Reuters News. Retrieved from http:/global.factiva.com/ 
R336 Griffiths, P. (2005, July 26). Blair urges public to help catch London bombers. Reuters News. Retrieved from http://global.factiva.com/

R337 Griffiths, P. (2005, July 26). Blair discusses new anti-terror laws. Reuters News. Retrieved from http:/global.factiva.com/

R338 Majendie, P. (2005, July 26). Blair vows to give "not one inch" to terrorists. Reuters News. Retrieved from http://global.factiva.com/

R339 Holden, M., Holton, K. (2005, July 27). British police arrest suspected train bomber. Reuters News. Retrieved from http://global.factiva.com/

R340 Holden, M., Baldwin, K. (2005, July 28). Britain may face more bombers - police chief. Reuters News. Retrieved from http://global.factiva.com/

R341 Hull, C.B. (2005, July 28). For London bomb motives, Africa says look at home. Reuters News. Retrieved from http://global.factiva.com/

R342 Shacinda, S. (2005, July 29). Zambia arrests Briton wanted by US, Britain sources. Reuters News. Retrieved from http://global.factiva.com/

R343 Hay, A. (2005, July 29). Grieving Brazil buries man shot by London police. Reuters News. Retrieved from http://global.factiva.com/

R344 Gray, A., Stewart, P. (2005, July 30) UK police quiz bomb suspects, Italy launches raids. Reuters News. Retrieved from http://global.factiva.com/

R345 Stewart, P., Picchio, G. (2005, July 30). Reuters News. Retrieved from http:/global.factiva.com/

R346 Stewart, P., Chambers, M (2005, August 1). UK seeks return of bomb suspect from Italy. Reuters News. Retrieved from http://global.factiva.com/

R347 Falloon, M. (2005, August 4). British Muslims feel backlash after bomb attacks. Reuters News. Retrieved from http://global.factiva.com/

R348 Chambers, M. (2005, August 4). UK security fears raise new civil rights dilemmas. Reuters News. Retrieved from http://global.factiva.com/

R349 (2005, August 5). Unanswered questions from the London bombings. Reuters News. Retrieved from http://global.factiva.com/

R350 (2005, August 8). French report warned of al Qaeda attack on Britain. Reuters News. Retrieved from http://global.factiva.com/

R351 (2005, August 9). Radical Islamic cleric says will return to UK. Reuters News. Retrieved from http:/global.factiva.com/ 
R352 Holden, M. (2005, August 11). Britain to deport 10 foreigners seen as threat. Reuters News. Retrieved from http://global.factiva.com/

R353 Holton, K. (2005, August 13). No terror mastermind behind London bombers report. Reuters News. Retrieved from http:/global.factiva.com/

R354 Tattersall, N. (2005, August 19) Expelling radical Islamists heightens their appeal. Reuters News. Retrieved from http:/global.factiva.com/

R355 Noueihed, L. (2005, August 19). Bakri says Britain tightens noose on Muslims. Reuters News. Retrieved from http:/global.factiva.com/

R356 Gray, A. (2005, August 21). London police chief defends handling of shooting. Reuters News. Retrieved from http://global.factiva.com/

R357 Long, G. (2005, August 22). Bombs test London's strength in diversity to limit. Reuters News. Retrieved from http://global.factiva.com/

R358 Peacock, M. (2005, September 1). Would-be UK leader attacks Blair's Iraq "disaster". Reuters News. Retrieved from http://global.factiva.com/

R359 Bayoumy, Y. (2005, September 1). Qaeda deputy, London bomber warn of more attacks. Reuters News. Retrieved from http://global.factiva.com/

R360 Holden, M. (2005, September 23). UK “warrior” gets 15 years for terrorism offenses. Reuters News. Retrieved from http://global.factiva.com/

R361 Szep, J. (2005, October 3). Experts see parallels in Bali and London attacks. Reuters News. Retrieved from http://global.factiva.com/

R362 Boyle, J., Trevelyan, M. (2005, October 11). Al Qaeda exploits "blue-eyed" Muslim converts. Reuters News. Retrieved from http://global.factiva.com/

R363 Peacock, M. (2005, November 2). UK's Blair loses key ally, retreats on terror law. Reuters News. Retrieved from http://global.factiva.com/

R364 Holden, M. (2006, January 1). Six months after bombs, London looks for normality. Reuters News. Retrieved from http://global.factiva.com/

R365 (2006, January 14). Al Qaeda's Zawahiri the brains behind bin Laden. Reuters News. Retrieved from http://global.factiva.com/

R366 (2006, January 19). Bin Laden tape aired on al Jazeera. Reuters News. Retrieved from http://global.factiva.com/

R367 Trevelyan, M. (2006, January 19). New tape, old threats as bin Laden breaks silence. Reuters News. Retrieved from http:/global.factiva.com/ 
R368 Sedarat, F. (2006, March 4). Al Qaeda's Zawahiri calls for strikes against West. Reuters News. Retrieved from http://global.factiva.com/

R369 Griffiths, P. (2006, March 13). Police chief apologises over taped phone calls. Reuters News. Retrieved from http://global.factiva.com/

R370 Long, G. (2005, June 29). One year on, London remains a terrorist target. Reuters News. Retrieved from http://global.factiva.com/

R371 Long, G. (2006, July 3). Britons uneasy as 7/7 bombings anniversary nears. Reuters News. Retrieved from http://global.factiva.com/

(2006, July 4). The London bombers' background. Reuters News. Retrieved from http://global.factiva.com/

R373 Trevelyan, M. (2005, July 4). London 7/7 bombs show homegrown threat to Europe. Reuters News. Retrieved from http://global.factiva.com/

R374 Holden, M. (2006, July 6). From bomb survivor to renowned blogger. Reuters News. Retrieved from http://global.factiva.com/

R375 Jones, M. (2006, July 6). Compensation still an issue after 7/7 bombings. Reuters News. Retrieved from http://global.factiva.com/

R376 Long, G. (2006, July 6). One year on, uneasy Britons mark London bombings. Reuters News. Retrieved from http://global.factiva.com/

R377 Long, G., Malik, T. (2006, July 6). One year on, London police warn of more bombings. Reuters News. Retrieved from http://global.factiva.com/

R378 (2006, July 7). Bin Laden shows new life in tapes flooding air waves. Reuters News. Retrieved from http://global.factiva.com/

CP1 Kjaer, J.S. (2008, June 2). Danish-Pakistani man reported killed in bombing "not employed" by embassy. Politiken. Retrieved from http://wnc.dialog.com/

CP2 (2008, June 2). Fatalities have been reported after a bomb explodes. Copenhagen Post. Retrieved from http://www.cphpost.dk/

CP3 Ritzau Bureau. (2008, June 3). Danish foreign minister not ruling out having soldiers guard Danish embassies. Politiken. Retrieved from http://wnc.dialog.com/

CP4 (2008, June 4). Danish Muslims report harassment, assaults after embassy bomb blast. Politiken. Retrieved from http://wnc.dialog.com/ 
CP5 Lindhardt, C. (2008, June 5). Danish security intelligence service: Embassy bombing planned "for a long time." Politiken. Retrieved from http://wnc.dialog.com/

CP6 Faurfelt, R., Elver, J. (2008, June 5). Danish prime minister says no apology to alQa'ida after Islamabad bombing. Politiken. Retrieved from http://wnc.dialog.com/

CP7 Borsting, $\mathrm{M}>$ (2008, June 5). Danish social liberal leader rejects apology to alQa'ida, seeks policy shift. Politiken. Retrieved from http://wnc.dialog.com/

CP8 (2008, June 6). Bombed embassy had received threats. Copenhagen Post. Retrieved from http://www.cphpost.dk/

CP9 Jan, S., El-Gourfti, F.F. (2008, June 7). Swedish terrorist expert says al-Qa'ida announcement "very serious" for Denmark. Politiken. Retrieved from http://wnc.dialog.com/

CP10 (2008, June 10). Denmark delays condolences. Copenhagen Post. Retrieved from http://www.cphpost.dk/

CP11 Ritzau Bureau. (2008, June 12). Denmark not planning to close Islamabad embassy, foreign minister says. Politiken. Retrieved from http://wnc.dialog.com/

CP12 (2008, June 12). Bombed embassy had received several threats prior to attack. Copenhagen Post. Retrieved from http://www.cphpost.dk/

CP13 Astrup, E. (2008, June 20). Denmark upgrades security at Islamabad embassy. Politiken. Retrieved from http://wnc.dialog.com/

CP14 (2008, Spetember 5). Al-Qa'ida commander reported threatening Denmark in new video. Politiken. Retrieved from http://wnc.dialog.com/

CP15 Davidsen-Nielsen, H., Maltesen, B. (2008, September 16). Danish foreign ministry unveils 100-million-krone plan to boost embassy security. Politiken. Retrieved from http://wnc.dialog.com/

N1 Tirmizi, M. (2008, June 2). Suicide blast rocks Danish embassy. The Nation. Retrieved from http://wnc.dialog.com/

N2 Mehmood, A. (2008, June 2). UK's new travel advice plan for Pakistan. The Nation. Retrieved from http://wnc.dialog.com/

N3 Special correspondent. (2008, June 2). US, UN condemn attack on Denmark embassy. The Nation. Retrieved from http://wnc.dialog.com/

N4 Khan, A.A. (2008, June 3). Bombing of Danish embassy. The Nation. Retrieved from http://wnc.dialog.com/ 
N5 Shakob, A. (2008, June 4). Testing times. The Nation. Retrieved from http://wnc.dialog.com/

N6 Our staff reporter. (2008, June 4). Two arrested over Danish embassy blast. The Nation. Retrieved from http://wnc.dialog.com/

N7 Gauhar, H. (2008, June 7). The limits of freedom. The Nation. Retrieved from http://wnc.dialog.com/

N8 Zarfraz, E. (2008, June 9). Tourists shy away from Pakistan. The Nation. Retrieved from http://wnc.dialog.com/

N9 Our staff reporter. (2009, January 30). Families of held "terrorists" reject police allegations. The Nation. Retrieved from http://wnc.dialog.com/

AR1 Malakawi, F., Ashtiwi, J. (2005, August 20). Azzam's son dissociates himself, father, from Aqaba attack. $A l-R a$ 'y. Retrieved from http://wnc.dialog.com/

AR2 Al-Amir, M. (2005, August 21). Jordan: IAF official says attacks on US soldiers in Jordan "impermissible." Al-Ra'y. Retrieved from http://wnc.dialog.com/

AR3 Al-Majali, H. (2005, August 21). Jordan: Muslim scholars react to Al-Aqabah attack; Stress remedial approach report from Amman. Al-Ra'y. Retrieved from http://wnc.dialog.com/

AR4 Kurashan, A. (2006, March 16). Jordanian bill of indictment on Amman, alAqabah bombings. Al-Ra'y. Retrieved from http://wnc.dialog.com/

JT1 (2005, August 21). Al-Aqaba attack "worrying development", security cooperation needed. Jordan Times. Retrieved from http://wnc.dialog.com/

JT2 Kurashan, A. (2005, August 21). Roundup on circumstances of al-Aqaba attack, arrests made. Jordan Times. Retrieved from http://wnc.dialog.com/

JT3 (2005, August 21). King Abdallah message emphasizes role of schools in combating extremism. Jordan Times. Retrieved from http://wnc.dialog.com/

JT4 Al-Kilani, M. (2005, August 21). Jordanian writer says al-Aqaba attack "direct challenge" to Jordan peace efforts. Jordan Times. Retrieved from http://wnc.dialog.com/

JT5 (2005, August 22). Jordan: Report on arrests over al-Aqabah attacks, Jordan interior minister cited. Jordan Times. Retrieved from http://wnc.dialog.com/

JT6 (2005, August 25). Tourism sector "unaffected" by al-Aqabah rocket attacks. Jordan Times. Retrieved from http://wnc.dialog.com/ 
JT7 Hamzeh, A.S. (2005, November 10). Jordan Times reports 57 killed, over 115 wounded in 9 Nov. Amman bombings. Jordan Times. Retrieved from http://wnc.dialog.com/

JT8 Al-Husayni, R. (2006, May 23). SSC postpones trials of Amman, al-Aqaba attacks until next week. Jordan Times. Retrieved from http://wnc.dialog.com/

JT9 Husayni, R. (2006, June 15). SSC listens to witnesses in Aqaba attacks case, other cases. Jordan Times. Retrieved from http://wnc.dialog.com/

JT10 Al-Husayni, R. (2006, June 22). State security court listens to prosecution witnesses on Aqaba rocket attack. Jordan Times. Retrieved from http://wnc.dialog.com/

JT11 Husayni, R. (2006, July 6). SSC listens to explosives expert in Aqaba attack case. Jordan Times. Retrieved from http://wnc.dialog.com/

JT12 Husseini, R. (2006, July 13). Jordan; Defendant claims he tried to stop Aqaba rocket attack. Jordan Times. Retrieved from http://wnc.dialog.com/

JT13 Husayni, R. (2006, August 4). Prosecution demands death penalty for 8 defendants in Aqaba attack case. Jordan Times. Retrieved from http://wnc.dialog.com/

EM1 (2004, March 12). Madrid's mayor urges remembrance of victims of rail bombings. El Mundo. Retrieved from http://wnc.dialog.com/

EM2 (2004, March 16). Premier must not "kid himself" about how he came to powerSpanish daily. El Mundo. Retrieved from http://wnc.dialog.com/

EM3 (2004, March 22). Spain's likely new foreign minister urges rethink on terrorism. El Mundo. Retrieved from http://wnc.dialog.com/

EM4 (2004, April 20). Spanish daily charts al-Qa'idah cell's activities in Madrid. El Mundo. Retrieved from http://wnc.dialog.com/

EM5 (2004, April 22). Spanish daily interviews new prime minister. El Mundo. Retrieved from http://wnc.dialog.com/

EM6 (2004, April 28). Spanish judge links Madrid attacks with 9/11 al-Qa'idah cell. El Mundo. Retrieved from http://wnc.dialog.com/

EM7 (2004, April 28). Spanish police sources: Accomplices in 11 March bombings were police informers. El Mundo. Retrieved from http://wnc.dialog.com/

EM8 (2004, May 4). May bombing suspects says he is Spanish police informer. El Mundo. Retrieved from http://wnc.dialog.com/ 
EM9 (2004, May 31). Islamist proposed joint terrorist attacks to ETA, daily reports. El Mundo. Retrieved from http://wnc.dialog.com/

EM10 (2004, June 1). Spanish daily reveals talks between ETA circles and armed Islamists. El Mundo. Retrieved from http://wnc.dialog.com/

EM11 (2004, June 2). ETA associates were in jail with 3/11 accomplices, Spanish daily reports. El Mundo. Retrieved from http://wnc.dialog.com/

EM12 (2004, June 9). Premier's Iraq police leaves Spain in "no-man's land" - daily. El Mundo. Retrieved from http://wnc.dialog.com/

EM13 (2004, June 10). Alleged Madrid train bombings mastermind traced via address book - daily. El Mundo. Retrieved from http://wnc.dialog.com/

EM14 (2004, June 16). Coach services were used to transport explosives for Madrid attacks - daily. El Mundo. Retrieved from http://wnc.dialog.com/

EM15 (2004, June 20). Spanish police had bugged, photographed 3/11 bombers in previous years. El Mundo. Retrieved from http://wnc.dialog.com/

EM16 (2004, June 21). Suspected Spanish al-Qa'idah chief protests innocence. El Mundo. Retrieved from http://wnc.dialog.com/

EM17 (2004, June 22). Another bomb could have gone off after Madrid attacks Spanish daily. El Mundo. Retrieved from http://wnc.dialog.com/

EM18 (2004, August 26). Allekema Lamari could be mystery Madrid suicide bomber Spanish daily. El Mundo. Retrieved from http://wnc.dialog.com/

EM19 (2004, September 13). Book on 3/11 bombs in Spain links Moroccan authorities with attack. El Mundo. Retrieved from http://wnc.dialog.com/

EM20 (2004, September 14). Book on Madrid attacks questions "hasty" release of suspect by Morocco. El Mundo. Retrieved from http://wnc.dialog.com/

EM21 (2004, September 28). Spanish police link Madrid bombings with Casablanca attack. El Mundo. Retrieved from http://wnc.dialog.com/

EM22 (2004, October 6). Spanish premier and predecessor to testify at Madrid bombings inquiry. El Mundo. Retrieved from http://wnc.dialog.com/

EM23 (2004, October 12). Spaniard alleged to have taught Madrid train bombers. El Mundo. Retrieved from http://wnc.dialog.com/

EM24 (2004, October 20). Alleged Islamist terror cell contacted ETA in Spanish jails daily. El Mundo. Retrieved from http://wnc.dialog.com/ 
EM25 (2004, December 9). Spanish intelligence doubts Egyptian masterminded Madrid bombings - daily. El Mundo. Retrieved from http://wnc.dialog.com/

EM26 (2004, December 15). Spanish daily profiles five suspected terrorists held by authorities. El Mundo. Retrieved from http://wnc.dialog.com/

EM27 (2005, January 26). Imam threatened in Spanish enclave "for not being fundamentalist." El Mundo. Retrieved from http://wnc.dialog.com/

EM28 (2005, January 29). Spanish judge orders face-to-face meetings with 11 March suspects. El Mundo. Retrieved from http://wnc.dialog.com/

EM29 (2005, February 16). USA shuns Spain on Secretary Rice's first foreign tour - exenvoy. El Mundo. Retrieved from http://wnc.dialog.com/

EM30 (2005, February 16). Madrid bombs said to resemble those of Palestinians, ETA. El Mundo. Retrieved from http://wnc.dialog.com/

EP1 (2004, March 16). Suspected Madrid bomber linked to pre-9/11 "summit" in Spain - daily. El Pais. Retrieved from http://wnc.dialog.com/

EP2 (2004, March 18). West "more threatened than ever" a year on from Iraq war Spanish daily. El Pais. Retrieved from http://wnc.dialog.com/

EP3 (2004, March 25). Premier-elect backs terror fight, but stands firm on Iraq. El Pais. Retrieved from http://wnc.dialog.com/

EP4 (2004, March 28). Spanish daily relates police reconstruction of 11 March bomb attacks. El Pais. Retrieved from http://wnc.dialog.com/

EP5 (2004, April 18). Daily backs Spanish premier's decision to withdraw troops from Iraq. El Pais. Retrieved from http://wnc.dialog.com/

EP6 (2004, May 1). Spain is considering legal measures to control mosques - interior minister. El Pais. Retrieved from http://wnc.dialog.com/

EP7 (2004, May 7). Police report links bin-Ladin threat to Madrid attacks. El Pais. Retrieved from http://wnc.dialog.com/

EP8 (2004, May 8). Spanish government was "repeatedly" warned of terrorist attack daily. El Pais. Retrieved from http://wnc.dialog.com/

EP9 (2004, May 9). Spanish intelligence gave warnings in 2003 of threat of Islamic terror. El Pais. Retrieved from http://wnc.dialog.com/

EP10 (2004, June 10). Alleged Madrid train bombings mastermind traced via address book - daily. El Pais. Retrieved from http://wnc.dialog.com/ 
EP11 (2004, July 25). Morocco tells Spain it has lost trace of 400 known extremists. El Pais. Retrieved from http://wnc.dialog.com/

EP12 (2004, August 1). Spanish daily recounts 3/11 terror suspect's time in Spain. El Pais. Retrieved from http://wnc.dialog.com/

EP13 (2004, September 2). Spain to boost number of antiterrorist police officers. El Pais. Retrieved from http://wnc.dialog.com/

EP14 (2004, September 9). Madrid bombings "also an attack on Iraq" - Iraqi vice president. El Pais. Retrieved from http://wnc.dialog.com/

EP15 (2004, October 10). Spanish intelligence pursuing four lines on the identity of alQa'idah spokesman. El Pais. Retrieved from http://wnc.dialog.com/

EP16 (2004, October 17). Spanish premier urges UN to create alliance of Western and Muslim worlds. El Pais. Retrieved from http://wnc.dialog.com/

EP17 (2004, October 19). Spain ordered arrest of suspected terrorist chief months before Madrid bombings. El Pais. Retrieved from http://wnc.dialog.com/

EP18 (2004, October 21). Islamic radicals "dispersed" around Spanish jails, reports daily. El Pais. Retrieved from http://wnc.dialog.com/

EP19 (2004, October 26). Abu Dahdah is "without doubt" 3/11 mastermind, says Spanish police chief. El Pais. Retrieved from http://wnc.dialog.com/

EP20 (2004, November 10). Islamist arrests in Spain since bombings tops 100. El Pais. Retrieved from http://wnc.dialog.com/

EP21 (2004, November 22). Spanish daily details investigations concerning Amer alAzizi. El Pais. Retrieved from http://wnc.dialog.com/

EP22 (2004, December 1). Spanish police rule out links between ETA and Islamists. El Pais. Retrieved from http://wnc.dialog.com/

EP23 (2004, December 10). Phone links Syrian to five alleged Madrid bombers - daily. El Pais. Retrieved from http://wnc.dialog.com/

EP24 (2004, December 14). Spanish daily hails prime minister's Madrid bombings inquiry testimony. El Pais. Retrieved from http://wnc.dialog.com/

EP25 (2005, January 24). Four alleged 11 March terrorists fled to Belgium, reports Spanish daily. El Pais. Retrieved from http://wnc.dialog.com/

EP26 (2005, February 1). Spain said considering role in Iraq. El Pais. Retrieved from http://wnc.dialog.com/ 
EP27 (2005, February 11). Spanish judge links Madrid bombings to al-Qa'idah global strategy. El Pais. Retrieved from http://wnc.dialog.com/

EP28 (2005, March 4). Al-Qa'idah chief in Europe said to have led Madrid bombings network. El Pais. Retrieved from http://wnc.dialog.com/ 


\section{Appendix I}

\section{CLAIMS ISSUED FOR ATTACKS \\ UNCLM: Unclaimed Attack \\ CLM: Claimed Attack}

1998 US Embassy Bombings, Kenya/Tanzania (UNCLM)

August 7, 1998

\begin{tabular}{|c|c|c|}
\hline Date Claim Issued & Claimant & Credible (Y/N) \\
\hline Aug. 8, 1998 & $\begin{array}{l}\text { Islamic Army for the Liberation of the } \\
\text { Holy Places }\end{array}$ & $\mathrm{N}$ \\
\hline Aug. 8, 1998 & Army for the Liberation of Holy Shrines & $\mathrm{N}$ \\
\hline Aug. 19, 1998 & Platoon of Martyr Khaled al-Said & $\mathrm{N}$ \\
\hline Dec. 25,1998 & Osama Bin Laden & Denial of Responsibility \\
\hline Mar. 20, 2007 & $\begin{array}{l}\text { Walid Muhammad [Tawfiq] bin Attash, al } \\
\text { Qaeda operative, confesses under interrogation } \\
\text { at Guantanamo Bay that he organized the } 1998 \\
\text { Embassy bombings and the } 2000 \text { USS Cole } \\
\text { bombing }\end{array}$ & $\begin{array}{c}\text { Confession (not considered } \\
\text { claim) }\end{array}$ \\
\hline
\end{tabular}

2008 Danish Embassy Bombing, Islamabad (CLM)

June 2, 2008

\begin{tabular}{|c|c|c|}
\hline Date Claim Issued & Claimant & Credible (Y/N) \\
\hline June 5, 2008 & $\begin{array}{c}\text { Yazid, commander of al Qaeda in } \\
\text { Afghanistan, claims credit via website }\end{array}$ & $\mathrm{Y}$ \\
\hline July 22, 2008 & $\begin{array}{c}\text { Yazid claims credit in an interview with } \\
\text { Pakistan's Geo TV program }\end{array}$ & $\mathrm{Y}$ \\
\hline
\end{tabular}

2000 USS Cole Bombing, Yemen (UNCLM)

October 12, 2000

\begin{tabular}{|c|c|c|}
\hline Date Claim Issued & Claimant & Credible (Y/N) \\
\hline Oct. 13, 2000 & Islamic Army of Aden-Abyan & $\mathrm{N}$ \\
\hline Oct. 13, 2000 & Mohammed's Army & $\mathrm{N}$ \\
\hline Oct. 13, 2000 & Islamic Deterrence Force & Denial of Responsibility \\
\hline Nov. 13, 2000 & Osama bin Laden & $\begin{array}{c}\text { Walid Muhammad [Tawfiq] bin Attash, al } \\
\text { Qaeda operative, confesses under interrogation } \\
\text { at Guantanamo Bay that he organized the1998 } \\
\text { Embassy bombings and the 2000 USS Cole } \\
\text { bombing }\end{array}$ \\
\hline
\end{tabular}


2005 Aqaba Rocket Bombings, Aqaba, Jordan (CLM)

August 19, 2005

\begin{tabular}{|c|c|c|}
\hline Date Claim Issued & Claimant & Credible (Y/N) \\
\hline Aug. 19, 2005 & $\begin{array}{c}\text { Abdullah al-Azzam Brigades of the al } \\
\text { Qaeda Organization in the Levant and } \\
\text { Egypt }\end{array}$ & $\mathrm{N}$ \\
\hline Aug. 23, 2005 & $\begin{array}{c}\text { Al Qaeda in Iraq (led by Abu Musab al- } \\
\text { Zarqawi) }\end{array}$ & $\mathrm{Y}$ \\
\hline
\end{tabular}

2004 Madrid Rail Bombings, Madrid, Spain (UNCLM)

March 11, 2004

\begin{tabular}{|c|c|c|}
\hline Date Claim Issued & Claimant & Credible $(\mathrm{Y} / \mathrm{N})$ \\
\hline Mar. 11, 2004 & Abu Hafs al-Masri Brigades & $\mathrm{N}$ \\
\hline Mar. 12, 2004 & $\begin{array}{l}\text { Abu Dujan al-Afghani, al Qaeda's } \\
\text { "spokesman in Europe" }\end{array}$ & $\mathrm{N}$ (actor not on record) \\
\hline 2006 & $\begin{array}{c}\text { Appears that there is no evidence that al Qaeda } \\
\text { Central helped plan, finance or carry out the } \\
\text { bombings, or even knew about them in } \\
\text { advance }\end{array}$ & -- \\
\hline 2008 & $\begin{array}{c}\text { Cell may have been trained by Mustafa } \\
\text { Setmarian Nasar, who was once affiliated with } \\
\text { al Qaeda Central but now functions } \\
\text { independently }\end{array}$ & -- \\
\hline
\end{tabular}

2005 London Subway Bombings, London, United Kingdom (CLM) July 7, 2005

\begin{tabular}{|c|c|c|}
\hline Date Claim Issued & Claimant & Credible $(\mathrm{Y} / \mathrm{N})$ \\
\hline July 7,2005 & $\begin{array}{c}\text { Secret Organization Group of al Qaeda of } \\
\text { Jihad Organization in Europe }\end{array}$ & $\mathrm{N}$ \\
\hline July 9,2005 & Abu Hafs al-Masri Brigades & $\mathrm{N}$ \\
\hline Aug. 13, 2005 & $\begin{array}{l}\text { The Independent reports initial findings of } \\
\text { investigation that bombers acted independently }\end{array}$ & -- \\
\hline Sept. 1, 2005 & $\begin{array}{c}\text { Ayman al-Zawahiri claimed } 7 / 7 \text { attacks via } \\
\text { video recording }\end{array}$ & $\begin{array}{c}\text { Y } \\
\text { (believed to be al Qaeda's video, } \\
\text { but the organization's role as } \\
\text { either active sponsor or source of } \\
\text { inspiration is not yet clarified; } \\
\text { video thought to be edited after } \\
\text { attacks) }\end{array}$ \\
\hline
\end{tabular}


Appendix II

BREAKDOWN OF ARTICLES BY NEWSPAPER

\begin{tabular}{|c|c|c|c|c|c|c|}
\hline & $\begin{array}{l}1998 \text { US } \\
\text { Embassy }\end{array}$ & $\begin{array}{c}2008 \\
\text { Danish } \\
\text { Embassy }\end{array}$ & $\begin{array}{l}2000 \text { USS } \\
\text { Cole }\end{array}$ & $\begin{array}{l}2005 \\
\text { Aqaba }\end{array}$ & $\begin{array}{c}2004 \\
\text { Madrid }\end{array}$ & $\begin{array}{l}2005 \\
\text { London }\end{array}$ \\
\hline $\begin{array}{c}\text { New York } \\
\text { Times } \\
\end{array}$ & $1-115$ & $116-122$ & $123-177$ & $178-183$ & $184-243$ & $244-371$ \\
\hline $\begin{array}{c}\text { Washington } \\
\text { Post } \\
\end{array}$ & $1-83$ & $84-87$ & $88-153$ & $154-160$ & $161-213$ & $214-300$ \\
\hline $\begin{array}{l}\text { Associated } \\
\text { Press }\end{array}$ & $1-124$ & $125-138$ & $139-234$ & $235-247$ & $248-371$ & $372-506$ \\
\hline $\begin{array}{c}\text { The } \\
\text { Guardian }\end{array}$ & $1-23$ & $24-33$ & $34-36$ & $37-40$ & $41-85$ & $86-238$ \\
\hline $\begin{array}{c}\text { Daily } \\
\text { Telegraph, } \\
\text { The Times }\end{array}$ & $1-19$ & $20-22$ & $23-26$ & $27-33$ & $34-116$ & $117-245$ \\
\hline Reuters & $1-127$ & $128-134$ & $135-188$ & $189-205$ & $206-280$ & $281-378$ \\
\hline $\begin{array}{c}\text { Politicken, } \\
\text { Copenhagen } \\
\text { Post } \\
\end{array}$ & -- & $1-15$ & -- & -- & -- & -- \\
\hline The Nation & -- & $1-9$ & -- & -- & -- & -- \\
\hline Al-Ra'y & -- & -- & -- & $1-4$ & -- & -- \\
\hline $\begin{array}{c}\text { The Jordan } \\
\text { Times }\end{array}$ & -- & -- & -- & $1-13$ & -- & -- \\
\hline El Mundo & -- & -- & -- & -- & $1-30$ & -- \\
\hline El Pais & -- & -- & -- & -- & $1-28$ & -- \\
\hline
\end{tabular}


Appendix III

CHI-SQUARE TEST OF STATISTICAL SIGNIFICANCE, PAST-FUTURE ATTACKS

\begin{tabular}{|c|c|c|}
\hline & Unclaimed Attacks & Claimed Attacks \\
\hline Future Attacks & $17^{1}$ & $23^{2}, 0^{* *}$ \\
\hline Past Attacks & $24^{3}$ & $39^{4}, 25^{* * *}$ \\
\hline
\end{tabular}

Chi-Square value (including London): 0.198

Chi-Square value ${ }^{* *}{ }^{* * *}$ (excluding London): $13.962^{+}$

Critical value at $\mathrm{p}=0.05: 3.84$

${ }^{1}$ NYT71, NYT199, NYT215, NYT236, WP51, WP78, WP79, WP75, AP325, G47, G61, DTT40, DTT41, R36, R37, R249, R280

${ }^{2}$ NYT253, NYT339, NYT322, WP221, WP223, WP236, AP402, AP451, AP453, AP497, G107, G109, G148, G170, G196, G227, G236, DTT147, DTT198, DTT240, DTT241, R335, R377

${ }^{3}$ NYT24, NYT39, NYT123, NYT127, NYT131, NYT133, NYT185, NYT195, NYT235, NYT243, WP170, WP213, AP2, AP6, AP147, AP148, G85, DTT24, DTT60, DTT62, DTT93, DTT103, DTT109, R172

${ }^{4}$ NYT178, NYT179, NYT247, NYT270, NYT273, NYT274, NYT276, NYT281, NYT288, NYT297, NYT348, WP84, WP87, WP154, AP125, AP127, AP133, AP134, AP237, AP238, AP239, AP240, AP244, G25, G26, G38, G39, G40, G105, G107, DTT20, R199, R201, R202, R203, R205, R299, R326, R340

** Without 2005 London bombing articles

*** Without 2005 London bombing articles: NYT178, NYT179, WP84, WP87, WP154, AP125, AP127, AP133, AP134, AP237, AP238, AP239, AP240, AP244, G25, G26, G38, G39, G40, DTT20, R199, R201, R202, R203, R205

${ }^{+}$Statistically significant 
Appendix IV

PAST-PRESENT ATTACKS: BREAKDOWN OF ABSOLUTES VS. RELATIVES

Absolutes

\begin{tabular}{|c|c|c|}
\hline & Unclaimed Attacks & Claimed Attacks \\
\hline Deadliest Ever & $16^{1}$ & $2^{2}$ \\
\hline First Ever & $6^{3}$ & $21^{4}$ \\
\hline Unprecedented & $12^{5}$ & $2^{6}$ \\
\hline Worst Ever & $43^{7}$ & $14^{8}$ \\
\hline
\end{tabular}

${ }^{1}$ NYT220, WP25, WP31, WP196, AP25, AP29, AP36, AP47, AP331, AP351, AP359, AP371, DTT42, DTT61, R275, EM25

${ }^{2}$ R295, R297

${ }^{3}$ NYT125, WP191, AP12, AP281, G52, DTT70

${ }^{4}$ NYT282, NYT284, NYT320, NYT332, WP238, WP243, WP245, WP252, WP332, AP417, AP419, AP422, AP492, G115, G237, R300, R304, R305, R364, R373, R377**

${ }^{5}$ NYT18, NYT184, NYT200, WP166, AP4, AP276, G2, G4, G53, G76, DTT37, DTT38

${ }^{6}$ G119, DTT198

${ }^{7}$ WP175, WP181, AP248, AP250, AP252, AP254, AP259, AP264, AP265, AP267, AP268, AP270, AP271, AP278, AP292, AP297, AP300, AP301, AP308, AP309, AP313, AP317, AP319, AP345, DTT45, DTT46, DTT61, DTT67, DTT108, DTT109, DTT110, DTT114, DTT115, R208, R213, R225, R232, R236, R237, R245, R247, R279, R280

${ }^{8}$ NYT277, NYT300, NYT364, WP240, WP242, WP246, WP250, WP300, AP501, G86, DTT120, DTT125, DTT143, DTT228

**Note that all data for "First Ever" in this section was drawn from references to "first ever suicide attack" in the 2005 London bombings 


\section{Relatives}

\begin{tabular}{|c|c|c|}
\hline & Unclaimed Attacks & Claimed Attacks \\
\hline Deadliest Since & $17^{1}$ & $5^{2}$ \\
\hline First Since & $11^{3}$ & $6^{4}$ \\
\hline Most Serious Since & 0 & $10^{5}$ \\
\hline Next in Series & 0 & $22^{6}$ \\
\hline Worst Since & $39^{7}$ & $23^{8}$ \\
\hline
\end{tabular}

${ }^{1}$ NYT185, NYT195, NYT209, NYT235, NYT243, AP194, AP196, AP197, AP277, AP302, DTT62, DTT93, DTT103, R233, R238, R243, R248

${ }^{2}$ AP125, AP127, AP133, AP134, NYT304

${ }^{3}$ AP2, AP11, AP139, AP142, AP152, DTT74, R235, R236, R254, R256, R263

${ }^{4}$ NYT178, WP154, AP237, G38, G39, G228

${ }^{5}$ AP238, AP239, AP240, AP244, AP247, G40, R201, R202, R203, R205

${ }^{6}$ NYT116, WP84, WP215, WP221, AP125, AP126, AP379, G25, G26, G29, DTT20, DTT21, DTT121, DTT122, R128, R129, R132, R281, R285, R286, R295, R357

${ }^{7}$ NYT123, NYT127, NYT131, NYT133, WP96, WP164, AP142, AP147, AP148, AP154, AP158, AP159, AP162, AP163, AP165, AP166, AP167, AP168, AP169, AP171, AP172, AP173, AP174, AP176, AP177, AP179, AP254, AP256, AP257, AP308, DTT24, DTT34, R206, R211, R213, R218, R221, R224, R231

${ }^{8}$ NYT247, NYT255, NYT269, NYT273, NYT276, NYT281, NYT288, WP225, WP226, WP229, WP289, AP379, AP381, AP384, AP387, AP391, AP392, AP393, AP394, AP406, AP444, AP466, DTT117

\section{CHI-SQUARE TEST OF STATISTICAL SIGNIFICANCE, PAST-PRESENT ATTACKS} (ABSOLUTES VS. RELATIVES)

\begin{tabular}{|c|c|c|}
\hline & Unclaimed Attacks & Claimed Attacks \\
\hline Past Absolutes & 77 & 39 \\
\hline Past Relatives & 67 & 66 \\
\hline
\end{tabular}

Chi-Square value: $6.510^{+}$

Critical value at $\mathrm{p}=0.05: 3.84$

\footnotetext{
${ }^{+}$Statistically significant
} 